Teaching and Learning Program

Doctoral School of Education

Faculty of Arts, University of Szeged

\title{
Testing the model of reading literacy:
} Examining the cognitive and non-cognitive factors influencing students' reading achievement in different text formats in grade 2

\section{Hódi Ágnes}

Supervisor:

Nikolov Marianne D.Sc. 



\section{TABLE OF CONTENTS}

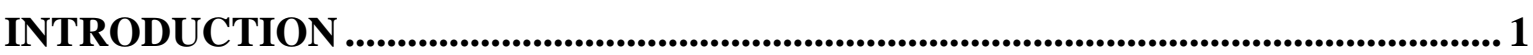

\section{PART I}

THEORETICAL BACKGROUND TO TESTING THE MODEL OF READING LITERACY.... 4

CHAPTER 1: The conceptualization of reading literacy: The reader, the text, the activity and the context .................................................................................................... 4

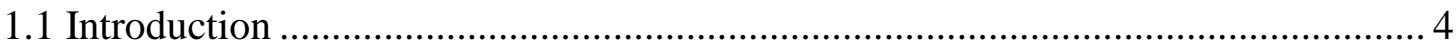

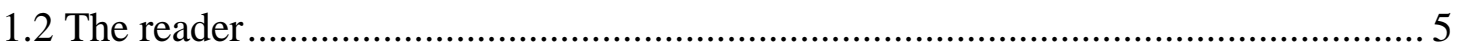

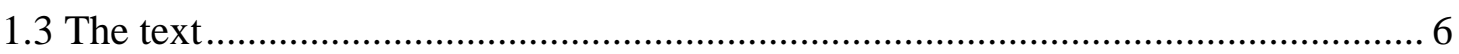

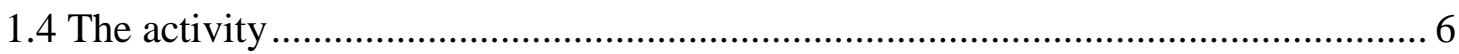

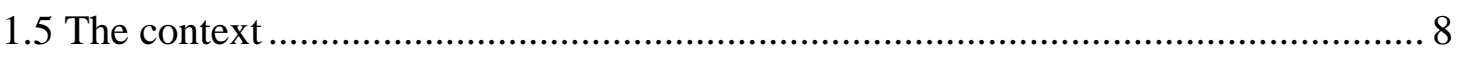

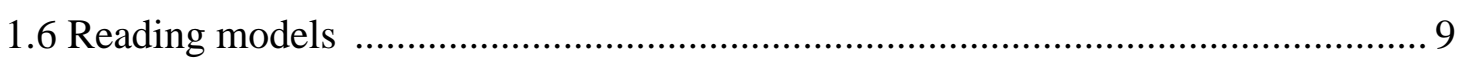

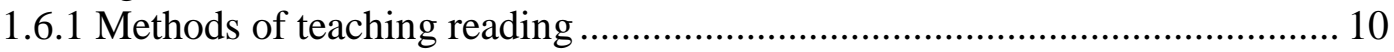

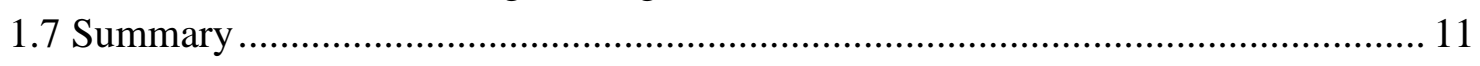

CHAPTER 2: System-level student assessment programs on reading ........................... 12

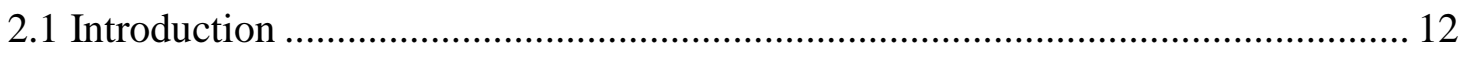

2.2 Measuring the sociocultural dimension of reading: From reading comprehension to reading literacy

2.3 The conceptualizations and operationalization of reading literacy for assessment purposes in international surveys of the Hungarian school-aged population

2.3.1 A comparative analysis of the frameworks of OECD PISA, IEA studies and PIRLS reading assessments

2.3.2 Results of Hungarian students in various data collection cycles of

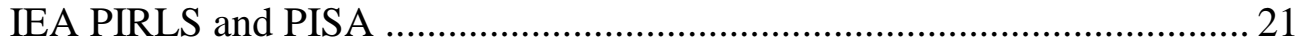

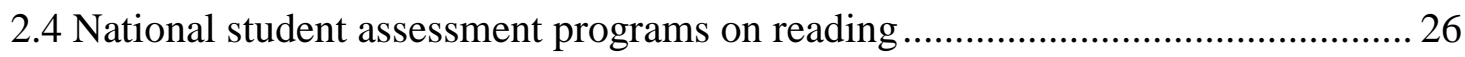

2.4.1 A brief overview of the emergence of national surveys............................. 26

2.4.2 The impact of international student assessment programs on the conceptualization of reading in national reading surveys

2.4.3 An overview of the reading assessment practices and frameworks of the Monitor assessments and the Hungarian National Assessment of Basic Competencies

2.4.4 Results in various data collection cycles of the Monitor assessment and $\mathrm{NABC}$

2.5 Summary of findings, conclusions and implications 
PART II

TESTING THE MODEL OF READING LITERACY: EXAMINING THE COGNITIVE AND NON-COGNITIVE FACTORS INFLUENCING STUDENTS' ACHIEVEMENT

IN DIFFERENT TEXT FORMATS

CHAPTER 3: Backround to the empirical studies on testing the model of reading literacy and examining the factors influencing students' achievement across

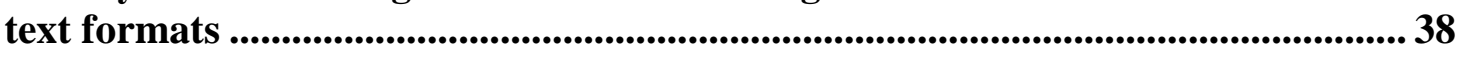

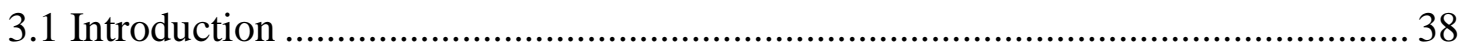

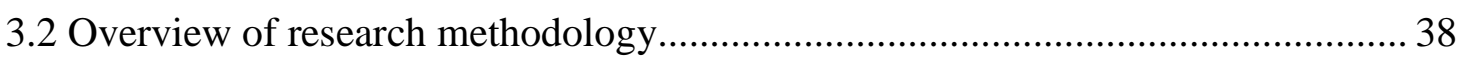

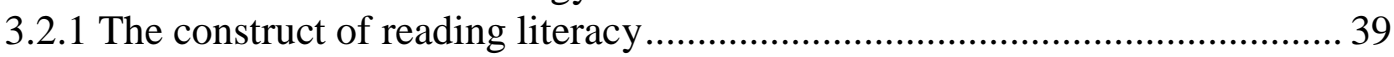

3.2.2 The first study: A longitudinal study on the model of reading literacy and the interaction between Hungarian students' reading achievement in different text formats and cognitive aspects to reading ........................... 41

3.2.3 The second study: A descriptive and correlational study on the role of student-related non-cognitive factors in students' reading literacy achievement in different text formats .

3.2.4 The third study: A descriptive and correlational study on the role of aspects of reading instruction in students' reading literacy achievement in different text formats

CHAPTER 4: A longitudinal study on the model of reading literacy and the interaction between Hungarian students' reading achievement in different text formats and cognitive aspects to reading .......................................................... 44

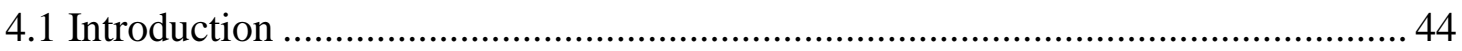

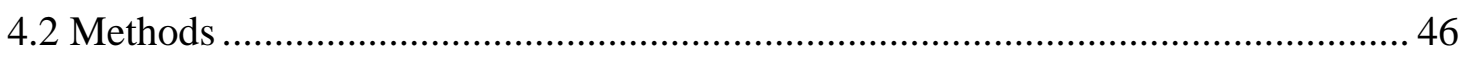

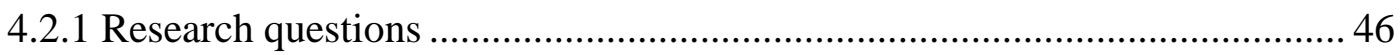

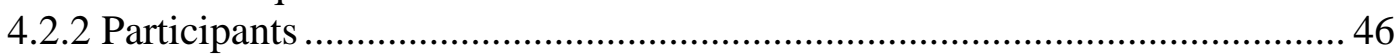

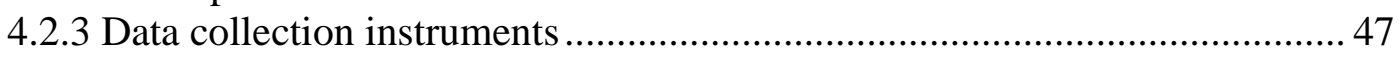

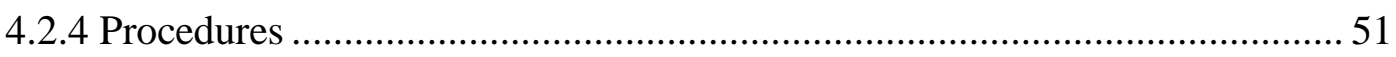

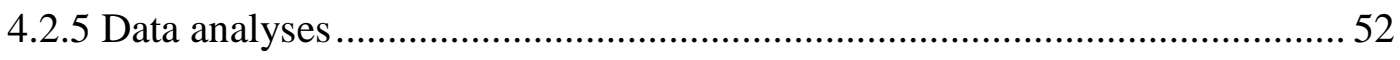

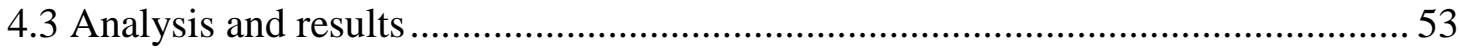

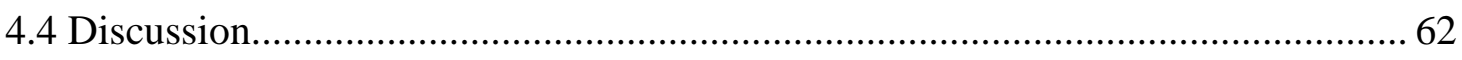

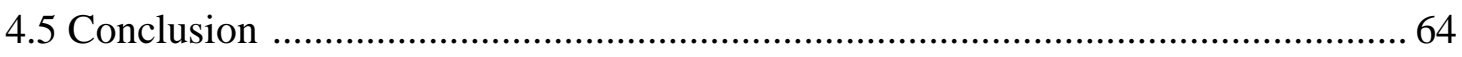

CHAPTER 5: A descriptive and correlational study on the role of student-related non-cognitive factors in students' reading literacy achievement in different text formats................................................................66

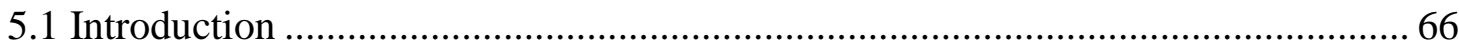

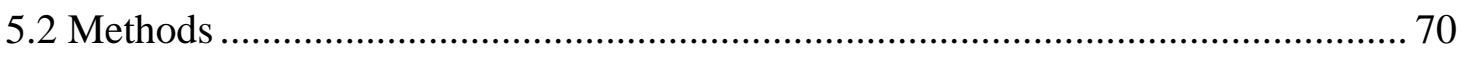

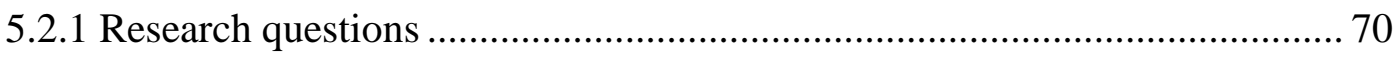

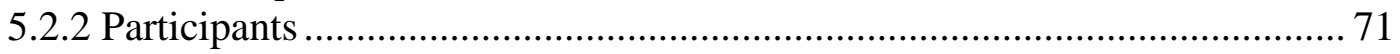

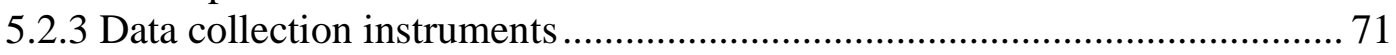

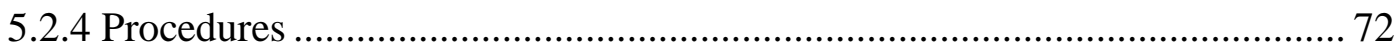

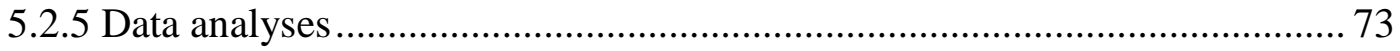

5.3 Analysis and results of the main questionnaire .............................................. 73

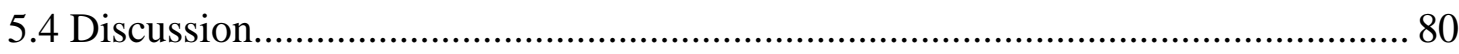

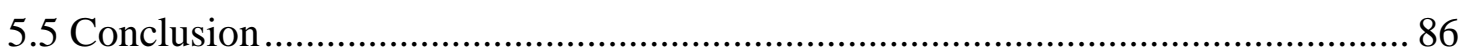


5.6 Analysis and results of the short questionnaire

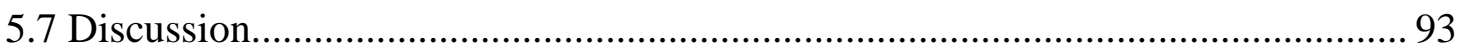

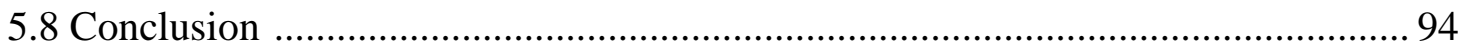

CHAPTER 6: A descriptive and correlational study on the role of aspects of reading instruction in students' reading literacy achievement in different

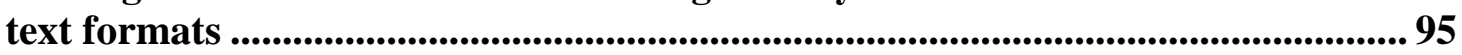

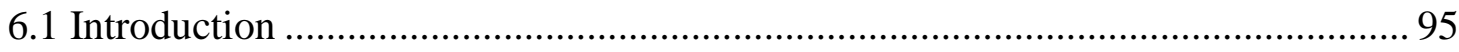

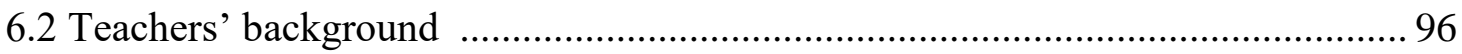

6.3 Aspects of teaching reading and reading development ...................................... 97

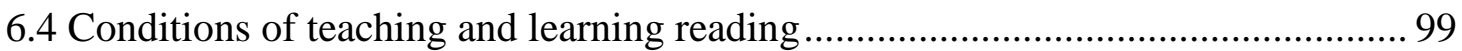

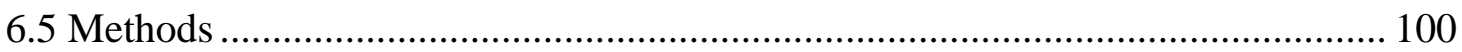

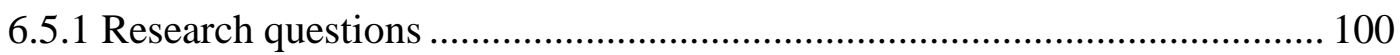

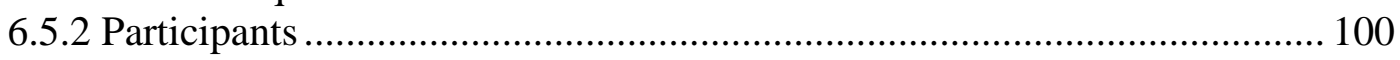

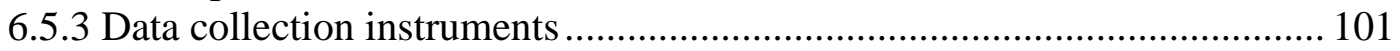

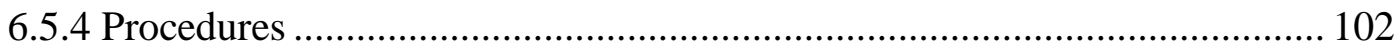

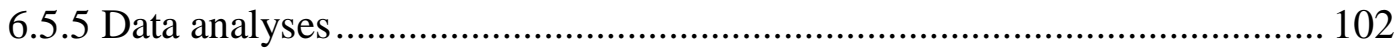

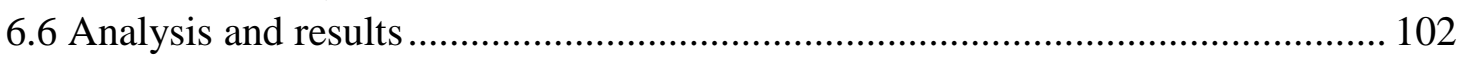

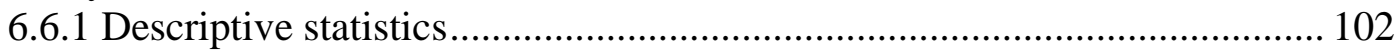

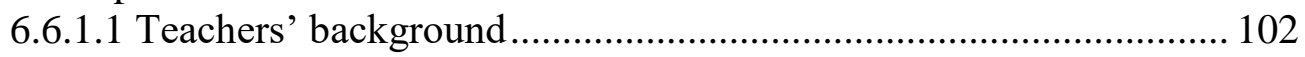

6.6.1.2 Aspects of teaching reading and reading development ................. 104

6.6.1.3 Conditions of teaching and learning reading ................................ 111

6.6.2 The relationship between aspects of reading instruction and second graders' reading achievement in the continuous, mixed and non-continuous subtests

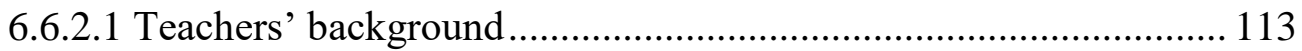

6.6.2.2 Aspects of teaching reading and reading development ................. 114

6.6.2.3 Conditions of teaching and learning reading ................................ 119



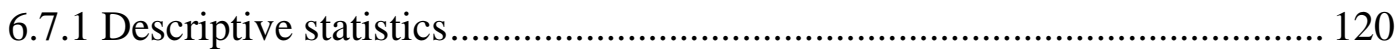

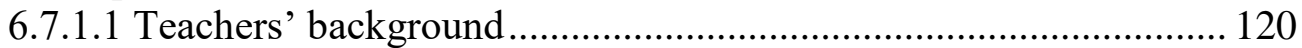

6.7.1.2 Aspects of teaching reading and reading development ................ 122

6.7.1.3 Conditions of teaching and learning reading ................................. 125

6.7.2 The relationship between aspects of reading instruction and second graders' reading achievement in the continuous, mixed and non-continuous subtests ................................................................... 126

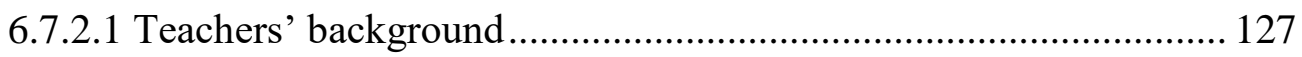

6.7.2.2 Aspects of teaching reading and reading development ................. 129

6.7.2.3 Conditions of teaching and learning reading ................................ 130

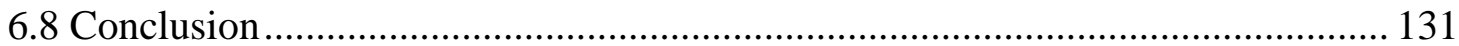

CHAPTER 7: Conclusions and future directions......................................................... 133

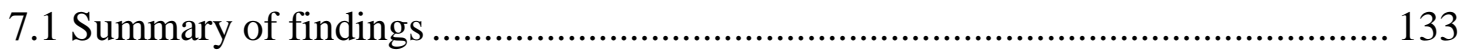

7.1.1 The main findings of the literature reviews........................................... 133

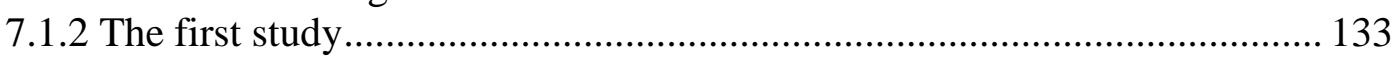

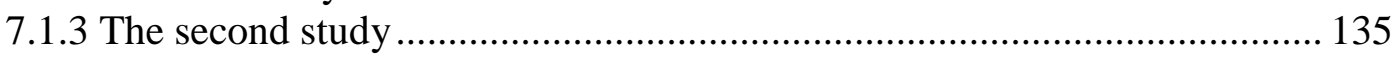

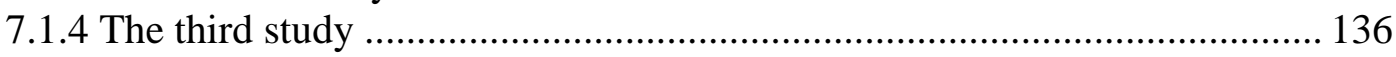

7.2 Theoretical implications and educational importance ........................................ 137

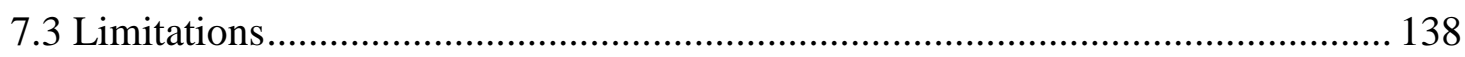




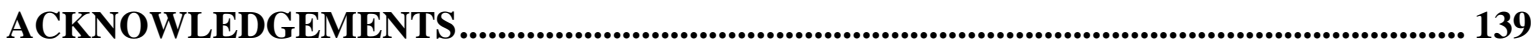

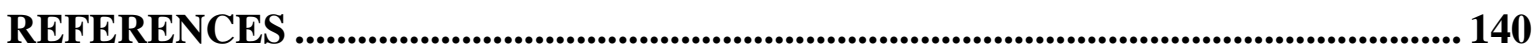

LIST OF FIGURES ................................................................................................................. 155

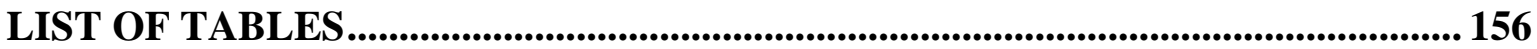

APPENDIX A: The reading literacy subtest with the continuous text......................... 158

APPENDIX B: The reading literacy subtest with the non-continuous text ................ 168

APPENDIX C: The reading literacy subtest with the mixed text ................................... 178

APPENDIX D: Student questionnaire...................................................................................... 191

APPENDIX E: Teacher questionnaire ...................................................................... 196

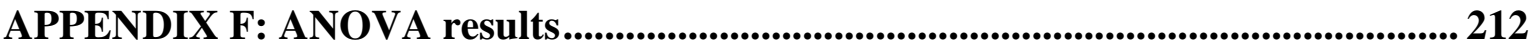




\section{INTRODUCTION}

Years ago, at the beginning of my studies, my supervisor advised me to keep reading. She said that one day the pieces would fall into place. Since I developed an interest in reading research, I soon realized that I was lucky to possess this skill. I belong to those who are fortunate enough to be able to understand and use the information conveyed by written materials for my own personal and professional development. However, I have become aware that there are many who are not as privileged as I am. In fact, for an increasingly high number of people, written words mean less and less.

As I was educated in the Doctoral School of Education, University of Szeged placing a strong emphasis on educational evaluation, I immediately started to familiarize myself with frameworks and reports of domestic and international assessment programs and related publications. Besides Hungarian students' deteriorating reading test scores, there was one issue that struck me in almost each and every paper. There is an achievement disparity regarding students' test scores in different dimensions of reading literacy with respect to text format. Hungarian students are better at understanding continuous texts than non-continuous ones, also known as documents. Furthermore, I also found that this inconsistency is present in almost every country. The reports briefly commented on this phenomenon and named the lack of inclusion of non-continuous texts in public education the scapegoat for the recurring pattern. After many years of thorough research these remarks now seem as encapsulations of naïve assumptions rather than facts based on findings grounded in empirical research. I found it especially puzzling that the assessment frameworks and the dimensions of reading literacy defined by them were not always in line with the data included in the reports. Even if they were consistent, they failed to provide an explanation as to how come the very same student does possess the skill to understand a text of a certain format but is not able to comprehend another one with a different organization. I thought that if the reason for underachievement is lack of familiarity with non-continuous texts, then there must be something that students need to possess to be able to read and understand. The following questions started to appear on my research agenda: Are we sure that non-continuous texts can be read the same way as their continuous counterparts are read? Are we absolutely positive that the same cognitive processes are operated when reading texts with different formats as defined by the frameworks? Somehow the whole thing did not add up. After I realized that research addressing the achievement disparity with respect to text formats is scarce in Hungarian as well as in international research studies, I planned an overarching research involving second graders to investigate the prevalence and underlying reasons for this phenomenon at an early stage of formal reading instruction. Thus, the dissertation was written with the aim to bridge the gap in common understanding regarding what reading and its development entails.

\section{RESEARCH QUESTIONS AND OVERVIEW OF THE DISSERTATION}

The purpose of my studies was to test the model of reading literacy with a special emphasis on the relationship between text formats and cognitive aspects to reading, to characterize Hungarian second graders' reading development in terms of text formats and cognitive aspects to reading and to explore contributing factors. For an overview of the main research questions see Table 1.1. 
Table 1.1 The data sources and methods of analysis used for the main research questions

\begin{tabular}{|c|c|c|c|}
\hline Studies & Research questions & Data sources & Methods of analysis \\
\hline $\begin{array}{l}\text { Study } 1 \\
\mathrm{~N}=3,229\end{array}$ & $\begin{array}{l}\text { 1) What is the underlying measurement model } \\
\text { for reading literacy? } \\
\text { 2) To what extent does students' reading } \\
\text { literacy develop in continuous, mixed and } \\
\text { non-continuous text formats between grades } \\
2 \text { and } 4 \text { ? } \\
\text { 3) To what extent does students' reading } \\
\text { literacy achievement differ along different } \\
\text { text formats in grades } 2 \text { and } 4 \text { ? } \\
\text { 4) How does students' reading achievement } \\
\text { change when they read the continuous, } \\
\text { mixed and non-continuous text? } \\
\text { 5) To what extent does students' reading } \\
\text { literacy develop in three cognitive aspects } \\
\text { to reading (information retrieval, } \\
\text { interpretation and reflection) in different } \\
\text { text formats between grades } 2 \text { and } 4 \text { ? } \\
\text { 6) To what extent does students' reading } \\
\text { literacy achievement differ in three } \\
\text { cognitive aspects to reading (information } \\
\text { retrieval, interpretation and reflection) in } \\
\text { different text formats in grades } 2 \text { and } 4 \text { ? } \\
\text { 7) Are cognitive aspects to reading universal in } \\
\text { all text formats? }\end{array}$ & $\begin{array}{l}\text { Reading literacy test } \\
\text { comprising a } \\
\text { continuous, a mixed } \\
\text { and a non-continuous } \\
\text { text }\end{array}$ & $\begin{array}{l}\text { Descriptive statistics } \\
\text { Paired-samples t-test } \\
\text { Confirmatory factor } \\
\text { analysis } \\
\chi 2 \text { difference test }\end{array}$ \\
\hline $\begin{array}{l}\text { Study } 3 \\
\mathrm{~N}=189\end{array}$ & $\begin{array}{l}\text { 1) How can second graders' teachers' } \\
\text { characteristics, pedagogical skills, practices } \\
\text { and conditions of teaching and learning be } \\
\text { characterized? } \\
\text { 2) How do teachers' characteristics, pedagogical } \\
\text { skills, practices and conditions of teaching } \\
\text { and learning impact second graders' reading } \\
\text { achievement in different text formats? }\end{array}$ & $\begin{array}{l}\text { Teacher } \\
\text { questionnaire } \\
\text { Reading literacy test } \\
\text { comprising a } \\
\text { continuous, a mixed } \\
\text { and a non-continuous } \\
\text { text }\end{array}$ & $\begin{array}{l}\text { Descriptive statistics } \\
\text { Two-sample t-test } \\
\text { Analysis of Variance } \\
\text { Tukey's-b and } \\
\text { Dunnett's T3 test }\end{array}$ \\
\hline
\end{tabular}


The dissertation is divided into two parts and six chapters. The broader theoretical background to the research studies is outlined in Part 1, which entails Chapters 1 and 2. Based on the heuristic model of reading, the first chapter gives an overview of the variables that play a role in reading comprehension. In addition, the most influential theories and models of reading are also summarized. Chapter 2 gives an overview about how the current concept of reading literacy used for assessment purposes emerged and how the evolution of the definition impacted assessment practices in terms of the inclusion of versatile text formats. Chapter 2 also provides an analysis of Hungarian and international reading assessment programs and a synthesis of Hungarian students' achievement in reading and understanding texts of different formats.

While Part 1 endeavors to place the key questions addressed in the dissertation into a theoretical framework, Part 2 contains three empirical research studies conducted to seek answers to these questions (Table 1.1). Part 2 comprises five chapters. Chapter 3 provides background to the context and to the participants of the research studies as well as outlines the research methodology employed in the three studies. Chapters 4, 5 and 6 present the three empirical studies aimed at exploring second graders' reading achievement in different text formats from different angles and perspectives. Chapter 4 comprises the first study, which involved 3,229 Hungarian second graders. The aim was to describe and analyze students' reading achievement in continuous, mixed and non-continuous texts. Data were collected with the help of a reading literacy test; descriptive statistics and paired-samples ttest were employed to obtain results. Data was also used to build and to test a model of reading literacy with advanced statistical methods. The second study is outlined in Chapter 5. This research study was based on the data of the very same population. The results of a background and a mini questionnaire were linked to second graders' achievement to arrive at a better understanding of why students' performance differs along text formats. The third study is presented in Chapter 6. Data were elicited by a background questionnaire, involving 189 primary school teachers teaching the second grader sample how to read. The main objectives of this investigation were to characterize teachers' characteristics, pedagogical skills, practices, the conditions of teaching and learning and to explore the extent to which these factors impact second graders' reading achievement in different text formats. The results of the three empirical studies complement one another. The final part of the dissertation, Chapter 7, comprises the conclusions and suggests a path forward by including the theoretical and practical importance of the findings. 


\section{PART I}

\section{Theoretical background to testing the model of reading literacy}

\section{CHAPTER 1 \\ THE CONCEPTUALIZATION OF READING LITERACY: THE READER, THE TEXT, THE ACTIVITY AND THE CONTEXT}

\subsection{Introduction}

Acquiring reading literacy is a complex process, which is influenced and shaped by numerous cognitive, affective and contextual factors (Chiu, McBride-Chang, \& Lin, 2012; Snow \& Sweet, 2003). The heuristic model proposed by Snow and Sweet (2003) provides an appropriate framework for understanding the multifactorial phenomenon called reading (Figure 1.1).

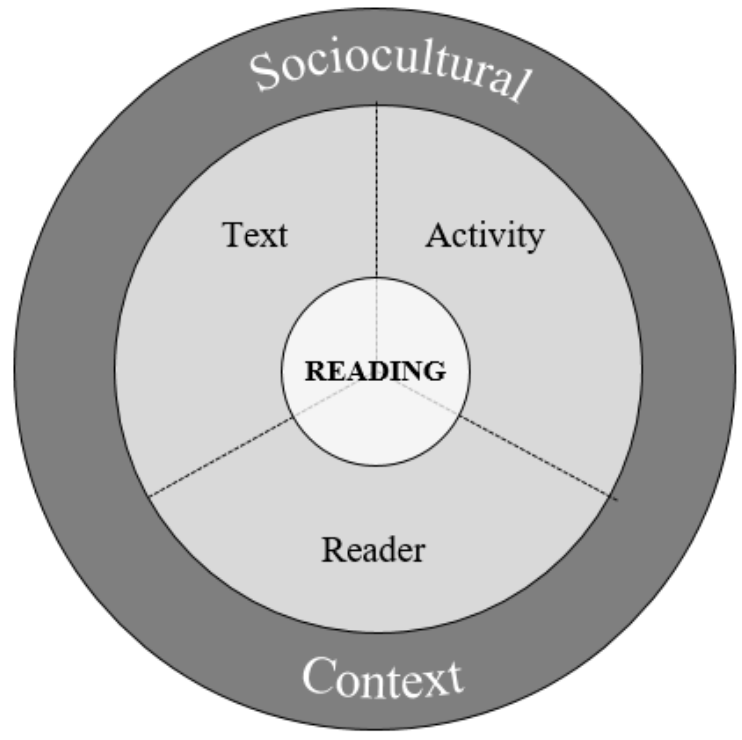

Figure 1.1. A heuristic model of reading comprehension (Sweet \& Snow, 2003, p. 3)

The framework that I adopted for my work defines reading comprehension ,,as the process of simultaneously extracting and constructing meaning through interaction and involvement with written language" (Snow \& Sweet, 2003, p. 1). In the heuristic model, comprehension entails three interrelated elements: (1) the reader, (2) the text and (3) the activity. As far as the reader is concerned, the model includes all the capacities, abilities, knowledge, and experiences that a person who is doing the comprehending brings to the act of reading. The text - whether it is in a printed or electronic form - refers to written pieces of information that is to be comprehended. The activity element of the model includes the purposes, processes, and consequences associated with the act of reading (Snow \& Sweet, 2003 , p. 2). The model also shows that reading comprehension defined by these three elements takes place in a sociocultural context that shapes and is shaped by the reader (Snow \& Sweet, 2003, p. 10). "Reading literacy goes beyond the traditional sense of text comprehension in that special emphasis is given to the comprehension of everyday texts that are of practical use for the individual or the society. In this sense, reading as a complex skill 
or system of skills is seen as a means to achieving social and individual goals and as an important domain of the application of knowledge acquired in and outside the classroom" (Józsa, Steklács, Hódi, Csíkos, Adamikné Jászó, Molnár, Nagy, \& Szenczi, 2012, p. 246). Thus, the heuristic model is also applicable for the conceptualization of reading literacy. The chapters that follow use these definitions and conceptualizations of reading comprehension and literacy as a starting point. The discussion of the components of the heuristic reading model incorporates the structure of international and Hungarian large-scale system-level assessments.

\subsection{The reader}

When considering the reader, a wide range of capacities and abilities have to be taken into account. These include cognitive capacities (like attention, memory, inferencing and fluency), motivation, attitude, a sense of self-efficacy as a reader and various types of knowledge such as vocabulary and students' prior domain and topic knowledge (Snow \& Sweet, 2003, p. 4). The readers' capabilities and knowledge may change during the reading activity. The change may either take a negative or a positive direction. For example, readers may experience an increase in their vocabulary, domain knowledge but fluency can also increase as a result of practice in reading. The success or failure during the reading experience may also shape the readers' affective characteristics such as motivation, attitude or self-concept. Instruction is also a key source of changes in the readers' knowledge and capacities. Effective teachers integrate both short- and long-term goals into their instruction. Their primary focus is on teaching students to understand a particular text but effective teachers also help students to become active, self-regulated and autonomous readers (Snow \& Sweet, 2003, p. 5).

Emphasizing the role of background knowledge, schema theory must be drawn on when discussing the reader as a component of the heuristic model of reading. Schema theory holds that "reading comprehension is an interactive process between the text and the reader's prior background knowledge" (Carrell \& Eisterhold, 1983, p. 553). It offers an explanation as to "how readers use prior knowledge to comprehend and learn from text" (An, 2013, p. 130). It is common to encounter different types of schemata in literature (Alderson, 2000). For example, Carrell (1983) makes a distinction between formal schemata referring to knowledge of language, including knowledge about text organization and genres and content schemata including knowledge of the world and text subject matter. Content schemata can also be further divided into the categories of background knowledge and subject-matter knowledge (Alderson, 2000). A recent review on the topic discusses formal schemata, content schemata, and linguistic schemata as different types of schemata (An, 2013).

Linguistic schemata - referring to the readers' existing knowledge about vocabulary and grammar - play a key role in reading comprehension and are the foundation of other schemata, as the reader cannot decode and understand a text without it (An, 2013).

Formal schemata are the organizational forms and rhetorical structures of written texts. They include knowledge of different text types and genres, text organization, and language structures. It is claimed that formal schemata can lead to increased reading comprehension but compared to linguistic and content schemata, formal schemata have a smaller contribution to the reading process (An, 2013).

Content schemata refer to the background knowledge of the content area of a text, or knowledge about the subject matter the text talks about. They include topic familiarity, cultural knowledge and previous experience in a field. Content schemata can make up for lack of language schemata to a certain extent and help learners understand texts by 
predicting, choosing information and removing ambiguities. The more readers know about a topic, the more easily and quickly they can extract information from the text (An, 2013).

Although schema theory dominated reading research in the 1970s (McVee, Dunsmore, \& Gavelek, 2005), it was widely criticized for lacking a consistent definition (Sadoski, Paivio, \& Goetz, 1991), for failing to account for how new information is handled and for how misunderstanding of the text can take place based on false similarities and comparisons (Alderson, 2000). Results of the empirical studies conducted to verify the existence of the schemata were also found highly questionable (Carver, 1992; Sadoski, Paivio, \& Goetz, 1991).

\subsection{The text}

The range of materials to be read can be categorized for assessment purposes in various ways: according to their format or their type. With respect to format, a text may be continuous, mixed, non-continuous or multiple (OECD, 2016c). Continuous texts are composed of a coherent sequence of sentences arranged in paragraphs (OECD, 2016c). Cohesive devices (grammatical devices, pronominal agreement, repetition, anaphoric and cataphoric reference) aid text processing. Non-continuous texts also known as documents are essentially defined by a list of text types. "These include tables, maps, user guides, posters, i.e., every text that is structured differently from "traditional" texts typical of school reading materials and that is crucial for text comprehension skills." (Józsa, Steklács, Hódi, Csíkos, Adamikné, Molnár, Nagy, \& Szenczi, 2012, p. 248) However, it is also acknowledged that non-continuous texts have "a descriptive, narrative, expository, argumentative or instructional purpose" (OECD, 2010a, p. 32). Compared to the prevalence of non-continuous texts in everyday life (a computer screen, a school timetable, posters in the streets all belong to this category), their inclusion in schoolbook reading materials is underrepresented (Józsa et al., 2012). Mixed texts are composed of a combination of continuous and non-continuous texts (Józsa et al., 2012; OECD, 2010a). Multiple texts are generated independently and make sense independently; they are juxtaposed for a particular occasion or may be loosely linked together. "The relationship between the texts may not be obvious; they may be complementary or may contradict one another. For example, a set of websites from different companies providing travel advice may or may not provide similar directions to tourists. Multiple texts may have a single "pure" format (for example, continuous), or may include both continuous and non-continuous texts." (OECD, 2016c, p. 53)

The assessment of reading literacy can also look at different text types. In this respect texts are classified according to their rhetorical goals as narration (e.g., novels, fictional texts), description (e.g., catalogues, geographical maps), exposition (e.g., graphs, scholarly essays), argumentation, and instruction (OECD, 2016c, p. 53).

"While reading, the reader constructs various representations of the text like the surface code (the exact wording of the text), the text base (idea units representing the meaning) and a representation of the mental models embedded in the text." (Snow \& Sweet, 2003, pp. 5-6)

\subsection{The activity}

The activity dimension of reading involves one or more (1) purposes, (2) operations to process the text and (3) consequences (Snow \& Sweet, 2003). (1) Purposes are inherent to reading since all readers have a particular purpose before reading. The purpose "can be either externally imposed (e.g., completing a class assignment) or internally generated (wanting to 
program an electronic device)" (Snow \& Sweet, 2003, p. 8). Once the purpose is recognized or accepted, the reader can engage in text processing, which will eventually have consequences.

Reading requires the integration and coordination of multiple processes. Inevitably, processing a text involves decoding but higher-level "linguistic and semantic processing and monitoring" also take place along the continuum of reading (Snow \& Sweet, 2003, p. 8). The literature generally mentions three cognitive processes that are highly important contributing factors in fluent reading (Blomert \& Csépe, 2012). These are phonological awareness, letter-speech-sound processing and rapid automatized naming (RAN). Phonological awareness has been in the focus of much research as a key element in early literacy acquisition and an important and reliable predictor of later reading ability (Furnes \& Samuelsson, 2011; Oulette \& Haley, 2013; Shanahan, 2012). Phonological awareness is an umbrella term (Goswami \& Bryant, 1990) used to refer to sensitivity to the sound structure of oral language and the ability to identify, discriminate and manipulate units of oral language (Sénéchal, Ouellette, \& Young, 2004). The development of phonological awareness forms a continuum. It develops from the ability to manipulate larger linguistic units (e.g., syllables) to eventual smaller phonological segment awareness (Carroll, Snowling, Hulme, \& Stevenson, 2003; Ziegler \& Goswami, 2005). Sensitivity to the smaller segments of individual speech sounds is referred to as phonemic awareness, distinguishing it from the more encompassing term, phonological awareness (Oulette \& Haley, 2013). Phonemic awareness also encompasses "rudimentary phonological skills" (Anthony \& Francis, 2005, p. 255), such as recognizing that two words rhyme and have a sound in common (Anthony \& Francis, 2005; Goswami \& Bryant, 1990). The second cognitive skill that has frequently been associated with reading is letter-speech-sound processing. Letterspeech-sound processing refers to the ability of knowing which letter corresponds to a particular speech-sound (Blomert \& Csépe, 2012). This skill constitutes the basis for fluent reading. Rapid automatized naming is the "fast, automatic naming of well-known visual items such as letters, digits, objects and colors" (Blomert \& Csépe, 2012, p. 23). RAN as a useful correlate of reading, "taps both the visual-verbal (language domain) and processing speed (executive domain) contributions to reading" (Denckla \& Cutting, 1999, p. 29).

Parallel to skills needed for successful decoding, (2) operations to process the text (also known as comprehension processes or cognitive aspects to reading) are also activated. There are different levels of text comprehension. However, essentially, three broad skills can be distinguished for assessment purposes. "At the simplest level of text comprehension, answering the question involves no more than the simple retrieval of information from the text. Questions requiring the reader to make inferences and those that even involve the use of prior knowledge for successful inference represent a higher level. The third level of reading comprehension involves reflection on the text" (Józsa et al., 2012, p. 249). When retrieving and interpreting information, the reader uses content from the text (OECD, 2016c). Reflection, on the other hand, requires the reader to draw primarily on outside knowledge (OECD, 2016c).

Information retrieval is the "process of selecting the required information" (OECD, 2016c, p. 55). When asked to retrieve information, students have to access and retrieve content relevant to the particular question or task and locate one or more pieces of information embedded in the text (Józsa et al., 2012). "Simple information retrieval tasks test students' ability to recover literal content, while more complex versions also require a minimum degree of reasoning" (Józsa et al., 2012, p. 239).

Interpretation "involves processing what is read to make internal sense of a text" (OECD, 2016c, p. 55). Tasks measuring interpretation aim at mapping out students' ability to navigate in the internal structure of texts. In order to complete these tasks, students have 
to identify of the basic idea or main theme of the text, or figure out the context-dependent meaning of an expression (Józsa et al., 2012). Students also have to engage in inferencemaking, i.e., link pieces of interconnected information that are separated from each other in the text. Inference is a process that help construct mental representations and "read between the lines" by relying on pieces of information extracted from different parts of the text and on the reader's background knowledge" (Józsa et al., 2012, pp. 239-240).

Reflecting refers to the process of "drawing upon knowledge, ideas or attitudes beyond the text in order to relate the information provided within the text to one's own conceptual and experiential frames of reference" (OECD, 2016c, p. 55). Reflecting tasks can further be classified into reflecting on content and reflecting on form tasks. The former processes are "concerned with the notional substance of a text", whereas "reflecting on form tasks are concerned with its structure or formal features" (OECD, 2016c, p. 54).

Finally, (3) consequences are also considered to be part of the reading activity. Consequences can range from an increase in the reader's knowledge through finding out how to do something (i.e. application consequence) to engagement.

\subsection{The context}

Sociocultural theories have emphasized the role of the interdependence between individual and social processes as a natural part of child development (John-Steiner \& Mahn, 1996; Vygotsky, 1978). In the classroom teachers and in the home environment parents are considered to be the most important providers of literary experiences. The interactions between children and adults are seen as channels of literacy transmission (Aram, 2010). Therefore, when studying literacy development, researchers should focus on classrooms and schools as well as the home environment as the settings where children learn the basic skills that establish the foundations for literacy development (Wasik \& Herrmann, 2004). Although an "important set of reading activities occurs in the context of instruction", children's background is also a determining factor in their reading development (Snow \& Sweet, 2003, p. 9).

The environment is a multifaceted phenomenon and thus can be characterized and grasped from many aspects (Burgess, Hecht, \& Lonigan, 2002). According to the broadest interpretation, the environment consists of the surroundings and attitudes, for example, classroom design, teacher's instruction, features and attitudes of the family that support the development of children's reading literacy (Chambers, 2011; Roberts, Jergens, \& Burchinal, 2005; Snow, Burns, \& Griffin, 1998).

Home environmental factors important to children's emergent literacy acquisition include the interactions of caregivers during joint book reading, exposure to literacy-related activities and the responsiveness of caregivers in the environment. A large body of research supports the influence of the amount of talk and style of parents' conversational interactions in facilitating children's vocabulary and other aspects of language development (cf. Sénéchal, 2011). In addition, the number of books in the home is also important for learning about the purpose and value of print and ultimately for learning to read (Bergen, Zuijen, Bishop, \& de Jong, 2017; Evans, Kelley, \& Sikora, 2014).

The effect of contextual factors such as the classroom learning environment (e.g., organizational grouping, use of technology, availability of different materials, the amount of teacher directed instruction) can also affect reading development (Snow \& Sweet, 2003).

Both the home and school environment can be subject to socioeconomic disparities. Since schools mirror the neighborhood context, it is not surprising that economic inequality among neighborhoods and regions go along with differences in the process and content of instruction, and the availability of instructional resources (Snow \& Sweet, 2003). 


\subsection{Reading models}

Since the 1960s reading models have helped to conceptualize reading (Chodkiewicz, 2014). "Several different theories and cognitive models have been proposed to explain how meaning is constructed during the process of reading comprehension" (Blomert \& Csépe, 2012 , p. 54). Rooted in cognitive psychology, these models made an attempt to explain and depict how the components of the reading processes work and how they relate to each other (Adamikné Jászó, 2006). Most of the models are universal and have general educational utility (Chodkiewicz, 2014). The different types of reading models can all be classified into one of three categories: (1) top down, (2) bottom-up, and (3) interactive (Adamikné Jászó, 2006; An, 2013; Lally, 1998). The terms top-down and bottom-up were borrowed from the literature on perception. They refer to whether an "individual perceives a stimulus by noticing separate defining features of the stimulus and assembling them into a recognizable pattern (bottom-up) or perceives a stimulus by use of the context and what is already known about the situation (top-down)" (Whitehurst \& Lonigan, 2003, p. 14). First bottom-up models were established. Then, top-down models gained ground and finally the interactive approaches started to proliferate by integrating the two previous ones by claiming that a successful reader cannot solely use either this or that approach but must rely on both sources of information to read.

(1) Theories underlying the bottom-up models (also referred to as serial-stage models, Stanovich, 1980) compare reading to solving a jigsaw puzzle. They argue that the process of learning to read is sequential: it starts from children learning the smallest textual units (i.e. letters) and progresses towards the understanding of whole texts and accessing meaning (i.e. the author's intended message) (Reutzel \& Cooter, 2012). The literature maintains that two bottom-up theories of the reading process remain popular even today (Adamikné Jászó, 2006; Reutzel \& Cooter, 2012). The first theory originates from Gough (1972). His (1972) "One Second of Reading model" describes the sequence of events that occur in one second of reading; therefore, his model is generally referred to as a sequential model. Iconic representation, letter identification, mapping, lexical research, and primary memory are the segments of the reading process, while character recognition, decoding and speed are the steps in reading acquisition (Gough, 1972). Another popular bottom-up theory is the theory of automatic information processing proposed by LaBerge and Samuels (1974). According to them, comprehension consists of two steps: first, the printed words have to be decoded, then, the decoded words have to be understood (Adamikné Jászó, 2006). LaBerge and Samuels (1974) hypothesize that the human mind functions like a computer and that visual input (letters and words) is sequentially entered into the reader's mind. The term "automaticity" implies that readers, like computers, have a limited ability to shift attention between the processes of decoding and comprehending (thinking about the meaning of the author's message in the text). The model predicts that if a large proportion of readers' attention and capacity is tied down by decoding the text, they will not be able to focus on the job of comprehending the author's message (Reutzel \& Cooter, 2012). Also, it is proposed that if reading is automatic with less focus on the decoding process, the result is improved comprehension (Adamikné Jászó, 2006). These early models were considered inadequate because they do not infuse crucial empirical findings in the reading literature and do not consider mechanisms "whereby higher-level processes can affect lower levels" (Stanovich, 1980, p. 34).

(2) A different approach to reading is represented by the top-down reading model. While "bottom-up processes take the form of a text-based decoding activity, top-down processes are reader-driven" (Lally, 1998, p. 268). They focus on what prior knowledge the reader possesses relevant to the text (Goodman, 1967; Lally, 1998). Smith (1971), a top- 
down approach advocate, opposed and completely rejected the hypothesis that decoding is a major constituent of reading (Adamikné Jászó, 2006; Smith 1978), in fact, reading, according to him, does not require precise decoding. In this model, readers extract meaning from the text without working out the sound of a word (Konza, 2006, p. 4). Instead, the emphasis lies on understanding. Goodman's (1967) strict top-down model, the psycholinguistic-transactional model describes reading as a psycholinguistic guessing game, a process "where the reader reduces his or her dependence upon the text through activities such as predicting and sampling" (Lally, 1998, p. 268). Top-down models have also been widely criticized for failing to account for fluent reading (Stanovich, 1980).

(3) The most recent model is the interactive one, it combines the important aspects of the bottom-up and top-down approaches. It is claimed that the interactive models function a more accurate conceptualization of reading than the purely bottom-up or top down models (Stanovich, 1980). The interactive model of reading (e.g., Rumelhart, 1977) hypothesizes that bottom-up and top-down processing "complement one another and function interactively as a process between the reader and the text" (Chen, Dronjic, \& Helms-Park, 2015). This model maintains that the knowledge the reader brings to the process of reading and specific data in the text are both important constituents of reading. "The interaction occurs at three levels: interaction between bottom-up and top-down processing, that between lower-level and high-level skills, and between reader's background knowledge and the background knowledge presupposed in the text. Bottom-up processing is activated by specific data from the text. Top-down processing starts with general predictions based on higher level schemata, then searches in the more specific level to confirm these predictions" (An, 2013, p. 134).

Stanovich's interactive compensatory model hypothesis (1980) further developed the interactive model by claiming that it is necessary to complete the lower level processes to initiate higher level ones. He proposes that a process at any level can compensate for deficiencies at any other level (Stanovich, 1980. p. 36).

Having argued that the components of comprehension processes can be separately studied, Kintsch and van Dijk (1978) developed an influential model of text comprehension. Their model assumes readers "for whom the decoding process has become automated" (Kintsch \& van Dijk, 1978, p. 364) but it is also claimed to have implications for readers who must invest a lot of resources into decoding. The model focuses on the semantic structures of the text interpreted as a set of propositions. It assumes that during reading, a text is transformed into several propositions. Besides the propositional structure of the text, the reader's prior knowledge is also an integral part of the model. Within this framework, meaningful comprehension occurs when the propositional structure of the text (i.e. text base) is integrated with the reader's prior knowledge and is "represented semantically in propositional form" (Vitale \& Romance, 2007, p. 96). It is assumed that the more cohesive the propositional structure of the text is, the less reader's prior knowledge is needed.

In sum, the reading models differ in the emphasis they place on the text and on the reader and what role they assign to smaller and larger units in texts.

\subsubsection{Methods of teaching reading}

Reading models provide a theoretical framework to methods of teaching reading (see Chapter 6). Generally, the approaches to teaching reading may be classified as analytical or synthetic (Robeck \& Wallace, 1990). The former refers to a more flexible absorption of language experience, whereas the latter includes the systematic and sequential acquisition of subskills (Adamikné Jászó, 2006). The synthetic practice is generally related to the bottomup model. Teachers who believe that this model represents the underlying mechanisms of the reading process the best start with teaching the detailed elements such as sounds of letters 
and syllables of language before moving on to larger chunks such as words, phrases and sentences (Robeck \& Wallace, 1990). The idea behind this method is that the processing of visual and auditory form of a particular word precedes the actual understanding of its meaning (Reutzel \& Cooter, 2012). The synthetic method relies on the phonological route to reading implying that a reader first breaks down words into smaller units and then gains access to their meaning (Temple, 1997).

The top-down model, on the other hand, assumes that the readers extract meaning by focusing on the whole word. It implies that good readers do not need to decode and make sense of shapes of letters because they initially focus on the whole word. After a child masters sight vocabulary, they break the larger units down into their constituent elements (Robeck \& Wallace, 1990). The whole language or whole word approach, where learners are taught to identify entire words rather than combinations of sounds, is an example of a top-down model (Reutzel \& Cooter, 2012). This approach gives priority to meaning construction (Snow, Burns, \& Griffin, 1998) and is associated with the semantic reading route (Csépe, 2014).

The interactive model encompasses the features of the bottom-up and top-down models. Teachers who opt for the interactive model use both instruction methods relying on phonics and a student's experiences with text, believing that each of them is equally important for understanding. In classrooms where the interactive model is preferred, students receive direct instruction on the speech sound-grapheme relationships in phonics as well as instruction in comprehension and reading strategies. Readers, therefore, with poor decoding skills could be more reliant on context than readers with good decoding skills (Reutzel \& Cooter, 2012).

\subsection{Summary}

This chapter aimed at providing a broad theoretical framework for the empirical chapters forming the second part of the thesis. The most fundamental concepts and models of reading were described so that the reader could identify the major components of reading that I elaborated on when conceptualizing reading and operationalizing it for assessment purposes. These discussions were meant to pave the way for the sections about reading literacy and system-level student assessment programs on reading (Chapter 2) and to allow readers to be able to see the associations between the theoretical and empirical parts more easily in light of what has been discussed so far. Chapter 3 provides a background to the empirical studies. Chapter 4 aims to cast light upon the relationship between the text and the activities with respect to different text formats. Chapter 5 puts the reader in the forefront of research, while Chapter 6 examines how the context shapes the understanding of texts with different formats. 


\section{CHAPTER 2}

\section{SYSTEM-LEVEL STUDENT ASSESSMENT PROGRAMS ON READING}

\subsection{Introduction}

Since the 1970s numerous national and international system-level assessment programs have aimed at mapping Hungarian students' reading achievement. However, an analysis of the studies and their scope in a chronological order suggests that the conceptualization of reading has gone through some reform over the decades. Changes reflected by the Study of Reading Comprehension as part of the Six Subject Survey (19701971) and the Reading Literacy Study (1990-1991) conducted by the International Association for the Evaluation of Educational Achievement (IEA) are the most tangible proofs. The former set out to be a cross national study on reading comprehension attainment, whereas the latter collected data on students' reading literacy in an international setting. The modification in terminology is quite apparent and it raises many questions. Is there a difference between reading comprehension and reading literacy as assessment constructs besides the apparent wording? What happened to reading comprehension? What factors and processes contributed to this change?

In what follows I set out to clarify these issues with the objective of contextualizing the discussion of reading literacy as a concept. The aim is to arrive at a better understanding of how reading became conceptualized in terms of a multiplicity of text formats and in particular how non-continuous texts came to be understood as reading. I have already discussed the definition and elements of reading comprehension in Chapter 1 at length. Therefore, in what follows, I shift my focus to literacy. First, the evolution of the term literacy and more specifically reading literacy is discussed. Second, the definitions adopted by the frameworks of international and national assessment programs on reading are described and compared. Finally, the results of Hungarian students in various data collection cycles are reported with respect to text format.

\subsection{Measuring the sociocultural dimension of reading: From reading comprehension to reading literacy}

The way system-level assessment programs define reading literacy has been fine-tuned over the years but ultimately, they reflect a broad notion about what reading means and what it is good for. Being the successor of IEA, the Progress in International Reading Literacy Study (PIRLS) relies on the principles adopted in the 1990-1991 assessment cycle. Currently, PIRLS uses the following definition of reading literacy:

Reading literacy is the ability to understand and use those written language forms required by society and/or valued by the individual. Readers can construct meaning from texts in a variety of forms. They read to learn, to participate in communities of readers in school and everyday life, and for enjoyment. (Mullis, Martin, \& Sainsbury, 2015, p. 12)

Similarly, the Programme for International Student Assessment (PISA) adopted a broad understanding of what reading infuses.

Reading literacy is understanding, using, reflecting on and engaging with written texts, in order to achieve one's goals, develop one's knowledge and potential, and participate in society. (OECD, 2016c, p. 49) 
Declaring to be in line with international practices, the Hungarian National Assessment of Basic Competencies (NABC) views...

...reading as the ability to understand, use and reflect on written texts in order to achieve one's goals, develop one's knowledge and ability, in order to recreate and successfully adapt to or participate in everyday communication [A szövegértés az írott nyelvi szövegek megértésének, használatának és a rájuk való reflektálásnak a képessége annak érdekében, hogy az egyén elérje céljait, fejlessze tudását, képességeit, kikapcsolódjék, sikerrel alkalmazkodjon vagy vegyen részt a mindennapi kommunikációs helyzetekben] (Balázsi, Balkányi, Ostorics, Palincsár, Rábainé Szabó, Szepesi, Szipőcsné Krolopp, \& Vadász, 2014, p. 11).

These definitions suggest that reading is not only viewed as the ability to understand written pieces of information but also as a means to accomplish an individual's goals in society. So, besides the ability of extracting and constructing meaning (see Chapter 1) the use of the information gained from the text is also considered as important. Moreover, they all take into account the social context of literacy.

The current definitions of reading literacy in the above measurements reflect the shift that the understanding and importance of reading has undergone over time alongside changes in society, economy, culture, academic research and learning (Kamerman, 2006, p. 147; OECD, 2006, p. 46). Thus, the history of the conceptualization of reading is closely intertwined with the changing definition of literacy.

Although the terminology and the exact evolutional path of literacy and reading literacy are not entirely clear, Kamerman's (2006) work and Berkman, Davis, and McCormack's (2010) study may serve as a good starting point in our discussions. According to Kamerman, being literate - for most of its history in English - referred to being familiar with and knowledgeable about literature or, in broader terms, being well educated and learned. In the late nineteenth century, another connotation was attached to the word literate. Since then "it has also come to refer to the abilities to read and write texts" (Kamerman, 2006, p. 148). Additionally, in an overview on the evolution of the concept of literacy, Berkman, Davis, and McCormack (2010) claim that initially the term literacy was used to denote an "individuals' ability to sign his name on a legal document" (p. 10) and then referred to the ability to read and write. Although at the time literacy was not a well-defined construct, it was used to identify completely illiterate individuals in the population. People who could reportedly read and write were termed literate, whereas those who did not possess these basic skills were considered illiterate.

In the twentieth century, a broader and more sophisticated approach to the conceptualization of literacy emerged taking into account the demands of the labor market and society. Efforts were made to make a difference between literate and functionally literate people (Graff, 1991). The term of functional literacy was coined by the Civilian Conservation Corps in the 1930s. It was tied to academic achievement. Functional literacy was defined in terms of years spent in formal education suggesting that "a person with that much schooling could read the necessary printed material of everyday life" (Champagne, 2008 , p. 65). The basic level of functional literacy initially meant having three or more years of schooling enabling individuals to compete in the labor market; however, today, completing higher levels of education is considered necessary to function in society (Kirsch, 2001, p. 5). The United Nations Educational, Scientific and Cultural Organization (UNESCO) World Conference of Ministers of Education on the Eradication of Illiteracy in 1965 did not only spice this concept with a new approach (Bhola, 1970) but it also had a decisive role in the evolution of ideas regarding education in general and literacy work in particular (UNESCO, 1965) with an aim to combat illiteracy which then affected almost half 
of the world's adult population. The first world congress aiming at decreasing the illiteracy rate declared that education could no longer be confined to school and defined functional literacy as...

...the essential knowledge and skills, which enable [one] to engage in all those activities literacy is required for effective functioning in [one's] group and community, and whose attainments make it possible for [one] to continue to use these skills towards [one's] own and the community's development (Graff, 1991, p. 3).

As a result of the movement, by the 1980's the prevalence of complete illiteracy was declining; yet, a significant proportion of the population was reported to have reading difficulties (Berkman, Davis, \& McCormack, 2010). From this point on the subsequent definitions of literacy have incorporated functional literacy (Champagne, 2008, p. 65).

The universal importance of reading as a component of literacy was highlighted yet again in 1990, named the "International Year of Literacy" by the UNESCO (Lietz, 1996). The underlying idea was to declare that reading was a fundamental human right and to emphasize that it was a basic requirement for individual and national development at the end of the $20^{\text {th }}$ century. Yet - in spite of the ongoing efforts to pare down illiteracy - for nearly one fifth of the earth's population (Elley, 1992, p. 1.), the printed word still had nothing to say. The alarming proportion of illiterate people called for educational efforts to ensure that students have acquired the necessary skills to read and understand "in order to participate fully in all processes and activities within their communities" (Lietz, 1996, p. 1). Motivated by and drawing on the same spirit as the previously mentioned movements, one year later the notion of literacy was also framed by the US National Literacy Act of 1991. It defined literacy as "an individual's ability to read, write and speak in English, and compute and solve problems at a level of proficiency necessary to function on the job and in society, to achieve one's goals, and develop one's knowledge and potential'" (The US National Literacy Act of 1991 cited by Irwin, 1991, p. 7). These definitions clearly show that social and economic expectations broadened the original idea of the literate person, thus the structure and composition of literacy also changed. In addition to reading and writing, computing and problem solving appeared as prerequisites of coping in society.

All in all, the definitions of literacy represent the bulk of skills needed for an individual to function well and be a successful member of society. Being literate has always been a relative label as standards for literacy have been changing over the decades (Kirsch, 2001). As a result of the increasing standards, literacy is no longer considered an ability only acquired in childhood to read and write. "Instead, it is viewed as an expanding set of knowledge, skills and strategies which individuals build on throughout life in various situations, and through interaction with their peers and with the larger communities in which they participate" (OECD, 2006, p. 46). In the $21^{\text {st }}$ century literacy has even been expanded to include newer forms of literacy (like digital literacy) more suitable for complex information environments (Masny \& Cole, 2009, p. 1).

So far we have seen how the concept of literacy has been molded with reading as a core linguistic ability over time; however, the emergence of the definition of reading literacy requires further clarification. With the expanding notion of literacy, it became a "serial collocated suffix in new terms" (Masny \& Cole, 2009, p. 1). While there are instances where we can attach a name and date to the birth of a particular literacy designating minimal competence required in a particular field (e.g., emergent literacy was first used by Marie Clay, 1966; visual literacy by John Debes, 1968; scientific literacy by Hurd, 1958; health literacy by Simonds, 1974) the emergence of the term reading literacy is less obvious. Bormuth (1973) published a paper on the definition and assessment of reading literacy in 1973 but I found no literature that would make mention of the inventor and first official use 
of the term. Based on my literature review, I assume that the need to express how well an individual reads in a quantitative way brought along increasingly well-defined measures with administrative or educational purposes that applied the distinctive term of reading literacy.

Literacy became a multifaceted entity that may be either conceived in a traditional sense rooted in empirical reading research or as a concept primarily reflecting socio-cultural expectations. The former is regarded as reading comprehension, the latter as reading literacy. Reading comprehension lays emphasis on the meaning making process and outcomes whereas reading literacy goes beyond this conceptualization. Reading literacy encompasses reading comprehension but the term is used to imply much more than decoding, reading aloud and meaning making. It highlights the importance of the optimal developmental level of reading skills both for the individual and their functioning in their broadest environment. This is a perspective that Csapó (2010) identifies as the social-cultural domain of knowledge. Csapó broadens the above conceptualization by referring to literacy as a domain specific but transferable knowledge and skills unlike expertise, which is only efficient in a specific domain (Csapó, 2004).

\subsection{The conceptualizations and operationalization of reading literacy for assessment purposes in international surveys of the Hungarian school-aged population}

Hungary has been taking part in international student assessment programs on reading for the past 40 years. The IEA has conducted research into Hungarian students' reading since the assessment cycle of 1970 . The PISA has assessed Hungarian students' reading literacy at three-year intervals since its conception in 2000, while the IEA Progress in International Reading Literacy Study (PIRLS) has been implemented every five years since 2001 with Hungary's participation.

The first international study that Hungary took part in was the Study of Reading Comprehension organized by the IEA in 1970-71. The instruments aimed at measuring, besides reading component skills, reading comprehension by means of continuous texts in three different age groups. The reading comprehension rationale explicitly excluded other forms of comprehension such as plans, diagrams, charts or maps (Bloom, 1969). The importance of reading lied in playing a key role in successful learning and understanding of most other subjects (i.e. instrumental to learning) (Bloom, 1969). Reading comprehension was identified as a "determiner of achievement in the more specific subject matter skills" (Thorndike, 1973b, p. 175). Although the pursuit to embed reading in a broader social context (i.e. read to function in one's community) emerged in the efforts summarized in the previous section, the IEA perspective suggests that this was not yet translated into the assessment framework of the Study of Reading Comprehension. Evidently, at that time no specific broader/socio-cultural purpose was attached to reading. Indeed, the view of "reading as reasoning" prevailed (Thorndike, 1973a).

Nevertheless, it is important to note that although the definition of reading comprehension did not show any resemblance to today's reading literacy terminology, in the reading comprehension test, reading categories, similar to what we call comprehension processes or cognitive aspects to reading now (see Section 1.4), were established based on the ability answering of an item requires. The reading categories included (1) following the organization of a passage, (2) responding to questions that are specifically answered in the passage, (3) drawing inferences from a passage, and (4) determining the writer's purpose (Lietz, 1996). These categories imply that reading was an entity moving way beyond decoding and pointing towards the cognitive aspects involved in measuring reading literacy.

Preparations for the next IEA large-scale study on reading, that Hungary was also part of, began in 1988 (Lietz, 1996). The instruments for what was called the Reading Literacy 
Study were designed for administration in two age groups (9- and 14-year-olds) in 1991. This time, for the data collection the IEA adopted a modified definition of reading literacy: "reading literacy is the ability to understand and use those written language forms that are required by society and/or valued by the individual" (Elley, 1994, p. 5). Comparing the titles and definitions of the first and second major IEA study reveals a paradigm shift from literal comprehension to functional literacy (Binkley \& Rust, 1994). While in 1970, reading was confined to comprehension of texts traditionally associated with reading (i.e. continuous texts) without taking into account the social benefits of being literate, 20 years later the social context was also included. It is noteworthy that along with the inclusion of the requirements of society the multiplicity of written language forms (reflected by the plural) that one encounters in society was also recognized and included in the definition. Reading literacy came to include "both a range of competencies and a set of habits and practices, arrayed along various dimensions such as reading stop signs to being aware of nuances in complex philosophic texts; from reading only what is necessary to pursuing one's further learning and recreation through books and journals" (Binkley \& Rust, 1994, p. 103).

In sum, one could be considered as literate if he or she was able to understand and use different written pieces of information both for pleasure and to function in society. However, Bechger, van Schooten, de Glopper, and Hox (1998) made an important point regarding the measured construct. Although the tasks should have assessed how students could understand and use written language forms, the short passages followed by multiple-choice tasks only measured reading comprehension rather than its functional nature (Bechger et al., 1998).

For the purposes of the Reading Literacy Study, three distinct domains were identified in reading, according to Binkley and Rust (1994, p. 103), representing different text types: (1) narrative, (2) expository and (3) documents. The former two clearly represent continuous texts of different types, style and designation. However, documents "referring to structured, tabular texts, such as forms, charts, labels, graphs, lists, and sets of instructions where the reading requirements typically involve locating information or following directions, rather than continuous reading of connected texts" (Binkley \& Rust, 1994, p. 104) clearly concern issues of different formats rather than text typology. So, besides the continuous texts used at the very first reading comprehension assessment of IEA, documents (i.e. non-continuous texts) also appeared in the test booklets. However, drawing on previous experiences and teachers' feedback, the PIRLS studies undertook to assess two major reading purposes: literary and informational. Literary texts are made up of short stories and novels, whereas informational texts include written materials with a wide range of content including scientific, geographical, and biographical (Mullis, Martin, \& Sainsbury, 2015). In informational texts prose is complemented with organizational and presentational materials such as maps, text boxes, diagrams, photos, illustrations, lists or tables. If we translate this information into categories of text format, we may conclude that PIRLS uses continuous, mixed and non-continuous texts to assess students' reading literacy.

It is also interesting that in Elley's report (1992) on the results the word reading is only used for continuous texts. In case of understanding and using information gained from documents (maps and timetables in the study - i.e. non-continuous texts) the word study is used. This suggests incoherence within the framework. The framework used texts with different formats to be able to provide a greater coverage of the domain of reading literacy but the wording of the report implies that dealing with non-continuous texts belong to a different construct unspecified in the framework.

Presumably, this survey marked the emergence of a clear and unified concept of reading literacy, as from this time on the term has been used in more or less the same way in different assessment practices. 
The Program for International Student Assessment (PISA) reading studies conducted under the auspices of the Organization for Economic Co-operation and Development (OECD) also defined reading literacy as "understanding, using and reflecting on written texts, in order to achieve one's goals, to develop one's knowledge and potential, and to participate in society" (OECD, 1999, p. 12). By the time of the first implementation, the OECD had had ample opportunity to draw from previously accumulated experiences in reading literacy assessment. The IEA Reading Literacy Study and the International Adult Literacy Survey were the primary sources of the adopted definition reflecting "the importance of reading skills for active participation in society (OECD, 2010a, p. 20). Briefly, PISA has been making attempts to provide an answer to the following question: "Can students read different kinds of texts in a variety of contexts, either for personal satisfaction or for practical reasons?" (OECD, 2010a, p. 30).

In line with the prevailing trends, from the very first PISA reading literacy survey in 2000, PISA utilized different text formats to cover the domain: continuous and noncontinuous texts; the latter are also referred to as documents (Adams \& Wu, 2002). OECD took a different approach to measuring reading literacy than IEA to overcome the bottlenecks concerning the coverage of reading literacy with tasks that actually match the requirements articulated in the definition. It used items that simulate the diverse literacy demands of daily life, which resulted in better construct validity (Bechger et al., 1998).

The recognition of the increasing prevalence of electronic texts in students' reading led to an expansion in how reading literacy was measured in both assessment program designs. In response to the challenges defining reading literacy in a digital environment posed, constructs such as electronic reading (OECD, 2010a) and web-based reading (Mullis, Martin, Kennedy, Trong, \& Sainsbury, 2009) emerged. This shift made text categorization even more complex: texts with mixed and multiple formats appeared on the agenda of discussions. In addition, the inclusion of materials to be read on an electronic medium led to the adjustment of the cognitive aspects as well (OECD, 2010a, p. 14).

In sum, Hungary entered these international reading assessment programs at their conception. The framework of the youngest program conducted by IEA revealed a major shift in terms of the measured construct between the first and the second assessment cycle. Over the twenty-year-period that elapsed between the two IEA reading assessments, reading literacy appeared on the agenda of the program instead of reading comprehension. The rest of the IEA studies relied on the reading literacy concept developed by IEA for the 1991 Reading Literacy. PISA drew on previous international experiences in this domain so, it immediately adopted the construct of reading literacy at the beginning of the program. Today, the above initiatives all use literacy in preference to reading comprehension by incorporating functional literacy into today's definitions (Champagne, 2008, p. 65). In order to be able to cope in academic as well as in everyday life, and successfully function in society, one has to understand and use the information written language forms include. It has come to be recognized that literacy occurs in a variety of language contexts and written information around us takes many forms from sequentially organized novels to less structured bus timetables and maps enriched with "pictorial and tabular data" (Mullis, Martin, \& Sainsbury, 2015, p. 15). As Binkley and Rust (1994) put it "reading literacy involves both a range of competencies and a set of habits and practices, arrayed along various dimensions such as reading stop signs to being aware of nuances in complex philosophic texts; from reading only what is necessary to pursuing one's further learning and recreation through books and journals" (p. 103).

This shift in emphasis also sheds light on how documents or non-continuous, mixed and multiple texts came to be understood as materials to be read (see Tables 2.1 and 2.2), although PIRLS uses the term 'purposes for reading' and associates that with different 
formats (Mullis, Martin, \& Sainsbury, 2015) and PISA is the one that explicitly uses text format as a structural component of the study. Initially, the IEA assessment privileged continuous texts but gradually texts have referred to anything that can be read for meaning. Nowadays, the definition of non-continuous text (see Section 1.3) shows that a text is to be interpreted in its broadest sense as a system of signs that can take any form "ranging from sequential ordering of written material to snippets of words and phrases arranged with pictorial and tabular data" (Mullis, Martin, \& Sainsbury, 2015, p. 16) and also visual displays, such as diagrams, pictures, maps, tables, graphs and comic strips" (OECD, 2016c, p. 50). The refined text categorization implies that reading is not a single skill suited to all text types and formats (Beach \& Appleman, 1984).

By providing a wide range of materials to read, these assessments do not only help identify why 'Johnny can't read' but also portray the extent to which students are capable of reading texts with different formats accurately. Admittedly, this point of view has become widespread in the field of assessment and evaluation. However, in reading research and theory studies focusing on non-continuous texts are scarce.

\subsubsection{A comparative analysis of the frameworks of OECD PISA and IEA PIRLS reading assessments}

The focus of PIRLS and PISA on reading literacy shares as many similarities as differences. The PIRLS and PISA differ from one another on several key features, including purpose, partners, population, and content coverage. I draw on the dimensions identified in Stephens and Coleman's (2007) work to compare and contrast the two assessments and enrich the picture with additional features in order to show how reading literacy, text formats and reading processes are defined in these studies. The present section relies on the assessment frameworks of the two surveys. The assessment frameworks define the content for the assessments, as "they contain a detailed, structured description of knowledge" (Csapó, Józsa, Steklács, Hódi, \& Csíkos, 2012, p. 190). They describe the content to be acquired, the processes to be performed, and the contexts in which knowledge and skills are to be applied (Cresswell \& Vayssettes, 2006). Thus, they help test developers and policy makers by offering a clear definition of the scope and method of testing. Tables provided in the following section will serve with more details on each of the assessment cycles dating back to the conception of the studies.

The efforts to increase the population's literacy level reached international organizations like the IEA or OECD sponsoring and commissioning international student assessment programs (Bechger, van Schooten, de Glopper, \& Hox, 1998; Tóth, 2014). In response to the need for internationally comparable evidence on student performance, the IEA pioneered in launching its surveys in 1960's whereas the OECD launched the Program for International Student Assessment (PISA) forty years later, which has become the hallmark of the organization's educational work. PISA brings together the governments of OECD countries as well as experts to "monitor the outcomes of education systems in terms of student achievement on a regular basis and within a common framework that is internationally agreed upon" (Adams \& Wu, 2002, p. 3). PISA is sponsored by the OECD but the Australian Council for Educational Research (ACER) undertook the design and implementation for the period 1998-2010 (Turner \& Adams, 2006).

\section{PURPOSE AND PROXIMITY TO CURRICULUM}

PIRLS by definition is a curriculum-based survey (Mullis, Martin, \& Gonzalez, 2004) which provides information on ,the reading achievement of students in the fourth grade and on related contextual aspects such as reading curricula and classroom practices across countries" (Stephens \& Coleman, 2007, p. 2). There is evidence from Elley (1992) that the 
first Reading Literacy test was "representative of the reading curriculum in achievement criteria" (p. 8). Although we know that the assessment content is based on what is taught in the given domain, in my opinion it is hard to understand what curriculum-based means in case of a skill the acquisition of which is a long and complex process extending over long years and beyond elementary education (e.g., Chall, 1996) and forms the basis of more than one school subject and academic discipline. According to the framework, the curricular nature of reading is best reflected in the two major types of reading materials used in its assessment: fiction or literary texts and non-fiction or informational texts because these are the types of materials that are reportedly read in schools across the participating countries (Mullis, Martin, \& Gonzalez, 2004).

The PISA measures the yield of education systems in terms of how students can apply the acquired knowledge and skills to real world contexts at the age of 15. PISA's literacy concept puts emphasis on the knowledge that fifteen-year-olds are supposed to possess and master to function in different situations in modern society (Csapó \& Csépe, 2012).

\section{PARTICIPATING COUNTRIES}

Information provided by reports on each and every cycle reveals that the circle of countries in which test administration takes place is not constant in any of the assessments and the PIRLS and PISA assessment also differ in terms of the participating countries. IEA and its PIRLS successor witnessed a huge enlargement since its first administration providing benchmarks with different groups of countries at each and every assessment cycle (IES NCES, 2017). The same holds true for PISA with the number of participating countries ranging from 43 to 75 between 2000 and 2015 (OECD, 2017). Up to the latest triennial PISA assessment cycle held in 2015, students representing more than 70 OECD and non-OECD economies have participated in the assessments.

The programs also vary in terms of the labels they apply for participants. The PISA makes a difference between OECD members and all other participating entities called "partner countries" or "partner economies". PIRLS differentiates between IEA members referred to as countries and benchmarking participants (IES NCES, 2017).

If we take OECD membership as a point of reference, we can see that there is an overlap between PISA and PIRLS participants.

\section{TARGET POPULATION}

Reflecting the previously discussed purposes, these surveys focus on different groups defining the target population either in terms of grade or age. PIRLS is grade-based, so it defines the target population "in terms of the amount of schooling students have received" (Joncas \& Foy, 2012, p. 1), whereas PISA is an age-based study. At present, PIRLS currently measures 4th graders' (the mean age at the time of testing is at least 9.5 years), whereas PISA intends to assess 15-year-old students' reading literacy. The former IEA studies on reading, which served as a basis for the PIRLS frameworks in many aspects, applied an agebased approach, but the PIRLS studies defined a target grade "that represents four years of schooling, counting from the first year of ISCED Level 1" from right on their conception (Mullis, Martin, Kennedy, Trong, \& Sainsbury, 2009, p. 60). This population was chosen for PIRLS because this grade is an important milestone in children's reading development. This period is marked by a transition from having learned how to read to having started reading to learn (Mullis et al., 2009, p. 8). PISA, however, focuses on the performance of students who, between the age of 15 years 3 months and 16 years 2 months, are in most countries near the end of compulsory schooling instead of a specific year of school.

PIRLS and PISA both apply exclusions applicable to students who cannot perform in the testing environment and situation due to functional and intellectual disabilities or insufficient language experience (Joncas \& Foy, 2012, pp. 5-6; OECD, 2014a, p. 67). 


\section{PERIODICITY AND FOCUS}

Both studies operate periodically but at different intervals. PISA takes place in every three years, whereas PIRLS operates on a five-year cycle. PIRLS is dedicated to solely measuring reading, whereas PISA assesses three domains in each cycle: reading, mathematics and science. However, only one domain is in special focus each time. Reading received an outstanding role in 2000 and 2009.

\section{DEFINITIONS OF READING LITERACY}

Both PISA and PIRLS adopted the term reading literacy to cover the construct that they intend to measure. According to PISA, "Reading literacy is understanding, using, reflecting on and engaging with written texts, in order to achieve one's goals, develop one's knowledge and potential, and participate in society" (OECD, 2013, p. 61). For PIRLS, "reading literacy is defined as the ability to understand and use those written language forms required by society and/or valued by the individual. Young readers can construct meaning from a variety of texts. They read to learn, to participate in communities of readers in school and everyday life, and for enjoyment" (Mullis et al., 2009, p. 11).

The two definitions overlap to a great extent. The keywords which the frameworks embrace are: understanding, using, written texts/language forms, and society. They are used deliberately to reflect an applied linguistic and functional approach to reading in various situations and for a wide range of purposes. The studies carefully avoid the employment of the term reading because reading is often understood by lay people "as simply decoding, or even reading aloud, whereas the intention of this survey is to measure something broader and deeper. Reading literacy includes a wide range of cognitive competencies, from basic decoding, to knowledge of words, grammar and larger linguistic and textual structures and features, to knowledge about the world" (OECD, 2013, p. 61). These approaches to reading literacy emphasize "the interactive nature of reading and the constructive nature of comprehension” (Mullis et al., 2009, p. 68; Mullis, Martin, \& Sainsbury, 2015, p. 16; OECD, 2016c, p. 49).

ORGANIZATIONAL ELEMENTS OF THE ASSESSED DOMAIN: TEXT FORMAT AND READING PROCESSES

Albeit having adopted a similar stance on reading literacy differences between the studies may be detected in how they go about providing a full coverage of the domain regarding text categorization and reading processes.

PISA works with a multiple array of texts associated with in-school and outside school environments and practices (OECD, 2013, p. 60). In its framework, text refers to coherent texts "in which language is used in its graphic form, whether printed and digital" (OECD, 2013, p. 61). The range of materials used in the assessment is classified along the dimensions of medium, environment, text type and text format. Students are required to activate reading literacy skills "that include finding, selecting, interpreting and evaluating information" in the texts (OECD, 2013, p. 60).

PIRLS essentially examines two aspects of reading literacy: purposes for reading in and out of school and the processes of comprehension (Mullis et al., 2009, p. 19). The purposes that young students read for are reading for literary experience and reading for information. These types of readings are in turn associated with different types of texts and text forms. Texts and the related tasks assessing reading for literary experience always take the form of a continuous text, whereas informational texts need not be continuous. They can be presented in the form of a brochure, graph, table etc. (Mullis et al., 2009, p. 23). Tasks measuring four types of comprehension processes are presented to students based on the passages of any form: (1) focus on and retrieve explicitly stated information, (2) make straightforward inferences, (3) interpret and integrate ideas and information, (4) evaluate and critique content and textual elements (Mullis, Martin, \& Sainsbury, 2015, p. 13). 
As far as text format is concerned, the basic principle of PIRLS is that "any given text type can take many forms and combinations of forms" (Mullis et al., 2015, p. 12). Since "reading literacy is the ability to understand and use those written language forms required by society and/or valued by the individual" (Mullis et al., 2015, p. 12) and PIRLS also seeks to include texts that students are likely to encounter across the curriculum or outside school. Thus, although not with these wordings, the frameworks distinguish two main types of text formats: (1) continuous and (2) non-continuous. However, since 2009, PISA has also been using the additional category of (3) mixed and multiple texts claimed to be prevalent in the digital medium.

Both PIRLS and PISA make reference to a relationship between text format and comprehension. PIRLS claims that "the content, organization, and style that may be typical of a particular text genre have implications for the reader's approach to understanding the text" (Mullis, Martin, \& Sainsbury, 2015, p. 16). Similarly, PISA maintains that the processes and strategies the reader uses in the meaning making process, which "are expected to vary with context and purpose as readers interact with a variety of continuous and noncontinuous texts" (OECD, 2016c, p. 49).

In sum, although there are some differences in coverage, periodicity and target populations, both assessment frameworks (1) adopted and operationalized the definition of reading literacy; (2) view reading as a constructive and interactive process; (3) use different text formats and reading aspects to ensure a wider coverage of the domain; and (4) note that the structural elements of text influence readers' strategies and understanding.

\subsubsection{Results of Hungarian students in various data collection cycles of IEA PIRLS and PISA}

In cooperation with the IEA up to the present day Hungary has participated in six data collection cycles measuring students' reading skills. Table 2.1 gives a snapshot of the evolution of the IEA assessment focusing on the constructs, the target groups, the assessed dimensions in terms of text formats and reported results based on students' mean achievement in different text formats.

As discussed in the previous section, the organizational elements of the domain in PIRLS differ from those used by PISA. While PIRLS makes a distinction between reading for literary and informational purposes, PISA clearly uses texts format as an organizational element of reading literacy. In PIRLS, the texts used for assessment in the domain differ from each other in the way they are organized. Texts with chronological organization are used for the assessment of reading for literary purposes, whereas texts with nonchronological organization are used for measurement purposes in the other dimension (Mullis, Martin, Gonzalez, \& Kennedy, 2003). Reading for literary purposes is mostly associated with fiction (Mullis et al., 2003). Therefore, the categories can be considered equivalent with the ones defined by PISA. Reading for literary purposes entails continuous texts, whereas reading for information is more likely to involve non-continuous texts. 
Table 2.1 An overview of the studies and results of Hungarian students' reading achievement in different text formats in assessment cycles conducted by the IEA from 1970 to date

\begin{tabular}{|c|c|c|c|c|c|}
\hline $\begin{array}{l}\text { Year of data } \\
\text { collection }\end{array}$ & $\begin{array}{l}\text { Measured } \\
\text { construct }\end{array}$ & $\begin{array}{l}\text { Population - } \\
\text { Age (Grade) }\end{array}$ & $\begin{array}{l}\text { Assessed dimensions in } \\
\text { terms of text formats }\end{array}$ & $\begin{array}{l}\text { Results based on mean } \\
\text { achievement in dimension } \\
\text { related to different text } \\
\text { formats }\end{array}$ & Additional findings on results along text formats \\
\hline $\begin{array}{l}1970-1971 \\
\text { (Six Subject } \\
\text { Survey) }\end{array}$ & $\begin{array}{l}\text { reading } \\
\text { comprehension }\end{array}$ & $\begin{array}{l}10,14, \\
\text { terminal level } \\
\text { of secondary } \\
\text { school }\end{array}$ & continuous text & not applicable & \\
\hline $\begin{array}{l}1991 \text { (Reading } \\
\text { Literacy Study) } \\
\text { (Elley, 1992) }\end{array}$ & reading literacy & $\begin{array}{l}9,14 \\
\text { (3rd, 8th) }\end{array}$ & $\begin{array}{l}\text { narrative, expository } \\
\text { and document }\end{array}$ & $\begin{array}{l}\text { 9-year-olds: narrative }> \\
\text { expository }>\text { document, } \\
\text { 14-year-olds: document }> \\
\text { expository }>\text { narrative }\end{array}$ & $\begin{array}{l}\text { Girls were consistently ahead in narrative and } \\
\text { expository reading. The smallest gender differences } \\
\text { were found in the documents domain. }\end{array}$ \\
\hline $\begin{array}{l}2001 \text { (PIRLS) } \\
\text { (Mullis, Martin, } \\
\text { Gonzalez, \& } \\
\text { Kennedy, 2003) }\end{array}$ & reading literacy & $4^{\text {th }}$ grade & $\begin{array}{l}\text { texts read for literary } \\
\text { and informational } \\
\text { purposes }\end{array}$ & literary $>$ informational & $\begin{array}{l}\text { Girls had significantly higher achievement than } \\
\text { boys for both major reading purposes. The gender } \\
\text { difference was smaller in the reading for } \\
\text { information dimension. }\end{array}$ \\
\hline $\begin{array}{l}2006 \\
\text { (PIRLS) (Mullis, } \\
\text { Martin, Kennedy, \& } \\
\text { Foy, 2007) }\end{array}$ & reading literacy & $4^{\text {th }}$ grade & $\begin{array}{l}\text { texts read for literary } \\
\text { and informational } \\
\text { purposes }\end{array}$ & literary $>$ informational & $\begin{array}{l}\text { For the literary reading purpose, girls had } \\
\text { significantly higher achievement than boys but no } \\
\text { significant difference was found between the } \\
\text { genders in informational reading. }\end{array}$ \\
\hline $\begin{array}{l}2011 \text { (PIRLS) } \\
\text { (Mullis, Martin, } \\
\text { Foy, \& Drucker, } \\
\text { 2012), }\end{array}$ & reading literacy & $4^{\text {th }}$ grade & $\begin{array}{l}\text { texts read for literary } \\
\text { and informational } \\
\text { purposes }\end{array}$ & literary $>$ informational & $\begin{array}{l}\text { Girls outperformed boys in both reading purposes. } \\
\text { The gender difference was less pronounced in } \\
\text { reading for information. }\end{array}$ \\
\hline $\begin{array}{l}2016 \text { (PIRLS) } \\
\text { (Mullis, Martin, } \\
\text { Foy, \& Hooper, } \\
\text { 2017) }\end{array}$ & reading literacy & $4^{\text {th }}$ grade & $\begin{array}{l}\text { texts read for literary } \\
\text { and informational } \\
\text { purposes }\end{array}$ & literary $>$ informational & $\begin{array}{l}\text { Girls had a greater advantage compared to boys in } \\
\text { literary reading than boys. The gender difference } \\
\text { was less pronounced in reading for information. }\end{array}$ \\
\hline
\end{tabular}


As far as the measured population is concerned, Table 2.1 shows that there has been a visible tendency to reduce the assessment scope to a young population when an important transition point in children's reading development occurs. This aspiration is explicitly stated in the frameworks of the PIRLS studies. Also, having adopted a grade-based approach instead of the initial age-based approach meant that years spent in formal education came to be used as a basis for sampling.

Results yield evidence that significant differences prevailed in Hungarian students' performances along the dimensions of reading for literary and informational purposes in all assessments. In the first study on reading literacy, the older population did better at reading non-continuous texts but the PIRLS reports repeatedly show that $4^{\text {th }}$ graders comprehend and use continuous texts significantly better than non-continuous ones. The report also mentions that many countries performed relatively better or worse in one purpose compared to the other (Mullis et al., 2003, p. 41).

In response to the results gained in 1991, Bechger, van Schooten, de Glopper, and Hox (1998) offered explanations for the differences in the reading literacy scores between domains. According to them, the special emphasis on certain types of reading material in a school system and time spent on reading differing across domains may serve as a meaningful explanation for the prevalent difference in achievement in different domains representing different text formats. Mullis, Martin, Gonzalez, and Kennedy (2003) extended the range of factors that can be tied to the achievement disparity. According to them, "differences may be related to one or more factors, such as emphases in intended curricula, or widely used textbooks, strengths or weaknesses in curriculum implementation, and the grade level at which certain reading comprehension strategies are introduced (Mullis et al., 2003, p. 41). However, the reports only include gender as a variable that gives us a more diverse picture on students' achievement in reading for different purposes.

Gender is a commonly used variable in the analysis and interpretation in empirical reading research. IEA has also been following this trend. Notably, girls consistently outperform boys in reading literacy. Taking into consideration text formats further enriches this phenomenon with additional information. With the exception of the 2006 assessment cycle, girls have consistently been ahead of boys in narrative and expository reading and reading for literary purposes. The smallest gender differences were found in the documents domain in every case.

Up to now Hungary has participated in six PISA reading literacy assessments (Table 2.2). The frameworks have been rather consistent in terms of the measured construct and the population. Therefore, no changes can be observed between the assessment cycles with regards to these. 
Table 2.2 An overview of the studies and results of Hungarian students' reading achievement in different text formats in assessment cycles conducted by the OECD from 2000 to date

\begin{tabular}{|c|c|c|c|c|c|}
\hline Year of data collection & $\begin{array}{c}\text { Measured } \\
\text { construct }\end{array}$ & $\begin{array}{l}\text { Population } \\
\quad-\text { Age }\end{array}$ & $\begin{array}{l}\text { Assessed dimensions in } \\
\text { terms of text formats }\end{array}$ & $\begin{array}{l}\text { Results based on mean achievement in } \\
\text { different text formats }\end{array}$ & $\begin{array}{l}\text { Additional findings on results along text } \\
\text { formats }\end{array}$ \\
\hline $\begin{array}{l}2000^{*} \\
\text { (Kirsch, de Jong, } \\
\text { Lafontaine, McQueen, } \\
\text { Mendelovits, \& } \\
\text { Monseur, 2002) }\end{array}$ & $\begin{array}{l}\text { reading } \\
\text { literacy }\end{array}$ & 15 & $\begin{array}{l}\text { continuous, } \\
\text { non-continuous }\end{array}$ & continuous > non-continuous & \\
\hline $\begin{array}{l}2003 \\
(\mathrm{OECD}, 2004 b)\end{array}$ & $\begin{array}{l}\text { reading } \\
\text { literacy }\end{array}$ & 15 & $\begin{array}{l}\text { continuous, } \\
\text { non-continuous }\end{array}$ & $\begin{array}{l}\text { The report does not include any } \\
\text { information on students' achievement } \\
\text { in different text formats }\end{array}$ & \\
\hline $\begin{array}{l}2006 \\
(\mathrm{OECD}, 2007)\end{array}$ & $\begin{array}{l}\text { reading } \\
\text { literacy }\end{array}$ & 15 & $\begin{array}{l}\text { continuous, } \\
\text { non-continuous }\end{array}$ & $\begin{array}{l}\text { The report does not include any } \\
\text { information on students' achievement } \\
\text { in different text formats }\end{array}$ & \\
\hline $\begin{array}{l}2009^{*} \\
(\mathrm{OECD}, 2010 \mathrm{~b})\end{array}$ & $\begin{array}{l}\text { reading } \\
\text { literacy }\end{array}$ & 15 & $\begin{array}{l}\text { continuous, } \\
\text { non-continuous, mixed } \\
\text { and multiple }\end{array}$ & continuous $>$ non-continuous & $\begin{array}{l}\text { Girls and boys perform better on the } \\
\text { continuous text subscale. Girls outperform } \\
\text { boys both in the continuous and in the non- } \\
\text { continuous subscale but the gap narrows } \\
\text { substantially between boys' and girls' } \\
\text { performance on the non-continuous subscale. }\end{array}$ \\
\hline $\begin{array}{l}2012 \\
(\mathrm{OECD}, 2014 \mathrm{~b}, \mathrm{~d})\end{array}$ & $\begin{array}{l}\text { reading } \\
\text { literacy }\end{array}$ & 15 & $\begin{array}{l}\text { continuous, non- } \\
\text { continuous, } \\
\text { mixed and multiple }\end{array}$ & $\begin{array}{l}\text { The report does not include any } \\
\text { information on students' achievement } \\
\text { in different text formats }\end{array}$ & \\
\hline $\begin{array}{l}2015 \\
(\mathrm{OECD}, 2016 a, b)\end{array}$ & $\begin{array}{l}\text { reading } \\
\text { literacy }\end{array}$ & 15 & $\begin{array}{l}\text { continuous, } \\
\text { non-continuous, mixed } \\
\text { and multiple }\end{array}$ & $\begin{array}{l}\text { The report does not include any } \\
\text { information on students' achievement } \\
\text { in different text formats }\end{array}$ & \\
\hline
\end{tabular}

Note. *: Years when reading literacy was a major domain of assessment. 
Also, text format as an organizational element of the domain has been used from the very beginning of the assessments. However, the year of 2009 brought along a change in the framework with respect to the array of text formats used in the studies. Electronic texts enriched the repertoire of written materials to be read. The appearance of the new digital medium affected text categorization to a great extent, although the necessity to include other text format categories for paper-based reading was also acknowledged. The original binary categorization was broadened and from then on, two additional formats have also been employed: mixed and multiple texts particularly prevalent in the electronic medium were included (OECD, 2010b, p. 31). However, in the report of the 2009 data collection only the continuous and the non-continuous format were used as the basis for building text format subscales (OECD, 2010b, p. 78).

As Table 2.2 shows, PISA only provided a subscale-level report in years when reading literacy was a major domain of assessment. The report on the results of the 2000 data collection revealed that Hungary was among the countries with a difference in means in favor of continuous texts (Kirsch, de Jong, Lafontaine, McQueen, Mendelovits, \& Monseur, 2002). However, the difference was so marginal (1 PISA scale point) that the authors concluded that students performed at least as well on the non-continuous text as on the continuous text subscale (Kirsch et al., 2002, p. 97). As far as the possible reasons for the differences between students' achievement in the continuous and non-continuous text subtests are concerned, the authors suggest that teaching language subjects based on traditional curricula or placing a "stronger emphasis on the development of reading literacy through prose literature and exposition, and less emphasis on non-prose texts found in academic or everyday contexts" may be factors worth looking into (Kirsch et al., 2002, p. 97). Data published by OECD in 2010 show that Hungarian 15-year-olds were much better at understanding continuous texts than non-continuous ones. Data showed variation across the countries in terms of mean achievement in the text format subscales, but its extent differed widely. Altogether 17 countries - including Hungary - performed significantly better (by at least 10 points) on the continuous text subscale than on the non-continuous one (OECD, 2010b, p. 85). The number of countries where data showed students' advantage in the non-continuous subscale was fewer. The authors of the analyses make only a brief comment on this phenomenon repeating the ideas expressed regarding the reasons for the achievement gap in the first assessment cycle: "the countries in this category may place more emphasis in their curricula on reading continuous texts, rather than reading a more diverse array of texts" (OECD, 2010b, p. 85).

Similarly to PIRLS, PISA also uses gender as a variable to give a more diverse picture on students' reading literacy. The finding on the relationship between gender and performance on the continuous and non-continuous subscales is consistent with PIRLS results: girls outperform boys in both domains but the achievement gap is much smaller in the non-continuous subscale.

Table 2.2 shows that the rest of the reports lack information about mean achievement on text format subscales as a main organizational element of the domain. Reporting over text format subscales does not take place when reading is a minor domain. The 2006 framework states that the number of items is reduced when reading is not a major domain (OECD, 2006). However, the amount of information should be sufficient to report trends over the text format subscales. Further analysis of data or the identification of trends with respect to text formats is not possible based on the reports. This shortcoming does not only prevent me from putting data in a historical perspective but it also shows that the reports are inconsistent with the frameworks. 


\subsection{National student assessment programs on reading}

In the previous sections I dealt with the international programs focusing on Hungarian students' reading assessment. In this part I will move on to the emergence and description of domestic system-level reading surveys. Table 2.3 shows that Hungary also monitors students' outcomes concurrently with international assessments at the national level.

Table 2.3 Current national and international system-level reading assessment programs in Hungary

\begin{tabular}{l|c|c|c|c|c}
\hline \hline \multirow{2}{*}{ Parameters } & \multicolumn{5}{|c}{ Grade } \\
\cline { 2 - 6 } & 4 & 6 & \multicolumn{2}{|c}{8} & \multicolumn{2}{c}{10} \\
\hline $\begin{array}{l}\text { Name of the } \\
\text { assessment program }\end{array}$ & PIRLS & NABC & NABC & $\begin{array}{c}\text { PISA } \\
\text { 15-year-olds }\end{array}$ & NABC \\
\hline \hline
\end{tabular}

Currently, the National Assessment of Basic Competencies (NABC) is the only element of the national assessment system that monitors students' reading achievement. Table 2.3 shows the stages of the Hungarian educational system at which the domestic and international reading assessments take place in order to provide directions for national policy, for school curricula innovation in instruction and for students' learning to improve the quality of education. As mentioned previously, PIRLS measures $4^{\text {th }}$ graders' reading literacy, while PISA targets the population of 15-year-olds. The national program NABC fills in the periods in between and even after the internationally covered age groups. The NABC includes three populations: grades 6,8 and 10. The following subsections will first give an overview of the emergence of large-scale surveys in Hungary. Then the international influences on the Hungarian initiatives will be described. Finally, the conceptual background of the NABC framework is analyzed.

\subsubsection{A brief overview of the emergence of national surveys}

Efforts to conduct empirical research to measure the quality and efficiency of the Hungarian educational system in terms of students' achievement emerged at the end of the 1950's in parallel with the spread of international large-scale studies (Báthory, 1997, p. 251; Csapó, 1998; D. Molnár, Molnár, \& Józsa, 2012). The very first Hungarian initiatives drawing on an immense professional knowledge base, teamwork, representative samples and survey techniques are associated with Árpád Kiss who measured elementary school and secondary school students' literacy (általános müveltség) (Kiss, 2003). Although the results of the assessments would have been appropriate for further utilization in educational policy, the decision-making bodies raised serious doubts concerning the research methods and the relevance and usefulness of the feedback gained from them in everyday practice. However, 1968 brought along a real breakthrough regarding the public acceptance of system-level assessments; that year Hungary joined the International Association for the Evaluation of Educational Achievement (IEA) enabling the international comparison of students' outcomes in different domains and education system optimization. The following years witnessed an ever-growing embrace in educational empirical research, especially the survey technique, in a plethora of domains at national, institutional and subject level (Csapó, 1998).

1979 marked the administration of the first system-level reading literacy assessment (OPI-MM) using different text types and text formats (D. Molnár, Molnár, \& Józsa, 2012). 
However, the so-called TOF- 80 was the very first national representative sample based study implemented in 1980 by the Department of Curriculum Theory of the National Pedagogical Institute (Csala \& Ranschburg, 2002). The TOF-80 assessed $4^{\text {th }}$ and $8^{\text {th }}$ graders' achievements in various subject areas, including reading, mathematics and science (Balázsi, 2007) in order to evaluate the impact of the national curriculum reformed in 1978 (D. Molnár, Molnár, \& Józsa, 2012; Tóth, 2014a). No subsequent cycles were organized using the framework of this assessment. Nevertheless, the impetus and accumulated experience in using survey-techniques paved the way to laying the foundations of a well-designed regular national assessment program entitled Monitor assessments. The Monitor student assessment programs primarily aimed at helping shape the educational policy and serving decisionmaking purposes by measuring the same student population' achievement in the same domains every four or five years "in grades that are important milestones in the Hungarian education system" (Balázsi, 2007, p. 2). By acknowledging the importance of internationally measured literacy skills, from the very conception until the termination of the program one of the measured domains was reading which mirrored the fundamental importance of this skill.

2001 witnessed the implementation of yet another large-scale survey, the National Assessment of Basic Competencies (NABC). The paradigm shift in the concepts of knowledge became accepted in the Hungarian educational system, which led to an attribution of a greater role of competency development besides domain specific knowledge. The underlying intention of running NABC was to ease and speed up the transition in everyday practice. Similarly to the Monitor assessments, "the goal of the National ABC studies is to assess whether students are able to use their knowledge and skills in real life situations and gain further information - and not to assess the level of student success in internalizing factual knowledge set by the curriculum" (Balázsi, 2007, p. 2).

\subsubsection{The impact of international student assessment programs on the conceptualization of reading in national reading surveys}

Hungary's participation in international large-scale reading assessments in the past 50 years does not only enable us to compare Hungarian students' reading achievement in the international educational arena and identify the relative merits and shortcomings of our education system but it also provides us with an opportunity to trace the conceptualizations of reading comprehension in the assessment frameworks. The core documentations and reports suggest that the international trends left a clear mark on Hungarian perceptions of reading assessments (Adamikné Jászó, 2006; D. Molnár, Molnár, \& Józsa, 2012). As mentioned earlier, the adaptation of the survey techniques influenced the formation of national educational assessments and joining one of the major organizations involved in educational research enhanced public trust in this field. In addition, it is also apparent that in accordance with international trends reading as a fundamental skill to be mastered for successful life purposes has been present in each and every national assessment. Consequently, the canonized interpretation of reading comprehension as an assessment construct (i.e. reading literacy) is reflected in the conceptualization of the Hungarian systemlevel data collections on reading. However, data show that national and international educational reading assessments have not always been completely aligned. Disparities in the past may be detected both in terms of how test designers understood and applied the term reading and its components and how they tried to cover the domain with different text formats and cognitive aspects for a better understanding of how students read. Evidently, the present status is a result of constant adaptations and fine-tuning.

The IEA study of Reading Comprehension conducted in 1970-71 with Hungary's first participation in an international reading assessment program comprised different measures 
of verbal ability. It inquired into students' reading comprehension, reading speed and word knowledge. Although no national large-scale assessment ran parallel with this initiative that could serve as a point of comparison, we can draw some conclusions about the prevailing trends based on some previous literature concerning the topic. The majority of practicing teachers could identify with this approach to a great extent, as at that time a good reader was defined as someone who could read a text aloud quickly, flawlessly and with proper expression (D. Molnár, Molnár, \& Józsa, 2012). Thus, mastery of reading was primarily viewed as reading fluency. This rather simplistic view of reading proficiency only fulfils the requirements of decoding (Nagy, 2006), the first stage of the tenets of teaching reading in elementary schools dating back to the $19^{\text {th }}$ century (Bárány, 1896) and ignores a major component of reading: comprehension. However, in that period the development and processes of meaning making received much less attention than decoding in Hungary. They were only themes of scholarly discourse in a narrow circle. However, the fact that first national system-level studies already used documents as materials to be read suggests that the narrow circle whose members were also responsible for the design of the reading assessments followed the mainstream thinking on reading and viewed it as skills inevitable for independent learning (D. Molnár, Molnár, \& Józsa, 2012).

Two decades later, getting an impetus from the UNESCO's declaration of 1990 as the "International Year of Literacy" the IEA Reading Literacy Study was administered. The second survey with the inclusion of Hungary aimed at measuring 9- and 14-year-old students' reading literacy and witnessed an unparalleled participation in the history of IEA. Although literacy was in focus, writing, the other side of the coin, was deliberately excluded from the scope of study (Elley, 1992). Educational stakeholders noticed and claimed that surveys of the era shifted the emphasis from curricular knowledge to general key competencies such as reading literacy (Halász \& Lannert, 2000). The Monitor assessments conducted between 1986 and 2005 quickly adopted this new functional approach to reading and started to integrate it into the assessments under the terminology 'kulturális eszköztudás', meaning that reading is viewed as a tool to attain individual and societal goals (e.g., Mullis, Martin, \& Sainsbury, 2015; Vári, Andor, Bánfi, Bérces, Szipőcsné Krolopp, \& Rózsa, 1998). The construct implies basic knowledge, techniques, skills and abilities to use these for independent learning and self-sufficient life. In the Hungarian educational nomenclature literacy has been seen as a binary opposite to curricular content knowledge. The distinction is always exclusive rather than overlapping. Of course, this distinction may stand its ground in the other assessed domains such as mathematics and science, where subject matter is taught and learnt in a very different way from how this knowledge can be used in everyday life. However, in my view, in the case of reading comprehension, a domain of interdisciplinary nature, reading at school and in everyday life cannot be sharply separated because the same cognitive processes are activated and only the contexts are different where they are applied.

Starting in 2001, the NABC admittedly borrowed PISA's concept and methodology (Bajomi, Berényi, Neumann, \& Vida, 2009). In the following years reading literacy definitions with more or less the same wording were used by national and international largescale assessments alike, albeit with various terms covering the same construct in the Hungarian context (funkcionális olvasási műveltség: Józsa \& Steklács, 2009; szövegértés: National Assessment of Basic Competencies; olvasási kultúra: Csíkos, 2006). As a result, nowadays, the national and international assessment frameworks are identical in terms of the construct, its definition, its coverage by text types, text formats and cognitive aspects to reading.

This overview clearly shows that the international trends have impacted the national assessment projects in many ways. The assessment domains and content in turn affect both 
the education systems and the teaching-learning processes. Their impact on the latter element is also manifested in the enhanced content of students' books with more emphasis on improving reading comprehension (Adamikné Jászó, 2006). However, content analysis of tasks in students' books carried out on the distribution of cognitive aspects to reading revealed that there is still room for improvement. Tasks requiring less complex mental representations of the text (i.e. information retrieval and interpreting) outnumber tasks requiring more complex reading skills (i.e. reflection and evaluation) (e.g., Adamikné Jászó, 2006; Csépány, 2008).

\subsubsection{An overview of the reading assessment practices and frameworks of the Monitor assessments and the Hungarian National Assessment of Basic Competencies}

In the previous sections the historical background and underlying rationale for organizing national reading assessments were discussed. In what follows we will give an overview of two national assessment programs: (1) the Monitor assessments and (2) the National Assessment of Basic Competencies (NABC) for two reasons. Although there were several instances for occasional data collections in reading over the past decades, we only focus on those that occurred at regular intervals and measured reading literacy. The Monitor assessments are not operated any more but we consider their conceptualization of reading and the operationalization of the construct an important milestone in rethinking the aims and tasks of education and knowledge. By reviewing official technical reports and publications of the results, we aim at exploring how the measured constructs were defined, what text formats and text types were used to cover the domain, what results students attained in different text formats, and finally, what factors accounted for the disparities in results along text formats.

\section{THE MONITOR READING LITERACY ASSESSMENT}

"The Monitor Studies, first implemented in 1986, were created with the goal of regularly providing data on student performance and the factors affecting the National educational system in grades that are important milestones in the Hungarian educational system" (Balázsi, 2007, p. 2). The Monitor assessments can be viewed as the Hungarian adaptation of the IEA studies. They aimed at keeping track and record of the dynamic nature of students' knowledge constantly changing over time. This aim was fulfilled by including anchor items in the tests (Halász, 2000).

In the very beginning these assessments took place at irregular intervals, but from 1995 on data collection took place every two years (Csapó, 1998). With a special emphasis on reading and mathematics, these assessments provided information on the status of the education system between the international survey cycles until its termination in 2005 .

As mentioned earlier, in the Monitor assessments the term literacy was used to denote basic abilities and skills essential for independent learning. The program distinguished traditional knowledge areas and literacy domains. Reading literacy was considered an interdisciplinary domain (Vári, Andor, Bánfi, Bérces, Szipőcsné Krolopp, \& Rózsa, 1998).

In order to gain a deeper insight into students' reading performance the tests were enriched with different subtests representing subdomains of the measured construct. Three different text types were included in the reading literacy test: documents, narratives and expository texts (Vári et al., 1998). Their definitions were in line with the internationally canonized ones. Since documents are best distinguished by their form and organization (Balkányi \& Ostorics, 2012), they represent what is referred to as the non-continuous dimension by PISA.

Additionally, cognitive aspects cut across the domains, namely: (1) reproduction (reproducing factual elements in the text), (2) identification (identifying facts and data) (3) production (recognizing answers implicit in the text), (4) interpretation of words, phrases, 
sentences and paragraphs, (5) recognition of relations (6) communicative aspects (perception of the impact of the author's stylistic devices etc.) (Adamikné Jászó, 2006, p. 265; Balkányi \& Ostorics, 2012; Horváth, 1997, p. 115).

The Monitor assessments made an undeniable contribution to the development of the reading skills in Hungary. Textbooks started to emphasize comprehension tasks, which in turn had an impact on the teaching and learning process. However, the more complex cognitive aspects remained underrepresented in the plethora of tasks (Adamikné Jászó, 2006). As far as the inclusion of non-continuous texts in the curriculum is concerned, Halász (2000) criticized educational policy for almost entirely neglecting documents which were attributed an ever more important role in society. He also noted that this phenomenon gives reasons for concern because students who face difficulties in understanding documents (i.e. non-continuous texts) will have problems coping with practical, real-life situations such as making sense of a timetable, operating a household device based on a manual or filling in tax forms (Halász, 2000, p. 312).

\section{The NATIONAL AsSESSMENT OF BASIC COMPETENCIES}

In the past 15 years studies designed and conducted by international organizations have become frequent and many countries have developed their own national educational assessment programs in order to improve their education systems. The emerging reforms have brought along a governmental demand to interpret the success and efficiency of the educational systems in terms of students' knowledge and to hold schools accountable for the efficient use of allocated resources based on their educational outcomes. In addition, a major role was dedicated to supporting the institution level improvement of education, the teaching and learning process (Looney, 2011). The assessment programs may contribute to the improvement of the efficiency and success of the education systems by providing stakeholders with assessment feedback. Governments running the student assessments based accountability systems use students' test achievements to define the efficiency of education; the results provide a solid foundation for creating incentive schemes differentiating between well and poorly performing institutions and teachers to facilitate the improvement of learning and instruction. Numerous studies conducted overseas pointed out that the introduction of test based accountability programs had an impact on students' improvement (e.g., Carnoy \& Loeb, 2002; Hanushek \& Raymond, 2005; Jacob, 2005).

In line with international trends, Hungary has been developing its own national assessment system since 2001. At present, the system is based on two pillars: (1) the DIFER school-readiness test battery administered to children when entering formal education and (2) the National Assessment of Basic Competencies (NABC) carried out in grades 6, 8 and 10. Another pillar, the Diagnostic Skills and Ability Assessment (DSAA), assessing fourth graders' basic mathematical skills, reading skills, reasoning, and writing skills, was an element added to improve the quality of the Hungarian education system between 2006 and 2012. It was a criterion-referenced assessment serving no accountability purposes. Data of a representative sample (200 schools) chosen from the entire $4^{\text {th }}$ grade population were centrally processed by the Educational Authority. In addition, national standards were published to allow schools to compare their performances. However, since 2013, schools have not been legally required to carry out the DSAA. Its tests have been made publicly available online and schools process its results themselves. The data collection of the NABC and the DSAA were carried out on the same day.

The first pillar of the system, the DIFER school-readiness test is optionally administered at the beginning of schooling. The test battery is a research-based, validated, reliable and standardized instrument for the diagnostic assessment of basic skills (Nagy, Fazekasné Fenyvesi, Józsa, \& Vidákovich, 2004). It measures the developmental level of seven basic skills (e.g., motor coordination for writing, vocabulary of relations, elementary 
arithmetic, comprehension of relations, and social skills), the acquisition of which are considered a gateway opening up or preventing further development in reading as well. In addition to scores in the basic skills, a composite skill index is calculated, which has been shown to be an appropriate measure of school-readiness. DIFER scores place students in one of five performance categories indicative of the stage they are in as regards the acquisition of the targeted skill: preparatory, beginning, intermediate, advanced and optimum levels.

The DIFER test does not only provide detailed information on students' developmental level of the measured basic school-readiness skills but it also has a strong predictive value on students' academic performance in reading. Reading through which we can access information, ideas, and feelings about the world plays an essential role in students' lives, as mastering this skill not only influences their achievement but it also determines how they can cope in everyday life. Having empirical evidence on developmental patterns in reading and the range of related skills that prove to be strong predictors of reading performance is of crucial importance. Furthermore, regular feedback on students' performance and the early diagnosis of students' shortcomings enable stakeholders to develop effective intervention programs. Previous studies showed that a Hungarian school-readiness test battery has a marked influence on students' academic progress (e.g., Molnár, Józsa, Molnár, \& B. Németh, 2007) as well as on students' reading performance.

The second pillar of the system, NABC has a twofold function: (1) in addition to playing an important role in supporting learning and instruction, (2) it is also a powerful tool of institutional accountability. Introduced in 2001, other key objectives of the program were to expand PISA's sample and to introduce novel tools and methodologies of competencybased assessments for teachers. As a result of the paradigm shift in assessment from curriculum-based knowledge to how well students can apply what they have learnt in school in real life situations, the study made an attempt "to ease the transition as well as speed it through the assessment of competencies - a process that would otherwise take considerably longer time to reach schools" (Balázsi, 2007, p. 3). The NABC initially aimed at measuring $5^{\text {th }}$ and $9^{\text {th }}$ graders' achievements in reading and mathematical literacy. The grade-based initiative witnessed many changes throughout the following three years until it gained its present form. However, the shifts only affected the timing of the assessment during the academic year and the measured population, but not the domains or the constructs. At present, the NABC measures students in the full Hungarian student population in grades 6, 8 , and 10 annually. The NABC is a high-stakes mandatory assessment at the end of the academic year. Besides a national report, school level and school provider level reports are also accessible to the general public and parents can have access to the individual results of their children. Both the publicity of the results and the sanctions associated with the weak results of NABC signify the presence of accountability in the Hungarian education system.

\section{THE NABC FRAMEWORK FOR READING LITERACY ASSESSMENT}

Following the paradigm shift in reading assessments, the NABC aims at mapping the socio-cultural dimension of reading. Therefore, the tests measure to what extent students can use their reading skills in their studies and everyday life besides meeting curricular requirements (Balázsi, 2007, p. 3). The framework of the program, which defines the assessed domains, the task types, their distribution and the text types, was established by law (Tóth, 2015). I use the details provided by the latest document to introduce the major points of the framework related to the main topic (Balázsi, Balkányi, Ostorics, Palincsár, Rábainé Szabó, Szepesi, Szipőcsné Krolopp, \& Vadász, 2014).

Drawing on national experiences and adopting the same stance on reading literacy as international research committees, the commissioning body of the NABC defines reading literacy as the individual's ability to comprehend, use and reflect on written texts to reach 
their own goals, develop their skills and knowledge, recreate and adapt to and participate in everyday communication (Balázsi et al., 2014, p. 11).

In line with this, texts of different types and formats and items requiring a diverse set of cognitive skills ensure the coverage of the domain. Initially, the categorization of text types followed the same pattern as the Monitor studies by distinguishing narrative, expository and document text types (Balázsi, Felvégi, Rábainé Szabó, \& Szepesi, 2006; Balkányi \& Ostorics, 2012). From 2014 on, these categories were renamed (élményszerző, magyarázó, adatközlö) but their content remained the same. In 2014, text format (continuous and non-continuous) as an organizational element of the domain was also introduced (Balázsi et al., 2014). I assume that the authors realized that the umbrella term text type they used to refer to texts with different types and formats was misleading as the documents serve to denote written pieces of information with fragmented organization; therefore, a more appropriate grouping would have been along both text types and text formats (see Chapter $1)$.

The tasks requiring the use of cognitive processes linked to the comprehension of texts range from identifying and retrieving information (e.g., facts, data), recognizing logical and content relations, interpreting the content and stylistic characteristics to comprehending the message of the whole or some parts of the text (Balázsi et al., 2014, p. 15). Again, similarly to the frameworks of its national predecessor and international counterparts, the reading skills move along a wide spectrum: from relatively easy and straightforward to more complex, sophisticated subskills. However, the term interpretation for some reason is used to denote what is called reflection or evaluation in the international literature (Mullis, Martin, \& Sainsbury, 2015; OECD, 2016c), as these tasks require students to evaluate the text and reflect on its content and format.

As was mentioned earlier, the NABC clearly articulated its aspiration to impact classroom practices by raising teachers' awareness of the concept of literacy and familiarizing them with its assessment methods and instruments. Bridging the gap between theory and practice proved to be partly successful with respect to the inclusion of documents and non-continuous texts in public education. A qualitative study carried out by Tóth (2014b) focusing on teachers' view on system-level assessments revealed that using texts of different type and format in students' reading development soon appeared on teachers' lesson plans; thus, teachers consider the reading of diverse texts as a key aspect of equipping students with valuable reading skills and preparing them for challenges in life-long learning. However, responses also show that teachers find textbooks insufficient in this respect (Tóth, $2014 b, p .133)$. It is also noteworthy that practitioners teaching subjects other than Hungarian language and literature also integrate non-continuous texts into their teaching-learning process, therefore, students are provided with more opportunities to encounter these texts in different contexts and make their understanding more efficient (Tóth, 2014b). The results of Tóth and Hódi (2014) also showed that system-level testing leads to changes in teachers' instructional practice such as teaching to the test, which may also lead to an increased inclusion of different text formats in teachers' syllabus.

In sum, the international programs share similar characteristics and have a lot in common with the Hungarian national assessment programs on reading literacy, including the studied domains, definition, conceptualization, structure and coverage of the domain in terms of text type, text format and cognitive processes. However, they were designed to serve different purposes, they involve different age groups and are based on a unique framework. The above mentioned programs had an impact on the education system at many levels. Adopting the new concept of reading (i.e. reading literacy) first brought along a shift in emphasis from decoding to comprehension; another change is apparent in the inclusion of 
non-continuous written materials in the body of texts to be read in the teaching and learning process as well as in the tests.

\subsubsection{Results in various data collection cycles of the Monitor assessment and NABC}

The first Monitor study was conducted in 1986 and it took five years to witness the second cycle. The last cycle took place in 2005, however, the last published results were those of the 1999 assessment cycle (D. Molnár, Molnár, \& Józsa, 2012, p. 36). Table 2.4 presents the information about the data collection and results I managed to collect and recover from reports and previous literature. The boxes were left empty if I did not manage to access information regarding the given parameter.

Although the program measures students' reading literacy, the Hungarian terms denoting the construct vary to a certain extent. The measured populations ranged from third to twelfth graders and in cycles 1993 and 1999 the Monitor assessments only measured one population. Based on the available reports, students' reading achievement in different text formats varied in different grades between 1995 and 1999. In 1995, students in different grades achieved higher test scores in reading documents than reading continuous texts. In the 1997 cycle, all populations had worse results in the documents subscale than in the continuous dimensions except for the eighth graders. The achievement pattern that data yielded in 1997 was commented as follows. The reason for the fact that fourth and sixth graders did better in reading narratives than documents may be that the reading comprehension of young populations is positively influenced by tales that they read earlier (Halász \& Lannert, 1998, p. 284). In my view, this argument implies that the authors consider understanding narratives to be a completely different and separate dimension of reading than extracting meaning from diagrams and tables. Following this thread of thought, reading tales in early childhood only exerts its impact on reading texts with the same format and organization. However, this possible link has never been confirmed or rejected. Based on the results, Vári, Andor, Bánfi, Bérces, Krolopp, and Rózsa (2008) concluded that the educational system did not prepare students to understand a complex graph, a train schedule or a many-page-long manual. In response to the poor results students achieved in the documents dimension in 1999, Halász (2000) noted that documents are completely excluded from public education.

As far as the NABC is concerned, the cycles and the main modification the assessment went through is described and summed up by Balázsi et al. (2014). The reading results of Hungarian students is available in national reports on the website of the Educational Authority (www.oktatas.hu). I read through all the published reports (Balázsi, Szabó, Szabó, Szalay, \& Szepesi, 2006; SuliNova Kht., 2007; Oktatási Hivatal, 2007; Oktatási Hivatal, 2008; Oktatási Hivatal, 2009; Balázsi, Lak, \& Szabó, 2011; Balázsi, Lak, Szabó, \& Vadász, 2013; Balázsi, Lak, Szabó, Szabó, \& Vadász, 2014; Balázsi, Lak, Ostorics, Szabó, \& Vadász, 2015; Balázsi, Lak, Ostorics, Szabó, \& Vadász, 2016; Balázsi, Takácsné Kárász, Lak, Ostorics, Szabó, \& Vadász, 2017) but they do not contain any information on how students managed to understand texts with different formats. 
Table 2.4 An overview of the studies and results of Hungarian students' reading achievement in different text formats in Monitor assessment cycles between 1986 and 1999

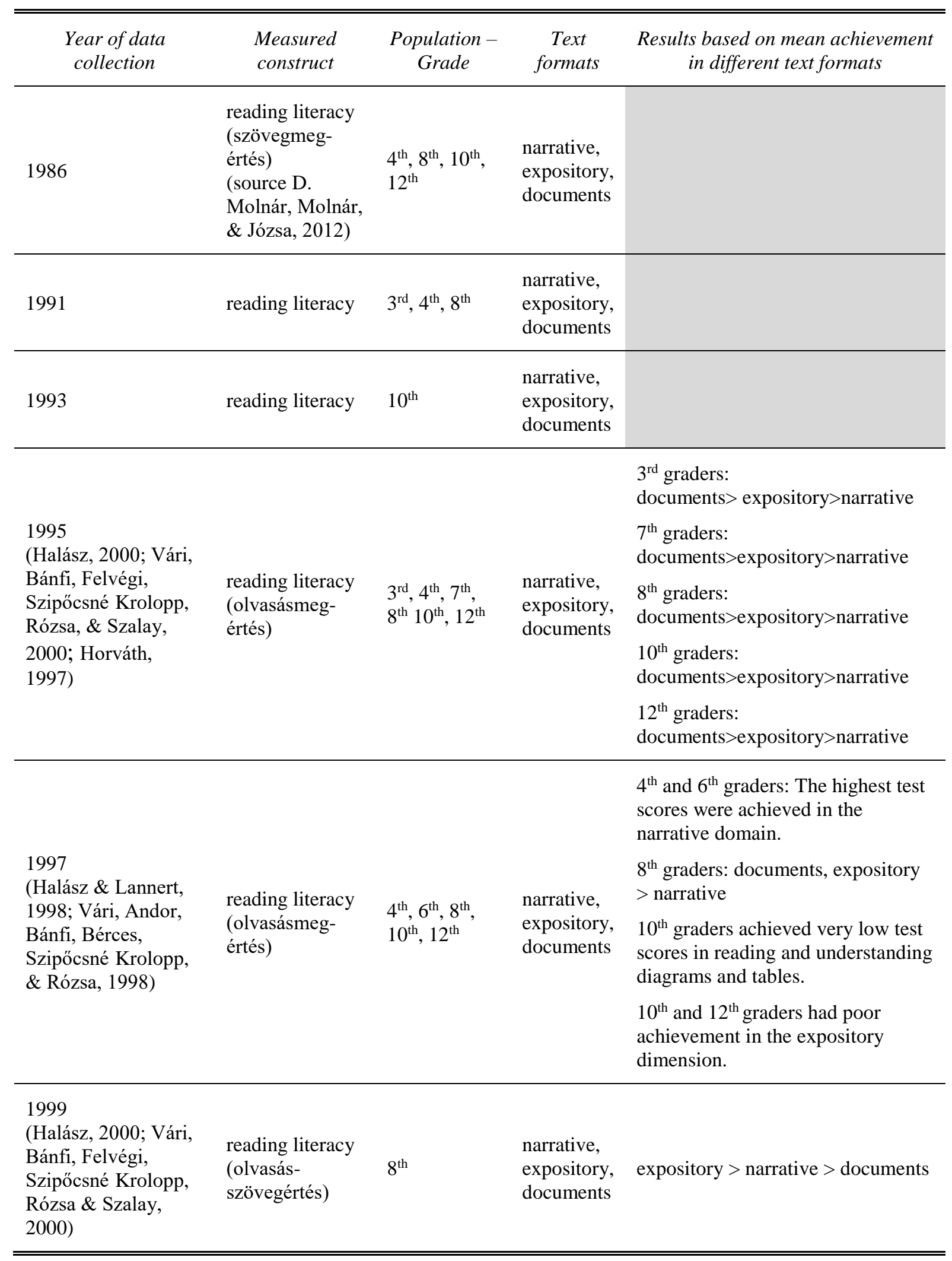


I assumed that the modification regarding the explicit inclusion of continuous and noncontinuous text formats in the updated version of the framework in 2014 had an impact on how the Educational Authority reports on students' achievement but unfortunately, no information was available on students' achievement in different text formats. Therefore, just like in case of the PISA, further analysis of data or the identification of trends with respect to text formats is not possible. In case of NABC, in addition to the national level, reporting also takes place at local level to the maintainers, at school level and student level. Student reports are accessible online by students, parents and teachers with an identification number. This platform provides information on students' achievement on all items but the items are not categorized in terms of text format. So, all items are accessible here but no text format filter option is available, which makes the interpretation of results more difficult. Besides the reports the FIT software helps schools and teachers to gain a more detailed insight into students' achievement. This software enables users to filter data and carry out further data analysis according to text format, item type and cognitive aspects to reading. These findings indicate that the framework and the reports are not consistent.

\subsection{Summary of findings, conclusions and implications}

This chapter provided an overview of the emergence of the concept of reading literacy and national and international system-level assessments in reading. At the international level two on-going international comparative surveys (PIRLS and PISA) studying educational outcomes at different ages were compared along different dimensions. At the national level, we overviewed the framework of NABC, an on-going national system-level assessment program and its predecessor the Monitor assessments (Balkányi \& Ostorics, 2012) to analyze trends and practices in conceptualizing and operationalizing reading for assessment purposes.

Although these studies exhibit some differences concerning the purposes and methodology and their terms vary to some extent, a careful analysis of the definitions show that they have significant similarities in the constructs they cover (i.e. reading literacy), in the definition they adopted for the assessments and in how they categorize texts to cover the domain with real-life texts. The common feature is that the main organizational elements of the frameworks are - albeit occasionally termed differently (Table 2.5) - text and cognitive aspects to reading enabling simple to more complex and deeper understanding of the written material.

Table 2.5 The terms used by the assessment programs PIRLS, PISA, Monitor and NABC showing what text formats are included in the measurement

\begin{tabular}{l|llll}
\hline \hline $\begin{array}{l}\text { Organization } \\
\text { al element }\end{array}$ & \multicolumn{4}{|c}{ Assessment program } \\
\hline $\begin{array}{l}\text { The } \\
\text { dimension } \\
\text { under which } \\
\text { text format is } \\
\text { distinguished }\end{array}$ & $\begin{array}{l}\text { Purposes for } \\
\text { reading (reading } \\
\text { for literary } \\
\text { experience and } \\
\text { reading for } \\
\text { information) }\end{array}$ & $\begin{array}{l}\text { Text format } \\
\text { (continuous, } \\
\text { non-continuous, } \\
\text { mixed and } \\
\text { multiple texts) }\end{array}$ & $\begin{array}{l}\text { Text type } \\
\text { (narrative, } \\
\text { expository and } \\
\text { documents) }\end{array}$ & $\begin{array}{l}\text { Text format } \\
\text { (continuous } \\
\text { and non- } \\
\text { continuous) }\end{array}$ \\
\hline \hline
\end{tabular}


The programs essentially use texts with continuous, non-continuous and mixed formats to provide a broader coverage of the domain that includes real-life texts that one is likely to encounter in everyday situations. The frameworks distinguish text formats in terms of organization and the signs they contain but the cognitive processes involved in reading these materials are not distinguished along text types or text formats.

In order to clarify the rationale underlying large-scale assessments and to differentiate reading as decoding from reading comprehension and from reading literacy I critically analyzed the evolution of the construct of reading literacy over time. I showed how economic and social trends and attitudes towards literacy as marketable knowledge and skills having economic value for both individuals and society have shaped the construct. First, identifying the individuals' ability to read and write was the core issue. Measurements focused on labeling people either literate or illiterate. Then, higher expectations were set. Reading skills hardly beyond illiteracy were not considered satisfactory. Literacy became increasingly understood as a set of skills needed for individuals to function as efficient members of society rather than solely used in the school environment. Around the second half of the $20^{\text {th }}$ century in scholarly circles literacy became to denote functional knowledge valued by society and served as a core part of newly coined terms giving a face lift to "old" terminologies (in this case reading) and completely new $21^{\text {st }}$ century skills were specified by adding literacy to the identified domain. Large-scale assessments focusing on reading became more and more elaborate and sought to meet societal expectations. They hold that individuals at an optimal developmental level of reading literacy in an everyday situation should be able to access, understand and use information in a wide range of reading materials bearing different formats. From 1990 on assessing reading comprehension has not been limited to literary passages with continuous format. Understanding written pieces of information in form of graphs, charts and tables has also been included as requirements.

The Hungarian education system has been closely aligned with international trends. Hungarian students were first tested by the IEA reading surveys as early as 1970. Ten years later system-level assessments in reading appeared on the agenda of the national educational authorities. Towards the end of the 1980s the first system-level assessments focusing on reading were implemented, and soon became operated at regular intervals. The international assessments had a marked influence on the formation and adoption of the new concept of reading literacy at national level, which in turn affected the teaching and learning process gradually. The traditional approach to texts as entities comprising sets of words and sentences were extended to non-continuous texts. Text was soon referred to as a system of signs, which can take the form of words or images. The graphocentric and logocentric privilegization of the term written text was reconceptualized. Consequently, reading has been extended to anything out of which meaning can be extracted rather than purely decoding or reading continuous texts of any type.

Data in the assessment reports reveal that variation is common in students' performance on the subscales representing different text formats. There is a significant difference in Hungarian students' achievement between reading continuous and noncontinuous texts: students tend to obtain higher test scores on the continuous scale than on the non-continuous one.

Gender is the most frequently used variable included in reports. Strikingly, data reveal a recurring tendency in the assessments. The differences in gender performance are quite marked when comparing the two subscales directly. Girls perform consistently better on the continuous subscale, whereas the gap tends to narrow between boys and girls on the noncontinuous tasks.

Occasionally, there have been attempts to cite gender and lack of inclusion of noncontinuous texts in the curriculum to account for the achievement difference with respect to 
text formats. However, no in-depth examination of this issue has been included in these reports and these arguments have never been empirically examined, proven or rejected.

The reports do not go further in explaining why these differences are prevalent in the measured populations. Furthermore, most studies do not provide any data on the text formats let alone the reading processes broken down into text formats, although both variables are used to manipulate text difficulty. It is not possible to get an insight into the relationships between these factors and the role they play in reading achievement.

The literature review presented in Chapter 2 has resulted in the following questions: If text formats vary in organizational and presentational elements to a great extent how can we claim that the very same cognitive processes are at play that were initially identified? How come the category of text formats has been broadened over time but the reading processes originally associated with comprehending continuous texts remained the same? To what extent does text format influence the cognitive processes involved in reading comprehension? What factors influence the understanding of texts with different formats? Do the same factors influence the understanding of texts with different formats? Is their impact the same? Part 2, the empirical part of the thesis, seeks to answer these questions. 


\title{
PART II
}

\author{
Testing the model of reading literacy: Examining the cognitive and non-cognitive \\ factors influencing students' achievement in different text formats
}

\section{CHAPTER 3}

\section{BACKGROUND TO THE EMPIRICAL STUDIES ON TESTING THE MODEL OF READING LITERACY AND EXAMINING THE FACTORS INFLUENCING STUDENTS' ACHIEVEMENT ACROSS TEXT FORMATS}

\subsection{Introduction}

Research has demonstrated that reading is an essential skill, which not only helps individuals to become successful and responsible citizens but it also has a significant impact on students' academic achievement in most school domains. Students' reading achievement has been the focus of numerous large-scale student assessment programs over the past decades (e.g., PISA - OECD, 2016c; PIRLS - Mullis, Martin, Foy, \& Drucker, 2012). These studies provide feedback on students' performance along continuous and non-continuous text formats but they fail to further analyze students' achievement in terms of the possible bottlenecks of improvement in reading texts in different formats from early elementary school years (Chapter 2). The aim of my empirical studies is to complement the results of previous research on students' reading development by carrying out detailed analyses along various text formats and to identify factors that support or hinder further improvement.

The second part of the thesis aims (1) to find empirical evidence for the multidimensional model of reading literacy with respect to text format and (2) to examine some cognitive factors inherent to reading and non-cognitive factors influencing students' achievement across different text formats at early stages of reading development.

Chapter 3 evolves around the introduction of the research methodology applied to reach the objectives. Additionally, the three studies carried out in order to map out the internal structure of the construct of reading, students' development in different text formats (see Study 1), and the relationship between students' reading achievement in different text formats and non-cognitive student and teacher related variables are described broadly (see Studies 2 and 3).

\subsection{Overview of research methodology}

The benefits of quantitative methods were used to collect information and data in the three studies aiming to explore the cognitive and non-cognitive factors influencing students' reading achievement in grades 2 and 4 (ages 7-8 and 9-10). Before planning the study, an extensive literature review was conducted and existing practices in large-scale reading literacy assessments were reviewed in Chapter 2. Earlier on the fixed and set research objectives were integrated into the Hungarian Educational Longitudinal Program (Csapó, 2014); therefore, the unique potentials, limitations and previous experiences of such a largescale and overarching program had to be taken into consideration in the research design. From the sample data, generalizable results were expected to be obtained.

After preliminary considerations, a four-step assessment program was designed to reach the goals of the study. The program essentially focused on gathering data in two domains: students' reading literacy development and background data from multiple sources 
that help put students' achievement into context. Students' reading literacy achievement was measured by means of computer-based reading literacy tests at two data collection points (in grades 2 and 4), and two types of survey questionnaires were used to collect additional information. A survey design was chosen because it provides a "numeric description of trends, attitudes, or opinions of a population" (Creswell, 2003, p. 153). The survey questionnaires were given to students and teachers who participated in the program. Student questionnaires collected information on participants' demographic characteristics, opportunities to learn and read in and outside the classroom, and educational experiences. Teacher questionnaires gathered information on teachers' personal characteristics, demographic data, academic background and prevailing professional and instructional practices teaching reading to the assessed student population.

Both the reading literacy test items and the survey questions underwent a multi-step research-based development process before they were used. This process included testing questions with small samples of participants as well as piloting draft questions with larger samples. Expert groups including practicing teachers, subject-area experts and educational researchers reviewed the test and survey questions and provided input at each stage of the process (Alderson, Clapham, \& Wall, 1995; Osterlind, 2001).

The studies introduced in the present chapter follow the structure of the multi-step research agenda. First, a student achievement survey was carried out in grade 2 in 2013, which was repeated two years later in grade 4 . After the first reading literacy test a student and teacher questionnaire was administered to contextualize students' reading literacy test scores. Accordingly, the first study focuses on testing the underlying measurement model of reading literacy (see Chapter 4) and the interaction between Hungarian students' reading achievement in different text formats and cognitive aspects to reading in grades 2 and 4 . The second study is a descriptive and correlational study on examining the role of non-cognitive factors in students' reading literacy achievement in different text formats unveiling the results of a student questionnaire (see Chapter 5). The third study examines teachers' personal characteristics, demographic data, academic background and prevailing professional and instructional practices teaching reading to the assessed student population (see Chapter 6).

The first and second study (Chapters 4 and 5) include lines, threads of thoughts, and structural elements introduced at international conferences (EARLI, EARLI JURE and AERA) based on accepted papers/abstracts in 2013, 2014 and 2015 revolving around the analyses of the association between cognitive and non-cognitive factors and Hungarian students' reading achievement in different text formats in different grades. In 2013, I coauthored a conference paper with Tóth Edit in this topic focusing on 6th graders (Hódi \& Tóth, 2013). In 2014, I collaborated with Török Tímea and Kiss Reáta in a small-scale study focusing on the assessment of first, second, third and fourth graders and presented its results in Nicosia (Hódi, Török, \& Kiss, 2014). Additionally, a talk was given about the results of the same study from a different angle at AERA were Török Tímea was the coauthor (Hódi \& Török, 2015). Chapter 6 includes parts of a study published in Magyar Pedagógia in 2017 about the aspects of reading instruction influencing students' reading achievement in grade 2 coauthored with B. Németh Mária and Tóth Edit (Hódi, B. Németh, \& Tóth, 2017).

\subsubsection{The construct of reading literacy}

This study puts reading literacy into the focus of research. The construct of reading literacy moves beyond reading as decoding. Reading literacy may be viewed as an equivalent of reading comprehension broadly defined: the ability to "develop a coherent representation of the text that matches the intended message to the reader" (O'Reilly \& McNamara, 2007, p. 164). More specifically, "reading literacy is understanding, using, reflecting on and 
engaging with written texts, in order to achieve one's goals, develop one's knowledge and potential, and participate in society" (OECD, 2013, p. 62). However, reading literacy goes beyond the traditional sense of text comprehension in that special emphasis is given to the comprehension of everyday texts that are of practical use for the individual or the society. "Reading literacy is the ability to understand and use those written language forms required by society and/or valued by the individual. Readers can construct meaning from texts in a variety of forms. They read to learn, to participate in communities of readers in school and everyday life, and for enjoyment" (Mullis, Martin, \& Sainsbury, 2015, p. 12). The evolution of the concept of reading literacy and its operationalization for assessment purposes is presented in Chapter 2.

In this sense, reading as a complex skill or system of skills is seen as a means of achieving social and individual goals and as an important domain of the application of knowledge acquired inside and outside the classroom. For the purposes of the present study, the construct of reading literacy is defined in line with the conception of the international frameworks cited above representing the applicational or in other words the social-cultural dimension of reading (Csapó, Józsa, Steklács, Hódi, \& Csíkos, 2012). The measurement of reading literacy follows the aspects in Table 3.1 covering text parameters and the cognitive skills needed for text comprehension (For a broader discussion of the categories see Chapter $1)$.

Table 3.1 Categories for the domain coverage of the construct of reading literacy

\begin{tabular}{ll}
\hline \hline Medium & Computer (Digitized) \\
\hline \multirow{2}{*}{ Text format } & Continuous \\
& Mixed \\
& Non-continuous \\
\hline \multirow{2}{*}{ Cognitive aspect } & Information retrieval \\
& Interpretation \\
\hline \hline
\end{tabular}

"An important classification of texts is the distinction between continuous and noncontinuous texts" (OECD, 2013, p. 65). Each of these three formats is elaborated as follows: Continuous texts are formed by sentences organized into paragraphs. These may fit into even larger structures, such as sections, chapters, and books. Non-continuous texts and continuous texts differ in the way they are organized, "and therefore require a different kind of reading approach. Non-continuous texts are most frequently organized in a matrix format, composed of a number of lists (e.g., lists, tables, graphs, diagrams, advertisements, schedules, catalogues, indexes and forms)" (OECD, 2013, p. 65). Many texts are single, "coherent artifacts consisting of a set of elements in both a continuous and non-continuous format. In well-constructed mixed texts, the constituents (e.g., a description or explanation, along with a graph or table) are mutually supportive through coherence and cohesion links at the local and global level" (OECD, 2013, p. 65).

The cognitive aspects are organized into three broad aspect categories: (1) information retrieval, (2) interpretation, and (3) reflection. These are the mental activities students engage in while reading (Snow \& Sweet, 2003). Retrieving information tasks, which focus the reader on separate pieces of information within the text, are assigned to the retrieval scale (OECD, 2013, pp. 66-67). Forming a broad understanding and developing an interpretation tasks focus the reader on relationships within a text or between parts of the text. Tasks addressing the last aspect, reflecting on the content and form of a text require the reader to draw primarily on knowledge outside the text and relate it to what is being read 
(OECD, 2013, p. 66). "Reflecting on text content tasks is concerned with the notional substance of a text; reflecting on text form tasks are concerned with its structure or formal features" (OECD, 2013, p. 66).

As far as the text format and cognitive aspects to reading are concerned, I rely on the OECD PISA reading assessment framework. This taxonomy provides sound explanations for the categories used in the study. The OECD PISA clearly distinguishes texts with different formats, whereas PIRLS primarily makes a distinction between reading purposes with which - as having marginal relavance - different texts may be associated (Mullis, Martin, \& Sainsbury, 2015, p. 15). "However, the purposes for reading do not align strictly with text types" (Mullis et al., 2015, p. 15). Thus, I did not find this classification satisfactory in a research where the key issue is text format. Also mirroring PISA practice, the comprehension processes are grouped into three major categories instead of the four processes of comprehension determined by PIRLS. The number of categories may have been reduced, however, the content remained intact. To reduce the number of test items to be assigned to each category, the four comprehension process categories and the related reading tasks defined by PIRLS include (1) focus on and retrieve explicitly stated information, (2) make straightforward inferences, (3) interpret and integrate ideas and (4) information evaluate and critique content and textual elements (Mullis et al., 2015, p. 15). These were reorganized into the categories of (1) information retrieval, (2) interpretation, and (3) reflection, by taking into consideration the PISA guidelines. Therefore, although in these respects, dominantly the PISA framework guided me in the research, the findings are relevant in the measured age group.

\subsubsection{The first study: A longitudinal study on the model of reading literacy and the interaction between Hungarian students' reading achievement in different text formats and cognitive aspects to reading}

The first study deals with the issues of construct validity, dimensionality and students' reading literacy development in their early years of learning to read. The structure is as follows. First, the underlying measurement model of reading literacy is examined. Second, the development along text formats and cognitive aspects is investigated. Third, the issue of the universal nature and the possible dimensionality of cognitive aspects along different text formats is discussed.

Prior to further analyses, my first aim was to examine the underlying measurement model of reading literacy because we wanted to confirm that the theoretical structure of the reading test could be supported empirically both at whole test and subtest levels. Surprisingly, to date no studies that I know of have dealt with or published results of construct validity analysis in reading literacy. Publications in this domain claim to be based on the available reading literacy assessment frameworks (e.g., Mullis \& Martin, 2015; Mullis, Martin, Kennedy, Trong, \& Sainsbury, 2009; OECD, 2010a; OECD, 2013) but no effort has been made to analyze data that could lend support to the fact reading literacy may be interpreted in terms of different text formats (i.e. continuous, mixed, and non-continuous). Reading models and common knowledge limit themselves to defining reading in relation to conventional forms, that is, continuous texts and verbal symbols communicated in writing. However, student assessment programs (National Assessment of Basic Competencies, PIRLS, PISA) have always integrated mixed and non-continuous text formats also containing visual symbols besides verbal ones into their tests to mirror the multi-faceted nature of authentic written pieces of information one encounters in life. The inconsistency between theories and models on reading and prevailing assessment practices emphasizing the social importance of reading have led to a gap in common understanding what the constituents of reading as a process are and how reading can be conceptualized. The question 
whether mixed and non-continuous texts can also be taken into consideration when talking about reading and whether they cover the concept I purport to measure is addressed in the first part of study one.

The second aim of the study is to explore how students in the lower elementary school years progress in reading literacy. Developmental tendencies are not only provided for text formats but for cognitive aspects as well. Hungarian studies including continuous, mixed and non-continuous text formats on young students' reading literacy are scarce (but see Molnár \& B. Németh, 2006). Thus, there is little information on the pace and extent of development in this age group. Previous data show that there are vast differences in students' achievement when they read conventional and non-conventional forms, which implies that success in understanding one format does not necessarily translate into an equally successful understanding of the other. This disparity may impact the developmental tendencies and the cognitive aspects alike.

The OECD reading literacy assessment frameworks state that the processes involved in reading are expected to vary as readers interact with a variety of text formats. This is in contrast with the fact that the frameworks consider cognitive aspects to reading as entities overarching all text formats. Information retrieval, interpretation and reflection are processes that are organizational elements of the domain, however, the same processes are attributed to reading each and every form of text. If it is recognized that the reading processes differ when we read different text formats and text structure influences reading achievement, a question is posed: Do the same reading process function when students or in more general, any reader, read continuous, mixed and non-continuous texts? Based on the knowledge I have accumulated so far in this domain, my hypothesis is that the cognitive aspects to reading could be distinguished based on the context in which they are used represented by text formats. The last part of the study plans to map out if we can differentiate cognitive aspects along texts with different formats by means of confirmatory factor analyses.

\subsubsection{The second study: A descriptive and correlational study on the role of student-related non-cognitive factors in students' reading literacy achievement in different text formats}

The second research was undertaken with the primary purpose of contextualizing second graders' test scores achieved in the continuous, mixed and non-continuous subtests. This study aims at exploring the contribution of the affective aspects of reading, attitudes and self-concept, and some technical aspects of reading such as reading diversity and the frequency of being engaged in reading texts with different formats when learning. Moreover, students' ICT use habits and the impact of students' screen viewing diet is also examined. In the component model of reading (Chiu, McBride-Chang, \& Lin, 2012), these factors are classified under the psychological and ecological components.

First, descriptive data gained from a newly developed student questionnaire is provided, since information on the above-mentioned aspects and circumstances of reading in groups of second graders is scarce. Second, the relationship of these aspects and circumstances with students' achievement in reading texts of different formats is mapped out. Third, the impact of these variables on students' test scores representing proficiency in reading continuous, mixed and non-continuous texts is investigated.

To date, innumerable research has been carried out to unpack the individual, social and cultural practices that motivate and mediate literacy practice and learning. The present study was motivated by the following changes in the foci of reading research identified by Kamil, Pearson, Moje, and Afflerbach (2011, p. xix). The first shift concerns the population of the experimental works in reading. In the past decade, the emphasis shifted from elementary reading to adolescent reading, defined, generally, as anything above grade 3. 
Additionally, research on elementary reading is very limited in the Hungarian reading research landscape. The second shift brought along a broadening definition of reading and the extension of the reading research agenda, implying the emergence of inquiry that more fully examines the complex contexts, varied texts and the diverse experiences of readers that converge in the act of reading. Also, the last decade of reading research is notable for an increased realization that cognitive variables involved in reading interact with and are "used by readers who are both individuals and cultural beings with specific goals, experiences and levels of achievement" (Kamil et al., 2011, p. xix).

In line with these changes, in the present study I chose second graders as the target population. Furthermore, beyond the examination of students' reading development trajectories I extended the scope of study to the examination of contributing factors in a variety of text formats.

The experiences, habits, and attitudes of readers were solicited by means of a newly developed assessment instrument integrating dimensions based on previous findings (e.g., Henk \& Melnick, 1995; McKenna \& Kear, 1990; OECD, 2010a; OH-OECD PISA, 2009). Analyses of empirical data have proven the benefit or adverse effect of the factors included in the student questionnaire to the reading proficiency of diverse age groups measured by continuous texts. However, the existence and directions of these associations with mixed and continuous texts have not been examined. The second study aims to bridge this gap by throwing light upon possible differences in the impact of non-cognitive variables on students' reading achievement along different text formats.

\subsubsection{The third study: A descriptive and correlational study on the role of aspects of reading instruction in students' reading literacy achievement in different text formats}

Study three focuses on yet another aspect of the teaching and learning process: the school environment in which the large proportion of reading development takes place. The efforts started in Studies 1 (Chapter 4) and 2 (Chapter 5) to explore why students demonstrate different achievement levels when reading texts with different formats is continued in this chapter of the dissertation. In study 1 , the reading processes were put to test in different dimensions of reading literacy, study 2 aimed at exploring how students' affective characteristics, ICT use and reading habits interact with reading achievement in different text formats. The third empirical study sets out to identify school-related factors that matter in understanding continuous, mixed and non-continuous texts in grade 2.

Many paths can be pursued in order to develop children's reading acquisition. One of them concerns the realm of education, more specifically, initiatives to improve the school and classroom environment, conditions of learning and instruction or teachers' competences. However, the majority of the body of knowledge available on characteristics of primary school teachers and on the role aspects of reading instruction play in students' reading development are dominantly from international research. We have some data about the composition of the Hungarian teacher population, but to my knowledge there has not been any multi-layered, comprehensive research conducted in this domain encompassing multiple aspects of reading instruction to date. This study aims at bridging this hiatus by providing a profile on aspects of reading instruction in grade 2 and providing a means to explore the impact of the background variables on students' reading literacy achievement in continuous, mixed and non-continuous texts.

First, descriptive data gained from a self-developed teacher questionnaire is provided since the Hungarian research landscape lacks current information on the aspects and circumstances of reading instruction. Second, the relationship of these aspects and circumstances with students' achievement in reading texts having different formats is examined. 


\section{CHAPTER 4}

\section{A LONGITUDINAL STUDY ON THE MODEL OF READING LITEARCY AND THE INTERACTION BETWEEN HUNGARIAN STUDENTS' READING ACHIEVEMENT IN DIFFERENT TEXT FORMATS AND COGNITIVE ASPECTS TO READING}

\subsection{Introduction}

Numerous system-level assessment programs have aimed at measuring Hungarian students' reading literacy since the 1970's (see Chapter 2). Reading literacy is commonly defined as "an individual's capacity to understand, use and reflect on and engage with written texts, in order to achieve one's goals, to develop one's knowledge and potential and to participate in society" (OECD, 2010a, p. 14). Although the large-scale studies exhibit some methodological differences, a common feature is that the main organizational elements of the frameworks are text format, text type, cognitive processes or aspects and the situation for which the text was constructed (e.g., Mullis \& Martin, 2015; OECD, 2010a). The scrutiny of the relationship between two of these components forms the scope of this study; therefore, in what follows the background will be narrowed down to text format and cognitive aspects.

As far as text format is concerned, the basic principle is that "any given text type can take many forms and combinations of forms" (Mullis, Martin, \& Sainsbury, 2015, p. 14). Since "reading literacy is the ability to understand and use those written language forms required by society and/or valued by the individual" (Mullis et al., 2015, p. 12), the frameworks unveil a distinction between three types of text formats: (1) continuous, (2) mixed, and (3) non-continuous. Non-continuous texts imply reading for information where the text organization is fragmented, that is, factual, quantitative, technical, or mathematical information is presented in maps, charts, graphs, time lines, tables, and diagrams, whereas continuous texts to traditional written forms and entail an underlying organizational and linguistic structure that may be more easily identified and comprehended. On the other hand, written forms where characteristics of both continuous and non-continuous texts are integrated in one single written entity and, therefore, are characterized by "the joint presentation of verbal and pictorial information" (Rouet, Lowe, \& Schnotz, 2008, p. 4) are referred to as mixed texts, multimedia texts or multimedia documents.

Understanding texts may take many forms; however, reading literacy is generally assessed in terms of how well individuals are capable of retrieving information, interpret and evaluate and reflect on the form and content of written pieces of information. Research into the processes underlying reading comprehension has revolved around two major issues, namely: (1) whether or not reading comprehension involves distinctly separate skills, and (2) whether or not these readings may be ordered hierarchically. Some researchers found evidence to support the existence of separate skills in reading depending on the processes involved in answering questions (Davis, 1968; Spearritt, 1972). Other findings did not provide evidence for the existence of multiple dimensions of reading (Carroll, 1993; Thorndike, 1973a). Others (Elley, 1992, 1994) have argued for a distinction between the processes that are involved when reading different types of reading materials. Present assessment practices define cognitive aspects to reading as separate skills "requiring many of the same underlying skills" (OECD, 2004a, p. 112). Alderson (2000), on the other hand, concluded that "answering a test question is likely to involve a variety of interrelated skills" (p. 49). But according to him, even if separate skills are involved in the reading process, which could be identified by a rational process of analysis of one's own reading behavior, 
"it appears to be extremely difficult if not impossible to isolate them for the sake of testing or research" (Alderson, 2000, p. 49).

Findings on the issue of hierarchic order are also controversial. For example, Kádárné Fülöp (1983) revealed that the reading aspects or processes form a hierarchical order and are characterized by increasing complexity from concrete to more abstract levels. Similarly, PISA holds that from a cognitive processing perspective the reading processes are semihierarchical: "it is not possible to interpret or integrate information without having first retrieved it, and it is not possible to reflect on or evaluate information without having accessed the information, and very likely made some sort of interpretation" (OECD, 2010a, p. 43). However, from a developmental perspective, they are viewed as "being in the repertoire of each reader at every developmental level" (OECD, 2004a, p. 112).

Readers bring their background knowledge into the meaning making process to a different extent. Information retrieval and interpretation tasks require students to use content primarily from within the text, whereas when reflecting readers draw primarily upon outside knowledge (OECD, 2013, p. 67). All readers are expected to demonstrate some level of proficiency with each of the aspects of reading on all text formats, since all are seen as being in the repertoire of each reader at every developmental level (OECD, 2010a). A vast literature is available on the nature and functioning of these reading processes. Nevertheless, their scope has been limited to conceptualizing the reading of continuous texts. Furthermore, there is insufficient research focusing on the students' development in extracting and constructing meaning out of the information conveyed by texts with different formats. In addition, studies examining the relationship between students' reading achievement in different text formats and cognitive aspects of reading are also scarce. Alderson (2000) recognizes this niche in research but he assumes that it is unlikely that separate skills exist for processing certain sorts of texts, even if the way in which literary texts are processed is different (p. 66).

This is somewhat surprising because it is a widely accepted theory that reading for meaning emerges from a dynamic, complex interaction among the reader, the text, and the context (Smagorinsky, 2001). Readers bring to this interaction their reading processes and knowledge about the structure of texts (Pressley \& Afflerbach, 1995). The results of previous research focusing on the impact of text type and text format on reading performance underpin the importance of fragmentation and typography in comprehension. Seidenberg (1989) and Williams (2005) found that understanding and recognizing text structure improves text comprehension and helps students understand global ideas or main theses. Furthermore, Dymock (2005) found that students who face difficulties comprehending informational texts cannot see the basic structure of texts implying that text format and its unique structure affect students' reading comprehension.

Assessment programs, however, seem to conceive text format as a variable that ensures the coverage of the construct rather than as a variable that influences the difficulty of a task (OECD, 2010a; OECD, 2013). Only features of continuous (e.g., length, explicitness and transparency of structure) and non-continuous texts (e.g., list structure, whether components are ordered and explicitly organized) are used to manipulate item difficulty (OECD, 2013, p. 71). Nevertheless, the frameworks acknowledge that the reading "processes and strategies are expected to vary with context and purpose as readers interact with a variety of continuous and non-continuous texts (OECD, 2013, p. 61) and different presentations of textual content can demand that readers apply different comprehension processes (Mullis, Martin, \& Sainsbury, 2015, p. 17), "a different kind of reading approach" (OECD, 2010a, p. 41) and "somewhat different reading strategies" (OECD, 2010a, p. 41). In addition, a study on the process of prediciting PISA item difficulty also names the 
structure of non-continuous texts as a possible variable to influence item difficulty (Alderson, de Jong, Kirsch, Lafontaine, Lumley, Mendelovits, \& Searle, 2009).

Data show that Hungarian students' performance is poorer when it comes to understanding and making use of information conveyed by the non-continuous and mixed texts than by their continuous counterparts (Balázsi, Ostorics, Szalay, \& Szepesi, 2010; Molnár, 2006; OECD, 2010b). Attempts have been made to identify the factors underlying the differences based on some background data. Gender and reading habits are most commonly associated with this disparity (Mullis, Martin, Foy, \& Drucker, 2012; OECD, 2010b). Findings also yield evidence that different text formats have a different relationship with performance measured in other cognitive domains such as school-readiness, inductive reasoning and mathematical literacy (Hódi \& Tóth, 2013). The interpretation of the results falls short in finding further text-related variables that might account for the difference in students' reading performance along text formats. However, the above findings suggest that text format plays an important role in reading and may significantly affect comprehension and the underlying processes.

\subsection{Methods}

\subsubsection{Research questions}

Students' reading literacy has been in the focus of numerous large-scale assessment programs over the past decades (see PIRLS, PISA). With PIRLS being an exception, these studies do not regularly provide feedback on students' performance on different text formats. Moreover, they lack further analysis on variables related to text structure that may impact students' achievement. The aim of my study is to complement the results of previous research by carrying out detailed analyses on how cognitive aspects function in the meaningmaking process in various text formats. In line with this, the following research questions were formulated.

1) What is the underlying measurement model for reading literacy?

2) To what extent does students' reading literacy develop in continuous, mixed and non-continuous text formats between grades 2 and 4 ?

3) To what extent does students' reading literacy achievement differ along different text formats in grades 2 and 4 ?

4) How does students' reading achievement change when they read the continuous, mixed and non-continuous text?

5) To what extent does students' reading literacy develop in three cognitive aspects to reading (information retrieval, interpretation and reflection) in different text formats between grades 2 and 4 ?

6) To what extent does students' reading literacy achievement differ in three cognitive aspects to reading (information retrieval, interpretation and reflection) in different text formats in grades 2 and 4 ?

7) Are cognitive aspects to reading universal in all text formats?

\subsubsection{Participants}

The sample for the study was drawn from 5,619 second-grade students and 4,684 fourth-grade students. In this study data of 3,229 students (males: 50.9\%; age $\left.\mathrm{M}_{\mathrm{at} \text { school entry }}=7.079, \mathrm{SD}=4.739\right)$ are analyzed. I only used the data for students whose reading test scores and background data (see Chapters 5 and 6) were available at all assessment points. Data collection was carried out in subsequent years in grade 2 and in grade 4 (ISCED 1) as part of the Hungarian Educational Longitudinal Program (Csapó, 2014). The 
longitudinal sample was selected to be nationally representative by region, settlement type/settlement structure and gender. A total of 193 classes from 110 schools participated in the study from seven Hungarian statistical regions. In the Hungarian education system, eight years of the first phase of compulsory schooling are divided into two parts of four years each (ISCED 1 and ISCED 2A). The developmental targets for reading and comprehending written information are provided for three main periods indicating significant milestones in reading acquisition. The first developmental milestone should be achieved by the end of grade 4 (age 10). Ideally, by this point students will have acquired the elements of the sign system, mastered quick and flawless decoding, started to familiarize themselves with comprehension techniques, possess cognitive aspects of reading enabling them to retrieve information from, interpret and reflect on written pieces of information. During the first four years fiction and non-fiction texts are introduced to students and they are expected to be able to recognize different text types (expository, argumentation, etc.) based on their characteristic features (Nemzeti alaptanterv, 2012, pp. 10662-10663).

\subsubsection{Data collection instruments}

The social dimension of reading has been thoroughly researched by the IEA PIRLS and OECD PISA surveys as well as the National Assessment of Basic Competencies in Hungary. In the present study, I apply the same approach to reading, so the background knowledge accumulated by the above programs provided a solid starting point for the development of the assessment instruments. Based on national and international assessment frameworks, an online test was developed to assess Hungarian students' first language reading literacy achievement. Reading literacy was measured by means of a first-generation computer-based test (Bennett, 1998): the original paper-and pencil items were transformed onto and adapted to a computerized environment but opportunities and benefits provided by the internet and web 2.0 applications (e.g., menus, hyperlinks) were not used in the testing environment. The conversion of conventional forms to computer-delivered format has been the predominant type of computer-based assessment for two decades (Singleton, 1997; Csapó, Molnár, \& R. Tóth, 2008).

The test consisted of three subtests representing different text formats: a continuous, a mixed and a non-continuous one. The subtest with a continuous text format comprised 32 items. The text was a children's narrative about two cubs doing gardening (Figure 4.1).

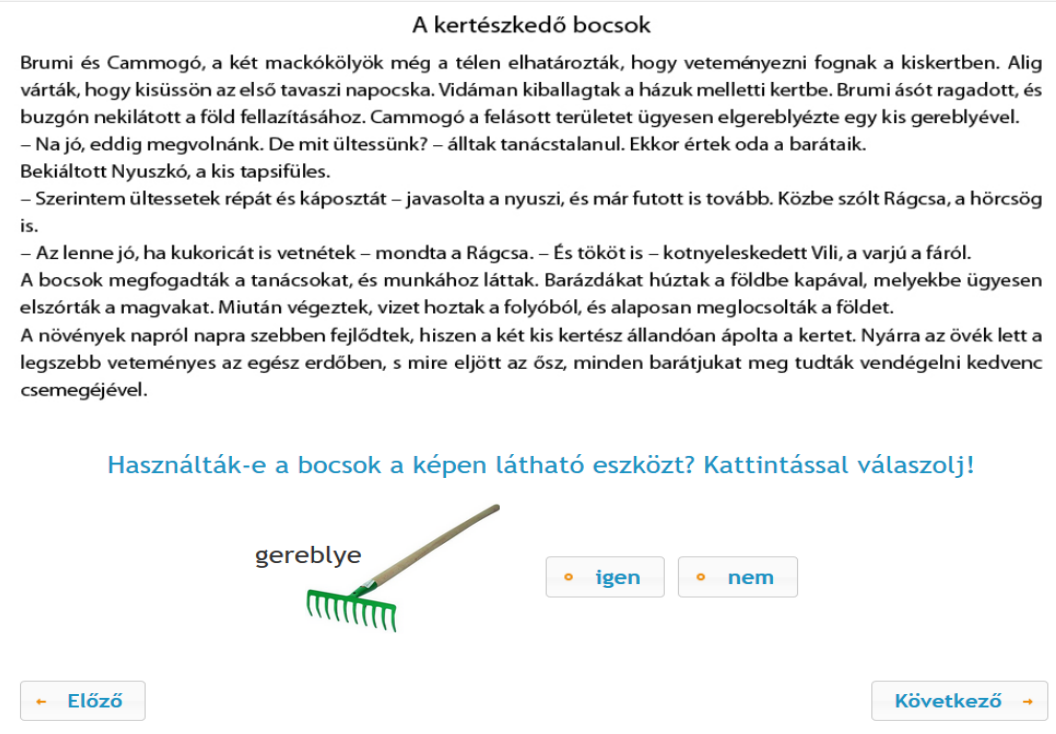

Figure 4.1. Sample item from the subtest with the continuous text 
The subtest with the mixed text format, in which the continuous format was complemented with a list, was an 18-item theatre poster about Szamárbőr királyfi (a fairy tale) performance (Figure 4.2).

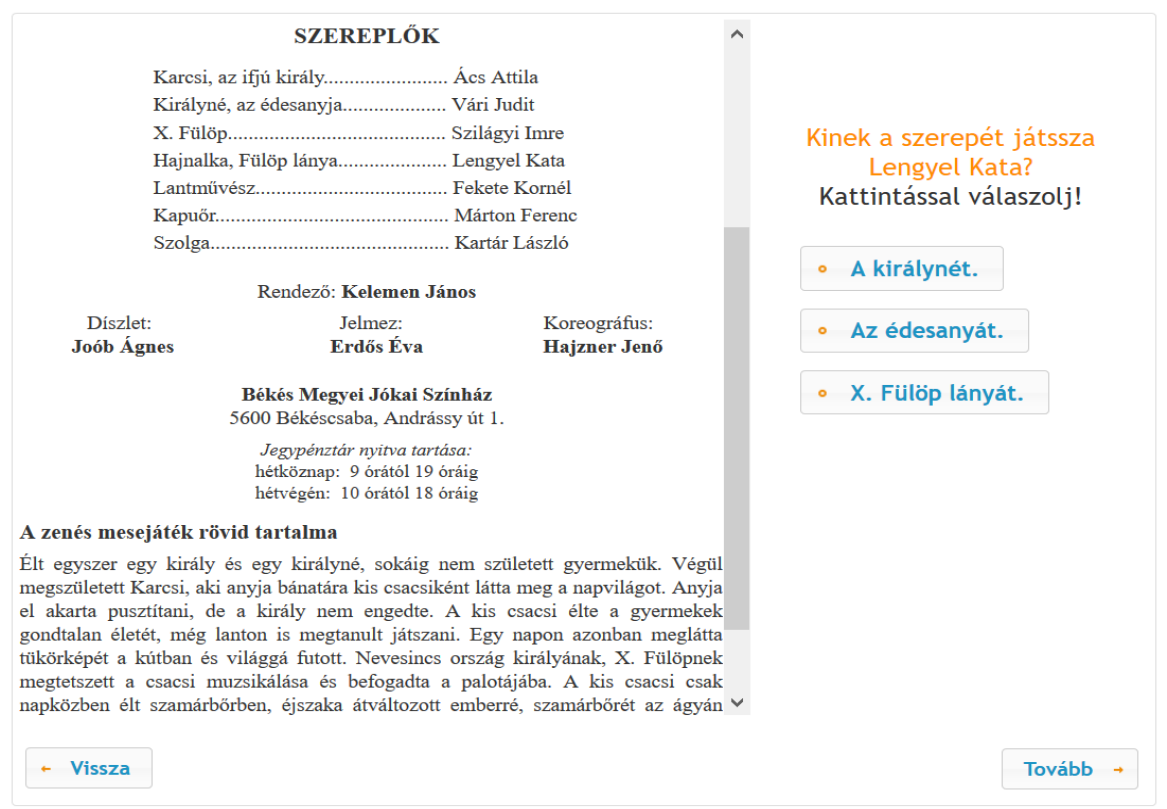

Figure 4.2. Sample item from the subtest with the mixed text

The non-continuous subtest (13 items) was a table containing some basic information (description, diet, breeding) about the white-tailed eagle (Figure 4.3). The paper-and-pencil format of the mixed and non-continuous subtest was developed by Éva Molnár and Mária B. Németh (For sample items in the paper-and-pencil mixed subtest see Molnár \& B. Németh, 2006).

\begin{tabular}{|c|c|c|c|}
\hline \multicolumn{2}{|c|}{ ÁLLOMÁNYADATOK } & \multicolumn{2}{|c|}{ FÉSZKELÉs } \\
\hline Megfigyelési idö (év): & 2003 & Fészkelö helye: & $\begin{array}{l}\text { ártéri erdök, vizek melletti } \\
\text { erdöségek, erdei tavas területek }\end{array}$ \\
\hline Fészkelö állomány nagysága: & 118-130 fészkelö pár & Fészek helye: & fán \\
\hline Hazai védettség: & fokozottan védett & Fészek típusa: & gallyfészek \\
\hline Pénzben kifejezett érték (Ft): & 1000000 & Fészkelési tipus: & magányosan fészkelö \\
\hline Európai veszélyeztetettség: & ritka faj & Fiókák száma $(d b)$ : & $1-3$ \\
\hline Hazai elöfordulási idöszak: & egész évben & Kikelési idö (nap): & 38.40 \\
\hline Hazai elófordulási státusz: & rendszeres fészkelö & Kirepülési idö (nap): & $80-90$ \\
\hline Telelési helye: & hazai élöhelyei & Fiókák fejlettsége: & fészeklakó \\
\hline Testhossz (cm): & $70-90$ & Évenkénti költés száma: & 1 \\
\hline Szárnyfesztávolság (cm): & $200-240$ & \multirow{2}{*}{ Életmódja; tápláléka: } & \multirow{2}{*}{$\begin{array}{l}\text { ragadozó; madarak (vízimadarak, } \\
\text { vadludak), halak, emlösök } \\
\text { (nyulak, nagyvadak zsigerei, } \\
\text { dögök) }\end{array}$} \\
\hline Hím tämege $(g)$ : & $3075-5430$ & & \\
\hline Tojó tömege $(\mathrm{g})$ : & $4080-6920$ & Ellensége, konkurenciája: & $\begin{array}{l}\text { kerecsensólyom (a fészkére } \\
\text { pályázik) }\end{array}$ \\
\hline
\end{tabular}

Mi a rétisas természetes ellensége? Kattintással válaszolj!

halászsas

kerecsensólyom

Figure 4.3. Sample item from the subtest with the non-continuous text

All students took all subtests. The subtests include the same test specification, instructions and response types. All subtests contained only closed items. Students were 
asked to retrieve information, interpret and reflect on the form and content of the written information. When developing the test, I took into consideration aspects of children's reading development (Wolf, 2008) and consulted studies on the results and structure of previous instruments. Furthermore, I consulted national and international assessment frameworks (e.g., Hódi, Adamikné Jászó, Józsa, Ostorics, \& Zsigriné Sejtes, 2015; OECD, 2013), students' reading books and teachers. Thus, the representations of cognitive aspects reflect the proportions based on the above guidelines and recommendations. Items requiring students to reflect on the non-continuous text were not included in the test because of their anticipated complexity and difficulty for the assessed population. The same tests were used in grades 2 and 4.

Table 4.1 Number of items and Cronbach's alpha indices for the reading literacy test and its subtests

\begin{tabular}{lcccccc}
\hline \hline \multirow{2}{*}{ Subtests } & \multicolumn{4}{c}{ Number of items } & \multicolumn{3}{c}{ Cronbach's alpha } \\
\cline { 2 - 7 } & Total & $\begin{array}{c}\text { Information } \\
\text { retrieval }\end{array}$ & $\begin{array}{c}\text { Interpreta- } \\
\text { tion }\end{array}$ & Reflection & Grade 2 & Grade 4 \\
\hline Continuous & 32 & 9 & 17 & 6 & .84 & .82 \\
Mixed & 18 & 7 & 7 & 4 & .72 & .74 \\
Non-continuous & 13 & 8 & 5 & 0 & .72 & .74 \\
\hline Total & 63 & 24 & 29 & 10 & .87 & .89 \\
\hline \hline
\end{tabular}

Table 4.1 shows the reliability coefficients (Cronbach's alpha) for the reading literacy test and its subtests. The values, ranging from .72 to .87 , indicate that the reliability of the instrument proved to be acceptable both at test and subtest levels.

There were other considerations that guided the test development. The indicators used by Mullis, Martin, and Foy (2013) and the parameters for text choice for different school grades recommended by Józsa, Steklács, Hódi, Csíkos, Adamikné Jászó, Molnár, Nagy, and Szenczi (2012) provided a solid foundation for text choice (Table 4.2). The descriptors of word number, symbolic language and the number of visual displays provide a more analytic insight into the composition of different text formats (Mullis, Martin, \& Foy, 2013).

Table 4.2 Characteristics of the continuous, mixed and non-continuous texts

\begin{tabular}{cccc}
\hline \hline \multirow{2}{*}{ Parameters } & \multicolumn{3}{c}{ Text format } \\
\cline { 2 - 4 } & Continuous & Mixed & Non-continuous \\
\hline Number of words & 173 & 218 & 94 \\
Symbolic language & - & 11 & 25 \\
Visual displays & - & - & 1 \\
\hline \hline
\end{tabular}

As a property of sentences, the number of words one must read is a basic element of readability included in many well-known readability formulae (e.g., Dale-Chall - Chall \& Dale, 1995) and Flesch-Kincaid - Kincaid, Fishburne, Rogers, \& Chissom, 1975) (Farrall, 2012, p. 274; Loch, 2003). In the measured population, a text between 200 and 250 words is considered as having an optimal length in terms of word number. Since the frameworks 
advise teachers to introduce non-continuous texts into their syllabi gradually with an increasing length, the present study also maintained this principle.

Understanding symbolic language also requires reading skills. These can include numerals (e.g., 3, 5, 40) as well as other symbols and abbreviations (e.g., +, =, cm) (Mullis, Martin \& Foy, 2013). The continuous text did not contain any symbolic references; however, the non-continuous text included the highest number of symbolic language. As far as the visual displays (pictorial representations of real world things, geometric shapes and figures, models and diagrams, tables, and graphs) are concerned, neither the continuous text nor the mixed one comprised visual illustrations that students needed to interact with to varying degrees in order to successfully complete the items. Naturally, the table as a non-continuous text was a visual display in itself (Table 4.2).

Features of text typography (letter size and font) were also carefully selected to enhance the reading experience, since bigger font size (Gósy, 2008) and sans serif fonts contribute to better readability.

Since the Hungarian National Corpus (HNC; Magyar Nemzeti Szövegtár -Oravecz, Váradi, \& Sass, 2014; Sass, 2009; Váradi, 2002) forms the basis of the 5,000 most frequent words from which the vocabulary of the test included in the Diagnostic Skills and Ability Assessment (DSAA) assessing 4th graders was drawn, I also use it to characterize the vocabulary of the continuous, mixed and non-continuous texts with respect to word frequency. The vocabulary of the subtests is characterized based on the frequency ranges published in the Hungarian Dictionary and Thesaurus in 2003. Five frequency groups were created. In each category, the lower limit of frequency was provided (Table 4.3). The proportion of words falling into the categories was determined using two sources: the Hungarian Dictionary and Thesaurus (2003) and the completed online HNC.

The Hungarian National Corpus (HNC) is claimed to be a representative general-aim corpus of present-day standard Hungarian. The HNC consists of press, literature, science, official and personal subcorpora. Texts from the news media (press category) make up almost half of the corpus, presenting a broad scale of dialects, both vertically and horizontally. The material of the Digital Literary Academy makes the literature subcorpus for Hungary. The source of science texts is the Hungarian Electronic Library. The official subcorpus contains regulations, laws, by-laws and parliamentary debates. The personal subcorpus contains discussions of internet forums. This language variant stands closest to spontaneous linguistic communication. In certain cases, it is very similar to spoken communication.

Table 4.3 The ratio of words included in the continuous, mixed and non-continuous texts based on word frequencies

\begin{tabular}{|c|c|c|c|c|c|c|c|c|c|c|}
\hline & \multicolumn{10}{|c|}{ Category (word frequency ranges) } \\
\hline Corpus & \multicolumn{2}{|c|}{$1(1-2000)$} & \multicolumn{2}{|c|}{$2(2001-10000)$} & \multicolumn{2}{|c|}{$3(10001-30000)$} & \multicolumn{2}{|c|}{$4(30001-60000)$} & \multicolumn{2}{|c|}{$5(60001<)$} \\
\hline $\begin{array}{l}\text { Text } \\
\text { format }\end{array}$ & $\begin{array}{c}\text { present } \\
\text {-day }\end{array}$ & 2003 & $\begin{array}{c}\text { present } \\
- \text {-day }\end{array}$ & 2003 & $\begin{array}{l}\text { present } \\
\quad-\text { day }\end{array}$ & 2003 & $\begin{array}{c}\text { present } \\
\text {-day }\end{array}$ & 2003 & $\begin{array}{c}\text { present } \\
\text {-day }\end{array}$ & 2003 \\
\hline Continuous & 45.73 & 68.29 & 20.17 & 14.05 & 12.8 & 9.75 & 8.30 & 3.04 & 13.00 & 4.87 \\
\hline Mixed & 47.61 & 65.47 & 22.02 & 19.06 & 14.28 & 13.09 & 6.54 & 1.19 & 9.55 & 1.19 \\
\hline $\begin{array}{l}\text { Non- } \\
\text { continuous }\end{array}$ & 18.18 & 34.34 & 29.29 & 32.32 & 21.21 & 23.23 & 15.15 & 6.06 & 16.17 & 4.05 \\
\hline
\end{tabular}


Table 4.3 shows that based on the frequency categories displayed in the Hungarian Dictionary and Thesaurus published in 2003, most of words (68.29\% and $65.47 \%)$ contained by the continuous and mixed texts, respectively, fall into the first category containing the 2,000 most frequent Hungarian words. Data also show that the proportion of words falling into the same category is $34.34 \%$ in case of the non-continuous subtest. The proportion of words belonging to the second category is the largest in case of the non-continuous subtest and is lower in case of the continuous and mixed subtests. Data also show that the fourth and fifth category representing the least frequently appearing words in the HNC contains the smallest proportion of words in case of each subtest (continuous: $7.91 \%$, mixed: $2.38 \%$, $10.11 \%)$.

Taking the present-day $\mathrm{HNC}$ as a basis for analysis yields different patterns in terms of the ratio of words in the frequency categories over time but the tendencies among the subtests remain similar. According to the present-day corpus, less than half of the words $(45.73 \%$ and $47.61 \%)$ contained by the continuous and mixed texts, respectively, fall into the first category, in case of the non-continuous text, this proportion is $18.18 \%$. The proportion of the words in the second category is quite balanced $(20.17 \%, 22.02 \%$ and $29.29 \%$ ). The proportion of less frequent words (category 4 and 5) is continuous: $21.30 \%$, mixed: $16.09 \%$ and non-continuous: $31.32 \%$.

Research showed that readers have to know the meanings of at least $95 \%$ of words in the text for successful comprehension. According to Nagy (2004a), 95-96\% of the vocabulary contained by everyday texts is made up of the most frequent 4-5,000 words. Calculations based on the 2004 state of the HNC showed that words in the first category (i.e. the most frequent 2,000 words) made up $88 \%$ of the corpus.

Unfortunately, there is no point of reference that could provide a sound basis for the comparison of the subtests. Since a readability formula has not been developed in Hungarian and the Hungarian landscape has also been lacking a comprehensive corpus including textbooks. Therefore, the above parameters were given to orient further research e.g., on students' vocabulary and its role in students' achievement in different text formats or revisiting the list of most frequent 5,000 words the DSAA draws on.

\subsubsection{Procedures}

The online data collection was carried out in spring 2013 and 2015. Students completed the tests during two 45-minute classes at school by means of the eDia (Electronic Diagnostic Assessment Platform; Csapó, Lőrincz, \& Molnár, 2012; Molnár, 2015) platform via the Internet in their schools' ICT labs. Students logged into the system using their student ID provided by the Educational Authority to maintain confidentiality throughout the project. The continuous text and the non-continuous items were administered first, followed by the subtest comprising a mixed text. The fact that computer-based tests are demonstrably faster, easier to administer and more efficient (Singleton, 1997; Csapó, Molnár, \& R. Tóth, 2008) motivated the development of first-generation computer-based tests.

To create a testing environment as similar to the traditional paper-and-pencil reading experience as possible, we made sure that students get access to the text and the related task at the same time. In each case, the test was presented on a vertically or a horizontally divided screen. On one side, students could read the text, on the other side, the task appeared.

As far as computer graphical user interfaces are concerned, students gave their responses by clicking (Figures 4.1, 4.2 and 4.3) and dragging and dropping functions (Figure 4.4). 


\section{A kertészkedő bocsok}

Brumi és Cammogó, a két mackókölyök még a télen elhatározták, hogy veteményezni fognak a kiskertben. Alig várták, hogy kisüssön az első tavaszi napocska. Vidáman kiballagtak a házuk melletti kertbe. Brumi ásót ragadott, és buzgón nekilátott a föld fellazításához. Cammogó a felásott területet ügyesen elgereblyézte egy kis gereblyével.

- Na jó, eddig megvolnánk. De mit ültessünk? - álltak tanácstalanul. Ekkor értek oda a barátaik. Bekiáltott Nyuszkó, a kis tapsifüles.

- Szerintem ültessetek répát és káposztát - javasolta a nyuszi, és már futott is tovább. Közbe szólt Rágcsa, a hörcsög

- Az lenne jó, ha kukoricát is vetnétek - mondta a Rágcsa. - És tököt is - kotnyeleskedett Vili, a varjú a fáról. A bocsok megfogadták a tanácsokat, és munkához láttak. Barázdákat húztak a földbe kapával, melyekbe ügyesen elszórták a magvakat. Miután végeztek, vizet hoztak a folyóból, és alaposan meglocsolták a földet.

A növények napról napra szebben fejlödtek, hiszen a két kis kertész állandóan ápolta a kertet. Nyárra az övék lett a legszebb veteményes az egész erdőben, s mire eljött az ősz, minden barátjukat meg tudták vendégelni kedvenc csemegéjével.

Húzogatással rakd helyes sorrendbe az eseményeket!

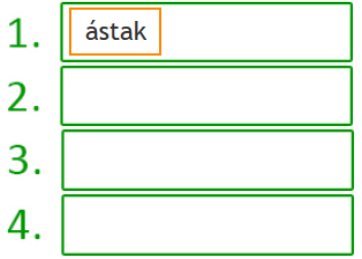

Figure 4.4. Sample item for the dragging and dropping function from the subtest with the continuous text

Navigation buttons enabled students to progress in the test from one item to another (see Figures 4.1, 4.2, 4.3 and 4.4). The scrollbar feature was integrated when the whole text could not be displayed on the screen at once. However, the necessity to use the scrollbar function was always used consistently, thus, the same text appeared on the screen the same way throughout the testing procedure. If scrolling down was required to read the text, students' attention was drawn to this fact. When devising the instrument, we relied on findings yielded by a study conducted by Molnár and Pásztor (2015) with first graders, which lent support to the assumption that online assessment instruments may be efficiently used as testing media in lower elementary school years. They concluded that even younger school-aged populations are able to apply a wide range of ICT skills including mouse and keyboard use but tasks requiring students to click should be dominant. Within the framework of this study practice items on ICT use were integrated into the beginning of the test to increase test validity. No student could start the testing procedure without completing the trial items because we wanted to make sure that the extent of ICT familiarity does not influence the reading test scores.

Teachers supervised the low-stakes procedure. Before the assessments teachers were given general information booklets so that they had an idea of what to expect during an assessment. The data collection was anonymous, students' assessment ID's were used to link data.

\subsubsection{Data analyses}

Confirmatory factor analyses (CFA) within structural equation modelling (SEM; Bollen, 1989) were used to test the underlying measurement model for reading literacy. All measurement models were computed with MPlus. Weighted Least Squares and Mean- and Variance-adjusted (WLSMV) estimation was used (Muthén \& Muthén, 2010). Different fit 
indices, such as the Tucker-Lewis Index (TLI), the comparative fit index (CFI) and the root mean square error of approximation (RMSEA) were computed to assist in determining model fit. Nested model comparisons were conducted using a special $\chi^{2}$ difference test for the WLSMV estimator (Muthén \& Muthén, 2010).

Data were also analyzed with descriptive statistical methods and paired-samples t-test.

\subsection{Analysis and results}

\section{DIMENSIONALITY OF READING LITERACY}

First, I examined the underlying measurement model of reading literacy step by step. I assumed that the main organizational element of the domain is text format. Based on the literature, a three-dimensional model of reading literacy that includes three different text formats as subtests (i.e. continuous, mixed, non-continuous) was proposed. The threedimensional models showed a good model fit in both grades (Table 4.4).

Table 4.4 Goodness of fit indices for testing the underlying measurement model of reading literacy in grades 2 and 4 (G2; G4)

\begin{tabular}{cccccccc}
\hline \hline Model & $\chi 2$ & $d f$ & $p$ & CFI & TLI & RMSEA (95\% CI) & $N$ \\
\hline 3-dimensional G2 & $2,063.66$ & 1,887 & .001 & .937 & .935 & $.024(.018-.020)$ & 3229 \\
1-dimensional G2 & $7,169.60$ & 1,890 & .001 & .906 & .902 & $.029(.029-.030)$ & 3229 \\
3-dimensional G4 & $3,977.95$ & 1,826 & .001 & .965 & .964 & $.019(.018-.020)$ & 3229 \\
1-dimensional G4 & $4,762.12$ & 1,829 & .001 & .952 & .951 & $.022(.022-.023)$ & 3229 \\
\hline \hline
\end{tabular}

The one-dimensional model combining the three factors (text formats) under one general factor was also tested. The fit for the 3-dimensional model and the 1-dimensional model was acceptable in the cases of both grades. However, according to the result from the special $\chi^{2}$-difference test, the three-dimensional model fit the data significantly better than the one-dimensional model in both grades $\left(\mathrm{G} 2: \chi^{2}=712.180 ; \mathrm{df}=3 ; \mathrm{p}<.001, \mathrm{G} 4: \chi^{2}=403.409\right.$; $\mathrm{df}=3 \mathrm{p}<.001$; Table 4.4), indicating empirical evidence for the construct validity of the reading test.

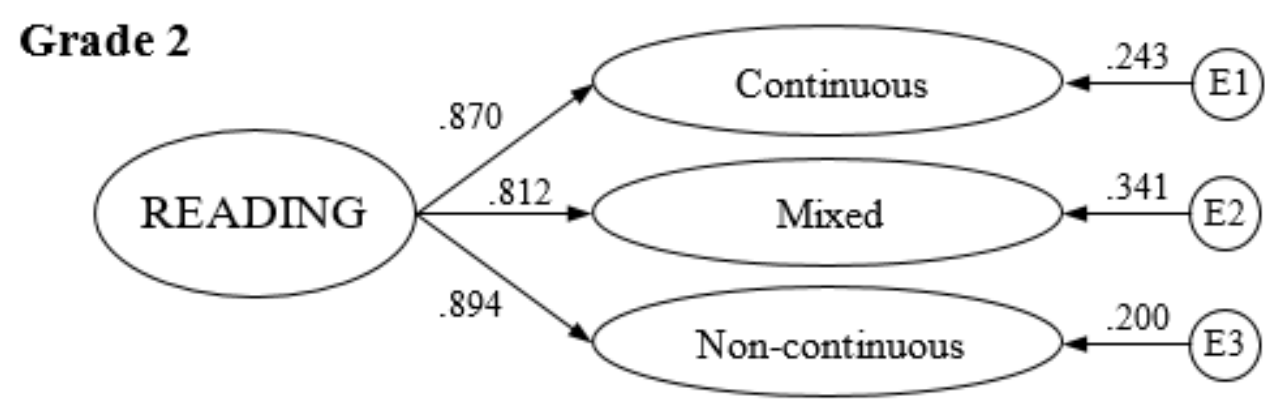

Note. Standardized parameter estimates are shown. All values are significant at a $\mathrm{p}<.01$ level. Latent variables are depicted by circles.

Figure 4.5. A structural model of reading literacy constituting three different text formats in grade 2 


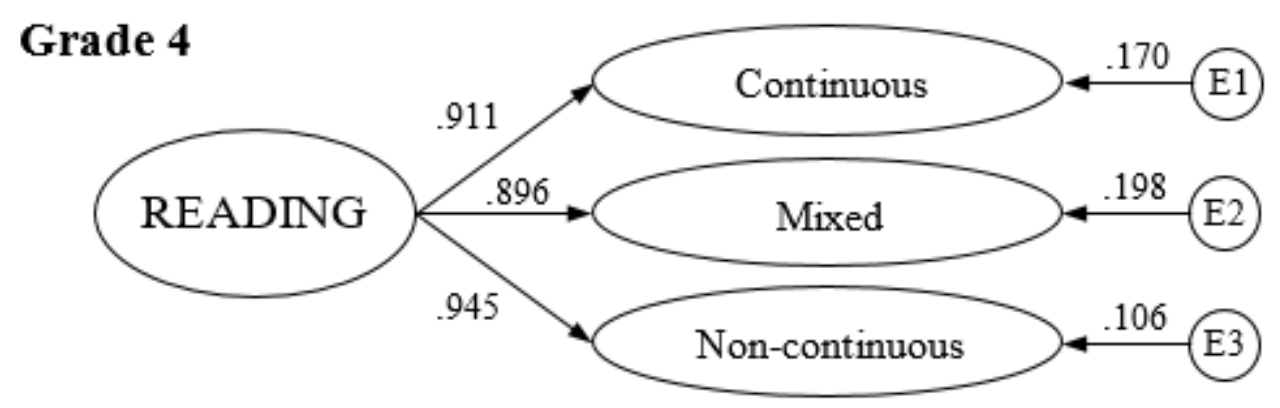

Note. Standardized parameter estimates are shown. All values are significant at a $p<.01$ level. Latent variables are depicted by circles.

Figure 4.6. A structural model of reading literacy constituting three different text formats in grade 4

Reading literacy as a latent factor has been specified by reading processes of continuous, mixed and non-continuous text formats (Figures 4.5 and 4.6).

\section{DIMENSIONALITY OF TEXT FORMATS}

Second, the dimensions of text formats were studied. I assumed that the tasks belonging to each text format represent three different cognitive aspects of reading. Based on the relevant literature, a three-dimensional model of reading literacy that includes three different cognitive aspects to reading (i.e. information retrieval, interpretation, reflection) in each text format was supposed. The three-dimensional models showed a good model fit in case of each subtest representing different text formats in both grades (Table 4.5).

Data in Table 4.5 also show that in grade 4 the models have better fit values than in grade two. A possible explanation for this phenomenon may be that in the second year of learning to read a huge emphasis is laid on the development of the psychological dimension of reading entailing reading precursors and basic reading skills contributing to decoding and reading fluency, whereas over two years there is a shift in teaching reading towards the development of comprehension skills and refining the application dimension of reading (Csapó, Józsa, Steklács, Hódi, \& Csíkos, 2012). In grade 4, at the more advanced stages of the acquisition of reading skills the aspects of knowledge that are pertinent to application operate in a more efficient and organized way - an achievement target articulated in the Hungarian National Core Curriculum (Nemzeti alaptanterv, 2012).

Table 4.5 Goodness of fit indices for testing the underlying measurement model of reading literacy for different text formats in grades 2 and 4 (G2; G4)

\begin{tabular}{lccccccc}
\hline \hline \multicolumn{1}{c}{ Model } & $\chi 2$ & $d f$ & $p$ & CFI & TLI & RMSEA (95\% CI) & $N$ \\
\hline Continuous G2 & $2,063.66$ & 461 & .001 & .936 & .931 & $.033(.031-.034)$ & 3229 \\
Continuous G4 & $1,640.62$ & 461 & .001 & .952 & .948 & $.028(.027-.030)$ & 3229 \\
Mixed G2 & 839.80 & 132 & .001 & .910 & .901 & $.041(.038-.043)$ & 3229 \\
Mixed G4 & 467.99 & 132 & .001 & .968 & .962 & $.028(.025-.031)$ & 3229 \\
Non-continuous G2 & 716.02 & 64 & .001 & .920 & .902 & $.560(.053-.060)$ & 3229 \\
Non-continuous G4 & 300.27 & 64 & .001 & .969 & .962 & $.034(.030-.038)$ & 3229 \\
\hline \hline
\end{tabular}

Note. $d f=$ degrees of freedom; CFI = Comparative Fit Index; TLI = Tucker-Lewis Index;

RMSEA $=$ Root Mean Square Error of Approximation; $\chi^{2}$ and $d f$ are estimated by WLSMV 


\section{THE MULTILEVEL DIMENSIONALITY OF READING LITERACY}

Third, I synthesized the information gained in the previous steps regarding the text formats and cognitive aspects to reading in order to present the multilevel underlying measurement model of reading literacy.

Figures 4.7 and 4.8 show that the sets of items measuring information retrieval, interpretation and reflection included in the assessment instruments measure comprehension of texts with different formats: continuous, mixed and non-continuous constituting reading literacy. The models have fit indices in both grades. It is also demonstrated that the shared context among items referring to a particular text is a source of systematic variance.

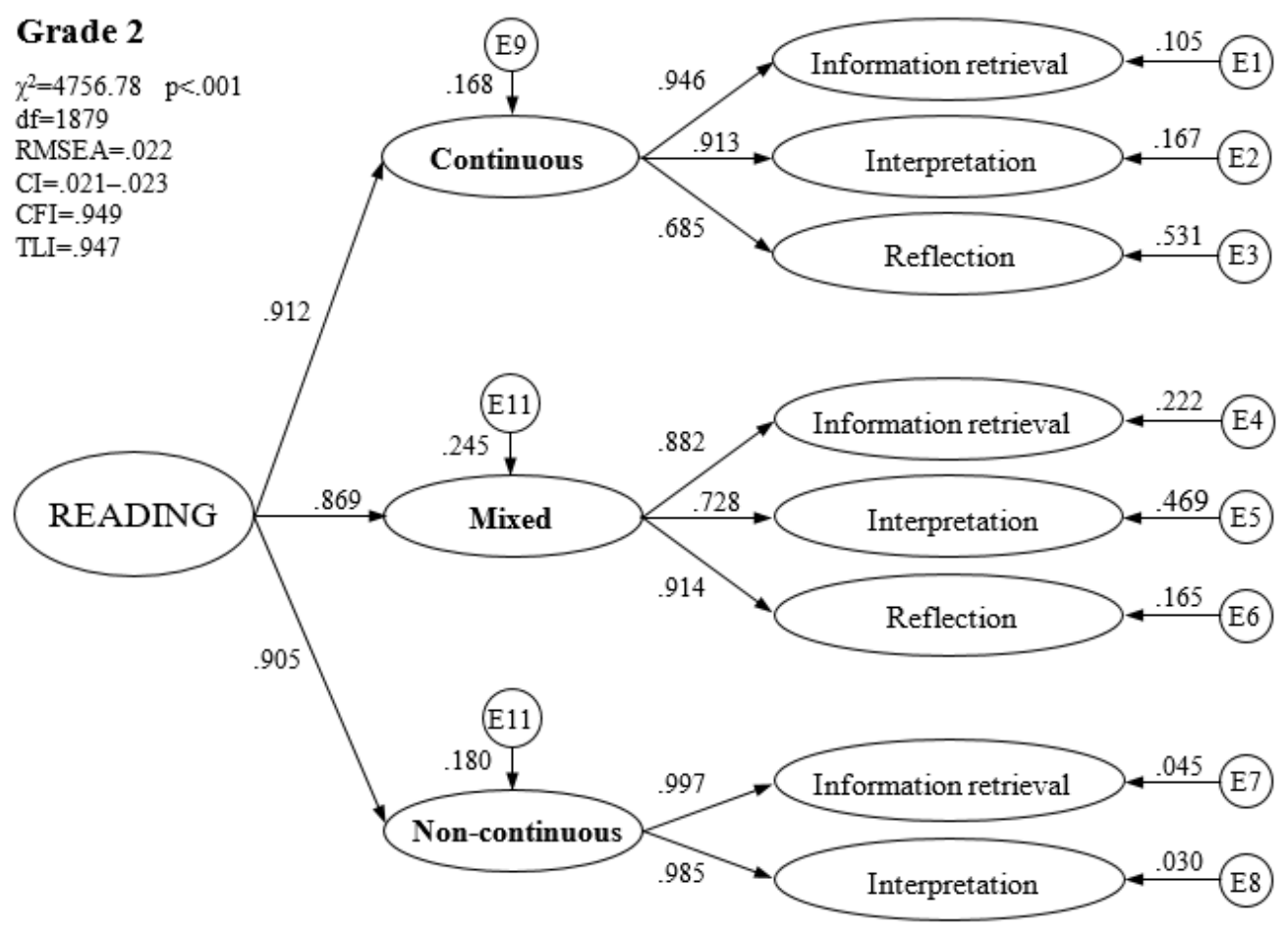

Note. Standardized parameter estimates are shown. All values are significant at a $p<.001$ level. Latent variables are depicted by circles.

Figure 4.7. A structural model of reading literacy in grade 2 


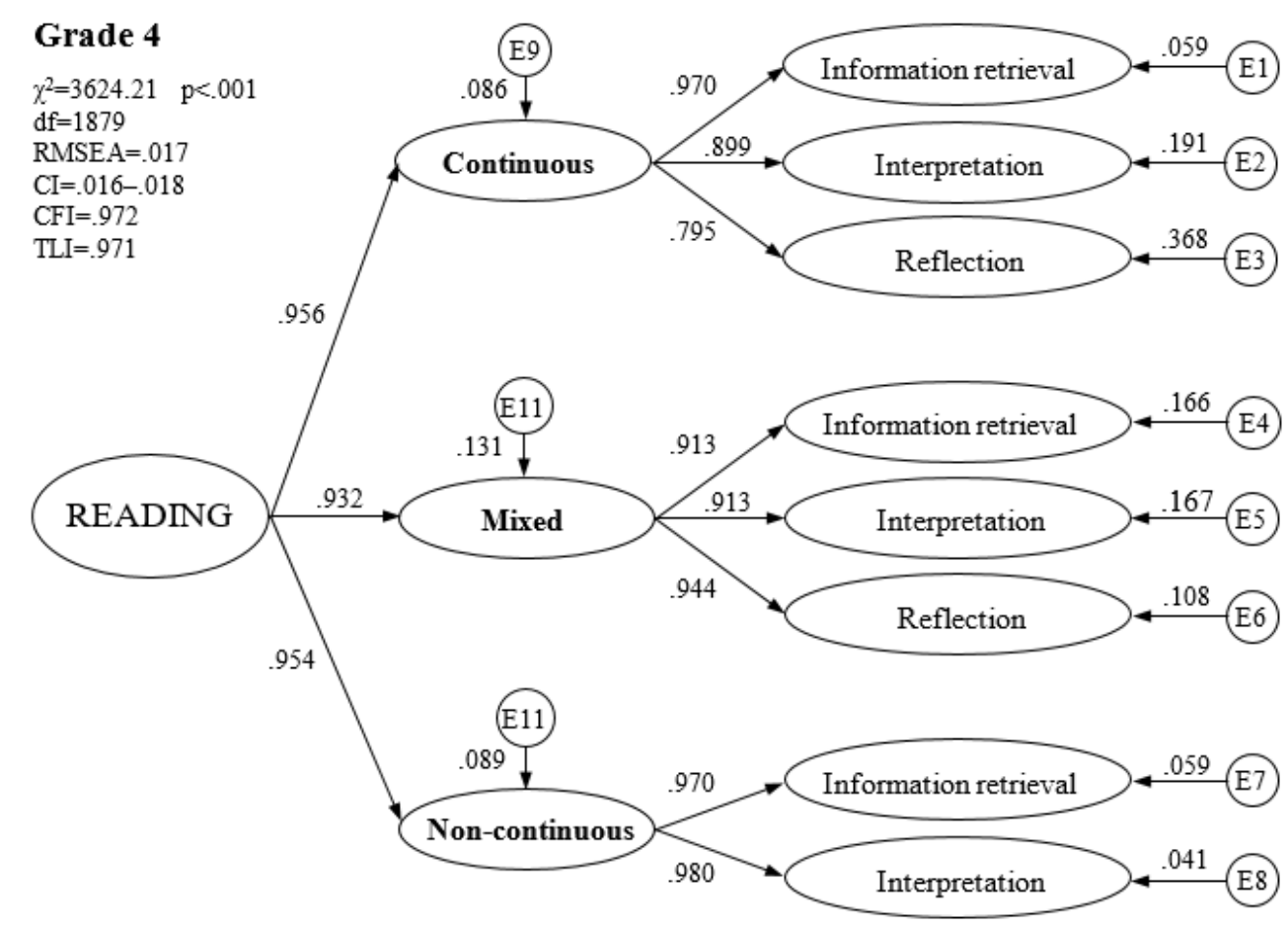

Note. Standardized parameter estimates are shown. All values are significant at a $\mathrm{p}<.001$ level. Latent variables are depicted by circles.

Figure 4.8. A structural model of reading literacy in grade 4

\section{DEVELOPMENT AND DIFFERENCES IN ACHIEVEMENT ALONG TEXT FORMATS}

To answer the second research question, we examined students' reading development along continuous, mixed and non-continuous text formats between grades 2 and 4 . Data in Table 4.6 show that students' reading achievements improved significantly on all three text formats between the two assessment points. In 2015 students' performance was significantly better than in 2013 but the extent of development is not balanced in the different text formats. Results indicate a slight but similar improvement in students' achievement on the continuous $(7.05 \%)$ and mixed texts $(7.57 \%)$. However, test scores on the non-continuous text increased substantially over the assessment period (13.99\%).

Table 4.6 Mean test scores and standard deviation between grades 2 and 4 and effect size at subtest level

\begin{tabular}{lcccc}
\hline \hline \multicolumn{1}{c}{ Subtest } & $\begin{array}{c}M(S D) \\
\text { Grade2 }\end{array}$ & $\begin{array}{c}M(\text { SD }) \\
\text { Grade4 }\end{array}$ & $\begin{array}{c}\text { Extent of change } \\
(\% p)\end{array}$ & Effect sizer \\
\hline Continuous & $73.75(16.25)$ & $80.8(14.18)$ & 7.05 & .225 \\
Mixed & $65.53(17.02)$ & $73.10(17.32)$ & 7.57 & .215 \\
Non-continuous & $62.61(22.83)$ & $76.60(20.09)$ & 13.99 & .309 \\
\hline \hline
\end{tabular}

To answer the third research question, I compared students' reading achievements along the three text formats within grades. There were significant differences in students' achievements on all subtests representing different text formats within both grades (Table 4.7). Findings indicate that in line with previous research results students performed significantly better on the continuous text both in 2013 and 2015 than on the mixed and noncontinuous texts. These findings also suggest that second graders had the most difficulty in 
answering questions related to the tasks on the non-continuous subtest, whereas students in grade 4 achieved significantly lower scores on the mixed text than on the other two text formats.

Table 4.7 Differences in students' achievement in continuous, mixed and non-continuous text formats in grades 2 and 4 with paired samples $t$-tests

\begin{tabular}{lcccc}
\hline \hline \multirow{2}{*}{ Subtest } & \multicolumn{2}{c}{ Grade 2 } & \multicolumn{2}{c}{ Grade 4 } \\
\cline { 2 - 5 } & $t$ & sig & $t$ & sig \\
\hline Continuous - Mixed & 27.557 & .001 & 30.577 & .001 \\
Continuous - Non-continuous & 33.934 & .001 & 15.903 & .001 \\
Mixed - Non-continuous & 7.942 & .001 & -11.756 & .001 \\
\hline \hline
\end{tabular}

It was also examined how students' reading achievement changes when they read the continuous, mixed and the non-continuous texts. First, the test scores achieved in the continuous text were divided into four equal groups since this text format is the one traditionally associated with reading; therefore, the text format students most often meet during learning to read (Chapters 5 and 6). Students' achievement in the mixed and noncontinuous text was also divided into quartiles to be able to examine the extent they overlap (Table 4.8).

Second graders' data show that the distribution of students is similar in case of the mixed and the non-continuous text. Results unveil the same tendencies: $57.99 \%$ and $57.50 \%$ of students being in the first quartile based on their achievement in the continuous subtest also fall into the lowest quartile in the mixed and non-continuous subtests. Yet, $16.98 \%$ and $10.66 \%$ of students in the lowest quartile scored in the third, upper quartile in the other two subtests. Additionally, $3.47 \%$ and $2.85 \%$ of them achieved test scores placing them in the highest quartile in the mixed and non-continuous subtests.

Table 4.8 The distribution of students in the quartiles of the mixed and non-continuous text based on the quartiles of the continuous text in grades 2 and $4(\%)$

\begin{tabular}{lccccccccc}
\hline \hline & & \multicolumn{1}{c}{ Continuous } \\
\cline { 2 - 10 } Subtest & Quartile & \multicolumn{9}{c}{ Grade 2} & \multicolumn{5}{c}{ Grade 4 } \\
\cline { 2 - 10 } & & 1 & 2 & 3 & 4 & 1 & 2 & 3 & 4 \\
\hline \multirow{3}{*}{ Mixed } & 57.99 & 27.85 & 9.54 & 4.58 & 65.43 & 21.53 & 10.29 & 2.73 \\
& 2 & 21.56 & 33.04 & 29.12 & 16.36 & 22.43 & 45.05 & 23.67 & 8.92 \\
& 3 & 16.98 & 23.89 & 28.25 & 30.86 & 10.41 & 23.27 & 40.02 & 26.27 \\
& 4 & 3.47 & 15.22 & 33.09 & 48.20 & 1.73 & 10.15 & 26.02 & 62.08 \\
\hline \multirow{3}{*}{ Non- } & 1 & 57.50 & 26.11 & 10.78 & 5.58 & 64.44 & 24.26 & 8.43 & 2.85 \\
continuous & 2 & 29.00 & 34.53 & 22.43 & 14.13 & 27.01 & 36.88 & 24.54 & 11.65 \\
& 3 & 10.66 & 25.99 & 34.94 & 28.38 & 7.68 & 26.24 & 37.55 & 28.50 \\
& 4 & 2.85 & 13.37 & 31.85 & 51.92 & 0.87 & 12.62 & 29.49 & 57.00 \\
\hline \hline
\end{tabular}

Students whose achievement fell into the second quartile in the continuous subtest reaching the highest quartile were still less likely to fall into other lower quartiles, however, 
a larger proportion of students (15.22\% and $13.37 \%)$ managed to achieve high test scores (fourth quartile) in the mixed and non-continuous text despite their relatively low achievement in the continuous text.

Students whose achievement is above the median in the continuous subtest show an opposite tendency than those whose data fell into the first two quartiles. The largest proportion of top performers (Q4) in the continuous subtest fell into the highest quartile in both the mixed and the non-continuous subtest (48.20\% and $51.92 \%)$ and only $4.58 \%$ and $5.58 \%$ fell into the first quartile. The ratio of students who were in the third quartile based on the continuous subtest scores was also small in the first quartile created based on the mixed $(9.54 \%)$ and non-continuous $(10.78 \%)$ data. However, their ratio was larger than that of the best performers in the same category.

In grade 4, data show that there is a growing tendency among the poor and top performing outliers in the continuous text to achieve test scores in the same quartile in the other two text formats as well. 65.43\% of students in Q1 based on their continuous achievement fall into the first quartile in the mixed subtest and this holds true for $64.44 \%$ of students in terms of the non-continuous text. Compared to results in the second grade, this means a $7.44 \%$ and a $6.94 \%$ increase in the two quartiles. At the same time, the likelihood for poor comprehenders of the continuous text to achieve above the median decreased.

Taking a look at the top performers' data, we can see a similar shift in the likelihoods in the opposite direction. In grade 4 , an increasing ratio $(62.08 \%$ and $57.00 \%)$ of students whose achievement fell into the highest quartile based on their continuous achievement fell into the highest quartile in the mixed and non-continuous subtest as well. Along this change, data also show that these students are less likely to have test scores below the median than in grade 2. In grade 4, results also yield evidence that students are more likely to maintain their quartiles in each subtest. This pattern was not yet so articulated in grade 2, especially in case of students falling into the second and third quartile.

\section{DEVELOPMENT AND DIFFERENCES IN ACHIEVEMENT ALONG COGNITIVE ASPECTS}

To get a more diverse picture on the differences between text formats, we also examined students' achievements on the cognitive aspect level between and within grades. Data show that students' achievements improved significantly between the grades in all cognitive aspects during the data collection period (Table 4.9). The most remarkable improvement was detected in case of the non-continuous text regarding both information retrieval and interpretation.

Table 4.9 Students' achievement on the cognitive aspects in different text formats within and between grades

\begin{tabular}{|c|c|c|c|c|c|}
\hline Subtest & Cognitive aspect & $\begin{array}{c}M(S D)(\%) \\
\text { Grade2 }\end{array}$ & $\begin{array}{c}M(S D)(\%) \\
\text { Grade4 }\end{array}$ & $\begin{array}{c}\text { Extent of } \\
\text { change (\%p) }\end{array}$ & Effect size $r$ \\
\hline \multirow{3}{*}{$\begin{array}{l}\text { Continu- } \\
\text { ous }\end{array}$} & Information retrieval & $78.97(18.58)$ & $85.72(15.79)$ & 6.75 & .211 \\
\hline & Interpretation & $76.50(19.33)$ & $82.94(16.84)$ & 6.44 & .175 \\
\hline & Reflection & $58.01(22.88)$ & $67.24(21.02)$ & 9.23 & .206 \\
\hline \multirow{3}{*}{ Mixed } & Information retrieval & $68.90(22.70)$ & $74.00(21.21)$ & 5.1 & .120 \\
\hline & Interpretation & $61.08(21.19)$ & 71.38 (19.47) & 10.3 & .245 \\
\hline & Reflection & $56.91(28.42)$ & $63.81(28.30)$ & 6.9 & .121 \\
\hline \multirow{2}{*}{$\begin{array}{l}\text { Non- } \\
\text { continu- } \\
\text { ous }\end{array}$} & Information retrieval & $69.90(24.89)$ & $83.51(20.01)$ & 13.61 & .305 \\
\hline & Interpretation & $52.28(27.66)$ & $65.54(27.04)$ & 13.26 & .235 \\
\hline
\end{tabular}


Within each grade we found significant differences in students' test scores in almost all the cognitive aspects in grade 2 and grade 4 alike (Table 4.10). In both grades students performed significantly lower in reflection in each text format than in the other cognitive aspects, whereas they achieved significantly higher scores in information retrieval. Students' ability to interpret the non-continuous text proved to be significantly weaker than any other cognitive dimensions in any other text formats in both grades.

Table 4.10 Differences in students' achievement in cognitive aspects to reading at subtest level representing different text formats in grades 2 and 4 with pairedsamples t-tests

\begin{tabular}{llcccc}
\hline \hline \multirow{2}{*}{$\begin{array}{c}\text { Cognitive } \\
\text { aspect }\end{array}$} & \multicolumn{1}{c}{ Subtest } & \multicolumn{2}{c}{ Grade 2} & \multicolumn{2}{c}{ Grade 4 } \\
\cline { 3 - 6 } & & \multicolumn{1}{c}{$t$} & sig & $t$ & sig \\
\hline \multirow{3}{*}{$\begin{array}{l}\text { Information } \\
\text { retrieval }\end{array}$} & Continuous - Mixed & 24.999 & .001 & 33,968 & .001 \\
& Continuous - Non-continuous & 24.793 & .001 & 7.222 & .001 \\
& Mixed- Non-continuous & -.376 & .707 & -25.550 & .001 \\
\hline \multirow{3}{*}{ Interpretation } & Continuous - Mixed & 34.782 & .001 & 31.160 & .001 \\
& Continuous - Non-continuous & 52.675 & .001 & 42.474 & .001 \\
& Mixed - Non-continuous & 15.715 & .001 & 12.074 & .001 \\
\hline Reflection & Continuous - Mixed & 1.884 & .060 & 6475 & .001 \\
\hline \hline
\end{tabular}

\section{ARE COGNITIVE ASPECTS UNIVERSAL?}

To examine whether cognitive aspects are universal, we aimed at decreasing the dimensionality of the variables and exploring how they could be grouped. To fulfil this aim, we carried out confirmatory factor analyses by involving the cognitive aspects of all text formats in the two grades. Based on the above results, two models were estimated and tested for the complete set of reading items in grades 2 and 4. The first model (Model 1) was based on the assumption that text formats exert a marked influence on the cognitive aspects of reading and, therefore, information retrieval, interpretation and reflection are different entities when they are activated in a shared context referring to a text with a particular format. In line with this, an 8-dimensional model was proposed. The second model (Model 2) was built to test the opposite of the first model assuming that cognitive aspects to reading bear similar properties regardless of the context in which they are applied. Thus, they are grouped into three factors each consisting of solely either information retrieval or interpretation or reflection. This reflects the universal nature of reading processes as described in the frameworks of large-scale assessments.

In grade 2, data gave a fit model to support only the first assumption, i.e. Model 1 $(\chi 2=5208.97 ; \mathrm{df}=1882 ; \mathrm{p}<.001 ; \mathrm{RMSEA}=.023 ; \mathrm{CI}=.023-.024 ; \mathrm{CFI}=.941 ; \mathrm{TLI}=.938)$. The cognitive aspects were defined as different variables used in different contexts (Figure 4.9). 
Grade 2

$\chi^{2}=5208.97 \quad \mathrm{p}<.001$

$\mathrm{df}=1882$

RMSEA $=.023$

$\mathrm{CI}=.023-.024$

$\mathrm{CFI}=.941$

TLI $=.938$

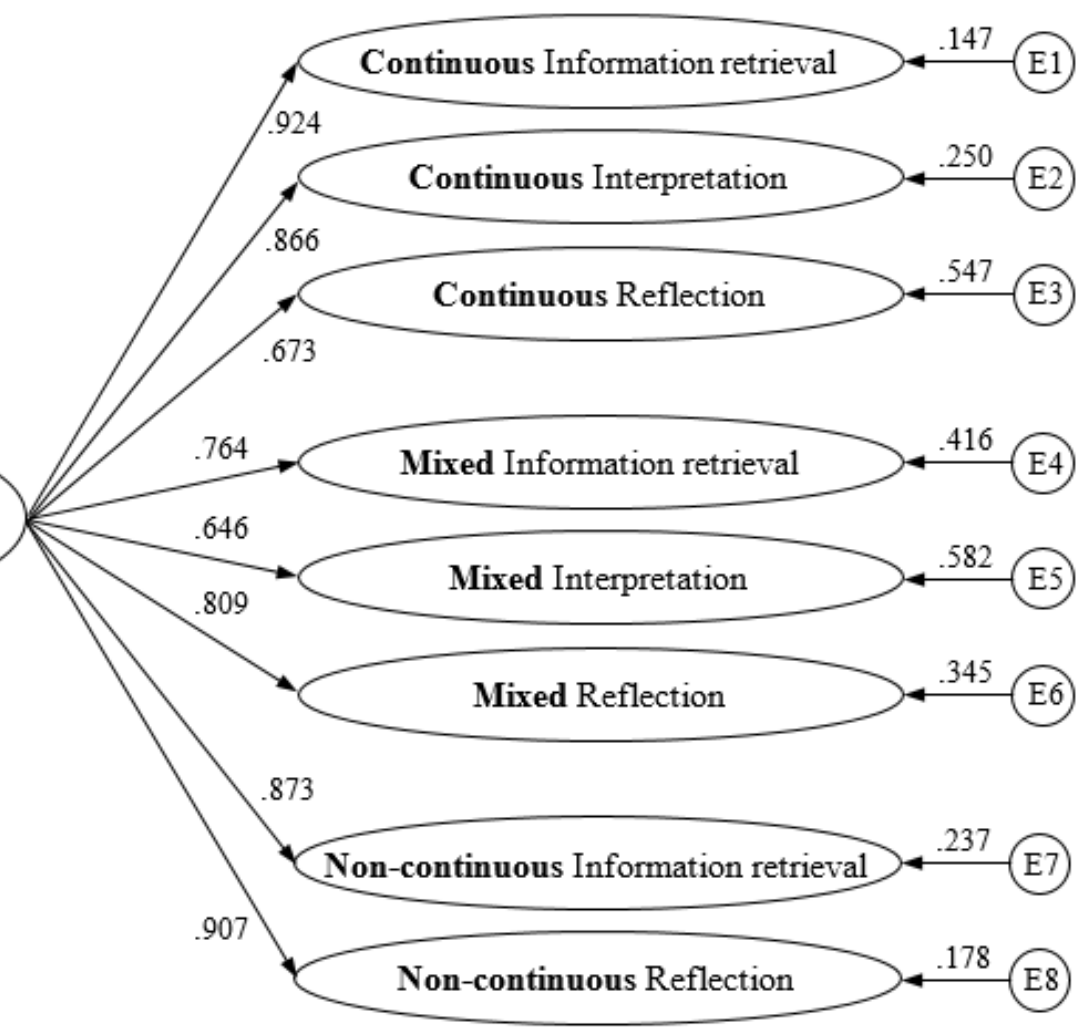

Note. Standardized parameter estimates are shown. All values are significant at a $p<.001$ level. Latent variables are depicted by circles.

Figure 4.9. An 8-dimensional model on the nature of cognitive aspects of reading in grade 2

In grade 4, both models (depicted in Figures 4.10 and 4.11) had fit values: Model 1: $\chi 2=3732.35 ; \mathrm{df}=1881 ; \mathrm{p}<.001 ; \mathrm{RMSEA}=.017 ; \mathrm{CI}=.017-.018 ; \mathrm{CFI}=.971$; TLI=.969; Model $2: \chi 2=4621.13 ; \mathrm{df}=1881 ; \mathrm{p}<.001 ; \mathrm{RMSEA}=.021 ; \mathrm{CI}=.020-.022 ; \mathrm{CFI}=.957 ; \mathrm{TLI}=.955$. 


\section{Grade 4}

$\chi^{2}=3732.35 \quad \mathrm{p}<.001$

$\mathrm{df}=1881$

RMSEA $=.017$

$\mathrm{CI}=.017-.018$

$\mathrm{CFI}=.971$

TLI $=969$

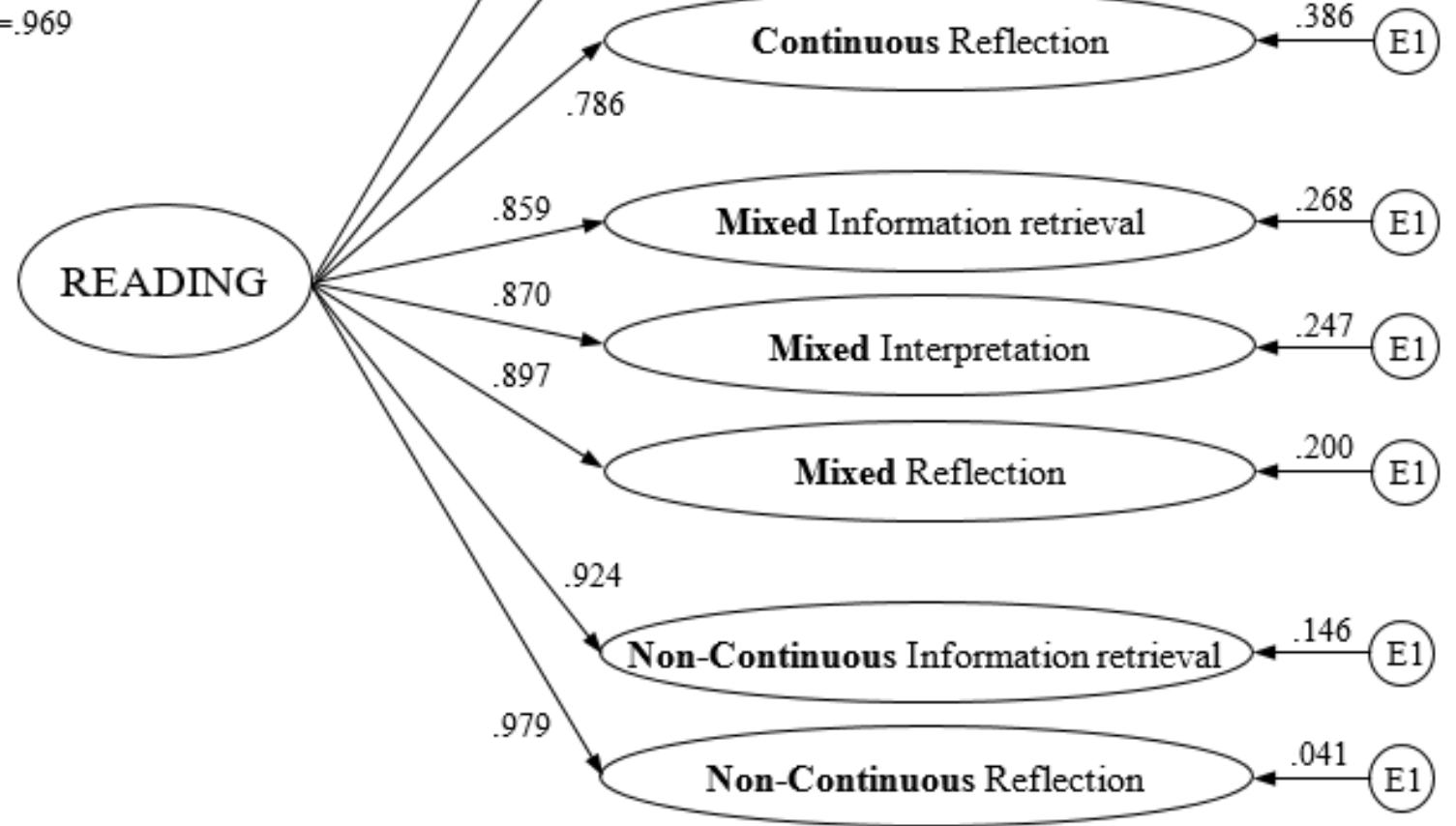

Note. Standardized parameter estimates are shown. All values are significant at a $p<.001$ level. Latent variables are depicted by circles.

Figure 4.10. An 8-dimensional model on the nature of cognitive aspects of reading in grade 4

\section{Grade 4}

$\chi^{2}=4621.13 \mathrm{p}<.001$

$\mathrm{df}=1887$

RMSEA $=.021$

$\mathrm{CI}=.020-.022$

$\mathrm{CFI}=.957$

$\mathrm{TLI}=.955$

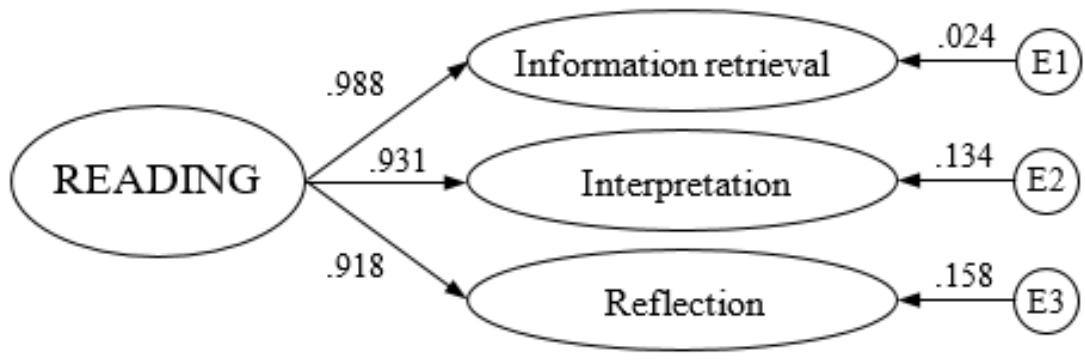

Standardized parameter estimates are shown. All values are significant at a $\mathrm{p}<.001$ level. Latent variables are depicted by circles.

Figure 4.11. A 3-dimensional model on the nature of cognitive aspects of reading in grade 4

However, according to the result of the chi-square for difference testing, Model 1 shown in Figure 9 fit the data significantly better than Model 2 presented in Figure 10 $(\chi 2=811.08, \mathrm{df}=5, \mathrm{p}<.001)$. 


\subsection{Discussion}

Findings yield evidence that text format can be considered a main organizational element in testing reading literacy in grades 2 and 4 . Data proved that it is adequate to cover and measure the domain of reading literacy by including texts with different formats in the tests. Some may argue that reading can only be conceptualized in terms of and in relation to continuous texts, as the word text only refers to "an extended structure of syntactic units [i. e. text as super-sentence] such as words, groups, and clauses and textual units that is marked by both coherence among the elements and completion" (Werlich, 1976, p. 23). However, the results of my study imply that the same mental construct is activated when it comes to reading continuous texts and random sequences of linguistic units such as sentences, paragraphs, or sections in any temporal and/or spatial extension. The three-dimensional reading model comprising continuous, mixed and non-continuous texts suggests that we have to broaden our perspectives on what constitutes a text and what we consider and accept as reading. Traditional theories of reading and reading comprehension narrow their scope to sentences as self-contained units; however, it may be more appropriate to frame reading theories in terms of how texts function in human interaction. The three-dimensional model also offers evidence that text can be defined as a communicative occurrence even if the seven standards of textuality (cohesion, coherence, intentionality, acceptability, informativity, situationality, and intertextuality; see de Beaugrande \& Dressler, 1981) are not entirely met. In the case of the non-continuous and mixed text formats, cohesion and coherence are not upheld or to only a certain extent. However, the texts still achieved their communicational goals, as comprehension processes were activated.

In sum, reading occurs not only when it comes to comprehending continuous texts, but also when readers extract information and meaningfully process fragmented written pieces of information.

Results also lend support to the assumption that although reading constitutes of two major processes (decoding and comprehension) that develop in a parallel manner, comprehension skills emerge and become refined and better organized gradually over time during the later stages of learning to read as early as between grades 2 and 4 .

Data also show that each subtest representing different text formats can be organized to match three different cognitive aspects of reading. During reading three essentially different cognitive processes are activated. These are information retrieval, interpretation and reflection, and the same structure holds true for each text format. Clearly, reading literacy includes one's familiarity with the nature, functions and uses of various text formats and cognitive aspects to reading necessary for further personal advancement in one's academic career or day-to-day coping.

As far as the learners' development is concerned, data show that in line with previous research results students performed significantly better on the continuous text than on the mixed and non-continuous ones (see Chapter 2). Scores indicate that there was no breakdown in communication when it came to reading texts with structures different from that of continuous texts. However, data show that students found it more difficult to understand the messages conveyed by the more fragmented non-continuous and mixed texts. This outcome underpins findings claiming that text structures with few or no cohesive devices are more difficult to recognize and comprehend. Students' performance differed to a lesser extent on the continuous and mixed texts than on the continuous and non-continuous texts. The distinctive organizational structure of the mixed test may account for this tendency. Mixed texts contain both continuous expository pieces of information and a fragmented part (a list), both of which are necessary to understand. The former may facilitate the recognition of the underlying structure and the message of the mixed subtest and may 
reduce the impediment caused by the lack of cohesive devices in the non-continuous part. Findings also imply that the comprehension of non-continuous texts is delayed.

Results gained from examining the distribution of students in the mixed and noncontinuous quartiles based on their achievement in the continuous subtest show that text format does make a difference in students' reading achievement. Findings suggest that poor performance in the continuous subtest goes hand in hand with students' poor performance in nearly every second case but poor performance on one does not evidently lead to a very poor understanding of the other two texts. Nevertheless, the likelihood of becoming a top performer in the mixed and non-continuous text for these students is far too little. Also, findings show that being a skillful reader of the continuous text does not guarantee top ranking in the mixed and non-continuous text although around half of the students ranked in the highest quartile based on their continuous achievement fall into the highest quartile in the other two subtests as well. However, these students are far less likely to achieve in the quartiles below the median suggesting a poorer performance on the mixed and noncontinuous subtests. Briefly, it is among the poorest performers and the top performers in the continuous subtest among whom we can observe a clear pattern as far as achievement in the other two subtests is concerned.

It is also remarkable that the ratio of students maintaining their achievement level across text formats increased over time. This outcome implies that achievement differences in reading are stabilized, furthermore, they become increasingly polarized. Very poor readers of continuous texts are increasingly more likely to perform very poorly in the mixed and non-continuous text, whereas readers skillful in undertsanding continuous texts are increasingly more likely to perform very well in the other two subtests as well as time goes by. This finding confirms previous results on the Matthew-effect in reading in a Hungarian context (Hódi, B. Németh, Korom, \& Tóth, 2015).

As far as achievement in different text formats is concerned, in grade 2, data showed a more divergent pattern, meaning that students' achievement was more likely to be scattered in quartiles indicating a better achievement in the mixed and non-continuous texts than in the continuous one. The growing convergence among data across text formats calls for the examination of aspects of reading instruction, students' reading self-concept and attitudes towards reading.

A positive developmental tendency can be witnessed when taking a look at students' achievements broken down according to the cognitive aspects. In grade 4, students performed much better in all cognitive aspects to reading in all three text formats. However, taking into consideration text format as a main organizational element provides us with a different perspective on the analyses of students' performances along the cognitive aspects. Although significant development takes place between grades 2 and 4 in all cognitive aspects in all three text formats, mean test scores suggest that the cognitive aspects operate with different efficiency in the three text formats. Except for two cases, there seems to be a difference in information retrieval, interpretation and reflection when it comes to reading a continuous, a non-continuous and a mixed text.

The results also confirm previous findings on the increasing complexity and difficulty of cognitive aspects (e.g. Kádárné Fülöp, 1983). Data yield evidence that completing tasks measuring information retrieval was the least difficult, whereas reflection proved to be the most challenging task for students at both assessment points. Furthermore, the same cognitive processes are operated at different efficiency levels in all the three text formats, which is an important outcome with implication for teaching and assessment.

The significant differences across the cognitive aspects in students' achievements in different text formats urged us to examine whether the cognitive aspects are universal or may be different along text formats. In both grades, Model 1 (representing an 8-dimensional 
model demonstrating that information retrieval, interpretation and reflection are different entities when they are activated in a shared context referring to a text with a particular format) proved to be the fittest model underlying the reading processes. The cognitive aspects related to the three text formats formed distinct factors, which implies that cognitive aspects to reading differ along text formats and may also be distinct. However, it is remarkable that in grade 4, Model 2 - assuming that cognitive aspects to reading bear similar properties regardless of the context in which they are applied - was also acceptable but not the best representation of the organization of the reading processes. The question whether reading texts with different formats requires different cognitive skills or the measured cognitive aspects differ in nature calls for further investigation. Given that in grade 4 data showed good fits for Model 2 as well, it also requires further inquiry whether the reading maturation process can refine the cognitive aspects to function the same way.

Nevertheless, we assume that reading texts with different formats requires the mastery of phonics-based reading to a different extent and the different ratio and location of cohesive, verbal and non-verbal textual elements can scaffold the reading processes in different ways.

\subsection{Conclusion}

In an attempt to explain the differences exhibited by test scores achieved in reading texts with different formats, this study investigated the measurement properties of the items used to assess second and fourth graders' reading literacy. Moreover, students' reading literacy developmental trajectories were examined in terms of text format and cognitive aspects to reading in the period of learning to read in grades 2 and 4 because results especially in the younger population are scarce. In sum, two elements of the heuristic model (see Chapter 1) were examined: the text that is to be comprehended and the activity "involving the operations to process the text at hand" (Snow \& Sweet, 2003, p. 7).

Data from the confirmatory factor analyses confirm the theoretical structure of reading literacy as a construct defined in this study relying on frameworks of large-scale assessments. Findings show that the items dedicated to measure different dimensions of the domain assess reading literacy. Data also demonstrated that the shared context among items referring to a particular text format is a systematic organizational element of the construct.

As far as students' development is concerned, a positive tendency was recorded between the two data collection points. In case of the non-continuous text the difference is more considerable. We can witness a sharper rise in the test scores, indicating a more noticeable improvement than in case of the other two text formats. Data also show that in terms of text format the continuous text was the easiest for students in both grades. Findings on the cognitive processes also prove that text formats other than the continuous one make it more difficult for students to retrieve information, interpret and reflect on. Even though information retrieval is the most elementary cognitive aspect to reading, the difficulty of completing items representing information retrieval increases as text formats get more fragmented.

Analyses on students' reading performance at the levels of cognitive aspects provided us with a more diverse picture. Paired samples t-tests were carried out as a first step to compare students' reading achievement between different text formats in three cognitive aspects to reading: information retrieval, interpretation and reflection. Results showed that performance on almost all cognitive aspects in each text format differ significantly from each other. These results imply that cognitive aspects to reading function differ along text formats to some extent and may also be distinct. My hypothesis was that the different organization of textual elements triggers the reading processes in different ways; therefore, the reading processes are organized differently and may not be identical when used in 
contexts represented by different text formats. The effect of text format on the functioning of reading processes was underpinned by the results of the confirmatory factor analyses, which demonstrated that information retrieval, interpretation and reflection used in reading continuous, mixed and non-continuous texts constituted separate factors, indicating that different skills are in use when solving tasks related to texts having different formats.

Findings also lend support for the importance of the full coverage of the domain in terms of text format when measuring reading as achievement in one text format does not necessarily imply achievement in other text formats. If only continuous texts are used for assessment in a classroom environment, teachers will not have knowledge on how students understand written pieces of information conveyed by texts having other formats. These data also corroborate the validity of the second model regarding the non-universal nature of reading processes along text formats. Findings yield evidence that the reading processes work differently in the three text formats placing students' reading achievement into a wide range of quartiles. Format as context has an impact on how students go about reading a particular text or may involve other cognitive skills to understand them as well.

It can also be concluded that there is no threshold in achievement above or below which the impact of text format would not be visible. Of course, I acknowledge that other factors such as affective factors and the circumstances of data collection, students' tiredness or anxiety also influence students' outcome, but the above results definitely point towards the importance of the role text format plays in reading.

In sum, the main results show that reading takes place on a continuum with respect to text format and text format has a significant impact on students' reading achievement and on cognitive aspects underlying text comprehension. Therefore, text structure and textual properties are crucial to consider when developing students' reading skills and interpreting test results. Results are hoped to pave the way for a more elaborate conceptualization of textbased theories and models of reading comprehension and to provide valuable insights for stakeholders involved in students' reading development. 


\section{CHAPTER 5}

\section{A DESCRIPTIVE AND CORRELATIONAL STUDY ON THE ROLE OF STUDENT- RELATED NON-COGNITIVE FACTORS IN STUDENTS' READING LITERACY ACHIEVEMENT IN DIFFERENT TEXT FORMATS}

\subsection{Introduction}

Reading is a complex cognitive process influenced by numerous non-cognitive factors in many ways (see Chapter 1). Abundant literature is available on the relationship between the non-cognitive factors and students' reading achievement. However, this link has only been identified and confirmed by using instruments measuring reading achievement on continuous texts. The present study sets out to further explore the reasons underlying the disparity observed between students' reading test scores in different text formats revealed in the first empirical study in Chapter 4.

Previous research has shown that Hungarian students, regardless of age or grade, perform significantly better in retrieving information, interpreting and reflecting on the content and format of continuous texts than non-continuous ones (e.g., Balázsi, Ostorics, Szalay, \& Szepesy, 2010; OECD, 2010b). International student assessment reports sporadically offer some information that cast light upon this phenomenon. PISA 2009 assessment results unveil that even though girls' overall reading achievement is significantly better than that of boys, boys tend to outperform girls in understanding information conveyed by non-continuous texts than continuous ones. This recurring tendency in gender gap may be associated with the kinds of reading preferred by boys and girls (OECD, 2010b, p. 90). More nuanced data on Hungarian 15-year-olds' digital reading results in 2009 show that the gender gap exists in favor of girls on all text format subscales, but the "gap narrows substantially between boys' and girls' performance on the non-continuous texts subscale, compared with the gap between them on the continuous texts subscale" (OECD, 2010b, p. 90). One explanation may be that boys are more familiar with more fragmented noncontinuous text structures lacking cohesive devices often including visual information than with those of linearly organized narrative and expository texts (OECD, 2010b). The 2011 assessment cycle of PIRLS casts light on the same trend among fourth graders (Mullis, Martin, Foy, \& Drucker, 2012). Their data also lends support to the prevalence of gender differences favoring girls in reading. However, further analysis also reveals a remarkable tendency among fourth graders. The largest differences between boys and girls are found in the literary domain on tasks related to reading continuous texts, whereas the smallest differences are found in the informational domain involving more fragmented text formats (Mullis et al., 2012, p. 7, pp. 104-105).

In sum, gender and reading habits are most commonly associated with this disparity but the interpretation of the results falls short in finding further non-cognitive variables that might account for the difference in students' reading performance along text formats. Since research on the relationship between understanding non-continuous or mixed texts and factors that are generally linked to reading performance on continuous texts is scarce, this research was designed in a way that makes it possible to contextualize test scores in each text format in light of students' reading self-concept, attitude, frequencies of computer and internet use, and reading continuous and non-continuous texts when learning. In what follows, I provide the theoretical framework for my work emphasizing the importance of the above affective and technical aspects of reading in how students read.

In order to be able to obtain a better understanding of what and how certain factors may account for the difference in students' achievement in the three different text formats, 
we developed a background questionnaire integrating factors fundamental to reading in the literature.

Literacy researchers have looked at what engages children and adults in reading and measured attitudes toward reading extensively (e.g., Cox \& Guthrie, 2001; McKenna \& Kear, 1990) and reading self-concept (e.g., Chapman, Tunmer, \& Prochnow, 2000). Reading self-concept and attitudes toward reading have been implicated as factors playing a role in reading comprehension. An individual's reading comprehension strongly correlates with affective factors such as reading self-concept and reading attitude in both children (F. Joó, 2013; Szenczi, 2013) and adults (Smith, 1990).

It is acknowledged that self-concept, defined as "one's perception of himself", "influences the ways in which he acts, and his acts in turn influence the ways in which he perceives himself" (Shavelson, Hubner, \& Stanton, 1976. p. 411). Reading attitude, as was suggested by Alexander and Filler (1976), is "a system of feelings related to reading which causes the learner to approach or avoid a reading situation" (p. 1). As implied in the definitions, both constructs have an impact on reading behavior. "Students who enjoy reading and who perceive themselves to be good readers usually read more frequently and more widely, which in turn broadens their reading experience and improves their comprehension skills" (Mullis, Michael, Kennedy, \& Foy, 2007, p. 139). Additionally, these factors strengthen each other's impact (Szenczi, 2013): there is a reciprocal relationship between reading self-concept and achievement (Retelsdorf, Köller, \& Möller, 2014). However, the predictive value of reading self-concept on reading achievement seems to be higher than vice versa (Retelsdorf et al., 2014).

As far as reading attitude is concerned, based on the work of McKenna and Kear (1990) we distinguished more dimensions within the rubric of reading attitude, since a positive global attitude by no means implies a positive attitude toward all types and contexts of reading: attitude toward recreational reading and attitude toward school-related academic reading.

These three dimensions assess students' sense of competence and predispositions to respond to reading in a favorable or unfavorable manner in different contexts (Fishbein \& Ajzen, 1975). These factors are correlated with reading achievement, but little is known about their relative importance in reading different text formats.

Being socially co-constructed, reading self-concept is formed by experiences with the environment and is influenced especially by reinforcements of significant others (Bong \& Skaalvik, 2003). Since children do much of their reading in school, feedback from teachers (as significant others besides parents and peers) plays a prominent role in shaping students' reading self-concept. As teachers' evaluation is more often based on reading continuous texts than non-continuous or mixed texts, I believe that the extent this dimension is related to achievement in the three subtests will differ significantly. Elementary school students, especially second graders, have more opportunities to encounter continuous texts; thus, it is assumed that reading self-concept will have a significantly stronger relationship with the continuous test scores than those achieved in the other two subtests.

Regarding the factors representing the attitudes, I expect a stronger correlation between each text format and academic reading attitude than with attitude toward recreational reading because of the compulsory nature of the reading assessment. Once a school received parental agreement about a students' participation in the assessment, students took the reading tests. The tests by nature represent and mirror educational expectations and contexts; therefore, I believe that this will be manifested in a stronger correlation between attitudes toward school-related reading. Students who are more dedicated to academic reading perform better in the reading assessment. However, I do not expect that the academic reading attitudes will account for the variance in students' 
achievement in different text formats to a notably different extent. On the other hand, I hypothesize that attitudes toward reading for recreational purposes will be correlated with continuous text achievement more strongly, as reading attitude may be broken down into subtypes according to interests. "Thus, one may have an attitude toward reading science fiction that differs considerably from one's attitude toward reading romantic fiction" (McKenna, Kear, \& Ellsworth, 1995 p. 934). Additionally, reading for literary experience from narratives representing continuous text formats is more common in this age group, therefore, we suspect a stronger predisposition toward reading these texts.

Two sets of dimensions were dedicated to examining how often students engage in reading texts of different types and formats and how often they are required to activate cognitive aspects to reading when learning either in a classroom environment or at home when doing homework. One factor represents items in relation to continuous and mixed texts, while the other one contains questions inquiring about the frequency of reading noncontinuous texts. It is acknowledged that students who read more frequently will accumulate more experience in reading, which in turn will improve reading comprehension. To translate this into the rubric of text formats, students who are engaged in reading continuous texts more often will have more experience in how to extract information from them and will have better achievement in this subtest. Similarly, the more often students are exposed to tasks aiming to retrieve information from, interpret and reflect on non-continuous texts, the better they will score in the non-continuous subtest. The question is whether the frequency of exposure to either text format contributes to students' reading achievement in all three text formats included in the study to the same extent. We assume that the frequency of reading continuous texts will correlate with continuous test performance more strongly than with the mixed and non-continuous text scores and we expect a stronger relationship between the non-continuous factor and reading achievement measured by the non-continuous text.

A final dimension of the instrument was integrated to seek information about second graders' computer and internet use for non-educational purposes. Undoubtedly, information and communication technologies are present in every domain of life changing the way people communicate, work and study, and elementary school students are no exception to these rules. Data yielded by a recent IEA study entitled International Computer and Information Literacy Study (ICILS, Fraillon, Ainley, Schulz, Friedman, \& Gebhardt, 2014) indicate that students in the eighth year of schooling were making widespread and frequent use of digital technologies when outside school. EU Kids Online provided data reflecting similar tendencies among 9- to 16-year-olds (Livingstone \& Haddon, 2009). The increasing availability of ICT at home has raised many questions about the relationship between ICT use and reading literacy (Leino, 2014). Leino's (2014) summary on the studies regarding this association gives us a glimpse about the versatile conclusions reached in this domain. For example, recent PISA data suggest a positive relationship between computer use at home and 15-year-old students' achievement (OECD, 2015c); however, previous experimental evidence in this field is inconclusive. Literature exhibits a mixture of positive, negative and null effects of computer use on reading achievement. The wide range of age groups involved in the studies, the different kinds of computer use and activities, and controlling for variables such as student home background or differences in school resources partly explain this inconsistency (Rosén \& Gustaffson, 2016). Regarding the impact of computer availability at home on reading achievement along text formats in grade 4, a study taking advantage of the IEA studies conducted from 1991 to 2006 found that the effects of home computer use were more strongly negative for continuous texts than for the non-continuous ones (Rosén \& Gustaffson, 2016).

According to Rosén and Gustaffson (2016), we can find several theories and hypotheses to explain why there may be an effect of computer use on reading achievement 
in the literature. Content theories and the displacement theory (Lee \& Leung, 2006; Neuman, 1988; Neuman, 1995) that have been increasingly dominating academic discourse overshadowing content theories need attention regarding the main topic of the present study. The displacement theory focuses on time as a limited commodity. It holds that the negative relationship between ICT use and reading achievement is caused by the fact that children spend time in front of the screen at the expense of other activities such as educational activities or reading that boost the development of reading skills. Content theories, on the other hand, argue that the effect of ICT is a function of the content of the computer use or the type of activity performed (e.g., searching for information, making a spreadsheet). This impact can be either positive or negative depending upon the content. For example, if a child consumes research-based educational programs, his or her school achievement increases. As far as ICT influence on reading texts with different format is concerned, Rosén and Gustafsson (2014) concluded that the displacement hypothesis best accounts for the negative effects. ICT use at home may affect skills in reading continuous texts rather than finding factual information in non-continuous texts such as graphs, maps, lists or sets of instructions, i.e., the text type that shares many similarities with how information is often presented on the computer screen.

Since data on ICT use and its relation to students' reading achievement among second graders are scarce, it is important to explore how the frequency of ICT use for recreational purposes impacts students' reading achievement at whole test and subtest levels. We do not know to what extent students can benefit from exposure to ICT at home at this age. However, in case of a positive linear relationship between these variables, we expect a stronger correlation between the factor representing frequency of computer and ICT use and students' achievement in the non-continuous texts. Drawing on the content theory, my expectations are based on the observation that online reading or reading in a digital environment and interacting with hypertext documents often use texts that are more likely to bear the characteristic features of non-continuous texts.

The issues of using computers for doing homework assignments and relying on adult assistance were also covered, but - due to data collection time constraints and students' potential negative perception of assessment load - to a limited extent in the assessment instrument.

Socio-economic status (SES) is a complex indicator for characterizing students' family background. Since Galton's studies of English scientists (1874) abundant studies have consistently yielded evidence that SES is a reliable predictor of cognitive outcomes (Snow, Burns, \& Griffin, 1998, p. 125). Research has confirmed that this holds true in terms of the relationship between SES and Hungarian students' reading achievement (e.g., Hódi, B. Németh, Korom, \& Tóth, 2015). In the Hungarian context, the impact of SES on students' reading skills needs special attention, since it accounts for $21 \%$ of the variance in students' achievement (OECD, 2016b). This is the third highest value in the rank order right after Argentina (26\%) and Peru (22\%). The impact of SES on test scores achieved in different text formats was not investigated in this dissertation since Molnár and B. Németh (2006) already addressed this issue by relying on data collected by means of the paper-and-pencil version of the mixed text and a continuous text having very similar characteristics to the one used in this study. Their large-scale assessment showed a moderate relationship between parents' education (maternal and paternal education used separately as well as a compound index) and reading achievement $(\mathrm{r}=.42)$. However, only a marginal difference was found between parental education and continuous test scores $(\mathrm{r}=.38)$ and mixed test scores $(\mathrm{r}=.34)$. This implies that SES is not a variable that underlies the differences between students' achievement in different text formats. 
Also, a growing body of research has focused on the effects that home environment may have on literacy development. Most studies seek to elaborate on and quantify a single dimension of the environment: the home and more specifically certain aspects of the parentchild interaction (e.g., storybook reading, writing and alphabetic activities using games). However, recent studies point out the importance of applying a broader approach to the conceptualization of the home literacy environment (Burgess, Hecht, \& Lonigan, 2002; Sénéchal, 2011; Wood, 2002). A study by Burgess et al. (2002) is based on complex conceptualizations of the home literacy environment that include not only literacy activities and beliefs, but also functioning family variables, routines and resources as well as the quality of relationships between family members and children's teachers (Kamil, Mosenthal, Pearson, \& Barr, 2008). A more complete model of home literacy was also proposed by Martini and Sénéchal (2012), who additionally took into consideration parental expectations about child literacy knowledge and beliefs about literacy. Due to the complex nature of home literacy environment, this domain was not covered in the study.

\subsection{Methods}

\subsubsection{Research questions}

This study forms the second part of an overarching research exploring to what extent cognitive and non-cognitive factors influence students' achievements when reading continuous, mixed and non-continuous texts. The aims of the second study were to examine the relationships between students' reading performance along different text formats and non-cognitive student variables and to explore how these non-cognitive variables account for the difference in students' reading achievement when reading continuous, mixed and non-continuous texts.

In Study 1 data yielded evidence that students equipped with a certain set of reading skills at a certain developmental level manage to understand texts of different formats to a different extent. As revealed in the introduction, there are numerous non-cognitive variables that are well-known contributors to reading success, however, research examining how these factors are related to reading texts with formats other than the traditional, continuous ones is limited.

The aim of this study is twofold. First, it aims to contribute to the growing body of reading research by providing descriptive information on second graders' reading attitudes, self-concept and habits. The study also aims at extending previous research results on factors influencing reading achievement in a continuous text to mixed and non-continuous texts. In line with these, the following research questions were formulated.

1) How can second graders' reading attitudes, self-concept, reading and ICT use habits be characterized?

2) How do gender differences in second graders' results mirror large-scale tendencies regarding achievement in different text formats?

3) What is the relationship between the non-cognitive factors measured by the student background questionnaire and students' reading achievement in different text formats?

4) To what extent do the non-cognitive factors measured by the student background questionnaire account for the variance in students' reading achievement in different text formats? 


\subsubsection{Participants}

The sample of this study is identical with the one included in the first study (see Chapter 4, section 4.2.2). A total of 3,220 students filled out the questionnaire (males: $51 \%$ ). Nine students who took the reading test did not fill out the questionnaire. Data collection was carried out in Grade 2 as a part of the Hungarian Educational Longitudinal Program (Csapó, 2014). The longitudinal sample was selected to be nationally representative by region, settlement type and gender. A total of 193 classes from 110 schools participated in the study from seven Hungarian statistical regions.

\subsubsection{Data collection instruments}

For the purposes of the present study, data gained from three assessment instruments were used: (1) a reading literacy test, (2) a long student questionnaire and (3) a short student questionnaire.

\section{THE READING LITERACY TEST}

Students' reading achievement was measured by an online reading literacy test described in details in section 4.2.3.

\section{LONG STUDENT QUESTIONNAIRE}

A questionnaire containing 36 items was designed to assess students' reading diversity, regularity of ICT use habits for recreational purposes outside of school, reading self-concept, different aspects of attitudes towards reading and personal and infrastructural assistance in doing homework. To develop the student questionnaire, I integrated research from reading motivation, attitude and self-concept literature and on literacy assessment. Table 5.1 presents the instruments I drew on.

Table 5.1 The dimensions of the long student questionnaire and the instruments used

\begin{tabular}{ll}
\hline \hline \multicolumn{1}{c}{ Dimension } & \multicolumn{1}{c}{ Assessment instrument } \\
\hline Reading self-concept & $\begin{array}{l}\text { The Reader Self-Perception Scale } \\
\text { (Henk \& Melnick, 1995). }\end{array}$ \\
\hline Reading diversity & PISA student questionnaire (OECD, 2009) \\
\hline $\begin{array}{l}\text { Frequency of activating cognitive aspects when } \\
\text { reading different text formats }\end{array}$ & $\begin{array}{l}\text { Questions about reading when learning } \\
\text { (OH-OECD PISA 2009) }\end{array}$ \\
\hline ICT use habits & PISA ICT familiarity questionnaire (OECD, 2008) \\
\hline Attitude towards books and leisure reading & $\begin{array}{l}\text { Elementary Reading Attitude Survey } \\
\text { (McKenna \& Kear, 1990) }\end{array}$ \\
\hline $\begin{array}{l}\text { Attitude towards school and school-related } \\
\text { reading }\end{array}$ & $\begin{array}{l}\text { Elementary Reading Attitude Survey } \\
\text { (McKenna \& Kear, 1990) }\end{array}$ \\
\hline \hline
\end{tabular}

Confirmatory factor analysis was used to confirm the theoretical structure of the questionnaire. A theoretical 7-factor structure shown in Table 5.2 was tested. Data show that a 6-factor model has an acceptable fit (CFI=.914, TLI=.902, RMSEA (90\% C.I.) $=.045$ $\left.(.043-.046), \mathrm{SRMR}=.042, \chi^{2}=2296.323, d f=509, \mathrm{p}=0.000\right)$. The identified factors represent the following constructs: (1) reading self-concept (2 items); (2) frequency of reading and activating cognitive aspects in reading continuous texts when learning (6 items); (3) frequency of reading and activating cognitive aspects in reading non-continuous texts when learning (5 items); (4) frequency of computer and internet usage for fun/for recreational 
purposes/for non-educational purposes (5 items); (5) attitude towards books and leisure reading (5 items); (6) attitude towards school and school-related reading (4 items). Based on the standardized model results estimate and minimum M.I. values, altogether 27 items constitute the confirmed model. The questionnaire appears in Appendix D.

Table 5.2 The theoretical and empirical factor structure of the long student questionnaire

\begin{tabular}{|c|c|c|c|}
\hline Theoretical factor structure & $\begin{array}{c}\text { Number of } \\
\text { items }\end{array}$ & Empirical factor structure & $\begin{array}{l}\text { Number of } \\
\text { items }\end{array}$ \\
\hline Reading self-concept & 2 & Reading self-concept & 2 \\
\hline $\begin{array}{l}\text { Frequency of reading continuous } \\
\text { texts when learning }\end{array}$ & 7 & $\begin{array}{l}\text { Frequency of reading continuous } \\
\text { texts when learning }\end{array}$ & 6 \\
\hline $\begin{array}{l}\text { Frequency of reading non- } \\
\text { continuous texts when learning }\end{array}$ & 5 & $\begin{array}{l}\text { Frequency of reading non- } \\
\text { continuous texts when learning }\end{array}$ & 5 \\
\hline $\begin{array}{l}\text { Personal and infrastructural } \\
\text { assistance in doing homework }\end{array}$ & 2 & - & - \\
\hline $\begin{array}{l}\text { Frequency of ICT use for } \\
\text { recreational purposes }\end{array}$ & 8 & $\begin{array}{l}\text { Frequency of ICT use for } \\
\text { recreational purposes }\end{array}$ & 4 \\
\hline $\begin{array}{l}\text { Attitude towards books and leisure } \\
\text { reading }\end{array}$ & 7 & $\begin{array}{l}\text { Attitudes towards books and leisure } \\
\text { reading }\end{array}$ & 5 \\
\hline $\begin{array}{l}\text { Attitude towards school and school- } \\
\text { related reading }\end{array}$ & 5 & $\begin{array}{l}\text { Attitudes towards school and } \\
\text { school-related reading }\end{array}$ & 4 \\
\hline Total number of items & 36 & & 26 \\
\hline
\end{tabular}

\section{SHORT STUDENT QUESTIONNAIRE}

Additionally, students were asked five questions about the texts and the tasks at the end of the reading testing sessions: (1) How much did you like the text? (2) How much did you like the tasks related to the text? (3) How difficult did you find the text? (4) To what extent were you familiar with the tasks related to the text? (5) Were you familiar with the text/topic of the text before the testing? The first four were four-point Likert items with a scale ranging from not at all to a lot. The fifth question required a yes/no response. In the next parts of the dissertation I am going to refer to this survey as the short questionnaire.

The questions about preference, perceived text difficulty and background knowledge were included in the assessment because during the test development some teachers, based on their everyday experience, raised concerns about the inclusion of the mixed and noncontinuous text in the test. The main reason was that the text format (i.e. list and table) and the topic (theatre and white-tailed eagle) are not so familiar for second graders.

\subsubsection{Procedures}

The online data collection was carried out in the spring of 2013. Students filled in the questionnaire in a 45-minute class at school by means of the eDia platform (Electronic Diagnostic Assessment; Csapó, Lörincz, \& Molnár, 2012; Molnár, 2015) via the Internet in the schools' ICT labs. Students logged into the system using their student ID provided by the Educational Authority to maintain confidentiality throughout the project. The online background questionnaire was administered following the administration of the subtest containing a mixed text format. Teachers were encouraged to help students read the items of the questionnaire in case students encounter difficulties or need any assistance. 


\subsubsection{Data analyses}

Confirmatory factor analysis within structural equation modelling (SEM; Bollen, 1989) was used to test the validity of the questionnaire. All measurement models were computed with MPlus and Maximum Likelihood (ML) estimation was used (Muthén \& Muthén, 2010). Different fit indices, such as the Tucker-Lewis Index (TLI), the comparative fit index (CFI) and the root mean square error of approximation (RMSEA), were computed to assist in determining model fit.

Additionally, descriptive statistics, independent-samples t-test, correlational analysis and regression analysis were used to analyze data.

\subsection{Analysis and results of the main questionnaire}

The results section on the student questionnaire contains the answers to the research questions in the order they were addressed. This section consists of two main parts. In the first part, second graders' reading self-concept, frequency of reading and activating cognitive aspects in reading continuous texts when learning, frequency of reading and activating cognitive aspects in reading non-continuous texts when learning, frequency of computer and internet usage for fun/for recreational purposes/for non-educational purposes, attitude towards books and leisure reading, and attitude towards school and school-related reading is described. The second part presents the results on the relationship between the factors extracted from the student questionnaire and students' reading achievement in the continuous, mixed and non-continuous subtests.

\section{READING SELF-CONCEPT}

Students were asked to indicate their perception of themselves as good or poor readers and as fast or slow readers. In this study, students' self-concept on reading was assessed based on their agreement with two statements about their ability to read: (1) I am a good reader and (2) I am a fast reader. Response options were on a 4-point Likert scale, as follows: fully agree, partly agree, partly disagree, and fully disagree.

Data show that second graders tend to view themselves as good, or at least moderately good readers: $82.36 \%$ of the students consider themselves good readers ( $46.47 \%$ fully agree; $35.89 \%$ partly agrees) and only $11.20 \%$ of the respondents have a somewhat negative and $6.44 \%$ of them have a very negative perception of themselves.

Students' characterization of themselves in terms of their speed of reading is also quite positive. However, a somewhat larger proportion of students reported that they did not consider themselves fast readers: $31.63 \%$ have a very positive view of their reading rate, $33.72 \%$ consider themselves as moderately fast readers, whereas $34.65 \%$ of second graders have a negative perception of their reading rate ( $12.85 \%$ fully disagree).

\section{FREQUENCY OF READING AND ACTIVATING COGNITIVE ASPECTS IN READING CONTINUOUS TEXTS WHEN LEARNING}

Table 5.3 presents how often students claim to read stories (continuous texts) and rely on cognitive aspects of reading when learning either in school or outside of school (i.e. when doing homework). The table shows the percentage of students that reported reading stories and activating cognitive aspects of reading in the past month as follows: never, once or twice, three or five times, more than five times. 
Table 5.3 Frequency distribution of reading continuous texts and activating cognitive aspects of reading when learning during the month before test administration (\%)

\begin{tabular}{lcccc}
\hline \multicolumn{1}{c}{ Activity } & Never & Once or twice & $\begin{array}{c}\text { Three or five } \\
\text { times }\end{array}$ & $\begin{array}{c}\text { More than } \\
\text { five times }\end{array}$ \\
\hline Read stories & 18.14 & 30.73 & 21.84 & 29.29 \\
\hline Explain what happens in the story & 27.60 & 37.02 & 21.17 & 14.21 \\
\hline Explain the characters' behavior & 22.94 & 35.50 & 21.23 & 20.33 \\
\hline Characterize characters & 23.31 & 40.63 & 18.87 & 17.19 \\
\hline $\begin{array}{l}\text { Explain the objective of the text or } \\
\text { author's intention with the text }\end{array}$ & 23.53 & 40.25 & 21.92 & 14.30 \\
\hline Learn a text by heart & 16.01 & 38.58 & 22.47 & 22.94 \\
\hline \hline
\end{tabular}

More than half of students $(51.13 \%)$ reported reading stories when learning more than three times in the previous month, and an additional third (30.73\%) once or twice. However, data also exhibits a significant percentage of students $(18.14 \%)$ who reported not having read stories when learning.

The frequency of relying on different cognitive aspects when reading continuous texts was also elicited from students. Responses regarding the frequency of providing explanations to different phenomena or parts of the story line, characterizing participants in stories or authors' intentions show a similar pattern. In this respect, between $22.94 \%$ and $27.60 \%$ of students reported that they were not required to do so in the month before the data collection took place. Data also show that the majority of students relied on these cognitive aspects once or twice in the one-month period. Engagement in these activities more than five times was chosen by the smallest proportion of students in each case.

Data indicate that memorizing a text is a key activity in second graders' academic life. The majority of respondents $(83.99 \%)$ claimed that they learnt a text by heart more than once during the month prior to test administration.

\section{FREQUENCY OF READING AND ACTIVATING COGNITIVE ASPECTS IN READING NON-CONTINUOUS TEXTS WHEN LEARNING}

Students were also asked to provide information on how often they were engaged in reading different non-continuous texts and retrieved information from them or identified the principles underlying text organization in the one-month period prior to test administration. Table 5.4 shows the percentage of students that reported reading non-continuous texts and activating cognitive aspects of reading on the same scale as in case of the continuous texts.

Compared to reading continuous texts, reading of non-continuous texts was more intermittent. Slightly more than half of the respondents did not read any maps $(53.74 \%)$ during the month before test administration. Fewer students reported not having had to read ads $(43.80 \%)$ and even fewer, one third of students $(33.71 \%)$ did not read tables at all. Data show that second graders encountered maps more than three times when learning during the month prior to testing the least frequently (16.25\%), and tables the most frequently (29.60\%). Reading non-continuous texts once or twice when learning was chosen by nearly one third of the students in case of maps, tables and ads. 
Table 5.4 Frequency distribution of reading non-continuous texts and activating cognitive aspects of reading when learning during the month before test administration (\%)

\begin{tabular}{lcccc}
\hline \multicolumn{1}{c}{ Activity } & Never & $\begin{array}{c}\text { Once or } \\
\text { twice }\end{array}$ & $\begin{array}{c}\text { Three or five } \\
\text { times }\end{array}$ & $\begin{array}{c}\text { More than } \\
\text { five times }\end{array}$ \\
\hline Read maps & 53.74 & 30.01 & 7.52 & 8.73 \\
\hline Read tables & 33.71 & 36.69 & 16.74 & 12.86 \\
\hline Read ads & 43.80 & 31.50 & 12.80 & 11.90 \\
\hline Retrieve information from tables or maps & 47.81 & 35.65 & 10.04 & 6.50 \\
\hline $\begin{array}{l}\text { Characterize how the information is } \\
\text { organized in a table or map }\end{array}$ & 45.60 & 36.87 & 11.97 & 5.56 \\
\hline \hline
\end{tabular}

A wide range of cognitive aspects may be activated during reading comprehension. Students were also asked to provide information on the frequency of retrieving information from non-continuous texts and identifying the underlying organizational principle of information in them. The trends in students' reports of how frequently they activated these two cognitive aspects when learning are in line with the data they provided on the occurrence of reading non-continuous texts. In both cases never represented the highest number of responses. Second graders who reported on doing these tasks did so once or twice the most frequently (retrieve information form tables or maps: $35.65 \%$, characterize how the information is organized in a table or map: $36.87 \%$ ).

A paired-samples t-test was conducted to compare the frequency of reading continuous and non-continuous texts when learning. There was a significant difference between the regularity of accessing and understanding continuous texts $(\mathrm{M}=2.38, \mathrm{SD}=.67)$ and reading and activating cognitive aspects to reading non-continuous texts $(\mathrm{M}=1.85, \mathrm{SD}=.61)$; $\mathrm{t}(3217)=46.90, \mathrm{p}<.000)$ in favor of the former.

\section{FREQUENCY OF COMPUTER AND INTERNET USE FOR FUN}

Due to the online nature of the data collection instrument, we included an item into the questionnaire about how long students had been using computers. Findings suggest that $84.50 \%$ of second graders have more than one year of experience in using computers: $34.25 \%$ have been using computers for $1-3$ years, $24.91 \%$ for $4-5$ years and an additional $25.34 \%$ have more than five years of experience in using computers.

An additional four items were included in this dimension to explore second graders' computer and internet use on a weekly basis. Data show (Table 5.5) that although only a relatively small percentage $(16.71 \%)$ reported on never using the computer or internet for fun on a weekly basis, more than half of them $(58.54 \%)$ do not use the internet to connect with people and write or read emails (67.67\% and $61.61 \%$ respectively). Although the frequency distributions of these activities show similar patterns, based on students' answers accessing the internet to write emails is the least prevalent activity.

\section{ATTITUDE TOWARDS BOOKS AND LEISURE READING}

To obtain a better understanding of second graders' attitude towards reading, questions regarding leisure reading and school-related reading were included in the questionnaire. In general, second graders seem to have a rather positive attitude toward books, reading in general and recreational reading (Table 5.6). 
Table 5.5 Frequency distribution of computer and internet use for non-educational purposes $(\%)$

\begin{tabular}{lcccc}
\hline \hline \multicolumn{1}{c}{ Activity } & Never & Once or twice & $\begin{array}{c}\text { Three to five } \\
\text { times }\end{array}$ & $\begin{array}{c}\text { More than five } \\
\text { times }\end{array}$ \\
\hline $\begin{array}{l}\text { Computer/internet use for fun } \\
\text { outside of school }\end{array}$ & 16.71 & 20.28 & 31.02 & 31.99 \\
\hline Social media use & 58.54 & 10.87 & 16.21 & 14.38 \\
\hline Writing e-mails & 67.67 & 10.47 & 13.63 & 8.23 \\
\hline Reading emails & 61.61 & 11.21 & 16.52 & 10.65 \\
\hline \hline
\end{tabular}

A high ratio of students $(79.44 \%)$ like to receive a book as a gift. Fewer, but still more than half of the respondents $(54.71 \%)$ enjoy the process of sharing what they read with friends or family. Nearly two thirds $(63.36 \%)$ of second graders have a predisposition toward recreational reading and enjoy reading in their free time. $41.61 \%$ reported that they even choose reading over playing. The majority of second graders $(77.61 \%)$ consider reading as an activity interesting.

Table 5.6 The distribution of students' attitudes towards books and leisure reading (\%)

\begin{tabular}{lcccc}
\hline \hline \multicolumn{1}{c}{ Variable } & $\begin{array}{c}\text { Disagree } \\
\text { a lot }\end{array}$ & $\begin{array}{c}\text { Disagree } \\
\text { a little }\end{array}$ & $\begin{array}{c}\text { Agree } \\
\text { a little }\end{array}$ & $\begin{array}{c}\text { Agree } \\
\text { a lot }\end{array}$ \\
\hline I like talking to people about what I am reading. & 27.34 & 17.95 & 23.95 & 30.76 \\
\hline I am happy when I get books as a gift. & 11.42 & 9.14 & 26.25 & 53.19 \\
\hline I think reading is boring. & 57.98 & 19.63 & 11.68 & 10.51 \\
\hline I like reading in my free time. & 19.35 & 17.29 & 25.23 & 38.13 \\
\hline I like reading instead of playing. & 32.29 & 26.10 & 21.21 & 20.40 \\
\hline \hline
\end{tabular}

Data show that there is a silver lining; however, there are second graders who developed a very negative attitude towards books and leisure reading. Almost every tenth respondent $(10.51 \%)$ answered that in their view reading is a very boring activity, and $11.42 \%$ claimed themselves to be unhappy when they get books as a present. Reading is not a preferred activity in $19.35 \%$ of second graders' free time and nearly one third of the respondents is highly unlikely to opt for reading instead of playing. The discussion of the read content with others was ranked least preferred by $27.34 \%$ of the respondents.

About half of the respondents strongly agree that they like going to school (49.24\%), reading lessons $(53.50 \%)$ and school reading $(57.67 \%)$. Fewer students, about one quarter of second graders have a moderately positive attitude toward the statements. Only 9.95$15.21 \%$ of students strongly disagreed with the statements: I like going to school, I like reading classes, I like reading during lessons and I like the texts that I read at school.

\section{ATTITUDE TOWARDS SCHOOL AND SCHOOL-RELATED READING}

Finally, a set of items asked students about their opinion regarding school and reading in the classroom. Data presented in Table 5.7 show that second graders have a favorable attitude toward going to school or school-related reading. 
Table 5.7 The distribution of students' attitudes towards school and school-related reading (\%)

\begin{tabular}{lcccc}
\hline \hline \multicolumn{1}{c}{ Variable } & $\begin{array}{c}\text { Disagree a } \\
\text { lot }\end{array}$ & $\begin{array}{c}\text { Disagree a } \\
\text { little }\end{array}$ & Agree a little & Agree a lot \\
\hline I like going to school. & 15.21 & 10.48 & 25.07 & 49.24 \\
\hline I like reading classes. & 11.76 & 9.67 & 25.07 & 53.50 \\
\hline I like reading during reading lessons. & 9.95 & 11.23 & 21.24 & 57.67 \\
\hline I like the texts that I read at school. & 10.51 & 10.45 & 27.34 & 51.70 \\
\hline \hline
\end{tabular}

There are sizeable differences between the two ends of the scales of recreational and school-related data. The differences between strong agreement and strong disagreement in the two attitude dimensions suggest a stronger preference of reading for learning purposes than for fun. A paired-samples t-test was conducted to compare students' attitudes toward recreational and school reading. Results show a significant difference in students' expression of favor toward reading for fun $(\mathrm{M}=2.83, \mathrm{SD}=.75)$ and disposition to reading at school $(\mathrm{M}=3.13, \mathrm{SD}=.82) ; \mathrm{t}(3214)=25.01, \mathrm{p}<.000$.

\section{GENDER DIFFERENCES}

Students' gender was also elicited in the questionnaire. The boy-to-girl ratio in the sample was almost even. The sample included $51.00 \%$ boys and $49.00 \%$ girls. Since gender is the variable that large-scale assessments relate to reading achievement (see Chapter 2), an independent-samples t-test was conducted in order to examine how gender interacts with excellence in understanding any of the text formats in grade 2 . Results indicate that there is a significant difference in the reading achievement between boys and girls. The results indicate that girls scored higher on the reading tasks in all three subtests than boys (Table $5.8)$.

Data also show that the items of the continuous text was the easiest to complete/answer for representatives of both genders in the sample (Tables 5.8 and 5.9), whereas tasks related to the mixed and non-continuous texts were significantly more difficult. However, no statistical difference was found between the mixed and non-continuous test scores of boys and girls.

Table 5.8 The comparison of boys' and girls' achievement in reading continuous, mixed and non-continuous texts in grade 2 with independent-samples $t$-test

\begin{tabular}{llccc}
\hline \multirow{2}{*}{ Parameters } & \multirow{2}{*}{ Variables } & \multicolumn{3}{c}{ Text format } \\
\cline { 3 - 5 } & & Continuous & Mixed & Non-continuous \\
\hline \multirow{2}{*}{ Boys } & Mean (\%) & 71.45 & 61.00 & 60.33 \\
& SD (\%) & 16.93 & 16.73 & 22.53 \\
\hline \multirow{2}{*}{ Girls } & Mean (\%) & 76.15 & 65.49 & 65.07 \\
& SD (\%) & 22.74 & 16.82 & 22.74 \\
\hline \multirow{2}{*}{ Levene's Test for Equality } & $\mathrm{F}$ & 33.293 & .720 & .505 \\
& Sig. Variances & .000 & .396 & .477 \\
\multirow{3}{*}{ t-test for Equality of Means } & $\mathrm{t}$ & -8.305 & -7.585 & -5.926 \\
& df & 3216 & 3216 & 3216 \\
& Sig. (2-tailed) & .000 & .000 & .000 \\
\hline \hline
\end{tabular}


Table 5.9 The comparison of boys' achievement in the continuous, mixed and non-continuous subtests in grade 2 with paired samples t-tests

\begin{tabular}{|c|c|c|c|c|c|c|c|c|c|c|}
\hline \multirow[t]{2}{*}{ Gender } & & \multirow{2}{*}{ Parameters } & \multirow{2}{*}{ Sig. (2-tailed) } & \multirow{2}{*}{$S D$} & \multirow{2}{*}{$\begin{array}{l}\text { Std. Error } \\
\text { Mean }\end{array}$} & \multicolumn{2}{|c|}{$\begin{array}{l}\text { 95\% Confidence Interval of the } \\
\text { Difference }\end{array}$} & \multirow[t]{2}{*}{$\mathrm{t}$} & \multirow[t]{2}{*}{$\mathrm{df}$} & \multirow[t]{2}{*}{ Sig. (2-tailed) } \\
\hline & & & & & & Lower & Upper & & & \\
\hline \multirow{3}{*}{ Boys } & Pair 1 & Mixed-Continuous & -10.40760 & 17.13503 & .42235 & -11.23599 & -9.57920 & -24.642 & 1645 & .000 \\
\hline & Pair 2 & Mixed - Non-continuous & .70048 & 20.71408 & .51056 & -.30094 & 1.70191 & 1.372 & 1645 & .170 \\
\hline & Pair 3 & Non-continuous-Continuous & -11.10808 & 18.59095 & .45823 & -12.00686 & -10.20929 & -24.241 & 1645 & .000 \\
\hline \multirow{3}{*}{ Girls } & Pair 1 & Mixed-Continuous & -10.63914 & 15.99261 & .40221 & -11.42807 & -9.85022 & -26.452 & 1580 & .000 \\
\hline & Pair 2 & Mixed - Non-continuous & .43816 & 20.99938 & .52813 & -.59775 & 1.47407 & .830 & 1580 & .407 \\
\hline & Pair 3 & Non-continuous-Continuous & -11.07731 & 18.58896 & .46751 & -11.99431 & -10.16030 & -23.694 & 1580 & .000 \\
\hline
\end{tabular}

Note. non significant 
Table 5.10 Correlation coefficients between the factors and students' reading achievement in three different text formats

\begin{tabular}{lccc}
\hline \multicolumn{1}{c}{ Factors } & Continuous & Mixed & $\begin{array}{c}\text { Non- } \\
\text { continuous }\end{array}$ \\
\hline Reading self-concept & .29 & .32 & .31 \\
\hline Activities related to reading non-continuous texts & -.06 & -.05 & n.s. \\
\hline Activities related to reading continuous texts & .09 & .06 & .09 \\
\hline ICT use & -.06 & -.06 & $-.04^{*}$ \\
\hline Attitude towards school reading & .20 & .18 & .18 \\
\hline Attitude towards recreational reading & .18 & .15 & .17 \\
\hline \hline
\end{tabular}

Note. n.s.: non significant, all other values are significant at a $\mathrm{p}<.001$ and ${ }^{*}<<.005$ level.

Positive correlations are found between reading self-concept, frequency of reading continuous texts when learning, attitudes toward school-related reading and recreational reading and students' reading achievement in each subtest representing different text formats (Table 5.10). However, data do not exhibit pronounced differences between the magnitude of the correlational values of the factors and test scores of the different text formats. The correlation coefficients indicate that the relationship is the strongest between reading subtest scores and the factors of selfconcept and the two factors representing students' attitudes. The correlational values range between .15 and .32 .

Frequency of ICT use for fun is negatively associated with the results on the three different text formats: the degree of relationship ranges from -.06 to -.04. Frequency of reading non-continuous texts when learning has a significant weak negative relationship with achievement measured by the continuous and mixed subtests. The null hypothesis was only confirmed regarding the relationship between the non-continuous factor and achievement in the non-continuous subtest.

Multiple regression analyses were performed to examine to what extent the different non-cognitive factor variables influence students' achievement in the continuous, mixed and non-continuous text formats (Table 5.11).

Table 5.11 The impact of non-cognitive factors on students' achievement in reading continuous, mixed and non-continuous texts $(r * \beta * 100)$

\begin{tabular}{lccc}
\hline \multicolumn{1}{c}{ Factors } & Continuous & Mixed & $\begin{array}{c}\text { Non- } \\
\text { continuous }\end{array}$ \\
\hline Reading self-concept & 9.68 & 7.01 & 8.54 \\
\hline Activities related to reading non-continuous texts & 0.56 & 0.70 & 0.10 \\
\hline Activities related to reading continuous texts & 0.28 & 0.79 & 0.62 \\
\hline ICT use & n.s. & 0.26 & 0.12 \\
\hline Attitude towards school reading & 0.95 & 1.07 & n.s. \\
\hline Attitude towards recreational reading & n.s. & 1.19 & 0.82 \\
\hline $\mathrm{R}^{2 * 100}$ & 11.49 & 11.04 & 10.23 \\
\hline \hline
\end{tabular}

Note. n.s.: non significant 
Data presented in Table 5.11 show that the six factors account for $10.23 \%$ to $11.49 \%$ of the variance in students' reading achievement. Reading self-concept, an affective factor, has the greatest impact on students' reading test scores in all three subtests with explained variances ranging from $7.01 \%$ to $9.68 \%$. Regarding the impact of the factors on the different text formats, data show that although reading self-concept has a marked influence on students' reading achievement in general, its impact is the greatest in case of the continuous text.

Another affective factor, attitude plays the second most important role in students' achievement; however, the regression coefficients represent much smaller and in some cases non-significant values. Attitude toward school reading has a significant influence on reading performance in the continuous $(0.95 \%)$ and mixed text format $(1.07 \%)$, whereas attitude toward recreational reading accounts for achievement in all text formats but the continuous one. Its impact is slightly higher on the mixed test scores.

Results show that students' ICT use habits predict their performance to the smallest extent. Students' ICT use habits have a significant but little impact on their achievement in the mixed $(0.26 \%)$ and non-continuous text format $(0.12 \%)$. However, it is a slightly higher figure in case of the former.

The frequency of reading continuous texts also explains the reading test scores to a small extent with values ranging from $0.28 \%$ to $0.79 \%$, showing the lowest predictive value in case of the continuous text. Similarly, the non-continuous factor has the weakest explanatory value in case of the non-continuous test scores $(0.10 \%)$.

\subsection{Discussion}

In this section the results are going to be discussed by answering the research questions and critically reflecting on the literature.

\section{HOW CAN SECOND GRADERS' READING ATTITUDES, SELF-CONCEPT, READING AND ICT USE HABITS BE CHARACTERIZED?}

Findings show that the majority of second graders in the sample consider themselves good and fast readers. Therefore, they have a positive reading self-concept. Positive student attitudes toward reading and a healthy reading self-concept are the main objectives of the reading curriculum in most countries; students who enjoy reading and who perceive themselves to be good readers, usually read more frequently and more widely, which in turn broadens their reading experience and improves their comprehension skills.

Although second graders exhibit a wide range of reading diversity in terms of the text formats they encountered during the month before taking the reading tests, data imply that they read and interpreted continuous texts (i.e. stories) more frequently than non-continuous texts (i.e. tables, maps). This tendency is in line with the guidelines of the Hungarian National Core Curriculum (Nemzeti alaptanterv, 2012). According to the requirements, students are familiarized with texts of different types and formats gradually, grade by grade, starting with continuous texts of narratives first, and then, with explanatory types. This may explain the dominance of continuous texts reflected by the responses. Accordingly, students reported a good deal of using cognitive processes contributing to the interpretation of continuous texts during the one month period preceding the administration of the test. Information retrieval and more complex tasks requiring the interpretation of non-continuous texts, however, seem to have appeared at less frequent intervals. 
According to the results, the vast majority of students had expertise in using computers before the data collection and one quarter of them had been users for more than five years before they took the test and the survey. Given that the mean age of the population was about seven years at their start of school, students started to use computers at or around the age of three. Data also show that more than half of the second graders had never used the internet for social communication and exchange of information and about two thirds had never written or read emails. The high rate of occurrence of computer and internet use for fun more frequently than three times a week $(63.01 \%)$ suggests that students use them for purposes other than the ones listed in the questionnaire (see for example Livingstone \& Haddon, 2009). Although EU Kids Online measured the media the internet use of Hungarian children aged between 9 and 16 in 2011, its data on 9-10-year-olds serve as valid point of comparison to this study. EU Kids revealed that $35 \%$ of 9-10-year-olds use the internet on a daily basis, which is in line with my results describing a somewhat younger population. EU Kids also showed that the vast majority of 9-16-year-olds watches videos, uses the internet for doing homework and to surf social media sites but the ratio of children with social media profiles is the lowest (38\%) in the younger population. Also, writing and reading emails are more prevalent in older age groups (Livingstone \& Haddon, 2009).

Data on students' attitudes toward reading in an educational environment is very promising. About half of the respondents fully agreed with the statements inquiring about attitudes towards going to and reading at school and about an additional one quarter of them have a moderately positive attitude towards these. The figures on attitude toward leisure reading show a significantly different, less enthusiastic, but still positive attitude toward reading for fun. Albeit measuring a younger population, the tendency found in this study is in line with the findings of Szenczi (2013) who examined older, fourth, sixth and eighth graders' attitude in these dimensions. Although the questionnaire items looking into attitudes were extracted into two different factors along leisure reading and school reading reflecting previous literature (McKenna \& Kear, 1990; Szenczi, 2013), the results should by no means be interpreted in a way that students never read for fun in school. This theoretical classification does not mean that these entities can be strictly separated and rubricated. These domains are interrelated (Szenczi, 2013). In this study, the results gained from the recreational and academic scale were used to provide an attitude profile of second graders in two different dimensions but the two scales of the instrument may also be utilized to improve instructional techniques by considering individual responses given in both scales (McKenna \& Kear, 1990). According to Szenczi's (2013) findings, Hungarian students' school attitude decreases sharply over time, so teachers should figure out programs and intervention techniques at an early stage to maintain the positive attitude towards school reading. It may be worthwhile to examine students' appreciation and the impact of rewards or different incentive systems on school-related reading attitude. The mastery motive of reading skills may also be studied related to this phenomenon.

\section{GENDER DIFFERENCES}

Since the 2009 PISA (OECD, 2010b) and PIRLS (Mullis, Martin, Foy, \& Drucker, 2012) reports touched upon the issue of achievement differences between text formats in terms of gender, we also examined whether these findings may be confirmed by my study carried out in a younger population. In line with previous findings, outcomes show consistent gender patterns in second-grade students' reading achievement in each subtest: girls outperformed boys in all three. It is surprising that data reflect disparities in students' achievement between genders as early as the second 
year of learning to read. This is a new finding previously not established in the literature. It is remarkable that these differences are present at this early stage of literacy development. PISA outcomes show that "gender gaps in academic performance are not determined by innate differences in ability" (OECD, 2015b, p. 4). Therefore, a joint effort by parents, teachers, policy makers and opinion leaders is needed to make sure that both boys and girls would be able to realize their full potential (OECD, 2015b).

Data also show that girls' advantage is the biggest in the continuous dimension, but the gender gap barely narrows in the mixed and non-continuous subscale - still in favor of girls. Although boys' advantage in the non-continuous scale cannot be seen in this study, it is possible that the gender gap decreases or boys even surpass girls in higher grades of elementary education. A deeper and more complex analysis involving the study of the relationship between gender, attitudes, reading habits, preferences and behavior (Logan \& Johnston, 2009) may provide insights into the areas that reading curricula and pedagogy could focus on in an effort to close the gender gap by improving boys' access to and engagement with different kinds of reading tasks and diverse texts (OECD, 2010b). In the Hungarian environment the potentials of gender-match phenomenon may also be examined and capitalized on in later grades to improve boys' reading development (see Chapter 6).

\section{WHAT IS THE RELATIONSHIP BETWEEN THE NON-COGNITIVE FACTORS MEASURED BY THE STUDENT QUESTIONNAIRE AND STUDENTS' READING ACHIEVEMENT IN DIFFERENT TEXT FORMATS IN GRADE 2?}

In line with previous findings (Retelsdorf, Köller, \& Möller, 2014; Mullis, Martin, Foy, \& Drucker, 2012), students' perception of themselves as readers has a positive linear relationship with their achievement. Although the correlation coefficients are in the weak-moderate range in case of all text formats (see Table 5.10), data seem to confirm my expectations regarding the strongest relationship between reading self-concept and reading achievement in the continuous text. Reading selfconcept and non-continuous and mixed test scores are correlated somewhat less strongly.

The rest of the factor variables are associated with achievement to a smaller extent than reading self-concept. The frequency of reading continuous texts has a weak positive relationship with achievement in all text formats suggesting that regular reading and interpreting continuous texts during the month before taking the reading tests is equally beneficial for reading texts of non-continuous and mixed formats as well. Nevertheless, the correlation coefficient is the weakest between this factor and the continuous text, which is in contrast with my expectations outlined in the introduction. We assume that the reason for the weaker association between these variables may be explained by the fact that students tend to be required to engage in more lower-order reading processes (tasks belonging to the spectrum of information retrieval) during reading classes in their second year of formal literacy development (Adamikné Jászó, 2006). Therefore, the factor predominantly comprising questions on the frequency of relatively more complex reading skills (like interpretation: explaining a character's motivation, explaining the reasons for events occurring in a narrative, describing characters) correlates with continuous reading test scores covering a wide range of cognitive aspects to reading to a smaller extent.

The factor comprising variables on the regularity of reading and comprehension of non-continuous texts is negatively correlated to achievement in the continuous and mixed text. However, no association was found between this factor variable and test scores achieved in the subtest with a non-continuous text. Based on these findings, it 
can be concluded that in the second year of learning to read, spending time on reading non-continuous texts leads to poorer achievement in the continuous and mixed text. The more time students spend reading non-traditional text format, the less successful they are in understanding texts associated with traditional reading or the other way round. It is worth comparing students' data regarding the relationship between the frequency of reading non-continuous texts and reading achievement with the results gained from teachers' data. Although the questions were differently formulated (students were asked how often they read non-continuous texts and used certain reading processes related to them when learning, whereas teachers were asked how often they used non-continuous texts for teaching during reading lessons, as will be discussed in Chapter 6) and the time frame was also different (students gave their answers for the month prior to the assessment, whereas teachers were asked about the frequency of relying on these text formats when teaching second graders on a weekly basis). Teachers' data also show that there is no association between the use of non-continuous texts and students' achievement in the three different subtests. For a broader discussion of this issue see Chapter 6.

All in all, while results show that students generally benefitted from reading continuous texts, having read non-continuous texts led to a poorer understanding of reading continuous and mixed texts. However, the lack of a significant relationship between the non-continuous factor and the non-continuous test scores calls for further investigation.

Findings also yielded evidence that the length and frequency of ICT use for noneducational purposes has a significantly negative relationship with students' achievement in reading continuous, mixed and non-continuous texts in the measured population. These results echo the arguments of the displacement theory (Rosén \& Gustaffson, 2014). Although the very weak values call for caution when interpreting this relationship, the negative values imply that at this age ICT use has an adverse effect on reading comprehension: the more students are engaged in ICT use for fun, the less likely they are to perform well in reading. Most probably, at this age, the studied activities may be classified as a waste of time, since engagement in these diminishes the time frame and motivation to read and is more likely to lead to a decrease in students' reading achievement. The correlation coefficients are somewhat higher in case of the continuous and mixed subtest scores than in the non-continuous one supporting the reasoning put forward by Rosén and Gustaffson (2016). Nevertheless, we maintain that it is very difficult to tell whether ICT use itself is the cause or result of different levels of reading skills and it is unclear from this study how these factors interact. It may easily be the case that the children of parents who do not motivate their children to use computers and the internet for "learning" benefit less from their use. ICT use can be very varied: if parents discuss with kids what they do and how they do it, it may be conducive to learning. Age, gender and socioeconomic status each have a unique contribution to the chance of gaining benefits from internet use (Livingstone \& Haddon, 2009). Rideout, Foehr, and Roberts (2010) found that children especially with low socioeconomic background are exposed to a wide array of media (TV, computers) ninety minutes more per day than children with more affluent parents. Nevertheless, within this extra time the use of computers for meaningful content creation or educational purposes is insignificant compared to their use for pure entertainment.

Attitude toward recreational and school reading are both positively related to proficiency in reading continuous, mixed and non-continuous text formats. The school attitude factor is associated with the mixed text scores the most and with the noncontinuous test scores the least. Attitude toward recreational reading correlates with 
achievement in the mixed subtest the most, and reading proficiency measured by the continuous subtest the least. Since attitude is a construct that mediates reading behavior, the dimensions of attitude and reading proficiency sustain each other in a reciprocal relationship. Students select their leisure activities based on what they enjoy the most. Students who choose to read more tend to be better readers and in turn better readers are likely to feel rewarded by reading more.

\section{TO WHAT EXTENT DO THE NON-COGNITIVE FACTORS MEASURED BY THE STUDENT QUESTIONNAIRE ACCOUNT FOR THE VARIANCE IN SECOND GRADERS' READING ACHIEVEMENT IN DIFFERENT TEXT FORMATS?}

The factors included in the background questionnaire account for about $11 \%$ of the variance in students' reading achievement in all three text formats (Table 5.11). The factor variables have the smallest impact on students' reading achievement in the noncontinuous text. Out of the measured variables, reading self-concept plays the most outstanding role in students' reading achievement. The extent of its impact differs by text formats, its value is the highest in case of the continuous text, the second highest in case of the non-continuous test and it has the smallest but still considerable effect on the mixed test scores. Self-concept is an affective construct that is fed by feedback from most significant others: in the case of reading, teachers and parents. Feedback triggers and guides behavior. The phenomenon may also be related to the "growth mindset", a term coined by Dweck (2008), referring to the underlying beliefs people have about learning and intelligence. In this case growth mindset means that the more children believe that they can do it, they can read well, the more they will be able to develop. Since students are more familiar with continuous texts since early childhood (i.e. childhood education - kindergarten and home environment: picture books with story lines, fairy tales, bedtime stories and stories about themselves told by parents) and meet continuous texts more often when learning, their reading self-concept is constituted by feedback either in form of marks or oral evaluation based on how they perform in understanding continuous texts. Hence the higher value.

Supposedly, students who consider themselves good and fast readers have a more positive attitude toward reading and will enjoy reading all types of texts. Self-concept is intertwined with mastery motivation (Jennings, 1993) and underlies attitude, beliefs and achievement. Although reading self-concept and reading attitude are interrelated entities (e.g., Szenczi, 2013), compared to reading self-concept, reading attitude explains only a small proportion (about one percent) of variance in the reading test scores. Recreational reading attitude has an impact on the mixed and non-continuous text scores but it does not seem to influence the achievement in the continuous text. A reason for this finding may be that students who enjoy reading in their free time may engage in reading materials of different formats, so just because students feel positively about leisure reading it does not necessarily mean that they always read continuous texts (let's just think about comic books).

The level of attitude toward school reading does have an impact on the continuous and mixed test scores but not on the non-continuous text scores. When students were asked about their feelings about reading in their classes and compulsory reading materials, most probably, they associated school-related reading with traditional text formats. Therefore, there is no significant impact of this factor variable on the noncontinuous test scores. "Traditionally, reading has been associated mainly with continuous texts" (OECD, 2010b, p. 79). Data collected from both students and teachers (see Chapter 6) regarding the frequency of reading non-continuous texts confirm that in the Hungarian school system reading is typically confined to continuous texts. 
Especially in upper grades "in other parts of the curriculum, however, proficiency in understanding and using non-continuous texts is at least equally important: for example, students need to be able to read and interpret maps and tables in the social sciences, and diagrams and graphs in the sciences" (OECD, 2010b, p. 79).

Print rich homes play an important role in children's literacy development (Bus, van IJzendoorn, \& Pellegrini, 1995; Senechal, \& LeFevre, 2002). From a rich literary home environment positive effects can be expected regarding reading self-concept and attitude as well. In print rich homes literacy is cherished and parents show a positive attitude towards reading, which motivate children to read, whereas homes that lack these resources most probably provide a less motivating atmosphere for reading. Tarelli and Stubbe's meta-analysis (2010) on the relationship between home literacy environment, SES and reading achievement based on the data collected by PIRLS in 2006 (Mullis, Martin, Kennedy, \& Foy, 2007) show that the index of Hungarian fourth graders' home literacy environment (HLE) scores (305) is significantly higher than the international average (300). The correlation between HLE - including factors such as family literacy activities that support formal reading instruction in school, parental attitudes towards literacy, and parental reading behaviors - and reading achievement was rather low (.116), HLE explained $5.3 \%$ of the variance in students' reading achievement. Students' SES was also analyzed in relation to HLE and reading achievement. The differences between the HLE index scores of children from families with high SES (329) and children from families with low SES (286) was around the international average (329 and 286, respectively). Hungary was among the countries where the highest correlation between SES and reading achievement (.385) and HLE (.324) was found. The correlation values imply that children with a more privileged family background enjoy a richer HLE and tend to perform better in reading tests.

The frequency of reading continuous and non-continuous texts significantly predicted reading scores in all three text formats. There are no previous findings available regarding the association among these variables. However, I assumed that students' frequency of engagement with a particular text format in the classroom has a greater contribution to achievement on that scale. Therefore, it came as a surprise that the factors related to the frequency of reading different text formats have the smallest impact on the text formats corresponding to the regularity of reading them when learning. The low values may be shocking in general, but what students do with the text and how they do it can be an alternative approach to studying the contribution of this factor to reading competence. Alternatively, it may also easily be the case that the first two years of literacy development do not allow for enough practice to study this relationship.

Variables grouped in the ICT factor accounts for students' reading literacy test scores achieved in the mixed and non-continuous subtests. Contrary to the consistent results of Rosén and Gustaffson's analysis of IEA data (2016), the frequency of the activities included in the ICT factor does not have a marked influence on students' achievement in reading continuous texts. Most probably, in this case the fact that students are familiar with continuous texts from early childhood and these types of texts are introduced to them first may compensate for the adverse effect of these ICT activities on reading traditional text formats. However, when students are at the early stages of developing their skills to read and understand other text formats, the frequencies of computer, internet and social media use for fun, and writing and reading emails have a negative, if hardly any, relationship with mixed and non-continuous test scores, even though in an electronic environment these formats are also prevalent (OECD, 2010b, p. 41). Another reason may be that the effects of ICT use are likely to 
vary depending on the context and the specific uses or they are mediated by other factors such as SES.

\subsection{Conclusion}

Similarly to other cognitive skills, "children's reading comprehension develops in a rich context of direct and indirect factors" (Katzir, Lesaux, \& Kim, 2009, p. 261). The present study aimed at mapping out how the reading literacy of second graders in three text formats vary by contextual factors that may be associated with reading proficiency. The methods utilized in this study included the analysis of a questionnaire survey and student responses to reading comprehension questions. In addition to discussing the development and structure of the instruments, findings were analyzed, with consideration to the contribution of non-cognitive factors to achievement in different text formats.

Educating students to become good and avid readers is one of the declared goals of the national curriculum. Emphasis on reaching this objective is laid on children's literacy development from the beginning of kindergarten. Although there are ever growing concerns about Hungarian students' gradually deteriorating attitudes toward reading, especially in upper grades (F. Joó, 2012; Szenczi, 2013), results on students' attitudes and self-concept triggering achievement behavior show that there is a silver lining. Second graders' attitudes toward academic and recreational reading and reading self-concept are overwhelmingly positive. Findings also showed that these affective variables, especially self-concept, are remarkable factors contributing to students' reading achievement. Interestingly, school-reading attitude does not account for the difference in students' achievement on the non-continuous text and the recreational attitude does not explain students' achievement on the continuous subtest. As attitude and self-concept influence students' achievement along many paths, further research is needed to unveil the interactions behind these relationships.

As for the frequencies of reading and understanding non-continuous texts in the month before test administration show, these activities only have a minor contribution to performance on the non-continuous texts. Furthermore, the negative direction of the relationship (even though the value is very weak) implies that the more frequently students engaged in these activities one month before test administration when learning, the worse they scored on the continuous and mixed subtests. A similar pattern emerged in case of the continuous text factor and its relation to the dependent variables. However, the regularity of reading continuous texts proved beneficial to reading proficiency in all subtests. It is possible that while reading comprehension as a complex skill is being shaped and the fundamentals being established in grade 2, developing more sophisticated and differentiated processes (as discussed in Chapter 4) students need to use to form an understanding of non-continuous texts takes away the effort from progress in continuous reading comprehension. Nevertheless, it is also possible that the quality over quantity approach should be pursued when further examining this issue. Perhaps, the questions also should frame how these activities are carried out and what they actually involve.

It is also noteworthy that the results gained from the confirmatory factor analysis carried out to confirm the structure of the background questionnaire show that the format of the texts and the cognitive processes associated with them are distinct as they were grouped into different factors. This corresponds with the findings of the first study (see Chapter 4), which also showed that the cognitive aspects to reading belong to different factors when it comes to reading continuous and non-continuous text formats. 
Results also show that although the majority of second graders claim to use computers and the internet for fun at different levels of regularity, they are not heavy social media users and do not regularly engage in electronic correspondence. I assumed that the length of computer use and time spent in front of the computer screen (characterized by certain activities) would have a positive relationship with students' reading achievement for two reasons. Relying on the content theory, first, I assumed that the frequency of engagement in an electronic environment leads to increased skills especially in reading and understanding mixed and non-continuous texts. Second, I expected exposure to written pieces of information to be advantageous regardless of the medium that carries the information. However, results did not support my hypothesis, as they made a strong case for the validity of the displacement theory. As far as the ICT factor's relationship with achievement in different text formats is concerned, data show a slightly weaker association with the non-continuous test scores than with those achieved in the other two subtests, debunking my expectations regarding the possible positive impact of ICT exposure to a variety of activities and reading in an electronic environment. The ICT factor had a very weak negative relationship with students' reading developmental level. Seemingly, during engagement with ICT second graders do not acquire skills that would boost their reading development or learn anything that pays off in their reading skills at this stage. The screen time diet of these students is apparently not beneficial to their reading.

All in all, the examined factors account for a significant proportion of the variance in second graders' achievement. However, their values do not show a significant difference along the text formats. Small differences were found: they have a somewhat smaller influence on achievements on the non-continuous tests. Findings suggest that we managed to identify and examine some factors underlying students' achievement in reading different text formats. They may not be sole factors but they are contributing factors to students' achievement measured by different text formats.

\subsection{Results of the short questionnaire}

In this section, first, descriptive statistics are provided on the frequencies of answers. Second, results of the paired samples t-tests are given, followed by data on the relationship between the variables included in the mini questionnaire and students' achievement in the continuous, mixed and non-continuous subtests. The results are presented in the order of questions.

Table 5.12 shows the distribution of answers given to the questions about the continuous, mixed and non-continuous text included in the mini questionnaire. 
Table 5.12 Frequencies (\%) of the short questionnaire based on the achievement quartiles in the three subtests

\begin{tabular}{|c|c|c|c|c|c|c|c|c|c|c|c|c|c|c|c|c|}
\hline \multirow{2}{*}{ Item } & \multirow{2}{*}{ Scale } & \multicolumn{5}{|c|}{ Continuous } & \multicolumn{5}{|c|}{ Mixed } & \multicolumn{5}{|c|}{ Non-continuous } \\
\hline & & 1 & 2 & 3 & 4 & Sum & 1 & 2 & 3 & 4 & Sum. & 1 & 2 & 3 & 4 & Sum. \\
\hline \multirow{4}{*}{$\begin{array}{l}\text { How much did you like the } \\
\text { text? }\end{array}$} & Not at all & & & & & & 36.87 & 26.26 & 23.46 & 13.41 & 5.56 & 52.80 & 24.00 & 10.40 & 12.80 & 3.92 \\
\hline & Rather no & 51.15 & 26.72 & 16.79 & 5.34 & 4.35 & 29.63 & 22.22 & 22.22 & 25.93 & 9.22 & 38.73 & 27.11 & 19.37 & 14.79 & 8.90 \\
\hline & Rather yes & 25.33 & 24.82 & 25.74 & 24.10 & 32.39 & 22.82 & 25.78 & 25.70 & 25.70 & 36.61 & 26.16 & 25.42 & 25.00 & 23.42 & 29.83 \\
\hline & A lot & 20.96 & 25.05 & 26.21 & 27.78 & 63.26 & 24.28 & 24.92 & 25.24 & 25.56 & 48.60 & 19.62 & 24.92 & 26.83 & 28.63 & 57.35 \\
\hline \multirow{4}{*}{$\begin{array}{l}\text { How much did you like the } \\
\text { tasks related to the text? }\end{array}$} & Not at all & 48.84 & 26.36 & 10.08 & 14.73 & 4.04 & 36.36 & 23.55 & 25.62 & 14.46 & 7.53 & 46.51 & 30.23 & 12.40 & 10.85 & 4.04 \\
\hline & Rather no & 44.67 & 20.90 & 20.49 & 13.93 & 7.64 & 27.29 & 26.86 & 23.14 & 22.71 & 14.25 & 33.04 & 26.61 & 23.39 & 16.96 & 10.70 \\
\hline & Rather yes & 23.50 & 25.73 & 28.12 & 22.65 & 36.62 & 23.76 & 26.24 & 25.29 & 24.71 & 42.56 & 23.85 & 25.00 & 27.79 & 23.37 & 32.54 \\
\hline & A lot & 20.52 & 25.24 & 24.94 & 29.30 & 51.71 & 23.04 & 23.21 & 25.39 & 28.36 & 35.66 & 21.48 & 24.51 & 24.87 & 29.14 & 52.72 \\
\hline \multirow{4}{*}{$\begin{array}{l}\text { How difficult did you find } \\
\text { the text? }\end{array}$} & Not at all & 14.69 & 22.94 & 28.79 & 33.58 & 42.00 & 18.79 & 24.65 & 25.95 & 30.60 & 33.65 & 17.94 & 23.08 & 25.29 & 33.68 & 30.02 \\
\hline & Rather no & 24.61 & 26.84 & 23.42 & 25.13 & 23.93 & 20.77 & 24.80 & 26.11 & 28.33 & 31.05 & 22.80 & 21.37 & 27.20 & 28.63 & 24.31 \\
\hline & Rather yes & 34.01 & 27.76 & 23.26 & 14.97 & 21.66 & 30.31 & 25.90 & 23.63 & 20.16 & 23.44 & 27.62 & 27.94 & 24.30 & 20.13 & 29.42 \\
\hline & A lot & 41.62 & 25.38 & 18.78 & 14.21 & 12.41 & 41.69 & 25.59 & 21.90 & 10.82 & 11.86 & 33.72 & 29.84 & 23.45 & 12.98 & 16.25 \\
\hline \multirow{4}{*}{$\begin{array}{l}\text { To what extent were you } \\
\text { familiar with the tasks } \\
\text { related to the text? }\end{array}$} & Not at all & 21.98 & 25.70 & 26.61 & 25.70 & 27.87 & 21.08 & 27.19 & 25.90 & 25.82 & 36.41 & 21.97 & 26.05 & 24.47 & 27.50 & 24.01 \\
\hline & Rather no & 29.50 & 25.31 & 22.38 & 22.80 & 15.02 & 26.05 & 22.55 & 26.05 & 25.35 & 17.93 & 28.50 & 24.35 & 24.70 & 22.45 & 18.29 \\
\hline & Rather yes & 26.40 & 25.48 & 23.55 & 24.57 & 30.95 & 25.62 & 24.44 & 24.56 & 25.39 & 26.42 & 23.98 & 24.08 & 25.57 & 26.37 & 31.63 \\
\hline & A lot & 22.45 & 24.01 & 26.77 & 26.77 & 26.17 & 30.62 & 23.78 & 23.13 & 22.48 & 19.24 & 24.73 & 26.55 & 24.97 & 23.76 & 26.07 \\
\hline \multirow{2}{*}{$\begin{array}{l}\text { Were you familiar with the } \\
\text { topic of the text before the } \\
\text { testing? }\end{array}$} & Yes & 35.54 & 26.08 & 21.12 & 17.26 & 33.98 & 39.80 & 25.03 & 20.51 & 14.65 & 25.38 & 38.55 & 28.43 & 21.57 & 11.45 & 30.53 \\
\hline & No & 19.05 & 24.72 & 27.13 & 29.11 & 66.02 & 19.93 & 25.04 & 26.54 & 28.49 & 74.62 & 18.47 & 23.69 & 26.74 & 31.10 & 69.47 \\
\hline
\end{tabular}




\section{(1) HOW MUCH DID YOU LIKE THE TEXT?}

Data show that a large proportion of students expressed their liking towards the three texts. In case of the continuous text, $63.26 \%$ of the respondents claimed that they liked the text about the gardening cubs a lot, in case of the mixed text and the non-continuous one, this ratio was $48.60 \%$ and $57.35 \%$, respectively. It is also noteworthy that while in case of the mixed and non-continuous text formats the answers ranged from not at all to a lot, there weren't any students who did not like the continuous text at all. The "not at all" point of the scale was chosen by $5.56 \%$ of students in case of the mixed text showing a theatre poster, and $3.92 \%$ of students chose the most negative answer in case of the non-continuous text about the white-tailed eagle (see the texts in Appendix A, B, C).

Paired samples t-tests (Tables 5.13 and 5.14) were conducted to compare the mean differences among the three text formats calculated from the answers given to the questions. Data show that students liked the continuous text the most, the second most preferred text was the non-continuous one, whereas the least preferred text was the mixed one.

\section{(2) HOW MUCH DID YOU LIKE THE TASKS RELATED TO THE TEXT?}

About the same proportion of students expressed extreme fondness towards the tasks included in the continuous $(51.71 \%)$ and in the non-continuous subtests $(52.72 \%)$, whereas in case of the mixed subtest a bit more than one third of students $(35.66 \%)$ said that they liked the tasks a lot. As far as the negative points of the scale are concerned (i.e. not at all and not really), tasks measuring the understanding of the mixed received the most negative evaluations $(21.78 \%)$, this was followed by dislike towards the tasks of the non-continuous text $(14.74 \%)$ and the continuous text $(11.68 \%)$.

Based on the results of the paired sample t-tests (Tables 5.13 and 5.14), no significant difference was found between the preference towards the tasks related to the continuous and non-continuous texts. However, students liked the tasks related to the continuous text and the non-continuous text significantly more than those belonging to the mixed text.

\section{(3) HOW DIFFICULT DID YOU FIND THE TEXT?}

Regarding students' perceived text difficulty, the not at all and rather not responses were the most frequent: continuous text $(65.93 \%)$, non-continuous text $(54.33 \%)$ and mixed text $(64.70 \%) .42 .00 \%$ of students perceived the continuous text, $33.65 \%$ the mixed text and $30.02 \%$ the non-continuous text as the least difficult. A small proportion of students ranging between $11.86 \%$ (mixed text) and $16.25 \%$ (non-continuous text) said that the text was very difficult for them.

Data show (Tables 5.13 and 5.14) that students found the non-continuous text the most difficult, the mixed text less difficult and the continuous text the least difficult.

\section{(4) TO WHAT EXTENT WERE YOU FAMILIAR WITH THE TASKS RELATED TO THE TEXT?}

Only $42.89 \%$ of second graders were not at all and not really familiar with the tasks measuring the understanding of the continuous text. Whereas $42.30 \%$ did not find the noncontinuous text familiar and $54.34 \%$ did so in case of the mixed text. The distribution of the answers in the other two points of the scale (rather yes and a lot) was $57.12 \%$ in case of the continuous text, $45.66 \%$ in case of the mixed text and $57.70 \%$ in case of the non-continuous text.

Tables 5.13 and 5.14 show that the rank order regarding task familiarity is as follows. Students were most familiar with the tasks measuring the understanding of the noncontinuous text, followed by the continuous text. The tasks related to the mixed text were the least familiar for second graders. 


\section{(5) WERE YOU FAMILIAR WITH THE TOPIC OF THE TEXT BEFORE THE TESTING?}

In all cases, more than half of the respondents claimed that they were unfamiliar with the text or the topic of the text. The proportion of 'no' answers ranged between $66.02 \%$ (continuous text) to $69.47 \%$ (non-continuous text) and $74.62 \%$ (mixed text).

Paired samples statistics show (Tables 5.13 and 5.14) that the most familiar text was the continuous one. Significantly more students knew the tale about the cubs than had any information about the white-eagle (non-continuous text) or were familiar with the tale about Szamárbör királyfi [Donkeyskin] represented in the mixed subtest. The paired samples ttests also show that Szamárbör királyfi was the most unfamiliar topic for the second graders in the sample.

Table 5.13 Means and standard deviations of the frequencies of answers regarding the continuous, mixed and non-continuous subtests

\begin{tabular}{|c|c|c|c|c|c|c|}
\hline \multirow{2}{*}{ Item } & \multicolumn{2}{|c|}{ Continuous } & \multicolumn{2}{|c|}{ Mixed } & \multicolumn{2}{|c|}{ Non-continuous } \\
\hline & Mean & $S D$ & Mean & $S D$ & Mean & $S D$ \\
\hline How much did you like the text? & 3.55 & 0.71 & 3.28 & 0.85 & 3.41 & 0.81 \\
\hline $\begin{array}{l}\text { How much did you like the tasks } \\
\text { related to the text? }\end{array}$ & 3.36 & 0.79 & 3.06 & 0.89 & 3.34 & 0.83 \\
\hline How difficult did you find the text? & 2.04 & 1.06 & 2.14 & 1.01 & 2.32 & 1.07 \\
\hline $\begin{array}{l}\text { To what extent were you familiar with } \\
\text { the tasks related to the text? }\end{array}$ & 2.55 & 1.15 & 2.28 & 1.15 & 2.60 & 1.11 \\
\hline $\begin{array}{l}\text { Were you familiar with the text/topic } \\
\text { before the testing? }\end{array}$ & 1.66 & 0.47 & 1.75 & 0.44 & 1.69 & 0.46 \\
\hline
\end{tabular}

In order to examine how students' achievement and rating of preference, perceived text and task difficulty and background knowledge are related, students' reading achievement divided into four equal groups was calculated for the points of the given scale (Table 5.12).

\section{(1) HOW MUCH DID YOU LIKE THE TEXT?}

As far as students' preference of the given text is concerned, data show that students' achievement is distributed in different proportions along the points of the Likert-scale: $51.15 \%$ of students who did not really like the continuous text fell into the first quartile, however, the test scores of the rest of their dissatisfied peers $(26.72 \%$ and $16.79 \%)$ fell into the second and third quartiles, respectively and 5.34\% performed in the highest quartile. In case of the continuous text, a moderately negative attitude towards the text resulted in very poor achievement for slightly more than half of the respondents. However, data also show that a negative attitude towards the continuous text does not necessarily lead to poor achievement but students in this category were less likely to have an achievement in the upper quartiles. 
Table 5.14 The comparison of means presented in Table 5.13 with paired samples t-tests

\begin{tabular}{|c|c|c|c|c|}
\hline Item & Subtest & $t$ & $d f$ & $\begin{array}{c}\text { Sig. } \\
(2 \text {-tailed })\end{array}$ \\
\hline \multirow{3}{*}{$\begin{array}{l}\text { How much did you } \\
\text { like the text? }\end{array}$} & Continuous - Non-continuous & 10.975 & 2998 & .000 \\
\hline & Continuous - Mixed & 13.061 & 3002 & .000 \\
\hline & Non-continuous - Mixed & 6.270 & 3181 & .000 \\
\hline \multirow{3}{*}{$\begin{array}{l}\text { How much did you } \\
\text { like the tasks related } \\
\text { to the text? }\end{array}$} & Continuous - Non-continuous & 1.224 & 3184 & .221 \\
\hline & Continuous - Mixed & 15.818 & 3180 & .000 \\
\hline & Non-continuous - Mixed & 14.760 & 3181 & .000 \\
\hline \multirow{3}{*}{$\begin{array}{l}\text { How difficult did you } \\
\text { find the text? }\end{array}$} & Continuous - Non-continuous & -16.376 & 3147 & .000 \\
\hline & Continuous - Mixed & -4.130 & 3141 & .000 \\
\hline & Non-continuous - Mixed & 8.107 & 3141 & .000 \\
\hline \multirow{3}{*}{$\begin{array}{l}\text { To what extent were } \\
\text { you familiar with the } \\
\text { tasks related to the } \\
\text { text? }\end{array}$} & Continuous - Non-continuous & -2.357 & 3142 & .018 \\
\hline & Continuous - Mixed & 10.814 & 3145 & .000 \\
\hline & Non-continuous - Mixed & 12.491 & 3127 & .000 \\
\hline \multirow{3}{*}{$\begin{array}{l}\text { Were you familiar } \\
\text { with the text/topic } \\
\text { before the testing? }\end{array}$} & Continuous - Non-continuous & -3.737 & 3202 & .000 \\
\hline & Continuous - Mixed & -8.330 & 3202 & .000 \\
\hline & Non-continuous - Mixed & -5.519 & 3200 & .000 \\
\hline
\end{tabular}

Note. non significant

The achievement distribution of students who expressed their liking towards the continuous text is even. The proportion of students who had a moderately or extremely positive attitude towards the text ranges between $20.96 \%$ and $27.78 \%$ in the quartiles.

In case of the non-continuous text the same pattern can be observed with students who did not like the text at all as in case of students having a moderately negative attitude towards the continuous text. The achievement of $52.80 \%$ of second graders who didn't like the noncontinuous text at all fell into the lowest quartile, $24.00 \%$ into the second, $10.40 \%$ into the third and $12.80 \%$ into the fourth quartile. This shows that a strong dislike of the text is more likely to result in poor achievement in the non-continuous text but data on about one quarter of the very negative respondents show that despite the very negative attitude, it is also possible, although less likely, to score in the upper quartiles. Like in case of the continuous text, the achievement of students who expressed a moderately or extremely favorable attitude towards the non-continuous subtest ranges in the four quartiles around the same proportion implying that a positive attitude may as well lead to either poor or good achievement.

In the case of the mixed text, similar tendencies arise regarding the distribution of students in the quartiles along the scale points to the case of the non-continuous text but there are also remarkable differences in case of the students who responded negatively to the question how much they liked the text. Only around one third of students (36.87\%) who did not like the text at all fell into the lowest quartile and a larger proportion of students $(23.46 \%)$ scored in the third quartile showing an increasing likelihood of better performance despite complete unfondness about the text in question. 


\section{(2) HOW MUCH DID YOU LIKE THE TASKS RELATED TO THE TEXT?}

In case of both the continuous and non-continuous text about half of the students responded $(51.71 \%$ and $52.72 \%$, respectively) that they liked the tasks a lot. In case of the mixed text, this proportion was $35.66 \%$. In each case, the achievement of nearly $30 \%$ of these students fell into the highest quartile and the test scores of around $20 \%$ fell into the lowest quartile.

The number of students who had a very negative attitude towards the tasks related to the texts was marginal (continuous text: $4.04 \%$, mixed text: $7.53 \%$, non-continuous text: $4.04 \%$ ); however, it is among these students where we can find the poorest performers. In the continuous subtest $48.84 \%$, in the mixed subtest $36.36 \%$ and in the non-continuous subtest $46.51 \%$, respectively, had test scores falling into the first quartile. Regarding the achievement of students who moderately disliked the tasks, this tendency is the most visible in case of the continuous text, whereas in case of the mixed text, the marked difference between the proportion of students in the first and the rest of the quartiles diminishes.

\section{(3) HOW DIFFICULT DID YOU FIND THE TEXT?}

Out of the students who found the text very difficult (continuous text: $12.41 \%$, mixed text: $11.86 \%$, non-continuous text: $16.25 \%$ ), a large proportion's (continuous text: $41.62 \%$, mixed text: $41.69 \%$, non-continuous text: $33.72 \%$ ) reading achievement fell into the lowest quartile. There was also a considerable number of students who considered the text very difficult but had better achievement on all subtests. However, the likelihood of scoring in upper quartiles among these students decreased as the achievement values in the quartile groups increased.

The achievement of students who responded that they didn't find the texts difficult at all (continuous text: $42.00 \%$, mixed text: $33.65 \%$, non-continuous text: $30.02 \%$ ) also fell into a wide range of quartiles. However, in this case, the largest proportion of students can be found in the best performing category represented by the fourth quartile (continuous text: $33.58 \%$, mixed text: $30.60 \%$, non-continuous text: $33.68 \%$ ). Students who did not perceive the texts difficult at all were more likely to score in higher quartiles and these students' achievements were less likely to fall into lower quartiles and the least likely to fall into the first, lowest quartile in each subtest.

The distribution of students in the quartiles is more balanced in case of students who found the texts moderately difficult, or not really difficult. No clear tendencies can be observed in these cases.

\section{(4) TO WHAT EXTENT WERE YOU FAMILIAR WITH THE TASKS RELATED TO THE TEXT?}

Taking a look at the data on the distribution of students in the achievement categories in the continuous, mixed and non-continuous subtests reveals that although familiarity with the tasks related to the text was rated differently by students covering all points of the scale, along this factor the distribution of students does not change markedly in the quartiles.

\section{(5) WERE YOU FAMILIAR WITH THE TEXT/TOPIC OF THE TEXT BEFORE THE TESTING?}

Even though $33.98 \%$ of second graders were familiar with the tale about the gardening cubs in the continuous subtest, $35.54 \%$ percent of them achieved in the lowest quartile, $26.08 \%$ in the second, $21.12 \%$ in the third and $17.26 \%$ in the highest quartile. Interestingly, as far as the yes answers are concerned, a very similar pattern emerged in case of the mixed and non-continuous texts. This means that text familiarity does not guarantee good performance in either case. However, the opposite also holds true: being completely unfamiliar with the text or topic conveyed by a certain text in the reading assessment does not evidently lead to a poor result. 


\subsection{Discussion}

The items included in the short questionnaire addressed students' attitude, opinion and background knowledge covering two aspects: text and task.

Data show that students had the most positive attitude toward the continuous text but their fondness of the tasks included in the continuous and the mixed text did not differ significantly. The possible reasons are that on the one hand, tales are closer to a child's world. Children meet these the most often from their birth either in their homes and in educational institutions. On the other hand, data may be explained by the fact that tales provide a unique literary experience that reading the mixed and the non-continuous text falls short of. Stories (narrative frames, scripts etc.) are the most important genre of learning about the world and constructing identity (Schank \& Abelson, 1977). Although tales and continuous texts in general are more often read and encountered by children, answers suggest that the tale included in the mixed subtest was much less familiar for second graders than the tale about the gardening cubs represented in the continuous text. Interestingly, second graders were more knowledgeable about the nesting habits of the white-tailed eagle than about the tale in the mixed subtest.

Findings also reveal that students had the most negative attitude towards the mixed text and the tasks belonging to them. Although the mixed text contained a list and a narrative part, the latter did not appeal to students.

In terms of text difficulty, students also gave answers in favor of the continuous text, they found it the least difficult. In contrast, second graders perceived the non-continuous text the most difficult. Even though students found the non-continuous text the most difficult, it was not the one receiving the most negative ratings as far as liking is concerned. Text difficulty, in other words, readability is influenced by numerous factors (see Chapter 4) but from this data set we cannot draw conclusions as to why students found the non-continuous text the most difficult. Schema theory described in Chapter 1 provides a solid framework for further inquiry. Was it the text format (i.e. formal schemata)? Was it the topic (i.e. content schemata)? Was it the vocabulary (i.e. linguistic schemata) or word frequency? These questions lend themselves to further investigation.

Albeit its perceived difficulty, the tasks measuring the understanding of the noncontinuous text proved to be the most familiar for second graders, followed by the continuous text. The tasks related to the mixed text were the least familiar for second graders. The almost equal distribution of students who responded positively and negatively to this question was around the same implying at least two issues. One is related to the relatively young age of the population. As second graders were in the beginning phase of learning to read, it is possible that they had not had the opportunity to meet a wide range of tasks measuring information retrieval, interpretation and reflection, which may be a plausible explanation for the data. The second issue concerns the question how the cognitive aspects to reading are operationalized for teaching and assessment purposes. It may be the case that teachers, textbook writers and researchers conceptualize and operationalize the reading processes differently and this is why many students found the tasks unfamiliar. Research in this direction may also be fruitful in gaining a full understanding of the phenomenon.

The short questionnaire was primarily administered to examine the extent to which students' responses and achievements in the three subtests are related. In this respect, data show a great deal of variety. Most importantly, findings yield evidence that having a negative or positive attitude towards and opinion about the measured text or task does not result in an obvious all or nothing achievement pattern. The most visible tendencies occur among the achievement of students who chose the two extremes of the Likert-scales and they are similar in case of each text format. For example, students who did not like the texts and the tasks at 
all were more likely to have poor achievement than those who had a positive attitude towards them. However, task and text/topic familiarity do not impact students' achievement in a way that it would noticeably change the ratio of students falling into the achievement quartiles in either of the subtests.

\subsection{Conclusion}

The short questionnaire provides important information for both researchers and practicing teachers in at least three ways. First, teachers should not hesitate to introduce a wide range of text formats to students even at a young age. By nature, mixed and noncontinuous texts lend themselves to reading for information rather than reading for literary experience but students may as well have a positive attitude towards these pieces of written information. Furthermore, the topic should not deter teachers either: all topics could be both attractive and boring, there are huge individual differences in what kids appreciate. Third, teachers as well as textbook writers should expand the range of tasks enhancing and measuring reading processes, so that students' reading literacy could be developed and measured from multiple aspects. The conceptualization of cognitive aspects to reading in teachers' syllabi, textbooks and research-based assessments also call for harmonization. The conclusion regarding the text and topic choice is also useful for researchers and textbook writers. These steps are expected to lead to a better understanding of written pieces of information regardless of their format. 


\section{CHAPTER 6}

\section{A DESCRIPTIVE AND CORRELATIONAL STUDY ON THE ROLE OF ASPECTS OF READING INSTRUCTION IN STUDENTS' READING LITERACY ACHIEVEMENT IN DIFFERENT TEXT FORMATS}

\subsection{Introduction}

The heuristic model of reading (see Chapter 1) suggests that the context in which reading instruction takes place is just as relevant in reading development as the activities students perform while reading the text and characteristics of the text (Chapter 4), or the capacities, abilities and experiences of the reader (Chapter 5). Compared to the number of research focusing on the cognitive processes involved in reading or students' characteristics, studies placing an emphasis on the impact of classroom practices on students' reading achievement is scarce especially in Hungary. Small-scale studies conducted in the past few decades produced results on a small segment of reading instructional practices. For example, Csépe's (2006) two-year-long experimental research lent support to the fact that analyticsynthetic method is the most fruitful reading method to teach Hungarian children to read, whereas the whole word method misses out on an important aspect of phonological awareness that is a building block in reading development (Csépe, 2006, p. 180). Adamikné Jászó's philological research on methods also yielded this conclusion (Adamikné Jászó, 2001a). Gósy (2008) reported on the results of an experimental research focusing on the application of different reading techniques. The study involving 40 third graders and 40 fourth graders employed oral and silent reading techniques to find out whether relience on the auditory and visual channels at the same time help poor and good readers in reading. Fluent reading and reading comprehension achievement of students show that poor readers' test scores increased if oral reading was also made possible. Although these studies have both theoretical and practical relevance, they are not comprehensive since they focused on continuous texts only and did not fully cover the construct of reading in terms of text format. Moreover, they worked with small samples, thus the results are not generalizable. Therefore, we do not know what role these aspects of instruction have in understanding mixed and noncontinuous texts.

System-level assessments are more comprehensive both in terms of the measured factors and the array of text formats. However, large-scale studies examining teachers' background and classroom practices in lower elementary grades are rare. A recent example for this is the study conducted by PIRLS in 2011 that also included a teacher survey (Mullis, Martin, Foy, \& Drucker, 2012). PIRLS collected data on Hungarian teachers' demographic characteristics, teacher preparation, and classroom instruction in order to be able to better understand the relationship between these factors and 9-10-year-olds' reading literacy achievement (Balázsi, Balkányi, Bánfi, Szalay, \& Szepesi, 2012). Results yielded evidence that students whose teachers took part in trainings specialised in language or reading and were more experienced and more satisfied with their carreer had higher tests scores than their peers (Mullis et al., 2012, p. 185). The report enables international comparison but fails to relate the background data to achievement in different text formats.

In sum, the link between aspects of reading instruction and reading achievement has only been identified and confirmed by using instruments measuring reading achievement on continuous texts or by using aggregate mean test scores of subtests including different text formats. The present study aims to further examine the reasons underlying the achievement gap identified between students' reading test scores in different text formats revealed in the first empirical study in Chapter 4. 
In order to be able to obtain a better understanding of what and how particular aspects of reading instruction explain the difference in students' achievement in the continuous, mixed and non-continuous text formats, a background questionnaire was developed by incorporating knowledge about prevailing practices and factors previous research identified as crucial in reading development.

It has been a long-debated issue how the context of instruction and specifically which teacher- and classroom-related aspects affect students' achievement. The Coleman Report published by the US government in the second half of the 1960s showed that differences in students' family backgrounds were substantially associated with achievement. Variation in school quality, by comparison, showed little association with educational attainment (Coleman, Campbell, Hobson, McPartland, Mood, Weinfeld, \& York, 1966). Following works on the added value of school with respect to student achievement refuted this argument and cast light upon variables that matter. The quality of teachers' work is influenced by several internal and external factors. Some authors emphasize the importance of internal features such as personal characteristics, abilities, skills and motivation (e.g., Bernard, 1972; Deci \& Ryan, 1987), while others highlight external factors like school infrastructure, equipment, or the acts, rules and regulations providing a framework for teachers' work (e.g., Edmonds, 1983). Based on the results of studies focusing on educational added value, there are five factors that have an influence on teachers' productivity: (1) teachers' qualification, (2) teachers' practices, (3) classroom environment, (4) time spent on professional development, and (5) learning opportunities in and out of school (Kuger, Klieme, Jude, \& Kaplan, 2016). The present study endavours to examine these elements and their added value with respect to students' reading achievement in subtests representing different text formats.

\subsection{Teachers' background}

In the present study, teachers' gender, age, qualification, years spent in the teaching profession, years spent teaching and the satisfaction aspect of teachers' professional selfconcept are examined. Empirical studies often study the relationship between teachers' gender, age and student attainment. Teachers' gender is also in the focus of studies exploring the gender match phenomenon. According to the gender match hypothesis (Elley, 1994; Johnson, 1974), students perform better when taught by a same-gender teacher. However, results on this topic are controversial. Other studies highlight that teachers' gender affects teachers' perceptions of students and students' engagement with academic material and these factors also have to be taken into consideration when interpreting the relationship. Literature reviews revealed that no such studies have been conducted on the effect of teachers' gender, more specifically, a same-gender teacher on students' reading achievement. With respect to gender, studies have been warning for years that the Hungarian teaching profession has been characterized by an increasing number of female practitioners (Borbáth \& Horváth, 2012; Pongrácz \& Tóth, 1999). The aging teacher population has also been a cause for concern in OECD countries, including Hungary, and this tendency has not improved in the past decade (OECD, 2014c).

Several research has proven that school plays a key role in students' achievement and the impact of school can be largely attributed to teachers (Darling-Hammond, 2000) and their training and qualifications (see Ferguson, 1991). Studies conducted overseas on the relationship between teachers' qualification and students' reading achievement are not entirely conclusive but they lend support for a positive correlation between the two variables. Analyses with the data drawn from the National Reading Panel showed that students whose teachers acquired a master's degree and were fully certified had significantly higher reading 
test scores than those who were taught by teachers having earned a lower level qualification (Darling-Hammond, 2000).

Besides qualification, a commonly applied indicator of teachers' quality is the number of years spent teaching. Every profession views work experience as a relevant factor that contributes to an increase in knowledge, skills and productivity over the years (Rice, 2010). Therefore, it seems self-evident that the ever-growing body of experience accumulated over the years spent in the profession (i.e. learning through work, Smith \& Betts, 2000) has an increasing added value. One would expect that students of more experienced teachers perform better than students who are taught by less experienced educators. Nevertheless, Rice (2010) claims that the added value of experience can be detected in the first few years of teaching but it diminishes as the number of years spent in the profession increases. Time and experience can help as well as hinder teachers' work. Experience helps teachers to develop strategies and routines to easily cope with recurring problems and situations, but it can also inhibit the enhancement of professional competences, tackling new and unusual situations and the integration of innovative methods and tools. Since 2013 Hungarian education policy 2013 also attributes a critical function to the number of years spent in the profession, as it is a fundamental element in the teacher career path (326/2013. (VIII. 30.) Korm. Rendelet). I assume that data gained from the present research will show that students' reading achievement increases as their teachers' experience, represented by the number of years spent in the profession, grows.

Having a positive self-concept plays an important role in all fields of life and it bears special relevance in case of educators (Roche \& Marsh, 2002). Findings of Hungarian studies in this domain verify this argument. Self-concept determines how we see ourselves and therefore, it affects our behavior. Self-concept as a learnt motive has an impact on how much effort and energy we invest in a particular activity or how successful or unsuccessful we consider our actions (Szenczi, 2008, p. 104). It is well-known that students' self-concept influences students' reading achievement (Szenczi, 2013), but we have surprisingly little knowledge about the relationship between reading teachers' self-concept and students' reading achievement. This study does not aim at a full exploration of this domain. Thus, selfconcept is examined from the perspective of teachers' satisfaction with their work in the measured class.

\subsection{Aspects of teaching reading and reading development}

A large number of items are dedicated to the examination of particular aspects of teachers' practices in connection with reading development. This dimension of the study focuses on teachers' choice and use of instructional, assessment and teaching methods, techniques, textbooks, texts with different formats and ICT.

Adamikné Jászó (2006) argues that the root of the problems in students' reading skills and abilities partly lie in teachers' choice of inadequate reading methods and insufficient practice (p. 42). There are three fundamental teaching methods a teacher can build on (see Section 1.6.1). Followers of (1) the whole word or analytic method attribute meaning to the visual sight of the word. The words are then broken down into individual letters or groups of letters after being able to read a number of words as whole units and build up a larger vocabulary of whole words they can recognize. It is beneficial since students' comprehension develops more easily as decoding and developing fluency does not require any effort. However, learning to read with the whole word approach is very time-consuming. In the beginning students can only read texts containing words that they recognize. A further disadvantage of this method is that students are more likely to be mistaken by words that are spelled in a similar way. (2) The phonics or synthetic method starts from the opposite 
direction, from bottom up. It teaches individual letters representing sounds and then moves on to larger linguistic units such as syllables, words, sentences and texts. The advantage of this method is that it provides students with fast-paced progress even with relatively limited letter knowledge. The drawback is that students have to pay attention to letter recognition, fluency and extracting meaning at the same time. The popular (3) analytic-synthetic method tries to merge the advantages of the previous two methods. The question which method works better to teach children to read attracted the attention of many researchers in the $20^{\text {th }}$ century. In the US, Chall (1967) - a reading expert and psychologist - was the first to clear out the confusion surrounding the debate between phonics and the whole word method. After having conducted an overarching research, she concluded that phonics is a more effective method to teach reading because it gives a good grounding in phonemic awareness and speech-sound-letter association. However, she also recognized the benefits of the whole word method and eventually claimed that methods combining the two approaches are the most beneficial for children.

Having a well-developed reading technique is a prerequisite of reading comprehension (Nagy, 2004b). Its development may take the following forms: practicing a meaningful and expressive rendition of a text and oral and silent reading (Adamikné Jászó, 2006, p. 41). The development of reading techniques dates back centuries. In the past, oral literacy and oral reading were very important in people's everyday lives and this was also manifested in classroom practices. A commonly accepted form of teaching reading was reading aloud for a long time. At the time of the first IEA assessments teachers of reading considered a student a good reader if he or she could read a passage aloud fluently and expressively (D. Molnár et al., 2012). Nevertheless, the dominance of this approach started to decline and silent reading came to the forefront. Educational researchers started to question the importance of oral reading and argued that due to its strong emphasis on meaningful and expressive reading, it takes away time and attention from comprehension. They claimed that oral reading was to be blamed for the emergence of reading problems (Rasinski, Reutzel, Chard, $\&$ Linan-Thompson, 2011) ${ }^{1}$. Although the upcoming era brought along an exaggerated and unreasonably excessive practice of silent reading in many countries, nowadays all researchers and practitioners are aware that both methods have a unique contribution to reading development. Oral reading is an inevitable tool for teachers to provide feedback on students' strengths and mistakes in decoding and to improve fluency since during students' oral reading a teacher can hear and detect the bottlenecks (Gósy, 2008). Teaching and employing silent reading is also important but teachers have to introduce this technique to students gradually and they have to ensure a proportionate balance between oral and silent reading. Silent reading should by no means overshadow oral reading.

In addition to the methods and techniques, educational tools, methods of teaching and educational assessment help teachers meet the desired objectives.

The concept of educational tool encompasses a wide range of tools with different functions and usability (Petriné Feyér, 2003, p. 318). This study examines the use of second and third generation of educational tools (i.e. textbooks, online reading programs, interactive whiteboard, computer and internet) for teaching reading.

The past 30 years brought along a rapid growth in the accessibility and use of ICT. Their integration into the teaching and learning processes are more and more common. Results of TIMSS 2011 showed that schools supplied a huge amount of computer access to reform their education and implement innovative practices (Mullis, Martin, Foy, \& Arora, 2012). Data also demonstrated that Hungary belongs to the group of nations that offer students numerous opportunities to exploit the potentials of ICT at school. $70 \%$ of students

\footnotetext{
'Adamikné Jászó (2001) discusses a misbelief related to the issue: the opposition of meaningless oral a silent
} meaningful reading. 
attend a school where every first or second student has one computer (Fraillon, Ainley, Schulz, Friedman, \& Gebhardt, 2014). The impact of ICT on students' achievement came to the forefront of international research. Studies yielded various outcomes in this respect. Some revealed a positive while others reported on a negative relationship between the variables. But there are some studies that confirmed the null-hypothesis. According to a British research (BECTA, 2000) students' reading achievement was higher in schools with better ICT infrastructure. PIRLS confirmed these findings by concluding that students' reading achievement was higher in classes where there were computers available for use. This result contradicted authors' hypothesis that in lower grades computers are rather useful for intervention and development (Mullis et al., 2012). By contrast, analyses of NAEP data by Johnson (2000), and Berthelot, Ross, and Tremblay (2001) rejected the existence of a relationship between students' reading attainment and students' weekly use of computers during classes.

Technological development transformed the process of reading and brought along a new wave of expectations about reading. Being able to access information in an online environment mostly dominated by texts with non-linear structure and organization poses readers new challenges compared to paper-based reading. Information displayed on the screens can take many forms providing a great opportunity to becoming familiar with reading texts with different formats. We have data on how Hungarian schools are equipped with computers (see Hagymási \& Könyvesi, 2016; Molnár \& Pásztor-Kovács, 2015) but no information is available on the frequency primary school teachers integrate these and other ICT into the teaching and learning reading process and what they use these tools for let alone their impact on understanding texts with different formats.

It is a key element in today's teaching reading that educators provide students with the opportunity to read texts with a wide range of types and formats. During his first and second grade reading textbook analyses Turcsán $(1998 \mathrm{a}, 1998 \mathrm{~b})$ found that although non-literary works and texts offering students an opportunity to read for information are present in the textbooks, they are underrepresented compared to texts lending themselves to reading for pleasure. However, he made no mention of materials or texts of different formats helping teachers' work. As system-level assessments also endeavor to measure students' reading literacy in different text formats, the present survey also explored whether primary school teachers are familiar with the frameworks, test and reports of these assessments and whether they integrate this knowledge into their everyday practice. Drawing on Lord Kelvin's (1883) thought on measurement "If you can not measure it, you can not improve it.", I also integrated items related to teachers' assessment. Answers were sought about what types of assessments teachers use and how often they share the results with parents and consult them about students' reading progress.

\subsection{Conditions of teaching and learning reading}

Teachers' productivity also depends on the circumstances in which the teaching and learning process is embedded. By taking into consideration findings of mainstream research and often recurring and current issues in education policy, I embarked upon the examination of factors like the weekly number of literacy lessons, the number of students with special education needs in the classes and availability of intervention specialist.

The possibility of extending the foundational phase of elementary education and first language development through upper grades has been lingering among stakeholders of education policy for years (see Nagy, 2008). One of the fundamental questions of education policy is whether more is better, in other words, whether dedicating a longer period or higher number of lessons in formal education leads to better achievement. This study seeks to 
answer this question by linking the weekly number of reading lessons and second graders' reading achievement.

The pursuit of educational equity and the inclusion of students with special education needs brought the problems of students displaying reading and writing difficulties into the forefront of theory and practice. Providing a standard education for students with diagnosed disabilities poses a complex task for educational institutions (Torda, 2006, p. 207). The fast pace of today's reading instruction makes it more difficult to teach these children how to read.

In sum, results of scientific reading research has shown that it is very important to have up-to-date and detailed information about primary school teachers involved in teaching reading and about the aspect of the context in which the teaching and learning to read takes place. However, research activity in these domains is moderate especially in Hungary. A possible explanation for this is that since the 1960s reading research landscape was dominated by linguistic, psychological, psycholinguistic and applied linguistic approaches overshadowing the previously canonized practical and methodological directions that helped practitioners develop best practices for teaching students to read (Gósy, 2008). On the one hand, the present study aims to fill this gap. On the other hand, it seeks to identify those characteristics of school that matter in the development of reading continuous, mixed and non-continuous texts. Molnár's work (2006) on literacy in school provided an additional impetus to conducting this study. According to her, at the time her manuscript was published, school was still looking for ways to fulfil the requirements of a broad - with respect to text format and purposes of reading - interpretation of reading literacy. She claimed that although signs of reforms were visible, the notion of reading should be advanced and a shift from constraining it to engagement in literary fiction should take place. She wrote that the good intentions of textbook writers could already be seen but a more harmonized effort was required to bring them in tune with expectations. To my knowledge, no other studies have dealt with the problems Hungarian students face when it comes to understanding noncontinuous texts since then. The present research was also directed to map out whether the changes indicated by Molnár (2006) took place and whether their impact could be shown.

\subsection{Methods}

\subsubsection{Research questions}

1) How can teachers' characteristics, pedagogical skills, practices and conditions of teaching and learning be described?

2) How do teachers' characteristics, pedagogical skills, practices and conditions of teaching and learning impact second graders' reading achievement in different text formats?

\subsubsection{Participants}

Like in the previous two empirical studies, in this chapter we analyze data collected in the Hungarian Educational Longitudinal Program (Csapó, 2014). The student sample $(\mathrm{N}=3,220)$ described in Chapters 4 and 5 of the national assessment was selected to be representative by region, settlement type/settlement structure and gender. Reading teachers of second graders who formed the sample of the first and second studies were administered a questionnaire in order to collect information about their reading instruction affecting reading comprehension outcomes in different text formats. The questionnaire was filled out by 189 teachers teaching in 189 classes of 116 different elementary schools. Based on the corresponding data recorded by Eurostat (Eurostat database, 2017), the teacher sample is 
representative by age and gender. Data regarding the age and gender of the sample form part of the research, so they will be presented and discussed in the results section of this chapter.

\subsubsection{Data collection instruments}

For the purposes of the present study, data gained from two assessment instruments were used: (1) a reading literacy test (data from the same reading test was used I analyzed in the previous two studies) and (2) a teacher questionnaire.

\section{THE READING LITERACY TEST}

Students' reading achievement was measured by the online reading literacy test described in details in section 4.2.3.

\section{TEACHER QUESTIONNAIRE}

The teacher questionnaire collects information about aspects of reading instruction in grade 2 for a broader interpretation of the data on students' achievement in different text formats. Conforming to the practices of international assessment programs like NAEP, PISA, PIRLS run under the auspices of different bodies, the 47 items of the online questionnaire was designed to cover three major thematic units (Table 6.1).

The first section of the questionnaire elicited information about teachers' professional background (9 items). Attributes such as gender, age, level of qualification, the number of years spent teaching in general and teaching reading, the time spent reading for professional development and reading for pleasure as a pastime and satisfaction with their work in the assessed class were examined.

Table 6.1 The structure of the teacher questionnaire

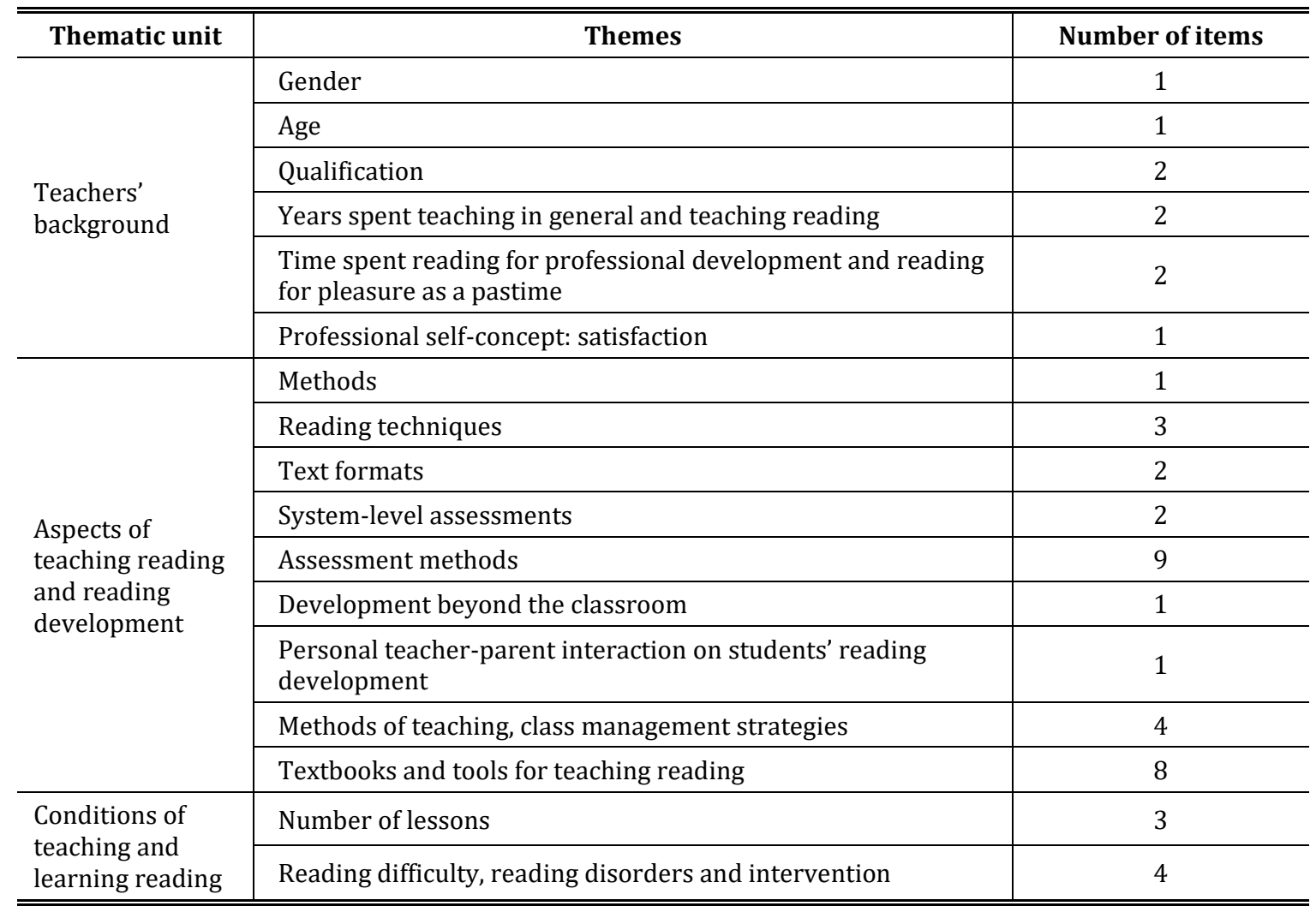


The second section of the instrument investigated aspects of teaching reading and reading development (31 items). Teachers were asked to respond to questions regarding the reading methods and techniques they use to teach pupils how to read, the instructional and evaluation methods they employed, the textbooks they used for instruction, the frequency of using continuous and non-continuous texts and ICT for teaching reading. Additional items regired answers regarding their opinions about the developmental level of students' decoding and reading comprehension and knowledge about and use of system-level reading assessment frameworks in their own syllabus.

The third thematic unit included seven items inquiring about the number of Hungarian reading, writing and composition lessons, the number of students in their class having reading difficulty or reading disability and opportunities for intervention and development.

The survey included close-ended items with dichotomous, multiple-choice and scaled questions making use of rating scales such as three-point, four-point and five-point scales. The full questionnaire appears in Appendix E.

\subsubsection{Procedures}

The survey was carried out in spring 2013 by means of the eDia platform (Electronic Diagnostic Assessment Platform; Csapó, Lőrincz, \& Molnár, 2012; Molnár, 2015). Teachers logged into the system with the OM ID and class ID (e.g., 2.a, 2.b). Teachers gave their responses with reference to the class/student population who took part in the reading assessment within a 6-week timeframe at time chosen voluntarily.

\subsubsection{Data analyses}

Descriptive statistics was used to describe the basic features of the assessed reading teacher population, valid percent figures were provided for each case. The answers given by teachers to the open-ended items were examined with content analysis. Frequencies in the particular age groups were compared by conducting $\chi 2$ tests. The relationship between the independent variables measured by the questionnaire and students' reading achievement was examined with independent two-sample t-tests or analyses of variance (ANOVA) depending on the scale. Independent two-sample t-tests were used to compare the means of two groups in case of the dichotomous items. The differences among the subsamples of the scale levels of non-dichotomous items were analyzed with ANOVA, and Tukey's-b or Dunnett's T3 tests depending on the results of the Levene statistic (Appendix F).

\subsection{Analysis and results}

The results are presented in two steps. First, descriptive information is provided following the three thematic units. Teachers' responses are analyzed item by item. Second, the results on the examination of the relationship between the backgorund variables and second graders' reading achievement in different text formats are presented.

\subsubsection{Descriptive statistics}

\subsubsection{Teachers' background}

Each and every teacher has unique personal characteristics that have an impact on the teaching and learning process and their productivity in terms of student achievement. Thus, in the first thematic unit of the questionnaire information was collected about teachers' demographic characteristics, qualification and work experience. 


\section{GENDER AND AGE}

In line with other studies (TÁRKI-TUDOK, 2010; OECD Education Database available at http://stats.oecd.org), the respondents were divided and grouped into four age groups in order to explore issues related to teachers' age: (1) younger than 30 years old, (2) teachers aged between 30-39, (3) 40-49, and (4) aged 50+. Similarly, ten year-intervals were used to describe the number of years spent teaching in general and teaching reading $(1-9,10-19,20-29,30-39 ; 40-49,50$ and above).

Data show that the vast majority of the respondents $(97.16 \%)$ is female and the average age of teachers is 47.47 ( $\mathrm{SD}=8.30$ years). The youngest respondent was 23 , the oldest respondent was 59 years old. The older age groups dominate the teacher population: $83.15 \%$ of the sample is older than 40 (34.24\% is between 40 and 49 and $48.91 \%$ is $50+)$, and only $4.89 \%$ is younger than 30 . Representatives of both genders can be found in each age group. The distribution of male teachers is similar in the younger populations: there is one male teacher in each of the first three age groups. Two male teachers can be found in the fourth age group including teachers older than 50 .

\section{THE NUMBER OF YEARS SPENT TEACHING IN GENERAL AND TEACHING READING}

As suggested by the frequencies exhibited by the age groups more experienced teachers constitute the majority of the sample. The average number of years spent teaching is 24.51 ( $\mathrm{SD}=9.79)$. The majority of respondents $(69.40 \%)$ had been teaching for more than 20 years at the time of the data collection (Figure 6.1). A relatively small proportion of the sample $(10.38 \%)$ had less than 10 years of teaching experience.

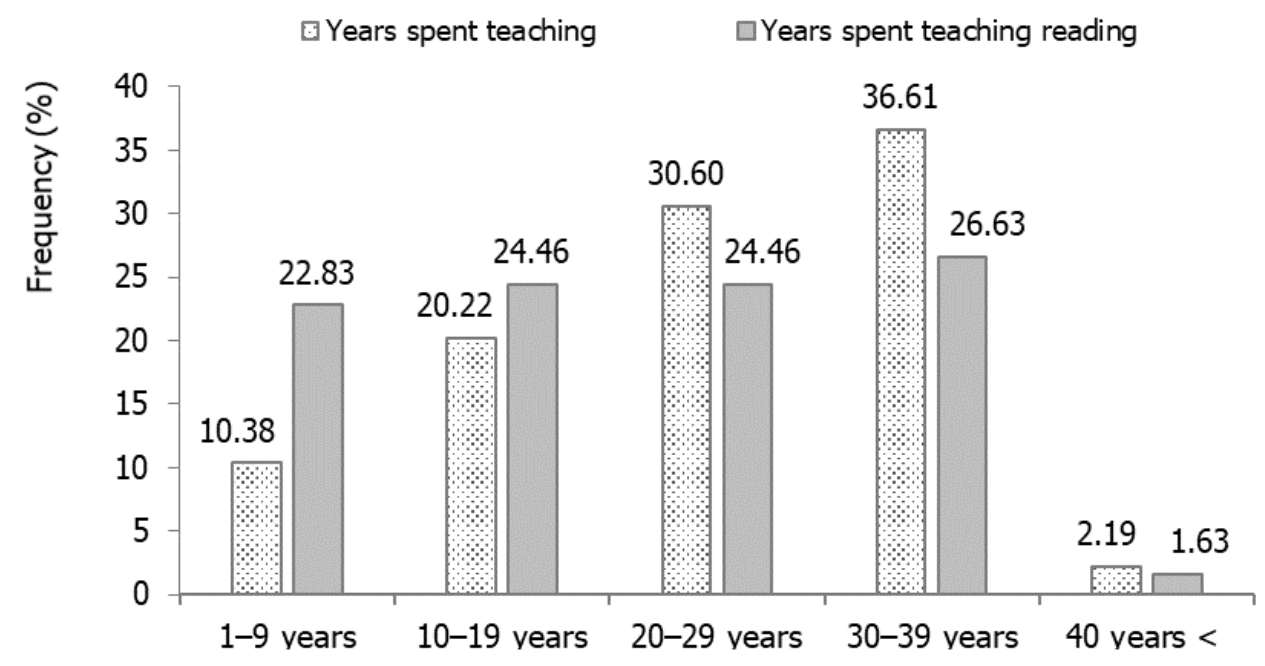

Figure 6.1. Years spent teaching and teaching reading

The surveyed teachers had been teaching reading for 20.24 years ( $\mathrm{SD}=11.15$ years) on average. The ratio of teachers having had a ten-year teaching experience in reading is $22.83 \% .1 .63 \%$ of the sample had been teaching reading for 40 years, and $2.17 \%$ for one year.

There is a strong correlation between number of years spent teaching and the number of years teaching reading $(\mathrm{r}=.96, \mathrm{p}<0.001)$. This confirms the pattern depicted by the frequencies that the majority of respondents had been teaching reading since the beginning of their teaching career. The number of years spent teaching reading also has a strong association with teachers' age $(r=.73, p<0.001)$, and the ten-year age group intervals $(r=.68$, $\mathrm{p}<0.001)$. Therefore, the age groups are used for further analysis. 


\section{QUALIFICATION}

Qualification is another factor influencing teachers' productivity and students' achievement. The data set is very homogenous in this respect as well. The largest part of the sample $(96.65 \%)$ completed their studies at a college, the remainder of the respondents $(3.35 \%)$ holds a university degree. There are not any teachers in the sample who earned a doctoral degree. All of the respondents $(100 \%)$ is a qualified primary school teacher, $3.70 \%$ has a Hungarian Language and Literature degree and 19.58\% earned a teacher degree and took part in formal teacher training specializing in other domains/subjects.

$78.09 \%$ of the surveyed teachers has primary school teacher qualification only. There are four teachers $(2.25 \%)$ in the sample who also holds a Hungarian Language and Literature and there are $32(17.98 \%)$ primary school teachers who completed other studies as well. The sample includes three educators (1.69\%) who earned three degrees (primary school teacher, Hungarian Language and Literature and other).

\section{TIME SPENT READING FOR PROFESSIONAL DEVELOPMENT AND READING FOR PLEASURE AS A PASTIME}

It is imperative that teachers continuously make efforts to be up-to-date and develop their knowledge accumulated during the teacher training either in an educational or in an everyday setting. Therefore, I also mapped out how much time teachers spend reading for professional development and reading for pleasure in their free time. In both cases, the most frequent answer was 2-3 hours a week. $49.72 \%$ of the respondents allocate this much time for reading for professional development and $42.31 \%$ spends $2-3$ hours a week reading for pleasure. There aren't any teachers in the sample who do not find time to enhance their professional knowledge by reading and altogether two teachers claimed $(1.12 \%)$ that they spare less than one hour a week for that. As far as reading for enjoyment in teachers' free time is concerned, data show that only one teacher $(0.55 \%)$ opts for activities other than reading in his/her free time. $7.69 \%$ of the respondents read for pleasure for less than one hour a week.

The proportion of teachers who spend one hour a week $(26.26 \%)$ and four hours or more $(22.91 \%)$ on enhancing their professional knowledge is similar. In case of reading for pleasure, there is a remarkable difference between the frequencies of these two categories. $12.64 \%$ of the respondents reads for pleasure for an hour a week on average, $36.81 \%$ does so for four hours or more than that.

\section{PROFESSIONAL SELF-CONCEPT: SATISFACTION}

The evaluation of teachers' own work, the extent they perceive it productive and efficient are indicators of their attitude towards their work, which in turn have an impact on the teaching and learning process and teachers' emotional state. Teachers were asked to rate on a four-point Likert scale (not at all, rather not, rather yes, a lot) how satisfied they were with the work done in the class that took part in the reading assessment in grade 2. Data yielded by the survey show that on the whole, the respondents are satisfied, the average level of satisfaction is $3.12(\mathrm{SD}=.43) .15 .85 \%$ of the sample was very satisfied, $80.33 \%$ was rather satisfied and $3.83 \%$ was not really satisfied. There were no teachers who responded very negatively in terms of their satisfaction with the work conducted in the class.

\subsubsection{Aspects of teaching reading and reading development}

\section{METHODS}

Methods are the backbone of teaching reading (see Chapter 1). Literature generally distinguishes three methods: (1) the whole word or sight word or look and see method, which applies an analytic approach (2) the phonics method, which employs a synthetic approach, 
and (3) the combination of the previous two methods called the analytic-synthetic method (Adamikné Jászó, 2006). According to Adamikné Jászó, the analytic-synthetic approach, which appeared in the middle of the $19^{\text {th }}$ century, is the most efficient method to teach reading in Hungarian $(2006$, p. 93, 95). In the study, teachers were asked to provide information on the method they employed to teach their second graders to read. 155 answers were analyzed with content analysis. Results show that $48.00 \%$ of teachers claimed they used the analytic-synthetic method, $38.29 \%$ used the synthetic method and $2.29 \%$ relied on the principles of the analytic method. $11.43 \%$ of the answers were ambiguous and because of their openness to multiple interpretations they were not included in the analysis.

\section{READING TECHNIQUES}

The question how often teachers employ different reading techniques during the reading lessons was also addressed. The items collected data on the frequency of students' oral and silent reading and the frequency of teachers' reading aloud to their students. $41.44 \%$ of teachers responded that they read lengthy passages aloud to students once or twice a week, $39.78 \%$ 3-5 times a week. $18.23 \%$ engaged in this activity more than five times a week.

There are many well-known oral reading techniques used for the development of students' reading fluency (Józsa et al., 2015). There were no teachers in the sample who did not use oral reading in their teaching at all. $47.25 \%$ of teachers used this technique once or twice a week. $28.57 \%$ resorted to oral reading 3-5 times a week and $24.18 \%$ of them asked students to read aloud more than five times a week. Similarly to oral reading, silent reading is also applied by every respondent with alternating frequencies: $36.07 \%$ more than five times, $28.96 \%$ 3-5 times, $34.97 \%$ once or twice a week.

These data were also examined in relation with the age groups (Table 6.2). Results show that there is a difference between the frequency of reading aloud by teachers who are younger and older than $40.55 .56 \%$ of teachers younger than 30 read longer texts aloud between three and five times a week, $11.11 \%$ did so more often than that. In the age group that includes teachers who are between 40 and 49 , this proportion is $43.33 \%$ in case of the 3-5 times a week category and $15.00 \%$ in case of the more than five times a week category.

Table 6.2 Frequency of using reading techniques in teachers' age groups a week (\%)

\begin{tabular}{c|c|c|c|c|c}
\hline \hline Age group & Reading technique & Never & Once or twice & $\begin{array}{c}\text { Three to five } \\
\text { times }\end{array}$ & $\begin{array}{c}\text { More than } \\
\text { five times }\end{array}$ \\
\hline \multirow{3}{*}{$<29$} & Teacher reads aloud & & 33.33 & 55.56 & 11.11 \\
\cline { 2 - 6 } & Student oral reading & & 55.56 & 22.22 & 22.22 \\
\cline { 2 - 6 } & Student silent reading & & 55.56 & 22.22 & 22.22 \\
\hline \multirow{3}{*}{$30-39$} & Teacher reads aloud & & 23.81 & 57.14 & 19.05 \\
\cline { 2 - 6 } & Student oral reading & & 38.10 & 33.33 & 28.57 \\
\cline { 2 - 6 } & Student silent reading & & 38.10 & 33.33 & 28.57 \\
\hline \multirow{3}{*}{$40-49$} & Teacher reads aloud & & 41.67 & 43.33 & 15.00 \\
\cline { 2 - 6 } & Student oral reading & & 51.61 & 25.81 & 22.58 \\
\cline { 2 - 6 } & Student silent reading & & 41.94 & 20.97 & 37.10 \\
\hline \multirow{3}{*}{$50<$} & Teacher reads aloud & 1.16 & 45.35 & 31.40 & 22.09 \\
\cline { 2 - 6 } & Student oral reading & & 47.06 & 29.41 & 23.53 \\
\cline { 2 - 6 } & Student silent reading & & 29.07 & 33.72 & 37.21 \\
\hline \hline
\end{tabular}


The proportion of teachers who employed the technique of oral reading with their students more than 5 times are similar in each age group $(22.22,28.57,22.58,23.53 \%)$. The majority of teachers $(55.56,38.10,51.61,47.06 \%)$ used oral reading once or twice a week. Silent reading was most frequently applied by teachers older than $50.70 .93 \%$ of them used this technique more than three times a week. Teachers in the younger age groups typically use silent reading with their students once or twice a week.

\section{TEXT FORMATS}

The National Core Curriculum (Nemzeti alaptanterv, 2012) regulates the use of texts with different formats in the process of teaching reading, but it does not include any other tangible criteria in this respect. For example, it does not specify the extent these should be included in teachers' syllabi and it does not define the frequency of integrating these formats in the teaching process either. Therefore, for a more profound understanding of students' achievement, information was collected about how often teachers use continuous and noncontinuous texts for teaching reading. Data show that working with continuous texts is widespread among the respondents. Every single teacher used them in their teaching practice with their second graders. $24.73 \%$ used them once or twice a week, $56.59 \%$ three to five times a week, $18.68 \%$ used them more often than that. Using non-continuous texts was less prevalent. $8.84 \%$ of teachers (16 teachers) claimed that they had never used non-continuous texts for teaching reading in the assessed class. $81.77 \%$ used them once or twice a week, $6.63 \%$ 3-5 times and $2.76 \%$ (5 teachers) used them more often than five times a week.

Including the age groups in the analysis show similar tendencies in the frequencies of using continuous and non-continuous texts in the four age groups. The majority of respondents work with continuous texts three to five times a week, whereas non-continuous texts are only used once or twice a week (Figures 6.2 and 6.3). Data show no significant difference among the age groups in the frequency of using continuous or non-continuous texts (continuous text: $\chi^{2}=.113 p<.990$; non-continuous text: $\chi^{2}=1.704 p<.636$ ).

\section{SYSTEM-LEVEL ASSESSMENTS}

I also explored whether teachers' knowledge about various system-level assessments (NABC, PIRLS, PISA) is associated with the frequency teachers use texts with different formats for teaching reading. Research conducted by Tóth (2015) focusing on teachers' assumptions about the National Assessment of Basic Competencies and about the effect of their results on the teaching practice served as a basis for including this idea in the study. According to her, teachers commonly use the method of teaching to the test and their work tends to be heavily focused on student preparation for system-level assessments. Thus, I assumed that teachers of reading who are more knowledgeable in this domain use a greater variety of text formats; the sample items and tests may provide additional guidelines for broadening their syllabi. However, data did not support this assumption.

The frequency of using continuous and non-continuous texts is similar among teachers who are familiar with and those who do not know anything about system-level assessments. Although one plausible explanation may be derived from Adamikné Jászó (2006) claiming that that textbooks are more and more aligned with the requirements of system-level assessments in terms of text formats and reading processes, more recent research-based information would be necessary to validate this. 


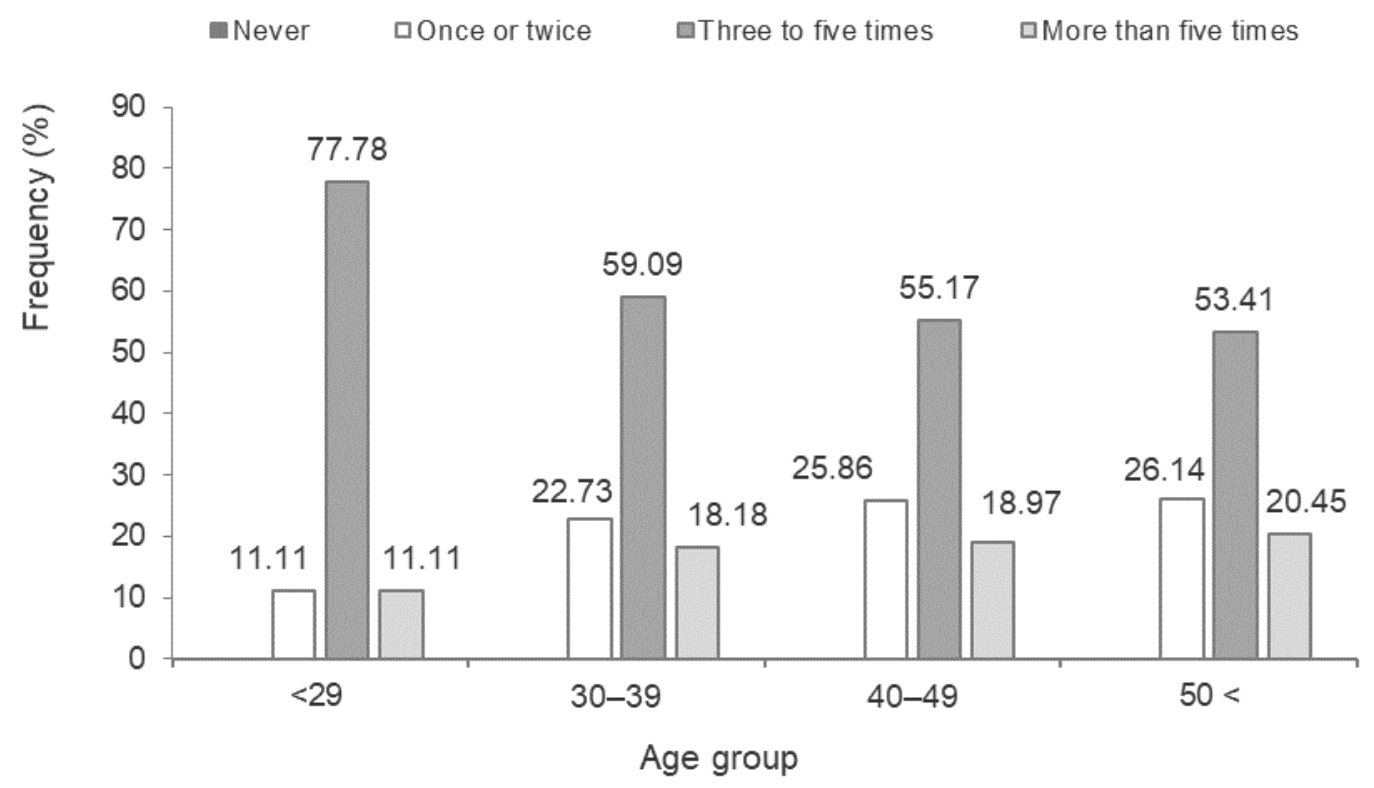

Figure 6.2. The frequency of using continuous texts for teaching reading a week in the different age groups

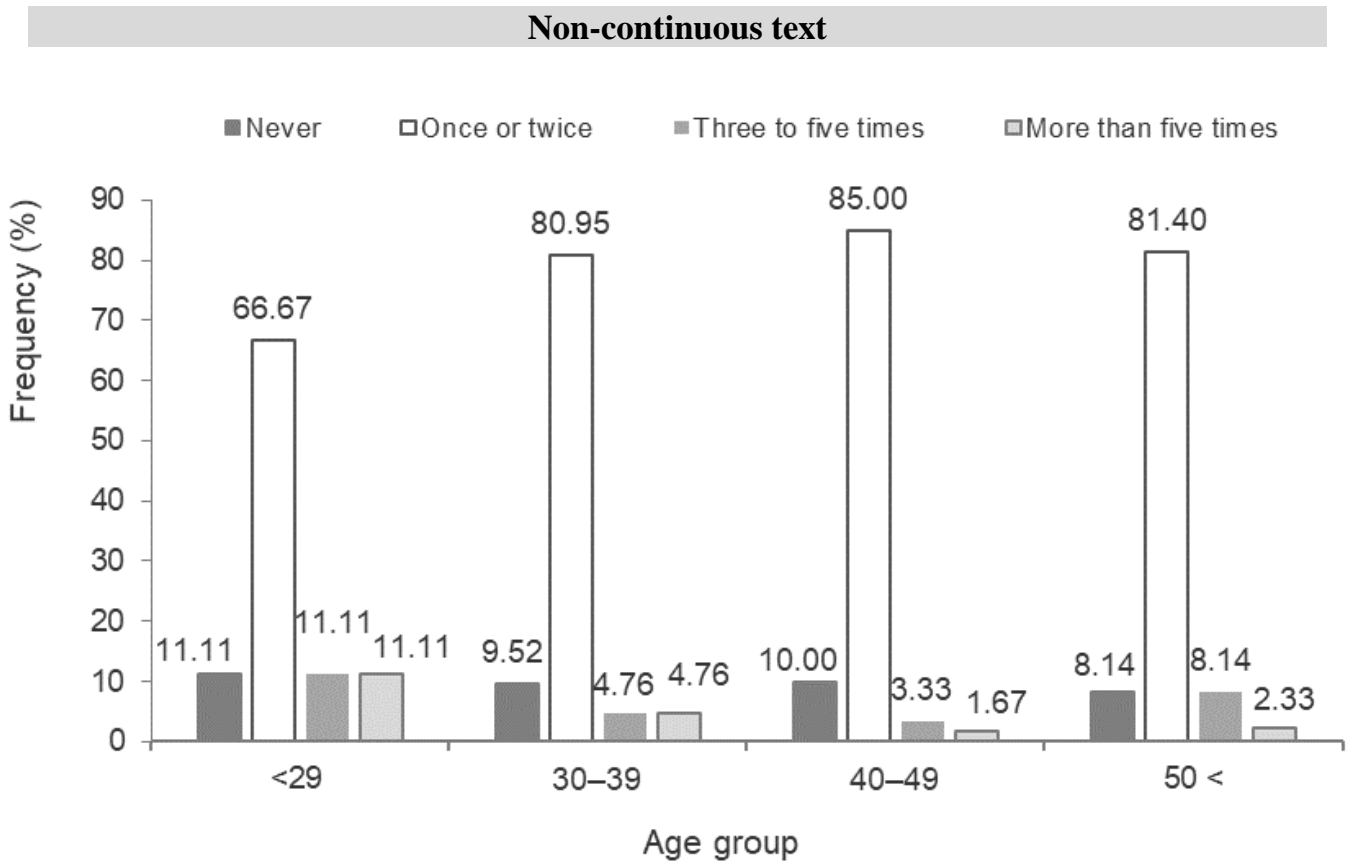

Figure 6.3. The frequency of using non-continuous texts for teaching reading a week in the different age groups

Data show that $42.86 \%$ of teachers enrich their work with any kind of information available on or from system-level assessments. Teachers were also asked to give reasons for their yes or no answers. 45 teachers explained why they opted for the yes answer, while 30 of them gave detailed information about the reasons for not integrating knowledge about system-level assessments into their work. The reasons for yes were put into eight different 
categories, whereas the reasons for no answers were placed into five different categories. The main reasons for using system-level assessment information for teaching reading are: to familiarize students with new, other types of texts and tasks (35.62\%), to integrate them into developmental and interventional programs, and to use them for individual developmental plans $(33.25 \%)$. A smaller proportion of teachers argued that they used the information accumulated by system-level assessments for the assessment of students' reading development (8.93\%). $6.67 \%$ of them drew on these resources because they found them interesting and useful. Another $6.67 \%$ responded that they integrate system-level assessment information into their work because of the main profile of the educational institute they work at. $4.43 \%$ claimed that they used this type of information for lesson planning but do not make students complete the reading tests developed by system-level assessment programs. Yet another two teachers $(4.43 \%)$ said that they made their own reading tasks based on these assessments.

When giving reasons for the no answers, most arguments evolved around lack of time (33.29\%). $30.04 \%$ of teachers claimed that due to the poor reading skills of students in their class they could only progress slowly and that way they did not have any time for additional activities. Three respondents $(9.90 \%)$ considered the application of the information gained from system-level assessments appropriate and useful from grade 4 on. Five teachers $(16.61 \%)$ were not familiar with system-level assessments and two of them (6.72\%) maintained that their lack of ICT-literacy or lack of school infrastructure prevented them from using system-level assessments in the teaching and learning process. One teacher (3.44\%) explained that: "I did not consider testing to be important in grade 2. I developed reading fluency and reading comprehension.” [,2. évfolyamon nem tartottam fontosnak még a tesztelést, a biztos olvasást és szövegértést fejlesztettem.”]

\section{ASSESSMENT METHODS}

As one of the objectives of the longitudinal program is to collect information on which intervention can be planned and how students' development can be shaped, the assessment methods used by primary school teachers were also investigated. Teachers could tick multiple options in terms of the assessment methods. Teachers' answers yield evidence that the most traditional assessment methods are used the most often: paper-based assessment instruments made by teachers themselves $(94.62 \%)$, oral assessment $(90.86 \%)$ and assessment instruments included in the textbooks $(88.17 \%)$. The student portfolio $(7.53 \%)$ and computer-based assessment instruments (13.98\%) proved to be the least preferred by teachers.

As a reading test was also administered to second graders parallel to the questionnaire filled out by teachers, and students' experience in testing may influence reading achievement, an item regarding the frequency of employing reading tests was also included in the questionnaire. Data show that the majority of teachers $(70.33 \%)$ did not use reading tests every single week for assessing students' reading developmental level, one quarter $(25.27 \%)$ of the sample used reading tests once a week, $3.85 \%$ of the respondents used these 2-3 times a week and $0.55 \%$ (one teacher) administered reading tests during every reading lesson.

In addition to the information gained by relatively objective assessment instruments, teachers often rely on the experiences, opinions and impressions gained during their interaction with their students. Thus, I also asked teachers' opinion about their students' developmental level of decoding and reading comprehension. Most respondents had a positive view of their students' decoding $(71.82 \%)$ and reading comprehension $(64.57 \%)$, so they agreed or strongly agreed that their students were good in these domains. To the question inquiring about decoding, altogether two teachers $(1.10 \%)$, whereas to the question 
regarding reading comprehension three teachers $(1.71 \%)$ expressed a very negative opinion about their students' developmental level and claimed that they were not good at all at these skills.

\section{DEVELOPMENT BEYOND THE CLASSROOM}

Besides the assessments, students' reading development can also be supported and advanced by means of tailor-made interventions outside the classroom (Hódi et al., 2015). The answers given to the question exploring the time teachers allot weekly to develop their students' reading skills beyond the classroom ranged between one and ten hours. Most of the teachers spend one (36.22\%) or two hours (35.14\%) a week on this. There weren't any teachers who do not engage in their students' extra development.

\section{PERSONAL TEACHER-PARENT INTERACTION ON STUDENTS' READING DEVELOPMENT}

The home environment, parental support, parent-child joint activities, and the cooperation of parents and teachers are all potential sources of children's development. In this sample, teachers typically (53.04\%) consulted parents once or twice a month. $14.36 \%$ of the respondents discussed students' reading development with parents more frequently, i.e. more than three times a month, but nearly one third of them (32.04\%) did not consult parents about this issue on a monthly basis but less frequently.

\section{METHODS OF TEACHING, CLASS MANAGEMENT STRATEGIES}

With the aim of mapping out methods of teaching, teachers were asked to rank frontal teaching, group work, pair work and role-play according to the frequency of their use. Data show (Figure 6.4) that frontal teaching is the most frequently used methodology. Most of the teachers $(42.93 \%)$ ranked frontal teaching first. Frontal teaching is followed by group and pair work (31.91\% and $21.93 \%)$. Role-play took the last position in the rankings $(4.28 \%)$. The least frequently used method having been ranked fourth besides role-play $(46.52 \%)$ is frontal teaching $(31.52 \%)$. This suggests that more and more teachers favor and apply methods of teaching other than the traditional, frontal method.

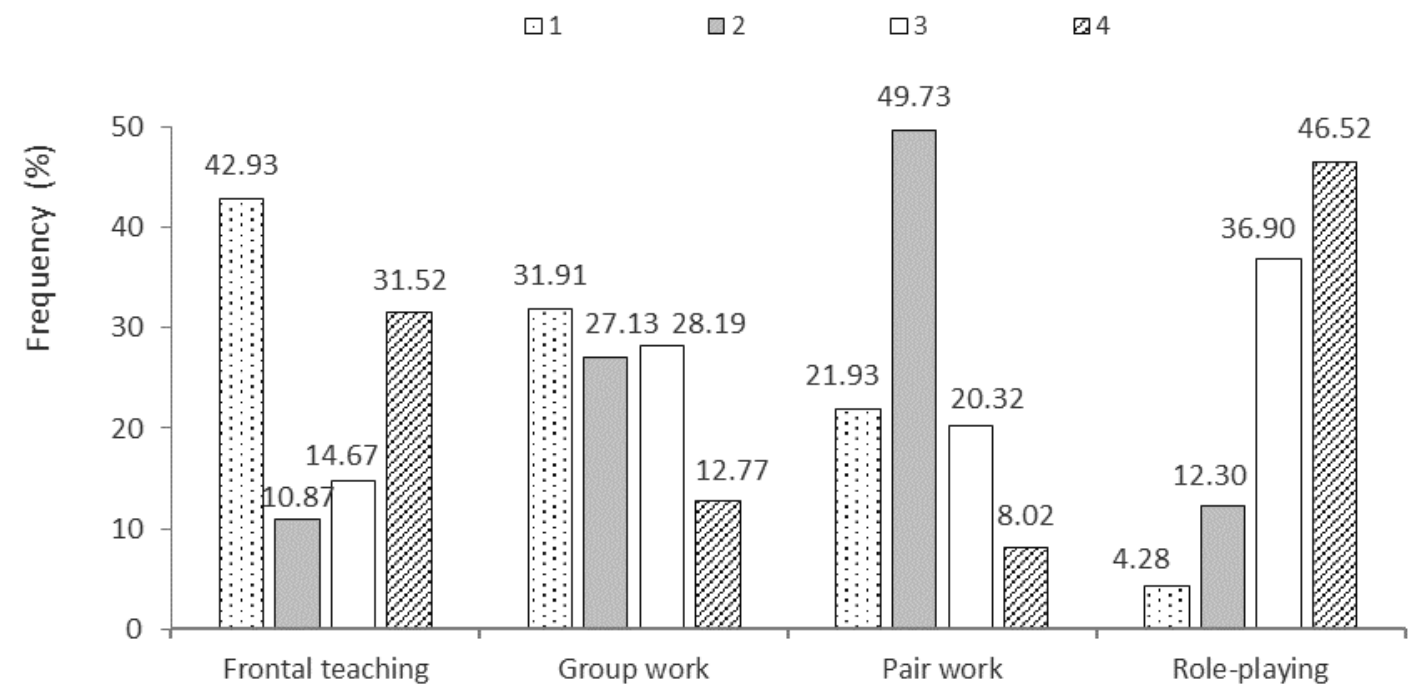

Figure 6.4. The frequency of using different teaching methods based on teachers' ranking

A similar tendency emerges regarding the frequency of use of teaching methods in every age group. There is no significant difference between the frequency of use among the age groups except for role-playing (frontal teaching: $\chi 2=2.542 \mathrm{p}<.468$; group work: 
$\chi 2=3.265 \mathrm{p}<.353$; pair work: $\chi 2=5.134 \mathrm{p}<.162$; role-playing: $\chi 2=9.366 \mathrm{p}<.025$ ). Roleplaying is the least frequently used method of teaching in every age group except for the age group including teachers above 50. Role-playing was ranked fourth by $66.67 \%$ of respondents younger than 30 . It received the same position from $61.90 \%$ of teachers aged $30-39$, and $54.84 \%$ of teachers aged $40-49.37 .78 \%$ of teachers above 50 marked roleplaying as the least frequently used method of teaching. It is in the subsample containing teachers younger than 30 where role-playing is the most and least preferred method of teaching (66.67\% of them ranked it fourth, $11.11 \%$ ranked it first).

\section{TEXTBOOKS AND TOOLS FOR TEACHING READING}

Nowadays the written pieces of information needed for a successful academic and everyday life appear in a printed and electronic environment alike. Students have to acquire the skills enabling them to comprehend texts in both print and electronic format. Textbooks and ICT help them to do so. Teachers were asked to provide bibliographic information on the textbooks they had used to teach reading (the data collection took place at the time of a plural textbook market). Since the answers were in many cases incomplete and in some cases, extremely complex, I categorized them based on the publisher. Data show that Apáczai Kiadó had a dominant role in the market: $52.49 \%$ of the sample preferred textbooks published by Apáczai. The second most popular reading textbooks among teachers were those published by Nemzeti Tankönyvkiadó (17.68\%). This is followed by Mozaik Kiadó with $11.60 \%$. The proportion of teachers using textbooks from other publishers is under 10.0\%: Dinasztia Tankönyvkiadó (7.18\%), Müszaki Kiadó (3.31\%), ROMI-SULI (2.76\%). However, there were teachers ( $4.97 \%$ of the total sample) who reported on a textbook change and taught from textbooks issued by different publishers in each grade.

Data on using ICT for teaching reading show similar patterns in case of the frequencies of interactive whiteboard and computer use per week. Nearly half of the teachers (46.20 and $46.52 \%$ ) had never used these tools for teaching the students assessed in the longitudinal program to read. $28.80 \%$ reported having used the interactive whiteboard more than three times a week. This proportion was $19.79 \%$ in case of the computer use. Using the internet for teaching reading was not common either. $15.63 \%$ of the respondents used it 3-5 times a week, and $13.54 \%$ used it more often than that. While half of the respondents had never used the interactive whiteboard and the computer during the reading classes, the proportion of teachers who had never integrated the possibilities offered by the internet is much smaller: 9.38\%. As teacher-training institutions have increasingly been incorporating ICT and innovative teaching methods into their curricula recently, one would expect that younger teachers use digital technology to a larger extent. Nevertheless, the examination of this phenomenon in the different age groups yielded no clear pattern in this respect. Data show that irraespective of age, the respondents underutilize ICT.

89 teachers answered the open-ended question regarding the purposes/reasons of computer use in teaching reading. A large number of answers contained a complex description and included more than one activity. Content analysis was conducted to interpret the heterogeneous data. Ten coding categories were derived directly from the data set. The three most frequent reasons for using computers during the reading classes were audiovisual support/illustration (48.32\%), collecting new information and more knowledge (40.38\%), and the use of interactive and digital materials and educational supplementary materials $(31.53 \%)$.

The answers reflect that the audiovisual support include teachers' presentations, showing pictures ("looking at pictures, which help students imagine the world at present and at that time" [,,képanyag megtekintése, amely segítséget jelent a világ, az akkori világ elképzeléséhez"], illustrations, tales and films, listening to music and literary works of art. 
The category of collecting new information includes looking up information in connection with the read materials, looking up unknown words and searching for synonyms, biographies of writers and poets. The following verbatim quotes give examples about teachers' explanations about what and in what circumstances they used these tools for.

\begin{abstract}
"I am in a lucky position because there is an own laptop and interactive whiteboard in my classroom, so we used these almost on a daily basis in grade 2 . I received interactive material to the Hungarian language and literature textbooks. I used this for reading and comprehension activities and teaching composition writing. We also did a lot of playful tasks and solved many puzzles available on the internet.” [,,Szerencsés helyzetben vagyok, mert az osztályomban van egy saját laptop és interaktív tábla, így ezeket szinte napi rendszerességgel használtuk 3. osztályban. Interaktív tananyagot kaptam a magyar irodalom és nyelvtan tankönyvekhez. Ezt használtam olvasás, szövegértés, nyelvtan tevékenységekhez, illetve fogalmazástanításhoz. Sok játékos feladatot, rejtvényt is megoldottunk az interneten találhatók közül.’]

"There is neither an interactive board nor a computer in our classroom. As we work in full-time education, in the afternoons we often get into the computer laboratory, where we carry out research on the internet. The classes have student laptops with educational supplementary material installed, we use these many times.” [„A tantermünkben nincs interaktív tábla és számítógép sem. Mivel egész napos oktatásban dolgozunk délutánonként, gyakran jutunk be a számítógép terembe, ahol interneten kutatómunkát végzünk. Az osztályoknak van tanulói laptopjuk, melyre feltelepített oktatási segédanyag is van, ezt sokszor használjuk.”]
\end{abstract}

A relatively large proportion of teachers used computers to make and edit tasks, and allow students to complete computer-based reading and comprehension tasks and tests $(22.47 \%)$. The same proportion of teachers used computers for intervention and nurturing talent $(22.51 \%)$. Some answers give evidence that computers were also used by students to carry out research individually or as part of a team (9.00\%). $2.17 \%$ used computers for cooperative learning, $2.17 \%$ used them for writing and yet another $2.17 \%$ used it for differentiated instruction.

I also asked teachers whether the second graders who completed the online reading literacy test had reading lessons in a computer lab and whether in these cases students had the opportunity to use the computers. In line with the figures on ICT use reported earlier, data show that more than one third of teachers $(34.00 \%)$ held a reading lesson in a classroom equipped with computers and most of the time (97.00\%), with very few exceptions students worked on the computers. Using computer labs for teaching reading was more prevalent among teachers over 40 than in the younger age groups (younger than 30: 0.00\%, 30-39year-olds: $9.38 \%$, 40-49-year-olds: $46.88 \%$, older than 50: 43.75\%).

Knowledge about programs, softwares and applications is a prerequisite for integrating digital methods into education. Data show that $36.02 \%$ of the sample know reading softwares available on the internet, but only $47.69 \%$ of them (16.40\% of the total sample) had actually used them in the classes that took part in the reading assessment. Breaking down the analysis into age groups yield evidence that more teachers used such programs in their work in the two older age groups (i.e. teachers above 40): younger than $30: 6.67 \%$; 30-39year-olds: $6.67 \%$, 40-49-year-olds: $40.00 \%$, above 50: $46.67 \%$.

\title{
6.6.1.3 Conditions of teaching and learning reading
}

\section{NUMBER OF LESSONS}

I also examined how many lessons per week second graders have in subjects focusing on language and reading development. Teachers included in this survey had $3.47(\mathrm{SD}=.53)$ reading lessons, $1.41(\mathrm{SD}=.74)$ writing lessons and $1.31(\mathrm{SD}=.65)$ composition lessons a week on average. Frequencies also indicate that the weekly number of writing and composition lessons were low in the classes taught by the respondents (Figure 6.5). 


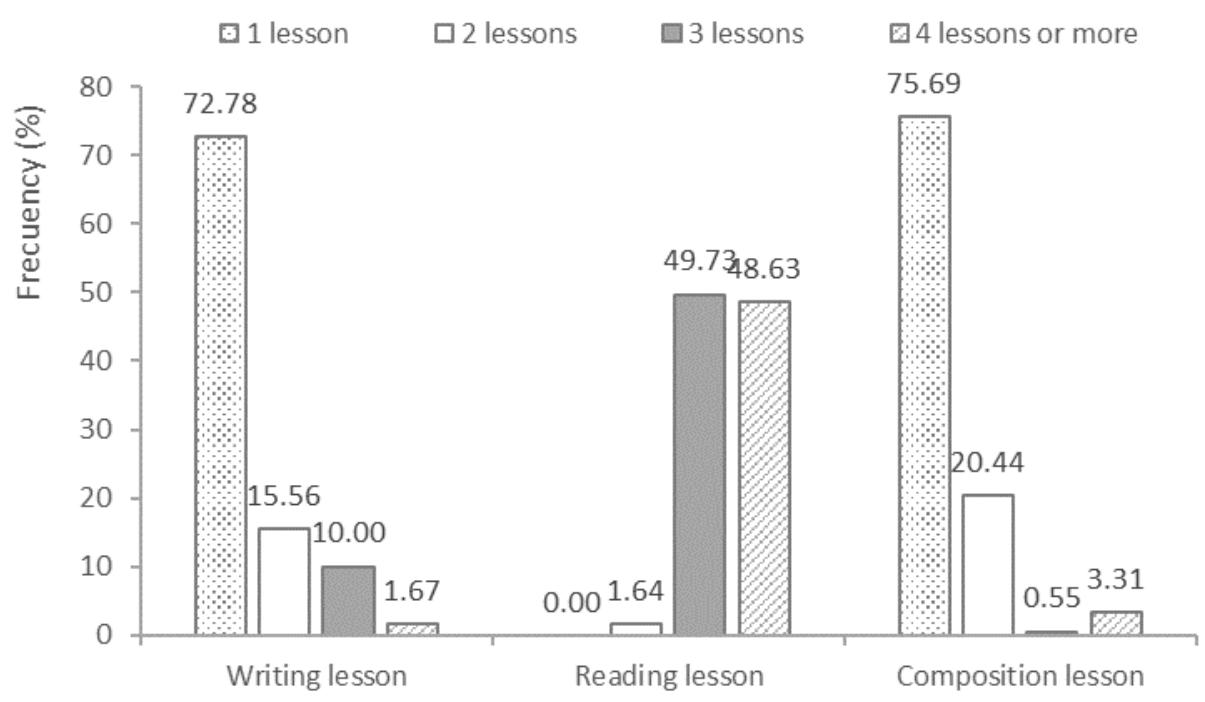

Figure 6.5. Frequencies of weekly first language acquisition lessons

The answers show that in the vast majority of cases $(98.36 \%)$ the number of reading lessons held a week is three or more. Three lessons are held by $49.73 \%$ of the sample, while four or more reading lessons are held by $48.63 \%$. Only a slim proportion (1.64\%) of teachers reported having two reading lessons a week with the measured class and there is no teacher in the sample who only had one lesson a week dedicated to teaching students how to read. An inverse tendency can be observed in case of the writing and composition lessons. One writing lesson was held a week by $72.78 \%$ of teachers and one composition lesson was held by $75.69 \% .11 .67 \%$ had three or more writing lessons a week, whereas $3.87 \%$ held three or more composition lessons a week. Cross-tabulation analysis showed that on average teachers have about one writing and composition writing lesson and three or four reading lessons.

\section{READING DIFFICULTY, READING DISORDERS AND INTERVENTION}

One of the most challenging tasks of teachers is to deal with students' individual differences. Teachers act as primary filters for the identification of reading difficulty and disorders. Many studies have suggested that children who have a delayed reading development also show a weakness in speech perception. Therefore, teachers were asked how many of their students experience difficulties with speech perception. The answers, which could be based on an experts' or specialists' official diagnosis or teachers' observations, reveal that no such problems were present or detected in the classes of $13.66 \%$ of the respondents. In $38.80 \%$ of the cases a maximum of three, in $47.54 \%$ of them four or more students had difficulty with speech perception. $4.37 \%$ of respondents (eight teachers) reported having an outstandingly high number of students (10-20) in the measured class who display difficulty in this domain.

Tailoring instruction to meet the needs of each and every individual in the classroom poses yet another challenge for educators. Regarding the number of dyslexic students in the class, data show that there was no student who suffered from reading disabilities in $58.89 \%$ of the respondents' classes. $34.44 \%$ of teachers taught in classes with a maximum of three dyslexic students but there were teachers who reported on teaching in a class where four or more students with reading disabilities attended (6.67\%). Altogether $1.67 \%$ of teachers reported having had six or seven dyslexic children. 59.15\% of students displaying problems receive targeted intervention or take part in specialized developmental programs. In the vast majority of these cases (94.03\%), teachers were assisted by a specialist as prescribed by law. 
The data on the occurrence of reading disorders are only quantitative indicators. Since students are affected to varying degrees, and dyslexia occurs on a continuum from mild to severe, more information on the condition would be necessary to link this data to students' reading achievement.

\subsubsection{The relationship between aspects of reading instruction and second graders' reading achievement in the continuous, mixed and non-continuous subtests}

As the dissertation revolves around the issue of achievement differences in the continuous, mixed and non-continuous subtests, the next step was to explore the impact of the measured background variables on the subtest scores.

In the analyses second graders' reading literacy is represented by the mean test scores achieved in the continuous, mixed and non-continuous subtests. I do not conduct comparison analysis with variables in terms of which the sample is highly homogenous (e.g., teachers' gender $-97.16 \%$ of primary school teachers teaching the assessed second graders to read is female). Furthermore, the impact of factors inherently resulting in a difference in students' achievement - such as the number of dyslexic children in a class or assistance given by intervention teachers - are not examined.

\subsubsection{Teachers' background}

Analysis of the relationship between teachers' age and students' achievement in the continuous, mixed and non-continuous subtests show a significant positive association between the variables $\left(F_{\text {cont. }}=3.089, p<.026 ; F_{\text {mixed }}=7.353, p<0.000 ; F_{\text {non-cont. }}=5.760, p<.001\right)$. However, post hoc multiple comparisons tests could only show which groups differ significantly in case of the continuous and mixed subtests. Teachers' age shows a different impact on students' achievement in the continuous and mixed subtests, but data also reveal a common pattern: students of teachers aged between 30-39 have the poorest performance in both of the subtests. It is also noteworthy that in case of the continuous text traditionally associated with reading, only students of teachers aged between 20-29 managed to attain significantly better reading test scores, whereas in case of the mixed subtest in addition to students of the youngest teacher population, students of the two oldest teacher subsamples outperformed the rest of their peers. Descriptive statistics revealed that teachers younger than 30 are more open to using non-continuous texts; however, the occurrence of texts with non-traditional formats is still very rare in teaching reading. Maybe this explains why analysis conducted on the non-continuous test scores did not show where the difference lies among the subgroups established by teachers' age.

Years spent teaching also cast light upon some remarkable differences across the dimensions of reading literacy if students' achievement in the different subtests are included in the post hoc multiple comparisons analyses as dependent variables. In case of the continuous and mixed subtests, subgroups of students whose teachers had been teaching for a maximum of ten years and students whose teachers had been in service between 20 and 29 years achieved higher test scores, whereas in case of the non-continuous subtest each subgroups of students performed significantly better than those whose teachers had been teaching for more than 40 years $\left(\mathrm{F}_{\text {cont. }}=4.589, \mathrm{p}<.003 ; \mathrm{F}_{\text {mixed }}=13.666, \mathrm{p}<.000\right.$; $\mathrm{F}_{\text {non- }}$ cont. $=17.949, \mathrm{p}<.000)$. It is possible that the late appearance of non-continuous texts in textbooks and teaching reading explains the tendency witnessed in case of the noncontinuous subtest. Years spent teaching show similar tendencies to those revealed by the examination of years spent teaching when contextualizing reading achievement $\left(\mathrm{F}_{\text {cont. }}=5.506, \mathrm{p}<.001 ; \mathrm{F}_{\text {mixed }}=8.410, \mathrm{p}<.000 ; \mathrm{F}_{\text {non-cont. }}=10.762, \mathrm{p}<.000\right)$.

Examining students' achievement in the three subtests in light of teachers' qualification showed that this independent variable accounted for the variance in students' 
achievement in the mixed $(\mathrm{F}=2.926, \mathrm{p}<.033)$ and non-continuous $(\mathrm{F}=9.341, \mathrm{p}<.000)$ subtests. Post hoc multiple comparisons tests showed where the difference lies only in case of the non-continuous subtest. Achievement does not change linearly with the increase in the number of completed degrees. Students whose teachers attained a Hungarian Language and Literature degree in addition to the lower primary teaching degree achieved significantly higher test scores, but achievement of students whose teachers also earned a qualification in yet another major besides the aforementioned ones did not differ significantly. Besides the potential that three majors do not have an extra added-value in teachers' productivity, the low number of cases in the two subsamples may also explain this finding.

Time spent reading for professional development only explains the variance in students' achievement in the mixed subtest $(\mathrm{F}=5.148, \mathrm{p}<.000)$, resulting in a significant difference between the achievement of students whose teachers spent less than one hour a week reading for professional development and students whose teachers did so four or more hours a week. The reason for this may be that teachers who consider the enhancement of their competence important are more open to integrating non-traditional text formats into their work. However, in this case, it remains a question why no significant relationship was found between this variable and achievement in the non-continuous dimension.

The impact of time spent reading for pleasure can only be detected in students' understanding of the continuous $(\mathrm{F}=3.876, \mathrm{p}<.002)$ and mixed text $(\mathrm{F}=5.785, \mathrm{p}<.000)$. Post hoc multiple comparisons tests could only yield evidence on the places of the differences in case of the continuous subtest. Data showed that students whose teachers never read in their free time at all achieved lower test scores than the rest of the measured population. Findings also revealed that the fact whether teachers spend less than one hour a week reading for pleasure or more does not make a significant difference in students' achievement. Simply put, the frequency of reading for pleasure does not influence students' achievement. In terms of achievement it only matters whether teachers engage in these types of activities or not. In my opinion, most probably teachers' lack of positive attitudes towards reading underlie this phenomenon. Attitudes generate and boost action. Having negative attitudes towards reading can result in no reading or no activation of a learning motive other than that of reading. These teachers may not share their own reading experiences with their students and they do not create and nurture positive reading attitudes in students.

The examination of the relationship between teachers' satisfaction with their own work in the assessed second grade class and students' achievement in the three subtests yielded evidence on a significant association in all cases $\left(F_{\text {cont. }}=25.928, p<.000 ; F_{\text {mixed }}=17.226\right.$, $\left.\mathrm{p}<.000 ; \mathrm{F}_{\text {non-cont. }}=3.327, \mathrm{p}<.036\right)$. In case of the continuous subtest, data showed three subgroups of students differing significantly in terms of achievement. Students whose teachers were very satisfied with their own work in the measured class achieved the highest reading achievement. Students whose teachers were rather dissatisfied reached the lowest reading test scores, whereas students whose teachers were rather satisfied fell in between. In case of the mixed and non-continuous subtests, data showed that students whose teachers were very satisfied reached the highest test scores, but the average achievement of students belonging to the subgroups of rather dissatisfied and rather satisfied categories did not differ significantly.

\subsubsection{Aspects of teaching reading and reading development}

An analysis of variance yielded significant variation among the achievement of students whose teachers prefer and use different methods of teaching in each subtest. However, Tukey's-b and Dunnett's T3 only showed which groups differ significantly in a few cases. ANOVA yielded evidence that the frequency of using role-play makes a difference in the variance of students' achievement in the continuous subtest $(F=3,669$, 
$\mathrm{p}<0,012$ ), but Tukey's-b could not indicate where the difference lies. Regarding the frequency of using pair work as a method of teaching ANOVA showed that there is a significant difference among subgroups in every subtest $\left(\mathrm{F}_{\text {cont. }}=2.993, \mathrm{p}<.030 ; \mathrm{F}_{\text {mixed }}=4.958\right.$, $\left.\mathrm{p}<.002 ; \mathrm{F}_{\text {non-cont. }}=3.617, \mathrm{p}<.013\right)$. The mixed text was understood the least by students whose teachers ranked pair work the fourth, indicating that they hardly ever use this method of teaching $([4]<[1,2,3])$. In case of the non-continuous subtest, data show that students engaged in pair work more often performed significantly better than their peers $([2,3,4]<[1,2,4])$. In case of the continuous subtest, Tukey's-b did not show where the difference lies among subgroups.

Analyses on the impact of group work revealed that there is a significant relationship between the frequency of using group work as a teaching method and students' achievement in the mixed and non-continuous subtests $\left(F_{\text {mixed }}=5.138, p<.002 ; F_{\text {non-cont. }}=3.100, p<.026\right)$. However, data only allowed us to identify the place of the differences among subsamples in case of the mixed subtest. There is a significant difference between those students' achievement whose teachers ranked group work first and second $([2,3,4]<[1,3,4])$, and students whose primary school teachers prefers using group work in the teaching and learning process the most reached higher test scores. In contrast, analyses involving frontal teaching showed that students whose teachers use this method the least frequently performed the best $([1,2,3]<[4] ; \mathrm{F}=6.156, \mathrm{p}<.000)$. The examination of the impact of frontal teaching on students' achievement in the continuous subtest yielded the same pattern (continuous text: $\mathrm{F}=9.623$, $\mathrm{p}<.000)$.

Analysis yielded evidence that reading method does make a difference on performance in the non-continuous subtest $(\mathrm{F}=6.812, \mathrm{p}<.001)$. Data showed that the whole word method is in students' favor when it comes to understanding the information conveyed by the table. Students taught to read with the whole word method achieved significantly higher test scores than students whose teachers used the phonics or the analytic-synthetic method.

The weekly frequency of guided oral reading by the teacher indicated an impact on students' continuous, mixed and non-continuous test scores alike $\left(\mathrm{F}_{\text {cont. }}=6.476, \mathrm{p}<.000\right.$; $\left.\mathrm{F}_{\text {mixed }}=7.811, \mathrm{p}<.000 ; \mathrm{F}_{\text {non-cont. }}=20.934, \mathrm{p}<.000\right)$, but data only revealed where the differences among the subgroups lie in case of the continuous and non-continuous subtests. Students comprehended the continuous text the worst in classes where teachers had never engaged in guided oral reading. In case of the non-continuous text, the achievement of students who belong to the subgroups of the two extremes of the scale (i.e. never and more than five times) differed significantly. It is difficult to explain what added value teachers' guided oral reading bears in students' achievement in the non-continuous subtest that cannot be grasped in the mixed subtest.

The examination of the relationship between students' oral and silent reading and students' understanding of the continuous, mixed and non-continuous texts yielded various patterns. The weekly frequency of asking students to read aloud has an impact on how students comprehend texts with non-traditional formats. In case of the mixed subtest, data showed that students who had the opportunity to read longer passages aloud during reading classes once or twice a week achieved lower test scores than students who were engaged in oral reading more than five times a week $(\mathrm{F}=3.473, \mathrm{p}<.031)$. However, in case of the noncontinuous subtest, data only revealed a significant difference between the achievement of students who read aloud once-twice and 3-5 times a week $(\mathrm{F}=7.746, \mathrm{p}<.000)$, but the benefits of doing so more than five times a week cannot be detected. Oral reading provides teachers an opportunity to identify bottlenecks in students' reading fluency. I assume that students who receive feedback from this source more often have fewer problems with decoding, therefore, they can focus on the characteristics of text formats more. 
The weekly frequency of silent reading had a significant relationship with the continuous $(\mathrm{F}=7.259, \mathrm{p}<.001)$ and mixed $(\mathrm{F}=5.587, \mathrm{p}<.004)$ subtests. In both cases, students who were engaged in silent reading more than five times a week achieved significantly higher test scores than their peers. However, no significant difference was found between those students' achievement who read silently once or twice and 3-5 times a week. Interestingly, while oral reading affects non-continuous test scores, silent reading has no traceable contribution to achievement in this dimension.

One would expect that the frequency of using continuous and non-continuous texts for teaching reading does make a difference in understanding texts with corresponding formats. In case of the continuous text, data confirmed this expectation, however, in case of the noncontinuous text analysis rejected the assumed relationship. The weekly frequency of using non-continuous texts impacted students' achievement in the mixed subtest ( $\mathrm{F}=3.490$, $\mathrm{p}<.015)$, but Dunnett's T3 did not reveal where the difference among the subgroups lie. In contrast, post hoc multiple comparisons tests showed the following differences among the subsamples created based by the weekly frequency of using continuous texts for teaching reading. Students who read continuous texts during lessons 3-5 times a week performed the best in both the continuous $(\mathrm{F}=7.44, \mathrm{p}<.001)$ and non-continuous $(\mathrm{F}=6.426, \mathrm{p}<.002)$ subtests. Nevertheless, we cannot conclude that the more frequent teachers use continuous texts for teaching reading, the better students will be able to comprehend them, since using them less and more frequently than 3-5 times a week does not reveal a significant difference in students' achievement. In case of the mixed subtest, analysis did not show where the difference lies.

The examination of students' reading achievement based on the textbooks used for instruction revealed a significant relationship in case of each subtests. In case of the continuous and non-continuous subtests post hoc multiple comparisons tests identified two significantly different groups in terms of achievement, whereas in case of the mixed subtest, three groups were distinguished $\left(\mathrm{F}_{\text {cont. }}=9.395, \mathrm{p}<.000 ; \mathrm{F}_{\text {mixed }}=43.062, \mathrm{p}<.000 ; \mathrm{F}_{\text {non- }}\right.$ cont. $=11.800, \mathrm{p}<.000)$. According to Dunnett's T3, students learning from the textbooks published by Apáczai, Mozaik, Dinasztia and ROMI-SULI achieved significantly higher test scores than students who used the reading textbooks of Müszaki Kiadó és Nemzeti Tankönyvkiadó. A slightly different pattern emerged in case of the mixed subtest: students learning from the ROMI-SULI textbook performed significantly worse than students in the other two subgroups.

Taking into consideration the facts that communication mostly takes a non-linear form in ICT and that students' reading assessment took place in an electronic environment, I expected that the frequency of using ICT impacts how students read and understand mixed and non-continuous texts. Analysis showed that those students' achievement whose teachers had never used interactive whiteboards and those whose teachers used them more than five times a week differ significantly in case of the continuous subtest $(\mathrm{F}=6.407, \mathrm{p}<.000)$, but data did not reveal a difference between the impact of applying interactive whiteboard once or twice and five times a week. The tendencies are different in the other two subtests. The poorest readers could be found in the classes of those teachers who had never used interactive whiteboards for teaching reading in case of the mixed and non-continuous subtests $\left(F_{\text {mixed }}=7.644, \mathrm{p}<.000 ; \mathrm{F}_{\text {non-cont. }}=7.470, \mathrm{p}<.000\right)$. The best readers of mixed and noncontinuous texts were taught by teachers who used this device once or twice a week. Data revealed that the lack of interactive whiteboard use yields poor performance in each and every subtest.

As for the weekly frequency of teachers' computer use, a similar pattern emerged in the continuous $(\mathrm{F}=6.019, \mathrm{p}<.000)$ and non-continuous $(\mathrm{F}=4.690, \mathrm{p}<.003)$ subtests. Data showed that the reading achievement of students whose teachers had never used computers 
for teaching reading is worse than that of the rest of the population. However, the frequency of computer use did not show clear patterns. Moreover, its impact on achievement in the mixed subtest could not be identified.

In the measured population, the independent variable of weekly frequency of teachers' internet use was only significantly related to achievement in the non-continuous subtest $(\mathrm{F}=3.098, \mathrm{p}<.026)$, and its impact is the opposite of what was expected. In the sample, those students achieved the lowest test scores whose teachers claimed to have used the internet during their reading classes more than five times a week. The only subtest where having had reading classes in computer labs resulted in achievement differences was also the noncontinuous one (Tables 6.3, 6.4 and 6.5). I expected that lessons exploiting the advantages of electronic environment would have a positive impact on the understanding of texts with non-linear structure. However, data showed that students who did not have reading classes in computer labs were more successful in comprehending the table in the test. Nevertheless, the fact whether students had to opportunity to use the computers during these lessons or not does not have an impact on any of the subtest achievements. Results of the two-sample ttests also revealed that students' achievements in each subtest are significantly related to teachers' knowledge about programs for teaching reading available on the internet (Tables 6.3, 6.4 and 6.5). It is noteworthy that in case of the non-continuous subtest, better results were achieved by students whose teachers responded that they were not familiar with such programs. The following findings underscore the complexity of this relationship. The frequency of using reading softwares for teaching reading only makes a difference in the mixed test scores, however, the benefits of frequent use are not obvious.

Table 6.3 Comparison of students' achievement in the continuous subtest based on the ICTand assessment-related items with two-sample t-tests

\begin{tabular}{|c|c|c|c|c|c|c|}
\hline Variables & $\begin{array}{c}N \\
\text { (yes/no) }\end{array}$ & $\Delta x(\% p)$ & $F$ & $p$ & $t$ & $p$ \\
\hline $\begin{array}{l}\text { Does the teacher know any programs for } \\
\text { teaching reading available in the internet? }\end{array}$ & $1105 / 2062$ & 1.37 & 0.908 & 0.341 & -2.120 & 0.034 \\
\hline $\begin{array}{l}\text { Has the teacher held reading lessons in a } \\
\text { computer lab? }\end{array}$ & $577 / 1147$ & -0.22 & 2.207 & 0.138 & 0.280 & 0.780 \\
\hline $\begin{array}{l}\text { If yes, did students have an opportunity to } \\
\text { use the computers? }\end{array}$ & $555 / 968$ & 0.09 & 4.474 & 0.035 & -0.103 & 0.918 \\
\hline \multicolumn{7}{|l|}{ Has the teacher relied on ... } \\
\hline ...system-level assessments? & $1317 / 1790$ & -0.35 & 0.044 & 0.834 & 0.586 & 0.558 \\
\hline ...oral assessment? & $2852 / 361$ & 1.93 & 0.908 & 0.341 & -2.120 & 0.034 \\
\hline $\begin{array}{r}\text {...self-developed paper-and-pencil } \\
\text { assessment instruments? }\end{array}$ & $2990 / 223$ & -1.32 & 0.399 & 0.528 & 1.168 & 0.243 \\
\hline $\begin{array}{r}\text {... assessment with instruments included in } \\
\text { reading textbooks? }\end{array}$ & $2767 / 446$ & 2.15 & 1.608 & 0.205 & -2.582 & 0.010 \\
\hline $\begin{array}{r}\text {... computer-based assessment } \\
\text { instruments? }\end{array}$ & $2734 / 479$ & 0.72 & 0.048 & 0.826 & -0.895 & 0.371 \\
\hline ... assessment with student portfolio? & $192 / 3021$ & 3.38 & 7.848 & 0.005 & -3.186 & 0.002 \\
\hline
\end{tabular}

Note: $\mathrm{N}$ : the number of students belonging to teachers having given yes/no response to the question

$\Delta \mathrm{x}=$ mean $_{\mathrm{yes}}-$ mean $_{\mathrm{no}}$ (the achievement difference between students belonging to teachers having given yes and no response to the question)

Grey background: the achievement difference is not significant 
Table 6.4 Comparison of students' achievement in the mixed subtest based on the ICT-and assessment-related items with two-sample t-tests

\begin{tabular}{|c|c|c|c|c|c|c|}
\hline Variables & $\begin{array}{c}N \\
\text { (yes/no) }\end{array}$ & $\Delta x(\% p)$ & $F$ & $p$ & $t$ & $p$ \\
\hline $\begin{array}{l}\text { Does the teacher know any programs for } \\
\text { teaching reading available in the internet? }\end{array}$ & $1105 / 2062$ & 3.33 & 0.010 & 0.922 & -2.762 & 0.006 \\
\hline $\begin{array}{l}\text { Has the teacher held reading lessons in a } \\
\text { computer lab? }\end{array}$ & $577 / 1147$ & 0.02 & 0.226 & 0.635 & -0.016 & 0.987 \\
\hline $\begin{array}{l}\text { If yes, did students have an opportunity to } \\
\text { use the computers? }\end{array}$ & $555 / 968$ & -0.49 & 0.055 & 0.814 & 0.407 & 0.684 \\
\hline \multicolumn{7}{|l|}{ Has the teacher relied on ... } \\
\hline ...system-level assessments? & $1317 / 1790$ & 1.34 & 0.788 & 0.375 & -1.577 & 0.115 \\
\hline ...oral assessment? & $2852 / 361$ & 3.61 & 0.010 & 0.922 & -2.762 & 0.006 \\
\hline $\begin{array}{r}\text {... self-developed paper-and-pencil } \\
\text { assessment instruments? }\end{array}$ & $2990 / 223$ & -1.28 & 0.027 & 0.871 & 0.791 & 0.429 \\
\hline $\begin{array}{r}\text {...assessment with instruments included } \\
\text { in reading textbooks? }\end{array}$ & $2767 / 446$ & 2.46 & 4.440 & 0.035 & -1.979 & 0.048 \\
\hline $\begin{array}{r}\text {...computer-based assessment } \\
\text { instruments? }\end{array}$ & $2734 / 479$ & 0,30 & 0,685 & 0,408 & $-0,261$ & 0,794 \\
\hline ...assessment with student portfolio? & $192 / 3021$ & 6,00 & 6,121 & 0,013 & $-3,840$ & 0,000 \\
\hline
\end{tabular}

Note: $\mathrm{N}$ : the number of students belonging to teachers having given yes/no response to the question

$\Delta \mathrm{x}=$ mean $_{\text {yes }}-$ mean $_{\text {no }}$ (the achievement difference between students belonging to teachers having given yes and no response to the question)

Grey background: the achievement difference is not significant

Table 6.5 Comparison of students' achievement in the non-continuous subtest based on the ICT- and assessment-related items with two-sample t-tests

\begin{tabular}{|c|c|c|c|c|c|c|}
\hline Variables & $\begin{array}{c}N \\
(\text { yes } / \text { no })\end{array}$ & $\Delta x(\% p)$ & $F$ & $p$ & $t$ & $p$ \\
\hline $\begin{array}{l}\text { Does the teacher know any programs for } \\
\text { teaching reading available in the internet? }\end{array}$ & $1105 / 2062$ & -1.84 & 1.418 & 0.234 & -3.759 & 0.000 \\
\hline $\begin{array}{l}\text { Has the teacher held reading lessons in a } \\
\text { computer lab? }\end{array}$ & $577 / 1147$ & -2.85 & 1.158 & 0.282 & 2.648 & 0.008 \\
\hline $\begin{array}{l}\text { If yes, did students have an opportunity } \\
\text { to use the computers? }\end{array}$ & $555 / 968$ & -1.74 & 2.686 & 0.101 & 1.153 & 0.121 \\
\hline \multicolumn{7}{|l|}{ Has the teacher relied on $\ldots$} \\
\hline ... system-level assessments? & $1317 / 1790$ & 0.39 & 1.438 & 0.231 & -0.458 & 0.647 \\
\hline ...oral assessment? & $2852 / 361$ & 4.87 & 1.418 & 0.234 & -3.759 & 0.000 \\
\hline $\begin{array}{r}\text {... self-developed paper-and-pencil } \\
\text { assessment instruments? }\end{array}$ & $2990 / 223$ & -0.44 & 0.142 & 0.706 & 0.272 & 0.786 \\
\hline $\begin{array}{l}\ldots \text { assessment with instruments included } \\
\text { in reading textbooks? }\end{array}$ & $2767 / 446$ & 1.42 & 2.010 & 0.156 & -1.197 & 0.231 \\
\hline $\begin{array}{r}\text {... computer-based assessment } \\
\text { instruments? }\end{array}$ & $2734 / 479$ & 1.37 & 13.834 & 0.000 & -1.341 & 0.180 \\
\hline ... assessment with student portfolio? & $192 / 3021$ & 7.19 & 18.061 & 0.000 & -5.475 & 0.000 \\
\hline
\end{tabular}

Note: $\mathrm{N}$ : the number of students belonging to teachers having given yes/no response to the question $\Delta \mathrm{x}=$ mean $_{\text {yes }}-$ mean $_{\text {no }}$ (the achievement difference between students belonging to teachers having given yes and no response to the question)

Grey background: the achievement difference is not significant 
As educational assessment is a component of the teaching-learning process affecting the whole system (Báthory, 1997), I also collected information on the ways teachers assess students and provide feedback to them. Analyses showed that in case of each subtests those students performed better whose teachers used oral assessment involving teacher-student interaction and whose teachers documented progress in a student portfolio thus offering a holistic approach to assessment. The use of assessment instruments included in reading textbooks had an impact on achievement only in the continuous and mixed subtests. A reason for this may be that the non-continuous texts are underrepresented in the textbooks (Turcsán, 1998a, 1998b) and non-existent or marginally represented entities cannot serve as input. The use of teachers' self-developed paper-and-pencil assessment instruments does not make a significant difference in students' achievement in any of the subtests. However, the weekly frequency of administering reading tests with adequate psychometric properties have a significant relationship with students' achievement in the continuous subtest $(\mathrm{F}=3.110$, $\mathrm{p}<.025)$ but Tukey's-b did not show where the difference among the subgroups lie. Moreover, data showed that the use of computer-based assessment instruments do not have a tangible contribution to increasing the efficiency of teaching reading in any of the assessed dimensions.

One way of giving feedback to parents on their children's reading development is consulting them in person on a regular basis Analyses showed that this action does not make a difference in students' reading achievement in any of the subtests $\left(\mathrm{F}_{\text {cont. }}=.520, \mathrm{p}<.721\right.$; $\left.\mathrm{F}_{\text {mixed }}=1.294, \mathrm{p}<.270 ; \mathrm{F}_{\text {non-cont. }}=1.376, \mathrm{p}<.240\right)$. The information provided by teachers on students' development can be used in the parent-child interaction in the home environment either in the form of targeted development (e.g., doing homework or extra assignments) or in form of other oral or written practice. The results do not lend support to the existence of this relationship. The reasons for this may be that parents do not or cannot assist their children in learning to read because of lack of time or adequate knowledge or the teachers specifically ask parents not to intervene in the process of learning to read because that may divert children from the developmental methods and targets the teachers assign them.

\subsubsection{Conditions of teaching and learning reading}

The weekly number of reading, writing and composition lessons aiming to develop students' literacy show a diverse relationship with students' achievement in the three subtests. It is surprising that the number of reading lessons do not have an impact on reading achievement in any of the subtests. Nevertheless, data indicated a significant relationship between the weekly number of writing lessons and achievement in all three dimensions of reading literacy $\left(\mathrm{F}_{\text {cont. }}=3.060, \mathrm{p}<.027 ; \mathrm{F}_{\text {mixed }}=8.773, \mathrm{p}<.000 ; \mathrm{F}_{\text {non-cont. }}=4.145, \mathrm{p}<.006\right)$. Post hoc multiple comparisons tests could only show where the difference lies among the subgroups in case of the mixed subtest. According to the results, an outstandingly high number of writing lessons a week (4 or more) does not benefit the understanding of the mixed text. The weekly number of composition lessons modulate students' achievement in the non-continuous subtest $(\mathrm{F}=7.460, \mathrm{p}<.000)$ but an unclear pattern emerged regarding the differences among the subgroups ([3 lessons a week $]<[1,2,4$ or more lessons a week]). The heterogeneous patterns call for further research.

Data show that teachers' opinion on the developmental level of their students' decoding is related to achievement in each dimension $\left(\mathrm{F}_{\text {cont. }}=43.993, \mathrm{p}<.000 ; \mathrm{F}_{\text {mixed }}=36.816\right.$, $\left.\mathrm{p}<.000 ; \mathrm{F}_{\text {non-cont. }}=23.756, \mathrm{p}<.000\right)$. Post hoc multiple comparisons tests showed that the difference among the subgroups lies at different scale points in case of the subtests. In case of the continuous subtest, there are three subgroups of students with significantly different achievement. Students' achievement is the worst in classes where teachers consider students' decoding very poor. Students achieved the highest reading scores in classes where teachers 
have a positive opinion (i.e. students' decoding is considered as rather good or very good) about students' reading developmental level. This does not hold true in case of the mixed and non-continuous subtests. The mixed text was least understood by students who were thought of as very poor decoders by their teachers. They were followed by the subgroups of students whose decoding developmental level was considered rather poor and rather good. Students who were judged to have the most developed decoding skills fell into the top performing subgroup. The picture is even more complex in case of the non-continuous subtest: there are overlaps among the subgroups of students belonging to the categories.

Data reveal more consistent patterns regarding the relationship between teachers' opinion on the developmental level of students' reading comprehension and students' achievement in the subtests. In each and every case, the achievement of subgroups of students belonging to the very good comprehender category differ significantly from the rest of the subgroups $\left(\mathrm{F}_{\text {cont. }}=22.445, \mathrm{p}<.000 ; \mathrm{F}_{\text {mixed }}=23.064, \mathrm{p}<.000 ; \mathrm{F}_{\text {non-cont. }}=12.616, \mathrm{p}<.000\right)$.

\subsection{Discussion}

I begin this part of the thesis with the discussion and interpretation of the data yielded by descriptive statistics. I embed and contextualize the findings by comparing the data with previous findings. Then, students' achievements are discussed in light of the influencing factors identified by the Tukey's-b and Dunnett's T3 comparison procedures and ANOVA used in conjunction with it.

\subsubsection{Descriptive statistics}

\subsubsection{Teachers' background}

One aspect of instruction examined in the survey was teachers' professional background. Primary school teachers are important points of references for children. Their feedback plays an important role in shaping students' self-concept and in the development of students' cognitive and affective skills. Over the years, an attachment develops between the teacher and student, which - ideally - lays the foundations of students' further academic carreer. Therefore, data were collected about teachers' characteristics that may have a relationship with students' reading achievement. The sample's composition was examined based on age, gender, qualification, years spent teaching in general and teaching reading. Results reveal that the second graders who took part in the reading assessment were predominantly taught by teachers older than 40 . The proportion of novice teachers who have relatively recently entered the teacher career pathway is small (4.89\%). This also reflects the palpable tendency of aging teacher population that has been observed in Europe in the past 20 years (Imre \& Nagy, 2003). According to OECD data, Hungary is in a worse position in this respect than the OECD average. In Hungarian elementary schools, the proportion of teachers below 40 is $10 \%$ less than the OECD average, whereas the proportion of teachers over 50 teaching in the first four years of elementary schooling is $3 \%$ higher (OECD, 2015a). The latest education policy overview published by OECD claims that although aging leads to shortage of teachers, the increase in the number of students enrolled into teacher training give reasons for optimism (OECD, 2015a). Another long-known trend is that teaching has become an increasingly female-dominated profession. Official figures published around the turn of the millenium (Imre \& Nagy, 2003) drew attention to the rise in the proportion of female teachers. The outstandingly high proportion of teachers in the sample (97.16\%) is in correspondence with the trend, however, it must be noted that such an extraordinary femaledominance does not occur in higher grades. In sum, the results on the age and gender are in line with the conclusions published by other studies (e.g., European Comission / EACEA / 
Eurydice, 2015) claiming that the average age and the number of female teachers in public education have increased (Imre \& Nagy, 2003).

The UNESCO-ICE declaration states that students' achievement first and foremost depends on teachers' quality (McKinsey \& Company, 2007; Radácsi, 2004). In the survey qualification as an indicator of teacher quality was measured. The composition of this sample regarding qualification is in line with PIRLS' s findings (Mullis et al., 2012. p. 188). The answers showed that the vast majority of teachers teaching the second graders involved in the reading assessment how to read has a primary school teacher degree issued by a teacher training college. The result came as no surprise since a teacher position in the first four years of elementary education can be filled in by a primary school teacher or conductor degree (Act LXXIX of 1993 on Education). The current regulations on the training and outcome requirements rule that primary school teachers are equipped with such skills, abilities and knowledge that enable them to teach in all domains in the first four years and at least one literacy domain in years $1-6$. However, there were no participants in the survey who pursued doctoral studies and tried to enhance their knowledge with a scientific approach. Hopefully, the career pathways model introduced in 2013 will bring a shift in this respect as well.

Another indicator of teachers' quality is work experience. Answers showed that the majority $(89.62 \%)$ of teachers teaching the assessed second grade population has more than 10 years of teaching experience and has been teaching reading for more than 10 years $(77.17 \%)$. It is a fundamental interest of education systems to keep qualified and experienced teachers in the profession. Data revealed that the majority of respondents $(69.40 \%)$ has been teaching for more than 20 years and if we also take into consideration the average age, we can conclude that they started teaching right after earning their degree. This implies that although the number of people entering this profession is low, the profession has the potential to keep teachers. It seems that the intention to quit teaching and pursue another career slacken gradually as the years spent in the profession increase.

A well-qualified teacher is of central importance in successful education systems. Government decree (277/1997. (XII. 22.) Kormányrendelet) regulates teachers' in-service training, however, the voluntary, self-initiated activities driven by intrinsic motivation also play a key role in development besides the formal and compulsory training elements. Printed or online journals of education and widely accessible methodological forums and workshops offer countless opportunities for teachers to improve their knowledge and competences. According to the present findings, the majority of respondents takes these opportunities and spends at least 2-3 hours a week keeping up-to-date with the latest developments concerning their profession. Reading for pleasure may also be conceived as an intellectual and spiritual food of the mind. The surveyed teachers - with one exception - dedicate some time to reading for enjoyment. They spend more than four hours a week shaping their thinking by reading literary works than by reading for information directly aiming to enhance their professional knowledge.

As for self-concept, teachers' satisfaction with their work and productivity is an important element in the teaching and learning process (Hercz, 2005, p. 167). Teaching can only be successful if teachers are well prepared, satisfied and emotionally, psychologically balanced. This way, they can be more efficient and ready to guide students toward intellectual joy and discoveries, achievement, success and cooperation (Réthy, 2016, p. 89). My research in this domain yielded positive results: $96.1 \%$ of the sample has a positive attitude towards their achievements and productivity in the measured class. Moreover, there were not any teachers in the sample who expressed complete dissatisfaction. 


\subsubsection{Aspects of teaching reading and reading development}

The second thematic unit of the questionnaire consisted of items seeking information about teaching reading and reading development. The present results do not indicate a change in terms of reading methods in the past decades. Nearly half of the surveyed teachers $(48.00 \%)$ state that they use the analytic-synthetic method that has been claimed to be the most efficient way for teaching reading in Hungarian (Adamikné Jászó, 2006; Csépe, 2006). A somewhat smaller but still a considerable ratio of teachers $(38.29 \%)$ teach their students how to read with the synthetic method (i.e. phonics). The proportion of teachers relying on the analytic (i.e. whole word) approach is marginal (2.29\%). As the preferred method can only be taught by means of the corresponding textbook, it is no surprise that half of the teachers use textbooks incorporating the principles of the analytic-synthetic approach published by Apáczai Kiadó. The textbooks enlisted by the respondents were typically published in the 1990s first. The textbooks were all known from previous works on textbook analysis. This implies that teachers did not use textbooks that had gone through a major improvement or development in their practice. However, it is important to note that for the 2014-2015 school year new generation textbooks had been published, which are currently used and piloted in grades 1, 2, 5, 6, 9 and 10 (www.ofi.hu).

Traditionalism is also apparent in methods of teaching. Less than half of the surveyed school teachers $(42.93 \%)$ marked frontal teaching as the most often used method of teaching reading. However, the preference of pair and group work (31.91\% and $21.93 \%)$ is also significant. The latter results are promising because student-centered activities make lessons more versatile and interesting. Furthermore, they do not only make students more engaged but they also contribute to the development of social competencies (e.g., cooperation and competition) and help students explore their strengths, weaknesses and abilities (Radnóti, 2007).

A wide range of teaching methods can be accommodated into the teaching reading process. For instance, the development of reading techniques can take place individually, in pairs or in groups. The development of reading techniques receives attention from grade 2 and is a daily task from this time on. The tasks may either target the development of oral or silent reading. Seemingly oral reading bears little added value to overall reading development, but research has proven its important role in the early years of learning to read (Gósy, 2008). Studies conducted among 1-3 graders showed that there is a strong relationship between oral reading achievement and reading comprehension (Ridel, 2007). Additionally, oral reading also affects silent reading. Each and every teacher in the sample uses the technique of oral reading. Nearly half of the respondents gives students oral reading tasks once or twice a week, and the rest of the sample does this more than three times a week. Data does not make it possible to tell the reasons for the difference in the frequencies of oral reading. One reason may be that teachers who use oral reading more often recognized the importance of this technique but it is also a possible explanation that the more frequent reliance on oral reading takes place because of students' poor reading skills and the need for intensive development aligned with it. Nevertheless, as reading fluency is a fundamental building block of successful reading comprehension, it is generally assessed by making students read aloud (Kim, Wagner, \& Foster, 2011).

Practicing oral reading can take many forms. One of these is called guided oral reading when generally the teacher reads a passage aloud, modeling fluent reading. Then, students reread the text quietly, on their own. Next, the students read aloud and then reread the same passage. More than half of the respondents $(58.01 \%)$ read a longer passage aloud to the students more than three times a week either with the intention to improve reading techniques or other skills and abilities. 
Research has also shown that silent reading is also related to reading comprehension but the findings are unequivocal (Kim et al., 2011). Silent reading provides more opportunity to concentrate on the content and meaning because reading words aloud accurately does not distract attention from comprehension. Silent reading is employed in the sample with alternating frequencies.

The frequency of using different reading techniques shows different patterns in the teachers' age groups. The frequency of oral reading is similar in every age group, while silent reading is primarily preferred and most frequently chosen by teachers older than 50 . Guided oral reading is employed the most frequently by teachers younger than 40 .

Regarding the presence of ICT in teaching reading, an important finding is that half of the surveyed primary school teachers had never used interactive whiteboard or computers for teaching the assessed second graders to read. This result gives reason for concern because the usage of the internet is widespread among the members of generation $\mathrm{Z}$ and meeting the demands of the $21^{\text {st }}$ century is impossible for them without these tools. Being comfortable and knowledgeable about ICT and knowing how to access information by means of them is imperative. In addition to these, students also have to master the skills necessary for comprehending electronic texts and reading in an online environment. The emergence of online data collection and electronic texts in research programs (see R. Tóth \& Hódi, 2011) and in the development of item banks (e.g., Csapó, Steklács, \& Molnár, 2015) mirror this requirement. However, it is promising that the respondents who actually do use ICT tools use it for targeted development and enable students to become familiar with computer-based reading and comprehension tasks. These students will be comfortable with reading and testing in an electronic environment, which may later mean an advantage for them.

Besides the innovative thinking of the teacher, using ICT for teaching reading is highly dependent on the ICT infrastructure available at schools and the condition the computers are in (e.g., level of maintenance, possibilities for upgrading etc.) (Tóth, Molnár, \& Csapó, 2011). Therefore, lack of school infrastructure and obsolete computers may also explain why almost a half of the respondents had never integrated ICT in the teaching and learning process. Although there is a guideline that each and every EU member state provides one computer for eight students in elementary education, a nationally representative study conducted by Tóth, Molnár, and Csapó in 2011 concludes that Hungary does not comply with this regulation. $55 \%$ of schools are not equipped in a way that a whole class could access a computer at the same time (e.g., for the purposes of online assessment) (p. 130). Nevertheless, the fact that more than one third of the respondents had already held a reading lesson in a computer lab is promising.

Teachers also lag behind in using technology-based reading programs accessible on the internet. More than half of the respondents (63.98\%) does not use and does not even know such programs. Less than half of the teachers who know internet-based reading programs use or had used them for teaching the assessed population. There can be many explanations for these tendencies but insufficient data in this domain limit discussions. One possible reason may be that the average age of the sample is high; therefore, at the time the majority of teachers attended college digital technology and digital literacy were not integrated in their syllabus. However, cross-tab statistics debunks this theory. While data did not show a clear pattern regarding ICT use in the age groups, being uninformed is very similar: the proportion of teachers who are familiar with online reading programs is less than $50 \%$. Besides the lack of information, distrust and lack of confidence are other factors that may account for the detected phenomenon as in fact, the online landscape lacks sufficient research-based online reading development programs (Fáyné Dombi, Hódi, \& Kiss, 2016). These findings are in line with outcomes of the review of the European Literacy Policy Network (ELINET) on international reading assessments. They reported that textbooks are 
the main sources of instruction for primary school teachers and only $5 \%$ of them (the EU average is $29 \%$ ) use children's books or other pieces of children's literature to supplement reading instruction in addition to textbooks. The proportion of teachers building reading instruction on reading softwares is marginal (3\%, it is around the EU average), but a larger proportion of teachers (39\%) use it as a supplement (Szabó, Szinger, Garbe, Kákonyi, Lafontaine, Mallows, Reményi-Somlai, Shiel, Valtin, \& Varga, 2016).

A major objective of the dissertation is to study second graders' reading developmental level in different text formats. Therefore, data were collected about the frequency teachers use these text formats when teaching reading. In line with expectations, teachers tend to use continuous texts. $8.84 \%$ of the respondents claimed that they had never used non-continuous texts for teaching reading in the measured class. The present results lead us to the conclusion that there has been a shift in terms of using different text formats compared to the findings of Molnár and B. Németh (2006), and Adamikné Jászó (2006). Some teachers integrate noncontinuous texts in their work even though the occurrences are still rare.

In what follows, I make an attempt to explain the ever-present dominance of continuous texts in teaching reading in the Hungarian educational realm by drawing on some relevant literature. The variety of texts one encounters in everyday life were first integrated into system-level assessments with the aim of providing a wide coverage of the construct of reading literacy in line with social and labor market expectations (Berkman, Davis, \& Mccormack, 2010). System-level assessment frameworks state that one does not only have to understand the information conveyed by continuous text formats traditionally associated with reading but it is also necessary for students to be able to retrieve information from and interpret more fragmented text formats like tables and graphs involving written symbols other than graphemes. Non-continuous texts appeared in textbooks much later. Considering non-continuous texts as texts and thinking about extracting information from these as reading are not widely accepted by Hungarian researchers either. Obsolete scientific theories, which in accordance with generativist and structuralist approaches argue that text is built from sentences and textuality is provided by the multilevel relationship (grammatical and semantic) among them (Dobi, 2011, p. 20), may account for this tendency. However, broader interpretations help accommodate non-continuous written pieces of information. These approaches conceive texts as a body of complex signs and claim that although texts are constituted by components, these components do not stem from grammar but from semiotics (Tolcsvai Nagy, 2001, p. 22). Interpreting texts as means of communication (Deme, 1979) also help to define non-continuous texts as texts. According to these, texts are linguistic entities that have the function of giving information or influencing and makes the impression of being complete. Based on this, every single coherent sign set carrying information can be defined as text. The latter approaches serve the aims of modern teaching better, since the sign systems surrounding us are extremely complex. Therefore, teaching students how to read cannot and must not be exclusively based on the traditional interpretation of texts. The framework defines reading texts of everyday communication (e.g., invitation, recipe) as teaching content in grade 3, but there are no passages ruling explicitly on these in grade 4 (Emberi Erőforrások Minisztériuma, 2012).

As data gained from system-level assessments (PISA, NABC) regularly show that Hungarian students' achievement is always worse in the non-continuous subtests, I assumed that non-continuous texts are used in teaching reading less frequently. Data confirmed this assumption. Even though some teachers rely on the knowledge gained from system-level assessments when planning their syllabus, it seems that this does not affect the frequency they use texts with different formats. In sum, non-continuous texts are rarely used for teaching reading compared to continuous texts. The younger generation of teachers seems to be more open to their use: respondents younger than 30 use non-continuous texts for 
teaching reading more often than their older colleauges. Possibly, they learnt about the potentials non-continuous texts offer during their studies but insufficient data do not allow us to jump to conclusions; further research is required in this area as well.

The preference of assessment methods shows that teachers in the sample tend to use the techniques that have been 'approved' and favored by previous teacher generations. Teachers' assessment culture is dominated by the oral and paper-and-pencil methods, whereas online assessment is marginal. Although paper-and-pencil tests are popular, teachers do not use them for tracking students' reading development on a weekly basis.

\subsubsection{Conditions of teaching and learning reading}

Although data collected on the conditions of teaching and learning reading do not lend themselves for generalization, they provide information about the sample involved in the study and are appropriate for contextualizing students' achievement. The number of weekly lessons necessary for efficient teaching has been a long-debated issue. The effective National Core Curriculum (Emberi Erőforrások Minisztériuma, 2012) only prescribes recommendations regarding the distribution and proportion of literacy domains. In lower elementary grades (grades 1-4) the annual number of lessons is provided in Hungarian Language and Literature (296-296-296-259), while the framework sets the requirements for the weekly number of lessons (Adamikné Jászó, 2006, p. 70). In grade 2, teachers have about eight lessons a week for the development of students' first language literacy (Adamikné Jászó, 2006). In the sample, figures on the number of reading, writing and composition lessons reveal that the vast majority of the institutions (98.36\%) lay an emphasis on teaching reading by dedicating three or more lessons to it a week. More than two thirds of the respondents have one writing and one composition lesson a week. The rest of the estimated weekly number of lessons dedicated to the development of students' first language literacy is devoted to the development of grammar and spelling. These findings are in line with the aims of 'raising readers' declared by the framework. However, the number of weekly first language lessons has dramatically decreased compared to the era before 1978. The period has witnessed a 50\% fall in this respect (Adamikné Jászó, 2006, p. 70). Putting the data into an international perspective also shows that the number of reading lessons is far too low. "In the US, primary grade teachers commit the bulk of their serious teaching time to reading; many of the comprehensive school reform plans prescribe a 90- to 150-minute literacy block" (Snow \& Juel, 2005, p. 501). "In the UK, each child receives one hour of literacy instruction each day through the elementary grades" (Snow \& Juel, 2005, p. 501). In sum, the present Hungarian time frame prescribed for teaching reading is narrow both in a historical and international perspective (OECD, 2015a).

Educational policy documents issued in the past few decades claim that the ratio of reading lessons a week has been larger than that of other subjects (e.g., writing) supporting students' literacy development. The present results are in accordance with this trend. Data show that teachers have 3-4 reading lessons a week but they have hardly more than one writing (1.41) and composition (1.31) lessons a week on average. The ratios may be surprising in light of the research results on the development of reading precursors arguing that writing can play an important role in the development of these skills (see Józsa et al., 2012). Based on this, ideally the ratio of reading and writing lessons should be more similar, almost equal.

Teaching a class how to read is influenced by the ratio of students having reading difficulties and reading disorders. Findings of the present study revealed that slightly more than half of the repondents (58.9\%) teach in classes that do not accommodate any students with special educational needs (SEN) in reading. Slightly more than one third of teachers reported that they teach a maximum of three students with specific learning disability in 
reading. $6.67 \%$ of teachers teach classes where the number of dyslexic children ranges from four to seven. National statistics provide information on the number of integrated SEN students. Figures show that the proportion of integrated SEN students in elementary school classes has been increasing (their proportion was $68.0 \%$ in $2015-\mathrm{KSH}, 2015$ ). As there are no publicly available statistics on the number of integrated dyslexic students in the first four years of elementary schooling, the national comparison of the present findings is not possible. Act (2011. évi CXC törvény; 32/2012. (X.8.) EMMI rendelet) regulates the education of students suffering from reading disorders. The intervention and development in a school environment can only take place when conducted by a teacher who completed a postgraduate special training course or by an intervention teacher with specialization or a special education teacher. The vast majority of teachers (94.03\%) having dyslexic students in the sample receives educational support from a specialist. It is possible that the ones who do not receive support in this respect have a special education qualification as well that enable them to work in an integrated environment. The rising number of children with SEN makes it imperative for teachers to acquire the necessary competencies that enable them to provide these students with quality education.

Compared to the numbers on dyslexic children, a shockingly large proportion of teachers $(86.34 \%)$ claimed to have children with a certain level of speech comprehension deficiency in their class. Conclusively, there are students displaying speech-processing problems in classes where the specialist committee has not diagnosed anyone with dyslexia. It may be the case that dyslexia was ruled out but the special education need was required because some other skills were affected by speech processing deficiencies. However, as the mechanisms of speech processing play a key role in learning to read (Gósy, 2008), it is very likely that problems in this domain will have a spillover effect and will later become apparent in the form of reading difficulties. Thus, I assume that it is more likely that teachers' responses to the question inquiring about the number of children with speech comprehension problems in the class were based on teachers' subjective judgment. It is an important question whether teachers can help students tackle these challenges and whether they report it to parents and specialists in each and every case. According to the findings of the present study, the majority of teachers consult parents about their children's reading development. These instances provide a great opportunity for teachers to share the observed problems.

\subsubsection{The relationship between aspects of reading instruction and second graders' reading achievement in the continuous, mixed and non-continuous subtests}

Very diverse patterns emerged from the analyses regarding the relationship between aspects of teaching reading and students' achievement in the different subtests. In most cases the results allowed us to identify which variables account for the variance in students' achievement at this early stage of learning to read but they did not provide an opportunity to predict the optimal quantity required for a maximum efficiency.

Teachers' age, years spent teaching, years spent teaching reading, time spent reading for pleasure, satisfaction, the frequency of using pair work, role-playing, frontal teaching, guided oral reading, students' silent reading and continuous texts in teaching reading show a significant relationship with achievement in the continuous subtest. All ICT-related factors have an impact on achievement in the continuous subtest except for the frequency of teachers' internet and teachers' or students' computer use. Oral assessment, the frequency of reading test administration, the use of assessment instruments found in textbooks and portfolio are factors that account for the variance in students' achievement in the continuous dimension of reading literacy. The weekly number of writing lessons, and teachers' opinion about students' developmental level in decoding and reading comprehension are also associated with how students understood the continuous text. 
In the case of the mixed text, the list of contributing teachers' background factors is longer, since teachers' qualification and time spent reading for professional development also determine students' understanding of the theatre poster. Except for role-play, all methods of teaching show a significant relationship with students' achievement in this dimension. Furthermore, the use of each and every studied reading technique affects test scores. Using continuous and non-continuous texts for teaching reading are contributing factors as well as teachers' use of interactive whiteboard, the used textbook and teachers' knowledge about and use of online reading programs available on the internet. As for the assessment-related factors findings show a similar pattern to that of the continuous subtest, but the administration of reading tests does not play a role in understanding the mixed text. Similarly to the continuous text, the weekly number of writing lesssons, and teachers' opinions about students' developmental level in decoding and reading comprehension are also associated with how students understood the mixed text.

Achievement in the non-continuous subtest is not influenced by time spent on reading for pleasure and professional development. Out of the variables on the classroom learning environment group and pair work, the textbook and inclusion of technology made a difference in how students understood the table. In fact, I found the most significant relationships with ICT-related variables in this dimension: the use of interactive whiteboard, teachers' computer and internet use, and use of and knowledge about online reading programs all proved to be contributing factors. Guided oral reading by teachers and students' oral reading are techniqes along the use of which difference was detected among the achievement of the subgroups. The used reading method and textbook, and the frequency of relying on continuous texts also showed a significant relationship with achievement in this dimension. As far as the assessment methods are concerned, it is only the oral assessment and portfolio that play a role in understanding the non-continuous text. Just like in the previous two dimensions, the weekly number of writing lessons, and teachers' opinion about students' developmental level in decoding and reading comprehension are also associated with how students understood the mixed text. Additionally, the weekly number of composition lesson also has an impact on achievement in the non-continuous subtest.

In sum, there are 34 factors showing a meaningful relationship with performance in any of the subtests. Out of these, analyses identified 16 factors that have an impact on students' achievement in the continuous, mixed and non-continuous subtests alike (Table 6.6). As the mixed text bears the characteristics of both the continuous and the noncontinuous formats, I assumed that the factors influencing its understanding show similar patterns at least with the continuous or the non-continuous text. Additionally, I expected to find the same contributing factors in case of the mixed text as in case of the other two formats. However, data revealed that this is a simplified approach and the nature of the relationships among the variables is much more complex.

\subsubsection{Teachers' background}

Teachers' gender was not included in the analyses due to the extremely femaledominant sample, thus the gender match hypothesis could not be tested. Teachers' age is a determining factor in students' achievement in all subtests. The poor reading performance of students whose primary school teachers' age is between 30-39 may not necessarily be attributed to the lack of qualification and preparedness to engage in reading texts with different formats in the classroom, characteristics of this stage in the life-cycle can also serve as an explanation for the emerged patterns, since this period generally requires an increasingly shared attention between work and family. 
Table 6.6 Summary of aspects of reading instruction influencing students' achievement in the continuous, mixed and non-continuous subtests

\begin{tabular}{|c|c|c|c|c|}
\hline Thematic unit & Variables & Continuous & Mixed & $\begin{array}{l}\text { Non- } \\
\text { continuous }\end{array}$ \\
\hline \multirow{7}{*}{$\begin{array}{l}\text { Teachers' } \\
\text { background }\end{array}$} & Age & $\mathrm{x}$ & $\mathrm{x}$ & $\mathrm{x}$ \\
\hline & Years spent teaching & $\mathrm{x}$ & $\mathrm{x}$ & $\mathrm{x}$ \\
\hline & Years spent teaching reading & $\mathrm{x}$ & $\mathrm{x}$ & $\mathrm{x}$ \\
\hline & Qualification & & $\mathrm{x}$ & $\mathrm{x}$ \\
\hline & Time spent reading for professional development & & $\mathrm{x}$ & \\
\hline & Time spent reading for pleasure & $\mathrm{x}$ & $\mathrm{x}$ & \\
\hline & $\begin{array}{l}\text { Teachers' satisfaction with their work in the measured } \\
\text { class }\end{array}$ & $\mathrm{x}$ & $\mathrm{x}$ & $\mathrm{x}$ \\
\hline \multirow{22}{*}{$\begin{array}{l}\text { Aspects of } \\
\text { teaching } \\
\text { reading and } \\
\text { reading } \\
\text { development }\end{array}$} & Frontal teaching & $\mathrm{x}$ & $\mathrm{x}$ & \\
\hline & Group work & & $\mathrm{x}$ & $\mathrm{x}$ \\
\hline & Pair work & $\mathrm{x}$ & $\mathrm{x}$ & $\mathrm{x}$ \\
\hline & Role-playing & $\mathrm{x}$ & & \\
\hline & Reading methods & & & $\mathrm{x}$ \\
\hline & Guided oral reading by teachers & $\mathrm{x}$ & $\mathrm{x}$ & $\mathrm{x}$ \\
\hline & Oral reading & & $\mathrm{x}$ & $\mathrm{x}$ \\
\hline & Silent reading & $\mathrm{x}$ & $\mathrm{x}$ & \\
\hline & Use of continuous texts & $\mathrm{x}$ & $\mathrm{x}$ & $\mathrm{x}$ \\
\hline & Use of non-continuous texts & & $\mathrm{x}$ & \\
\hline & Textbook & $\mathrm{x}$ & $\mathrm{x}$ & $\mathrm{x}$ \\
\hline & Use of interactive whiteboard & $\mathrm{x}$ & $\mathrm{x}$ & $\mathrm{x}$ \\
\hline & Teachers' computer use & $\mathrm{x}$ & & $\mathrm{x}$ \\
\hline & Teachers' internet use & & & $\mathrm{x}$ \\
\hline & Held reading lessons in a computer lab & & & $\mathrm{x}$ \\
\hline & Knowledge about online programs for teaching reading & $\mathrm{x}$ & $\mathrm{x}$ & $\mathrm{x}$ \\
\hline & Use of online programs for teaching reading & $\mathrm{x}$ & $\mathrm{x}$ & $\mathrm{x}$ \\
\hline & Oral assessment & $\mathrm{x}$ & $\mathrm{x}$ & $\mathrm{x}$ \\
\hline & $\begin{array}{l}\text { Assessment with instruments included in reading } \\
\text { textbooks }\end{array}$ & $\mathrm{x}$ & $\mathrm{x}$ & \\
\hline & Assessment with computer-based instruments & & & \\
\hline & Assessment with student portfolio & $\mathrm{x}$ & $\mathrm{x}$ & $\mathrm{x}$ \\
\hline & Frequency of administering reading tests a week & $\mathrm{x}$ & & \\
\hline \multirow{4}{*}{$\begin{array}{l}\text { Conditions of } \\
\text { teaching and } \\
\text { learning } \\
\text { reading }\end{array}$} & Number of weekly writing lessons & $\mathrm{x}$ & $\mathrm{x}$ & $\mathrm{x}$ \\
\hline & Number of weekly composition lessons & & & $\mathrm{x}$ \\
\hline & Teachers' opinion on students' decoding & $\mathrm{x}$ & $\mathrm{x}$ & $\mathrm{x}$ \\
\hline & Teachers' opinion on students' reading comprehension & $\mathrm{x}$ & $\mathrm{x}$ & $\mathrm{x}$ \\
\hline
\end{tabular}

Teachers' qualification plays a role in their students' understanding of texts that are organized differently from continuous texts. Students whose teachers also earned a degree in Hungarian Language and Literature besides the primary school teacher diploma outperform the rest of the population in the sample. Supposedly, training received in the 
Hungarian Language and Literature major equips teachers with such additional knowledge about reading skills and provides such a broad perspective on their development that have an added-value in teachers' productivity with respect to student achievement in the mixed and non-continuous subtests. Such additional knowledge may be that tables, maps and graphs can also be interpreted as texts and the processes involved in understanding them can be conceived as reading. Based on this train of thought, reading for the enhancement of teachers' own competences was expected to have similar benefits, however, this variable was only associated with achievement in the mixed subtest. Reading for pleasure was related to achievement in the continuous and mixed subtests. Presumably, reading for pleasure rarely involves reading texts with non-traditional formats and this may be the reason why no relationship could be found between this variable and achievement in the non-continuous subtest.

The findings of the present study regarding the relationship between years spent teaching and teaching reading and reading achievement are partly in tune with results gained from previous studies on teachers' productivity claiming that the impact of teachers' exprience on students' achievement is the strongest in the first few years of the carrer path. Data yielded evidence that the added-value of teaching experience is not consistent in any of the dimensions of reading literacy. This reinforces Rice's (2010) argument warning that the expectation that students of more experienced teachers have higher achievement is oversimplified. Just like age and time spent in the profession, teachers' satisfaction also has an impact on achievement in all three domains. It is generally held that teachers' satisfaction and students' achievement are proportionately aligned. Findings lend support to this. Satisfaction is part of the professional self-concept (Hercz, 2005), and self-concept and achievement are mutually related. The question that has been answered in case of students: what is the cause and what is the effect? (Józsa, 2007) can be addressed in case of teachers as well. I assume that the different extent of using continuous, mixed and non-continuous texts for teaching reading underlies the changing patterns across text formats. Mixed and non-continuous texts are used less frequently, information is seldom collected on how students understand them, therefore, they do not provide a sound basis for forming an opinion about satisfaction.

\subsubsection{Aspects of teaching reading and reading development}

Regarding methods of teaching, data show a clear pattern in each subtest: students' achievement is better where teachers use student-centered methods of teaching more frequently when teaching students to read. Instruction that is largely teacher directed is less beneficial in all of the domains.

It is a surprising outcome of the present study that even though no positive relationship was found between the chosen reading method and students' achievement at whole test level (Hódi, B. Németh, \& Tóth, 2017), a more detailed analysis yielded evidence that reading method does impact performance differently in the non-continuous subtest. Data showed that the whole word method is in students' favor when it comes to understanding the information conveyed by the table. I assume that the approach that starts from the whole text and moves towards the smaller units of sentences and words enables students to develop strategies or an approach that support the comprehension processes activated when reading non-continuous texts. Chall's argument (1967) that phonics nurtures logic, whereas the whole word method is based on memory can also be a future direction in studying the impact of reading methods on comprehension. Also, bottom-up processing is activated by specific data from the text, whereas top-down processing starts with general predictions based on higher level schemata (see Section 1.6). In other words, phonics is related to deductive 
reasoning, simple rules are applied, whereas with the whole word approach students recall and analyze too, but they seem to rely more on induction.

Results revealed that the chosen reading textbooks affect students' reading achievement, so teachers have to be mindful when making a choice. However, more precise analyses on the exact content and underlying instructional mechanisms are required to be able to identify the exact contribution of textbooks to the test scores of better performing students.

The findings also add to the critical dialogue on the role oral and silent reading plays in reading development, especially since the frequency of silent reading did have a significant impact on the understanding of the traditional continuous text, whereas oral reading did not. I do not intend to reinforce the false opposition of reading silently for understanding and reading aloud for speed. I wish to cast light upon the fact that these reading techniques and the extent they are used in the teaching and learning process have a unique contribution and role in understanding texts with different formats.

Findings yield evidence that using continuous texts for teaching reading provides a foundation for understanding the texts with mixed and the non-continuous formats. However, the use of non-continuous texts did not prove to be equally beneficial across the dimensions. Its impact was only visible in the case of the mixed subtest. Thus, it cannot be clearly concluded that teaching with a particular text format will guarantee success in the same dimension of reading literacy. This finding particularly holds true for the noncontinuous subtest.

The use of the studied ICT tools is related to second graders' achievement in various directions and to a variety of extent. Although data do not allow us to draw clear conclusions, findings imply that ICT may play a role in the development of students' skills in the continuous, mixed and non-continuous dimensions of reading literacy. However, data gained from the data collections make it visible that the effect is not uniform across the tested domains. In line with expectations, ICT-related factors are more likely to influence achievement in the non-continuous subtest. Primary school teachers' answers to the question what they use the computer for provide evidence that the internet is an integral part of reading classes (see descriptive statistics). The use of reading programs available on the internet has an adverse effect on the reading and understanding of non-linear texts. These results would offer a more straightforward interpretation if graphs, diagrams or other texts that do not include graphemes would have been used for assessment as a non-continuous text. However, the mere fact that the non-continuous text used for assessment (see Chapter 4 ) is dominantly constituted by letters and words, raises a question: why is there no positive impact of teachers' knowledge about online reading programs primarily focusing on the development of speech-sound associations on students' achievement in the non-continuous subtest?

Data also show that assessment instruments included in reading textbooks play a key role in students' development in reading continuous and mixed texts. The facts that teachers tend to rely on these tools and that their use is aligned with better performance suggest that textbook developers have a great responsibility. The lack of relationship between this variable and achievement in the non-continuous subtest is due to the lack or highly underrepresented nature of these text formats in reading textbooks. Textbook writers should guide teachers' teaching and assessment practices by including more non-traditional texts in their teaching materials.

\subsubsection{Conditions of teaching and learning reading}

Surprisingly, the weekly number of reading lessons dedicated to teaching students foundational skills that make them confident readers did not have a significant relationship 
with achievement in any of the subtests. However, the manifold influence of the weekly number of other lessons offering a variety of literacy-focused activities can be identified across the dimensions. According to the literature, reading supports synthesis, whereas writing enhances analysis and these two are related (Adamikné Jászó, 2006). Data provided evidence that writing is significantly related to the development of reading continuous, mixed and non-continuous texts. Additional information is needed to clarify how the weekly number of lessons modulate students' reading achievement. Most probably it is not the number of lessons that makes a difference but what teachers actually do and how they scaffold learners' development in their zone of proximal development.

Teachers' work and lesson plans are also influenced by what they think about the reading developmental level of their class. The present findings imply that in this period of teaching reading teachers can make more adequate judgments about their students' decoding than comprehension. However, they are uncertain when it comes to evaluating the quality of comprehension. An explanation for this may be that the processes of reading comprehension are in an early stage of development and students' problems with reading fluency can hinder comprehension which makes it difficult to form an adequate judgement about it. The results also yield evidence that teachers are best at evaluating students' developmental level of decoding in relation to reading continuous texts, as its development and assessment take place by means of texts associated with traditional reading. Conclusively, when it comes to the teaching and evaluation of decoding, teachers must have a more differentiated approach towards the construct of reading. Development and assessment must take place across different text formats.

\subsection{Conclusion}

We gain data on Hungarian students' reading literacy from numerous sources. Findings show that there is room for improvement. A lot of information is available on potential points of intervention but we have hardly any current data on the aspects of reading instruction and their impact on students' achievement in subtests representing different text formats during the period of learning to read. Most studies aiming to explore this domain measure only students' reading literacy with a continuous text or use a compound index calculated from students' average achievement in the different subtests. Therefore, the present large-scale assessment conducted among Hungarian second graders and their primary school teachers fills a niche. Yet another objective of this study was to start a scholary discussion on how the results can be refined and implemented into practice in order to improve Hungarian students' reading skills.

Primary school teachers' responses provide a snapshot on some aspects of teachers' background, aspects of teaching reading and reading development and conditions of teaching and learning reading at the time second graders' reading literacy was measured. In terms of teachers' background, the present findings confirm previous conclusions claiming that the teaching profession is characterized by a low number of new entries and the dominance of female teachers. Time spent reading for professional development leads us to the conclusion that many teachers are aware of the importance and necessity of life-long learning but this approach is not fully mirrored by the qualifications or the number of earned degrees. However, there are other prerequisites for advancement in teachers' carreer. Comparing the results with findings of previous studies, no remarkable changes can be reported regarding the employed reading and teaching methods, tools and weekly number of lessons dedicated to students' literacy development. Speech-processing problems are prevalent in the sample, and less than half of the classes are attended by students who need special education. These findings give reason for concern. 
Findings suggest that teachers' age, qualification, and satisfaction with their work in the classroom, the instructional and evaluation methods they employ, the textbooks they use for instruction, the frequency of using continuous texts and ICT for teaching reading, the number of Hungarian writing and composition lessons, and their opinions about the developmental level of students' decoding and reading comprehension may be key contributors to students' success in reading to a different extent across the dimensions of reading literacy. 


\section{CHAPTER 7}

\section{CONCLUSIONS AND FUTURE DIRECTIONS}

\subsection{Summary of findings}

This chapter summarizes the main findings of the issues explored in the literature reviews and the findings of the empirical studies in the order of they were presented. The studies were conducted with the aim of obtaining a better understanding of why students' reading achievement differs significantly when it comes to reading continuous, mixed and non-continuous texts. Drawing on the heuristic model of Snow and Sweet (2003) introduced in the theoretical part of the work, the first study examined the text and the reading processes, the second study focused on the reader, while the third study investigated the context of instruction. First, the conclusions and future directions are discussed. Second, the theoretical and practical implications are explored and finally, the limitations are looked into.

\subsubsection{The main findings of the literature reviews}

I can identify at least four main issues that emerged throughout my extensive review of the literature. First, there is a discrepancy in terms of text formats between the practices of system-level assessments and reading research in general since reading research both in Hungary and abroad does not typically feature a wide range of text formats. Second, the frameworks of system-level assessments are vague regarding the ways they claim strategies or approaches needed to read non-continuous texts to be different from the ones used when reading and understanding continuous texts. Third, the frameworks and the reports of system-level assessments are inconsistent with respect to text format as a main organizational element of reading literacy. Finally, the Hungarian research landscape is poor as it lacks empirical, especially representative research on many of the topics and domains covered in the studies.

\subsubsection{The first study}

The first study provides empirical evidence that reading texts with formats other than conventional ones belong to the construct of reading. Non-conventional text formats (i.e. mixed and non-continuous texts) including a wide-range of symbolic language and visual displays are legitimate components of reading comprehension. Top-down, bottom-up and interactive reading models (see Chapter 1) emphasize letter, sentence, paragraph and textlevel processing in the meaning making process and lack elaboration on what happens when e.g., words or sentences as self-contained units or grammatical cues are not present in the reading experience. Instructional reading programs have been guided by these theories (bottom up-phonic based instruction / top-down-whole word approach), therefore, prevailing reading methods keep conserving deficient thinking about reading comprehension. This view resulted in an overrepresentation of continuous texts in teachers' syllabi, which in turn lead to an incomplete formal schema referring to knowledge that different kinds of texts and discourses are distinguished by the ways in which the topic, propositions, and other information are linked together to form a unit (An, 2013). "Lack of such kind of knowledge also contributes considerably to the problems in reading comprehension" (An, 2013, p. 130). We argue that the gap in this knowledge should be bridged in order to improve students' reading literacy performance in mixed and non-continuous text formats.

Data yielded by the first study show that second graders' reading literacy develops significantly during the period of learning to read. The development is visible in all the three text formats. I assume that students' achievements are a result of both targeted instruction 
and an ever-growing familiarity with different text formats in everyday life and in the home environment. On the other hand, students' test scores differ along continuous, mixed and non-continuous text formats both in grades 2 and 4. A major future task is to follow up on the progress this cohort makes in reading literacy and to determine whether the achievement gap among text formats decreases or increases over time. The results suggest that the achievement disparity may disappear in upper elementary school grades, but according to OECD PISA reading literacy measures, this achievement gap seems to remain steady (OECD, 2016a).

A possible reason for this pattern of results was sought in the internal structure of reading literacy. Findings indicate that the extent to which cognitive aspects to reading literacy interact with different text formats could be a plausible explanation for the disparity in students' achievements. Data show that the cognitive aspects students use when reading a continuous text, a mixed text or a non-continuous text differ from each other. This is a promising finding: results indicate that putting the research question regarding the universal nature of reading processes into a developmental perspective can refine our knowledge accumulated in the present study. The question why and in what ways the cognitive aspects of the continuous text differ significantly from those of the mixed and non-continuous ones still remains unanswered. As the non-continuous text did not include reflection on form and content items requiring knowledge outside of the text, in upper grades the subtest needs to be extended to the whole range of cognitive aspects to reading to get a full picture on the dynamics between text format and cognitive processes.

Also, drawing on the versatility of non-continuous texts, in the next phase of the program, I plan to enrich the body of non-continuous texts with graphs and charts in order to examine how the dimensionality of cognitive aspects changes if the ratio of verbal and visual elements is modified and how it impacts the level of comprehension. Briefly, the precise nature of the link between text format and cognitive aspects needs to be further elaborated. Nevertheless, we argue that it is appropriate and useful for instructional purposes to classify processes involved in reading comprehension in terms of different forms of reading materials.

An alternative future direction may explore what role the reading precursors, especially, phonological awareness, rapid automatized naming and letter-sound processing have in reading non-continuous texts. The literature has found empirical evidence on the predictive power of these cognitive skills on later reading achievement in abundance; however, the relationship has only been established in relation to decoding and reading continuous texts (see Blomert \& Csépe, 2012; Török \& Hódi, 2015). These findings pose new questions: if these skills are claimed to be the constituents of reading models dominantly having letters, words and sentences as main constituents of texts to be read, what importance is attributed to reading precursors in reading texts where the coherence and cohesion is not provided with traditional constituents of texts?

Examining this phenomenon in other languages and countries may also be a way forward, since data show that although the text format achievement gap prevails in the majority of countries, there are countries with a difference in means in favour of noncontinuous texts (Kirsch, de Jong, Lafontaine, McQueen, Mendelovits, \& Monseur, 2002, p. 96).

I believe that the results provide valuable insights for stakeholders involved in students' reading development and pave the way for further analyses on the developmental tendencies regarding cognitive aspects (information retrieval, interpreting etc.) and text properties across genres and formats. 


\subsubsection{The second study}

The second study employed a student questionnaire and a mini questionnaire with twofold aims. The first objective was to collect descriptive data on Hungarian second graders' attitudes toward reading in general and the test, reading self-concept, the frequency of being engaged in reading texts with different formats when learning and students' ICT use. The second aim was to contextualize second graders' reading achievement in continuous, mixed and non-continuous text formats. In short, the study focused on the reader (Chapter 5). The characterization of such a young sample and linking the background data with reading proficiency filled a niche that no other studies have done so far. The questionnaire tapped into non-cognitive factors belonging to the psychological and ecological components of reading. Data showed that the psychological factors - with selfconcept having an outstandingly high value - play a key role in students' reading achievement. Evidently, ecological data is less directly related to achievement, the studied variables have only a minor contribution to students' reading proficiency. There were no substantial differences in the correlation coefficients between the examined variables across the text format subscales of reading literacy; the degree of relationship did not change markedly across text formats. Since the coefficients fell into the same range as far as the strength of correlation is concerned, we have to be cautious when interpreting the findings. Mostly minor differences were found, so I believe that involving other background variables in the study would be a more fruitful approach towards the meaningful investigation of the matter brought up in the dissertation.

Regression analysis showed that the majority of the factors account for students' achievement in different text format to various extents. However, we also have to be cautious when interpreting the explained variance of the independent variables on students' achievement in different text formats, since the difference between the regression coefficients is not substantial either. Path analyses would have been an adequate form for modeling the direct and indirect effects on reading achievement in the continuous, mixed and non-continuous format, however, despite repeated efforts towards building different models based on the literature, no model could be tested due to the small regression coefficient values. A meaningful relationship was demonstrated between the affective factors and between the school-related factors but these could not be linked to students' performance either at whole test or subtest level. This outcome also confirms the necessity of the expansion of the student questionnaire with more items and covering other domains like home environment and parent-child interaction.

The results of the mini questionnaire contribute to a better understanding of the relationship between students' attitude towards the test and the tasks measuring the skills that have been implicated as fundamental to proficient reading. Hopefully, it helped to put to rest any lingering doubts about the usability of different text formats and topics in teaching and assessment at a young age. It certainly showed that we need a more differentiated approach to the application of mixed and non-continuous texts and to the interpretation of the results achieved in these domains. The all-or-nothing perspective is not right in this case. We cannot simply say that it is natural that students achieve lower test scores in reading "non-traditional" texts because we assume that they are not familiar with them, they rarely, if at all read such texts at school or they do not like them or find them very difficult. Data show that the picture is even more diverse.

The heuristic model designed by Snow and Sweet (2003) provides a good starting point for further research (see Chapter 1). The reader, as one of the main elements of the comprehension model, can be studied from a wide array of perspectives. These include cognitive capacities like attention, memory and inferencing and various types of knowledge such as vocabulary, a more detailed examination of topic and domain knowledge than it was 
carried out in this study, and last but not least linguistic and discourse knowledge. Moreover, motivation also needs further multifaceted analyses, as was suggested by the work of Szenczi (2013).

Choosing other methods for studying the main issue addressed in this dissertation is also desirable. Interviews could contribute to a better understanding of why students gave a particular response to the questions. Additionally, concurrent and retrospective think-aloud protocols (Kuusela \& Paul, 2000) could be used to gather data involving students describing their actions, reporting on how they go about completing a task (Ericsson \& Simon, 1987).

\subsubsection{The third study}

The third study addressed the key issue of the dissertation from yet another angle: the context of teaching reading. Aspects of reading instructions were mapped out and related to second graders' achievement.

The acquisition of reading skills is a basic human right and a fundamental aspect of individual and national development. Yet, for many Hungarians, the printed word has little to say. Research has provided us with ample knowledge about why students encounter difficulties in reading. The importance of cognitive and affective factors and student background is clear. International surveys have shown that school-level factors also play significant roles in reading outcomes. However, a comprehensive examination of the personal, methodological and classroom aspects of reading instruction in second grade has not yet been carried out in a Hungarian context. The third study aimed to fill this gap by reporting on the results of a large-scale national study aiming to identify current trends in instructional practices in reading and to study the ways in which they relate to students' achievement in subtests representing different text formats. For these purposes, data from a questionnaire administered to 189 primary school teachers and a reading comprehension test completed by 3,220 second graders were linked.

Findings suggest that teachers' age, qualification, and satisfaction with their work in the classroom, the instructional and evaluation methods employed, the textbooks used for instruction, the frequency of using continuous texts and ICT for teaching reading, the number of Hungarian writing and composition lessons, and opinions about the developmental level of students' decoding and reading comprehension may all be key contributors to students' success in reading. However, the examination of the relationship between the study variables and achievement in the continuous, mixed and non-continuous subtests revealed changing patterns across the text formats that are difficult to interpret in light of the available data. It is clear that the aspects of teaching reading impact students' development in reading texts with different formats to varying degrees. Consequently, it is imperative that we further explore the underlying mechanisms so that teachers can differentiate, supplement or modify their existing practices to enable students to acquire an optimum level of reading skills. This study allows for framing new research questions and paves the way for new directions regarding students' development in different dimensions of reading literacy. I believe that future empirical studies focusing on this domain need to draw on a wide range of methods including classroom observation, analysis of teacherstudent interaction, case-studies and interviews. Additionally, it is important to broaden the horizons of the questionnaire and expand the reading literacy test, as was set forth regarding the future directions of the first study. For instance, the inclusion of geographical maps, floor maps or weather diagrams in the assessment as non-continuous texts would be beneficial. 


\subsection{Theoretical implications and educational importance}

This work has an important contribution to the body of knowledge that has been accumulated by reading research. First and foremost, the dissertation framed an issue and more specifically, set a research objective that has not been addressed and empirically examined so far. Students' reading literacy has been in the focus of numerous large-scale assessment programs over the past decades. With the exception of PIRLS, these studies rarely provide feedback on students' achievement in various text formats (Chapter 2). According to the reports, there is a significant difference between test scores achieved in the continuous and non-continuous subtests. However, analysis of this prevalent phenomenon falls short of the identification of variables related to the text, the reader and the context of instruction that may account for this achievement gap. The aim of the three studies was to complement the results of previous research by carrying out detailed analyses on how cognitive aspects function in the meaning-making process in various text formats, and how psychological and ecological factors work when reading texts of different formats. The dissertation provides a multilateral examination of the phenomenon based on the heuristic model of reading comprehension elaborated by Snow and Sweet (2003) in a relatively young sample. The results confirm the previously established points elaborated by Snow (2003) but also advance them. Results may pave the way for a more elaborate conceptualization of theories and models of reading comprehension. They may provide valuable insights for the stakeholders involved in students' reading development.

1. Theories defining texts as a complex sign system provide a more adequate framework for conceptualizing reading literacy than generativist and structuralist theories. Generativist and structuralist theories define text as an entity constituted by sentences and consider meaning as inherent at the levels of larger units of discourse. Theories defining texts as a complex sign system hold that even though texts are constituted by components, these components derive from semiotics.

2. The reading models and theories are insufficient and defective in that they rely on the formal features of language, mainly words and structure. They do not take into consideration that comprehending texts with different structures including symbols can also be viewed as reading.

3. The main methods used in reading instruction (i.e. phonics and whole word approach) stem from defective reading models. Therefore, they do not offer an appropriate platform for the development of skills required to understand non-continuous texts.

4. Both researchers, including textbook developers, and practitioners have to make sure that instruction, assessments and theoretical models provide an "adequate representation of the complexity of the target domain" (Snow, 2003, p. 193). Applying a single dimensional approach to reading literacy in terms of text format is not satisfactory.

5. A multiplicity of text formats must be integrated into the research design and the teaching and learning process, because the developmental level measured by a continuous text is not a reliable indicator of the reading developmental level in texts with other formats. Students' performance varies across text formats.

6. Text format determines how cognitive processes involved in reading comprehension work. Cognitive processes, at least in the first four years of formal reading development, are not as universal as suggested by the literature. For this reason, a differentiated approach should be taken in their assessment and development.

7. Current practices of reading instruction influence students' achievement in reading continuous, mixed and non-continuous texts to a different extent. Therefore, teachers need to modify or supplement them in order to be able to help students develop an optimum level of reading literacy in each of the dimensions. 


\subsection{Limitations}

The studies revealed several new and useful pieces of information but the research has at least four limitations. On the one hand, I am aware that reading as a cognitive process is a complex entity and students' reading achievement is influenced by multiple factors. Students' outcomes are affected by past school investments, family investments in the present and past, students' congenital skills and other coincidental circumstances (Kertesi, 2008). Not all of these could be integrated into the three studies. On the other hand, besides the larger picture outlined by using quantitative analyses, it is also important to look into the quality of the factors and resources. In the present dissertation, I applied a quantitative approach; thus, the findings have to be complemented and enriched by qualitative methods in order to be able to gain a more precise and deeper understanding of the relationships. Third, the reading assessments presented in the dissertation relied on closed-item formats for which reading assessment in general is frequently criticized (Sabatini \& O'Reilly, 2013). I acknowledge that reading is an interactive process where meaning is arbitrarily and creatively inferred by the reader and that closed-items put a constraint on the reader and guide and limit comprehension. However, the tests had to be developed by taking into consideration the features of the electronic assessment system (eDia). Finally, the use of scenarios in the reading assessment would have afforded more opportunities to make the assessment more diverse, purposeful, and motivating (Sabatini, O'Reilly \& Dean, 2013). However, I believe that measuring reading literacy in the traditional manner with unrelated texts was more appropriate to test the functioning of the reading processes when reading different text formats. Moreover, the execution of a test design infusing the principles of the Global Integrated Scenario-Based Assessment (Sabatini et al., 2013) was also hampered by the then-existing limitations of the testing platform. 


\section{ACKNOWLEDGEMENTS}

Words can hardly express how grateful I am to my supervisor, Nikolov Marianne, for her unremitting efforts to guide me in the maze of learning and instruction and generously sharing her expertise in multiple domains. Without her continuous encouragement, this dissertation would not have been possible.

I am indebted to Csapó Benő for guiding me towards the academic path and providing countless opportunities to improve professionally and personally. I owe special thanks to Fáyné Dombi Alice for opening doors for further professional development and believing in me.

I am grateful to the teachers of the Doctoral School of Education for introducing me to different aspects of learning and instruction. I am especially grateful to Molnár Gyöngyvér who was always available to discuss issues of statistical concern.

I am grateful to the reviewers, Hercz Mária and Szenczi Beáta, who were kind enough to read the whole dissertation, and offered useful, detailed feedback.

My appreciation also extends to my colleagues. Tóth Edit's friendship and relentless mentoring provided an invaluable contribution over the past decade. Her enthusiasm has always been a source of inspiration. Her astute insights and passion for educational research kept me on track with my research. Discussions with B. Németh Mária formed an inevitable part of each and every phase of the writing process. Her wisdom and knowledge played an indispensable role in the formation of the studies. They both provided insightful and encouraging critical feedback at all stages of the writing.

I would like to thank all the teachers and specialists for their participation in the development of the assessment instruments. My gratitude also extends to all the respondents for their cooperation in the studies.

I also thank all my former and present colleagues at the MTA-SZTE Research Group on the Development of Competencies for allowing me to access the assessment instruments and databases of previous research projects and providing a positive atmosphere and background where I could conduct research. I am deeply grateful to D. Molnár Éva, B. Németh Mária and Valuska Lajos whose tests paved the way for the online assessments used in the studies.

My coauthors have greatly contributed to shaping and refining my knowledge about reading over the years. Collaborating with them in different projects has been a pleasure.

This journey would not have been possible without my family who supported me in my pursuits and who have been riding the roller coaster of academic life with me. 


\section{REFERENCES}

Adamikné Jászó, A. (2001a). A magyar olvasástanitás története [The history of reading instruction in Hungary]. Budapest: Osiris.

Adamikné Jászó, A. (2001b). Hogyan tovább a harmadik évezredben? Az olvasástanítás történetének felhasználása az olvasáskutatásban és -tanításban [How to continue in the third millennium? Using the history of reading instruction in research and teaching practice]. Könyv és Nevelés, 3(1), 30-47. Retrieved from http://epa.oszk.hu/01200/01245/00009/cikk3.html

Adamikné Jászó, A. (2006). Az olvasás múltja és jelene: Az olvasás grammatikai, pragmatikai és retorikai megközelitésben [The past and present of reading: A grammatical, pragmatic and rethorical approach to reading]. Budapest: Trezor Kiadó.

Adams, R., \& Wu, M. (Eds.). (2002). PISA 2000 technical report. Paris: OECD Publishing. Retrieved from https://www.oecd.org/pisa/data/33688233.pdf

Alderson, J. C. (2000). Assessing reading. Cambridge: Cambridge University Press.

Alderson, J. C., Clapham, C., \& Wall, D. (1995). Language test construction and evaluation. Cambridge: Cambridge University Press.

Alderson, J. C., de Jong, J., Kirsch, I., Lafontaine, D., Lumley, T., Mendelovits, J., \& Searle, D. (2009). How can we predict the difficulty of PISA reading items? The process of describing item difficulty. Retrieved from https://www.researchgate.net/publication/267961453_How_can_we_predict_the_difficulty_of_PISA_rea ding_items_The_process_of_describing_item_difficulty

Alexander, J. E., \& Filler, R.C. (1976). Attitudes and reading. Newark, DE: International Reading Association.

An, S. (2013). Schema theory in reading. Theory and Practice in Language Studies, 3(1), 130-134. doi:10.4304/tpls.3.1.130-134

Anthony, J. L., \& Francis, D.J. (2005). Development of phonological awareness. Current Directions in Psychological Science, 14(5), 255-259.

Aram, D. (2010). Writing with young children: A comparison of paternal and maternal guidance. Journal of Research in Reading, 33(1), 4-19.

Bajomi, I., Berényi, E., Neumann, E., \& Vida, J. (2009). The reception of PISA in Hungary. Knowledge and Policy, Orientation 3: Supra-national instruments: fabrication, circulation and use, 309-317.

Retrieved from http://knowandpol.eu/IMG/pdf/o31.pisa.hungary.pdf

Balázsi, I. (2007). Results of the National Assessment of Basic Competencies in Hungary. Background paper prepared for the Education for All Global Monitoring Report 2008.

Retrieved from http://unesdoc.unesco.org/images/0015/001555/155573e.pdf

Balázsi, I., Szabó, A., Szabó, V., Szalay, B., \& Szepesi, I. (2006). Országos kompetenciamérés 2004. Összefoglaló tanulmány [The National Assessment of Basic Competencies 2006. A comprehensive study]. Budapest: SuliNova Kht.

Retrieved from

https://www.oktatas.hu/pub_bin/dload/kozoktatas/meresek/orszmer2004/OKM2004_osszefoglalo_tanulm any.pdf

Balázsi, I., Felvégi, E., Rábainé Szabó, A., \& Szepesi, I. (2006). Országos kompetenciamérés 2006 Tartalmi keret [Framework for the National Assessment of Basic Competencies 2006]. Budapest: SuliNova Kht. Retrieved from https://www.oktatas.hu/pub_bin/dload/kozoktatas/meresek/orszmer2006/tartalmikeret2006.pdf

Balázsi, I., Lak, Á. R., \& Szabó, V. (2011). Országos kompetenciamérés 2010. Országos jelentés [The National Assessment of Basic Competencies 2010. National report]. Budapest: Oktatási Hivatal. Retrieved from https://www.oktatas.hu/pub_bin/dload/kozoktatas/meresek/orszmer2010/orszagos_jelentes_2010.pdf

Balázsi, I., Lak, Á. R., Szabó, V., \& Vadász, Cs. (2013). Országos kompetenciamérés 2012. Országos jelentés [The National Assessment of Basic Competencies 2012. National report]. Budapest: Oktatási Hivatal. Retrieved from https://www.oktatas.hu/pub_bin/dload/kozoktatas/meresek/orszmer2012/OKM_orszagos_jelentes_2012.pdf 
Balázsi, I., Lak, Á. R., Szabó, V., Szabó, L. D., \& Vadász, Cs. (2014). Országos kompetenciamérés 2013. Országos jelentés [The National Assessment of Basic Competencies 2013. National report]. Budapest: Oktatási Hivatal. Retrieved from https://www.oktatas.hu/pub_bin/dload/kozoktatas/meresek/orszmer2013/Orszagos_jelentes_2013_03.pdf

Balázsi, I., Lak, Á. R., Ostorics, L., Szabó, L. D., \& Vadász, Cs. (2015). Országos kompetenciamérés 2014. Országos jelentés [The National Assessment of Basic Competencies 2014. National report]. Budapest: Oktatási Hivatal. Retrieved from https://www.oktatas.hu/pub_bin/dload/kozoktatas/meresek/orszmer2014/OKM_2014_Orszagos_jelentes.pdf

Balázsi, I., Lak, Á. R., Ostorics, L., Szabó, L. D., \& Vadász, Cs. (2016). Országos kompetenciamérés 2015. Országos jelentés [The National Assessment of Basic Competencies 2015. National report]. Budapest: Oktatási Hivatal. Retrieved from https://www.oktatas.hu/pub_bin/dload/kozoktatas/meresek/orszmer2015/Orszagos_jelentes_2015_2kor.pdf

Balázsi, I., Takácsné Kárász, J., Lak, Á. R., Ostorics, L., Szabó, L. D., \& Vadász, Cs. (2017). Országos kompetenciamérés 2016. Országos jelentés [The National Assessment of Basic Competencies 2016. National report]. Budapest: Oktatási Hivatal. Retrieved from https://www.oktatas.hu/pub_bin/dload/kozoktatas/meresek/orszmer2017/Orszagos_jelentes_2016.pdf

Balázsi, I., Balkányi, P., Ostorics, L., Palincsár, I., Rábainé Szabó, A., Szepesi, I., Szipőcsné Krolopp, J., \& Vadász, Cs. (2014). Az Országos kompetenciamérés tartalmi keretei. Szövegértés, matematika, háttérkérdőivek [Frameworks for the National Assessment of Basic Competencies. Reading, mathematics, background questionnaires]. Budapest: Oktatási Hivatal. Retrieved from: https://www.oktatas.hu/pub_bin/dload/kozoktatas/meresek/orszmer2014/AzOKMtartalmikeretei.pdf

Balázsi, I., Balkányi, P., Bánfi, I., Szalay, B., \& Szepesi, I. (2012). PIRLS és TIMSS 2011. Összefoglaló jelentés a 4. évfolyamos tanulók eredményeiröl. Budapest: Oktatási Hivatal. Retrieved from https://www.oktatas.hu/pub_bin/dload/kozoktatas/nemzetkozi_meresek/pirls/PIRLS_TIMSS_2011_ossze foglalo_jelentes_4evf_eredmenyeirol.pdf

Balázsi, I., Lak, Á. R., Ostorics, L., Szabó, L. D., \& Vadász, Cs. (2016). Országos kompetenciamérés 2015. Országos jelentés. Budapest: Oktatási Hivatal. Retrieved from https://www.oktatas.hu/pub_bin/dload/kozoktatas/meresek/orszmer2015/Orszagos_jelentes_2015_2kor.pdf

Balázsi, I., Ostorics, L., Szalay B., \& Szepesi, I. (2010). PISA 2009. Összefoglaló jelentés. Szövegértés tíz év távlatában [A report on Hungarian students' reading comprehension in the past decade]. Budapest: Oktatási Hivatal. Retrieved from https://www.oktatas.hu/pub_bin/dload/kozoktatas/nemzetkozi_meresek/pisa/pisa_2009_osszfogl_jel_110 111.pdf

Balkányi, P., \& Ostorics, L. (2012). A szövegértés tartalmi keretének változása [Changes in the reading framework]. Educatio, 24(3), 465-488.

Bárány, I. (1896). Tanitók könyve. Kalauz a nevelés és tanitás vezetésére [Teachers' guide to teaching and education]. Budapest: Lauffer Vilmos.

Báthory, Z. (1997). Tanulók, iskolák - különbségek. Egy differenciális tanitáselmélet vázlata (2 ${ }^{\text {nd }}$ ed.) [Students, schools and differences. An outline of a differential theory of instruction]. Budapest: OKKER Kiadó.

Beach, R., \& Appleman, D. (1984). Reading strategies for expository and literary text types. In A. C. Purves, \& O., S. Niles (Eds.), Becoming readers in a complex society: Eighty-third yearbook of the National Society for the Study of Education (pp. 115-143). Chicago: University of Chicago Press.

Bechger, T. M., van Schooten, E., de Glopper, C., \& Hox, J. J. (1998). The validity of international surveys of reading literacy: The case of the IEA reading literacy study. Studies in Educational Evaluation, 24(2), 99-125.

BECTA (2000). A preliminary report for the DfEE on the relationship between ICT and primary school standards. Coventry: BECTA.

Bennett, R. E. (1998). Reinventing assessment: Speculations on the future of large-scale educational testing. Princeton, NJ: Policy Information Center, Educational Testing Service. Retrieved from http://files.eric.ed.gov/fulltext/ED424254.pdf

Bergen, E., Zuijen, T., Bishop, D., \& de Jong, P. F. (2017). Why are home literacy environment and children's reading skills associated? What parental skills reveal. Reading Research Quarterly, 52(2), 147160. doi: 10.1002/rrq.160

Berkman, N. D., Davis, T. C., \& McCormack, L. (2010). Health literacy: what is it? Journal of Health Communication, 15(S2), 9-19. doi: 10.1080/10810730.2010.499985 
Bernard, W. H. (1972). Psychology of learning and teaching. New York, USA: McGraw - Hill Book Company.

Berthelot, J. M., Ross, N., \& Tremblay, S. (2001). Factors affecting Grade 3 student performance in Ontario: A multilevel analysis. Education Quarterly Review, 7(4), 25-36.

Bhola, H. S. (1970). Functional literacy - The concept and the program. Washington, D.C.: U.S. Department of Health, Education \& Welfare, Office of Education. Retrieved from http://files.eric.ed.gov/fulltext/ED055743.pdf

Binkley, M., \& Rust, K. (Eds.). (1994). Reading Literacy in the United States. Technical Report. Washington, D.C.: U.S. Department of Education, National Center for Education Statistics.

Blomert, L., \& Csépe, V. (2012). Psychological foundations of reading acquisition and assessment. In B. Csapó, \& V. Csépe (Eds.), Framework for diagnostic assessment of reading (pp. 17-78). Budapest: Nemzeti Tankönyvkiadó.

Bloom, B. S. (1969). Cross-national study of educational attainment: Stage I of the I.E.A. investigation in six subject areas (Vols. 1-2). Washington, D.C.: Office of Education (DHEW).

Bollen, K. A. (1989). A new incremental fit index for general structural equation models. Sociological Methods \& Research, 17(3), 303-316.

Bong, M., \& Skaalvik, E. M. (2003). Academic self-concept and self-efficacy: How different are they really?. Educational Psychology Review, 15(1), 1-40.

Borbáth, K., \& Horváth, H. A. (2012). Pedagógusnők - női szerepválságban? A mai magyar nőkérdés néhány összefüggése és közvetett hatásuk a tanulókra [Female educators in role crisis? Some insights into the Hungarian female issue and their indirect impact on students]. Új Pedagógiai Szemle, 62(11-12), 3-9.

Bormuth, J. R. (1973). Reading literacy: Its definition and assessment. Reading Research Quarterly, 9(1), 766.

Burgess, S. R., Hecht, S. A., \& Lonigan, C. J. (2002). Relations of the home literacy environment (HLE) to the development of reading-related abilities: A one-year longitudinal study. Reading Research Quarterly, 37(4), 408-426.

Bus, A. G., van IJzendoorn, M. H., \& Pellegrini, A. D. (1995). Joint book reading makes for success in learning to read: A meta-analysis on intergenerational transmission of literacy. Review of Educational Research, 65(1), 1-21.

Carnoy, M., \& Loeb, S. (2002). Does external accountability affect student outcomes? A cross-state analysis. Educational Evaluation and Policy Analysis, 24(4), 305-331.

Carrell, P. L. (1983). Some issues in studying the role of schemata, or background knowledge, in second language comprehension. Reading in a Foreign Language, 1(2), 81-92.

Carrell, P. L., \& Eisterhold, J. C. (1983). Schema theory and ESL reading pedagogy. TESOL Quarterly, 17(4), 553-573.

Carroll, J. B. (1993). Human cognitive abilities. Cambridge: Cambridge University Press.

Carroll, J. M., Snowling, M. J., Hulme, C., \& Stevenson, J. (2003). The development of phonological awareness in preschool children. Developmental Psychology, 39(5), 913-923.

Carver, R. P. (1992). Effect of prediction activities, prior knowledge, and text type upon amount comprehended: using raiding theory to critique schema theory research. Reading Research Quarterly, 27(2), 165-174.

Chall, J. S. (1967). Learning to read: The great debate. New York: McGraw-Hill.

Chall, J. S. (1996). Stages of reading development ( $2^{\text {nd }}$ ed.). Fort Worth, TX.: Harcourt Brace.

Chall, J., \& Dale, E. (1995). Readability revisited: The new Dale-Chall readability formula. Cambridge, MA: Brookline Books.

Chambers, A. (2011). Tell me (children, reading and talk) with The reading environment. Stroud: Thimble Press.

Champagne, M. C. (2008). Basic writing, binaries, and bridges: Difference and power in the production and reception of representations of students. Ann Arbor, MI: ProQuest LLC.

Chapman, J. W., Tunmer, W. E., \& Prochnow, J. E. (2000). Early reading-related skills and performance, reading self-concept, and the development of academic self-concept: A longitudinal study. Journal of Educational Psychology, 92(4), 703-708. http://dx.doi.org/10.1037/0022-0663.92.4.703

Chen, X., Dronjic, V., \& Helms-Park, R. (Eds.). (2015). Reading in a second language: Cognitive and psycholinguistic issues. New York, NY: Routledge. 
Chiu, M. M., McBride-Chang, C., \& Lin, D. (2012). Ecological, psychological, and cognitive components of reading difficulties: Testing the component model of reading in fourth graders across 38 countries. Journal of Learning Disabilities, 45(5), 391-405.

Chodkiewicz, H. (2014). Explaining the concept of 'reading to learn': A way forward in exploring the issues of L2/FL reading competence. In H. Chodkiewicz, \& M. Trepczyńska (Eds.), Language skills: Traditions, transitions and ways forward (pp. 238-255). Newcastle upon Tyne: Cambridge Scholars Publishing.

Clay, M. (1966). Emergent reading behavior. University of Auckland: New Zealand.

Cohen, J. (1988). Statistical power analysis for the behavioral sciences $\left(2^{\text {nd }}\right.$ ed.). Hillsdale, NJ: Erlbaum

Coleman, J. S., Campbell, E. Q., Hobson, C. J., McPartland, J., Mood, A. M., Weinfeld, F. D., \& York, R. L. (1966). Equality of educational opportunity. Washington, D.C.: U.S. Department of Health, Education and Welfare, U.S. Government Printing Office.

Cox, K. E., \& Guthrie, J. T. (2001): Motivational and cognitive contributions to students' amount of reading. Contemporary Educational Psychology, 26(1), 116-131.

Creswell, J. W. (2003). Research design: Qualitative, quantitative and mixed methods approaches ( $2^{\text {nd }}$ ed.) Thousand Oaks, California: Sage Publications.

Cresswell, J., \& Vayssettes, S. (2006). Assessing scientific, reading and mathematical literacy: A framework for PISA 2006. Paris: OECD Publishing.

Csala, I., \& Ranschburg, Á. (2002). Pedagógiai értékelés másképpen [Educational evaluation in a different way]. Új Pedagógiai Szemle, 52(1), 66-72.

Csapó, B. (Ed.) (1998). Az iskolai tudás [School knowledge]. Budapest: Osiris Kiadó.

Csapó B. (2004). A tudás és a kompetenciák [Knowledge and competences]. In B. Csapó (Ed.), Tudás és iskola [Knowledge and school] (pp. 41-55). Budapest: Müszaki Könyvkiadó.

Csapó, B. (2010). Goals of learning and the organization of knowledge. In E. Klieme, D. Leutner, \& M. Kenk (Eds.), Kompetenzmodellierung. Zwischenbilanz des DFG-Schwerpunktprogramms und Perspektiven des Forschungsansatzes (pp. 12-27). Weinheim u.a.: Beltz. Retrieved from http://www.pedocs.de/volltexte/2010/3343/pdf/Csapo_Goals_of_Learning_D_A.pdf

Csapó, B. (2014). A szegedi iskolai longitudinális program [The Hungarian Educational Longitudinal Programme]. In J. Pál, \& Z. Vajda (Eds.), Szegedi Egyetemi Tudástár 7. Bölcsészet- és társadalomtudományok (pp. 117-166). Szeged: Szegedi Egyetemi Kiadó.

Csapó, B., \& Csépe, V. (2012). Framework for diagnostic assessment of reading. Budapest: Nemzeti Tankönyvkiadó.

Csapó, B., Józsa, K., Steklács, J., Hódi, Á., \& Csíkos, Cs. (2012). Diagnostic assessment frameworks for reading: Theoretical foundations and practical issues. In B. Csapó, \& V. Csépe (Eds.), Framework for diagnostic assessement of reading (pp. 189-218). Budapest: Nemzeti Tankönyvkiadó.

Csapó, B., Lőrincz, A., \& Molnár, Gy. (2012). Innovative assessment technologies in educational games designed for young students. In D. Ifenthaler, D. Eseryel, \& X. Ge (Eds.), Assessment in game-based learning: foundations, innovations, and perspectives (pp. 235-254). New York: Springer. doi: 10.1007/978-1-4614-3546-4_13

Csapó, B., Molnár, Gy., \& R. Tóth, K. (2008). A papír alapú tesztektől a számítógépes adaptív tesztelésig: a pedagógiai mérés-értékelés technikájának fejlődési tendenciái [From paper-and-pencil tests to computerbased adaptive testing: the developmental tendencies of educational measurement and assessment]. Iskolakultúra, 18(3-4), 3-16.

Csapó, B., Steklács, J., \& Molnár, Gy. (Eds.). (2015). Az olvasás-szövegértés online diagnosztikus értékelésének tartalmi keretei [Framework for the online diagnostic assessment of reading]. Budapest: Oktatáskutató és Fejlesztő Intézet.

Csépány, N. (2008). A szövegértő olvasás megalapozása az első osztályban [Laying the foundations of reading comprehension in first grade]. Elektronikus Könyv és Nevelés, 10(1).

Retrieved from http://epa.oszk.hu/01200/01245/00037/csn_0801.htm

Csépe, V. (2006). Az olvasó agy [The reading brain]. Budapest: Akadémiai Kiadó.

Csépe, V. (2014). Az olvasás rendszere, fejlődése és modelljei. In Cs. Pléh, \&Á. Lukács Ágnes (Eds.), Pszicholingvisztika 1-2: Magyar pszicholingvisztikai kézikönyv (pp. 339-370). Budapest: Akadémiai Kiadó.

Csíkos, Cs. (2006). Nemzetközi rendszerszintű felmérések tanulságai az olvasástanítás számára [Lessons that reading instruction in Hungary can learn from the international assessment programs]. In K. Józsa (Ed.), 
Az olvasási képesség fejlödése és fejlesztése [The development and improvement of reading skills] (pp. 175-186). Budapest: Dinasztia Tankönyvkiadó.

D. Molnár, É., Molnár, E. K., \& Józsa, K. (2012). Az olvasásvizsgálatok eredményei [The results of reading surveys]. In B. Csapó (Ed.), Mérlegen a magyar iskola [Weighing the Hungarian school system] (pp. 1781). Budapest: Nemzeti Tankönyvkiadó.

Darling-Hammond, L. (2000). Teacher quality and student achievement: A review of state policy evidence. Education Policy Analysis Archives, 8(1).

Retrieved from https://bdgrdemocracy.files.wordpress.com/2011/08/teachereducation1.pdf doi: $10.14507 /$ epaa.v8n1.2000

Davis, F. B. (1968). Research in comprehension in reading. Reading Research Quarterly, (3)4, 499-545.

de Beaugrande, R., \& Dressler, W. U. (1981). Introduction to text linguistics. London: Longman.

Debes, J. (1968). Some foundations of visual literacy. Audiovisual Instruction, (13), 961-964.

Deci, E. L., \& Ryan, R. M. (1987). The support of autonomy and control of behavior. Journal of Personality and Social Psychology, 53(6), 1024-1037.

Deme, L. (1979). A szöveg alaptermészetéröl [About the fundamental nature of text]. In I. Szathmári, \& I. Várkonyi (Eds.), A szövegtan a kutatásban és az oktatásban [Text linguistics in research and education] (pp. 57-65). Budapest: Magyar Nyelvtudományi Társaság.

Denckla, M., \& Cutting, L. (1999). History and significance of rapid automatized naming. Annals of Dyslexia, 49(1999), 29-42. Retrieved from http://www.jstor.org/stable/23768281

Dobi, E. (2011). A szemiotikai textológia a magyar szövegtani kontextusban: Terminológiai kérdések a magyar nyelv szövegtanában [Semiotic textology in a Hungarian text linguistics context: Issues of terminology in Hungarian text linguistics]. In E. Dobi (Ed.), A szövegösszefüggés elméleti és gyakorlati megközelitési módjai. Poliglott terminológiai és fogalmi áttekintés [Theoretical and practical approaches to text cohesion: A polyglot overview of terms and definitions] (pp. 11-36). Debrecen: Debreceni Egyetemi Kiadó.

Dweck, C. S. (2008). Mindset: The new psychology of success. New York: Random House.

Dymock, S. (2005). Teaching expository text structure awareness. The Reading Teacher, 59(2), 177-181.

Edmonds, R. R. (1983). Search for effective schools: The identification and analysis of city schools that are instructionally effective for poor children (Final report). East Lasing: Michigan State University.

Elley, W. B. (1992). How in the world do students read? IEA Study of Reading Literacy. The Hague: IEA.

Elley, W. B. (1994). The IEA study of reading literacy: Achievement and instruction in thirty-two school systems. Great Britain, Exeter: Pergamon.

Ericsson, K., \& Simon, H. (1987). Verbal reports on thinking. In C. Faerch, \& G. Kasper (Eds.), Introspection in Second Language Research (pp. 24-54). Clevedon, Avon: Multilingual Matters.

European Commission/EACEA/Eurydice (2015). The teaching profession in Europe: Practices, perceptions, and policies. Eurydice report. Luxembourg: Publications Office of the European Union. PDF ISBN 978-92-9201-886-3. doi: 10.2797/031792

Eurostat database (2017). Retrieved from http://ec.europa.eu/eurostat/web/education-andtraining/data/database

Evans, M. D. R., Kelley, J., \& Sikora, J. (2014). Scholarly culture and academic performance in 42 nations. Social Forces, 92(4), 1573-1605. https://doi.org/10.1093/sf/sou030

Farrall, M. L. (2012). Reading assessment: Linking language, literacy, and cognition. Hoboken, New Jersey: John Wiley \& Sons.

F. Joó, A. (2012). Olvasási attitüd: fiú-lány különbségek [Reading attitude: gender differences]. Iskolakultúra, 22(10), 43-57.

F. Joó, A. (2013). Az olvasási attitüd kutatása Mathewson modellje alapján [The investigation of reading attitude based on Mathewson's model]. Anyanyelv-pedagógia, 2013(2).

Retrieved from http://www.anyanyelv-pedagogia.hu/cikkek.php?id=452

Fáyné Dombi, A., Hódi, Á., \& Kiss, R. (2016). IKT az óvodában: kihívások és lehetőségek [ICT in kindergarten: Challenges and opportunities]. Magyar Pedagógia, 116(1), 91-117. doi: 10.17670/MPed.2016.1.91

Ferguson, R. F. (1991). Paying for public education: New evidence on how and why money matters. Harvard Journal on Legislation, 28(2), 465-498. 
Fishbein, M., \& Ajzen, I. (1975). Belief, attitude, intention and behavior: An introduction to research and theory. Reading, PA: Addison-Wesley.

Fraillon, J., Ainley, J., Schulz, W., Friedman, T., \& Gebhardt, E. (2014). Preparing for life in a digital age. The IEA international computer and information literacy study. International report. Springer International Publishing: Switzerland. doi: 10.1007/978-3-319-14222-7

Furnes, B., \& Samuelsson, S. (2011). Phonological awareness and rapid automatized naming predicting early development in reading and spelling: Results from a cross-linguistic longitudinal study. Learning and Individual Differences, 21(1), 85-95.

Galton, F. (1874). English men of science: Their nature and nurture. London: Macmillan \& Co. Retrieved from http:/galton.org/books/men-science/pdf/galton-men-science-1up.pdf

Goodman, K. S. (1967). Reading: A psycholinguistic guessing game. Journal of the Reading Specialist, 6(4), 126-135. http://dx.doi.org/10.1080/19388076709556976

Gósy, M. (2008). A szövegértő olvasás. [Reading comprehension]. Anyanyelv-pedagógia, 2008(1). Retrieved from http://www.anyanyelv-pedagogia.hu/cikkek.php?id=25.

Gough, P. B. (1972). One second of reading. In J. F. Kavanagh, \& I. G. Mattingly (Eds.), Language by ear and by the eye (pp. 331-358). Cambridge, MA: MIT Press.

Goswami, U., \& Bryant, P. (1990). Phonological skills and learning to read. London: Lawrence Erlbaum Associates.

Graff, H. J. (1991). The literacy myth: Cultural integration and social structure in the nineteenth century. New Brunswick, New Jersey: Transaction Publishers.

Hagymásy, T., \& Könyvesi, T. (2016). Köznevelési statisztikai évkönyv 2014/2015 [Statistical yearbook of public education 2014/2015]. Budapest: Emberi Erőforrások Minisztériuma Köznevelésért Felelős Államtitkárság.

Halász, G., \& Lannert, J. (Eds.). (1998). Jelentés a magyar közoktatásról [Report on the public education of Hungary]. Budapest: Országos Közoktatási Intézet.

Halász, G., \& Lannert, J. (Eds.). (2000). Jelentés a magyar közoktatásról [Report on the public education of Hungary]. Budapest: Országos Közoktatási Intézet.

Halász, G. (2000). Az oktatás minősége és eredményessége [The quality and effectiveness of public education]. In G. Halász, \& J. Lannert (Eds.), Jelentés a magyar közoktatásról [Report on the public education of Hungary] (pp. 303-326). Budapest: Országos Közoktatási Intézet.

Hanushek, E. A., \& Raymond, M. E. (2005). Does school accountability lead to improved student performance?. Journal of Policy Analysis and Management, 24(2), 297-327.

Henk, W. A., \& Melnick, S. A. (1995). The Reader Self-Perception Scale (RSPS): A new tool for measuring how children feel about themselves as readers. The Reading Teacher, 48(6), 470-482.

Hercz, M. (2005). Pedagógusok szakember- és gyermekképe (gondolatok a kognitív fejlődésről vallott nézetek megismerésének tükrében) [Teachers' concepts of experts and children (reflections on examining interpretations of cognitive development). Magyar Pedagógia, 105(2), 153-184.

Hódi, Á., Adamikné Jászó, A., Józsa, K., Ostorics, L., \& Zsigriné Sejtes, Gy. (2015). Az olvasás-szövegértés alkalmazási dimenziójának online diagnosztikus értékelése [The online diagnostic assessment of the socio-cultural dimension of reading]. In B. Csapó, J. Steklács, \& Gy. Molnár (Eds.), Az olvasásszövegértés online diagnosztikus értékelésének tartalmi keretei [Framework for the online diagnostic assessment of reading] (pp. 105-190). Budapest: Oktatáskutató és Fejlesztő Intézet.

Hódi, Á., B. Németh, M., \& Tóth, E. (2017). Második évfolyamos tanulók szövegértés teljesítményének alakulása az olvasástanítás személyi, módszertani és környezeti feltételeinek tükrében [Aspects of reading instruction affecting second graders' reading comprehension outcomes]. Magyar Pedagógia, 117(1), 95136. doi: 10.17670/MPed.2017.1.95

Hódi, Á., B. Németh, M., Korom, E., \& Tóth, E. (2015). A Máté-effektus: a gyengén és jól olvasó tanulók jellemzése a tanulás környezeti és affektív jellemzői mentén [The Matthew-effect: The environmental and affective characteristics of good and poor readers]. Iskolakultúra, 25(4), 18-30. doi: 10.17543/ISKKULT.2015.4.18

Hódi, Á., \& Tóth, E. (2013). Analyses for a better understanding of students' reading achievement along different text formats. 15th Biennial Conference Earli, Munich, Germany, 27-31 August 2013.

Hódi, Á., \& Török, T. (2015). The relationship between students' reading achievement in different text formats and cognitive aspects to reading. In Toward justice: Culture, language, and heritage in education 
research and praxis. Chicago, USA, 16-20 April 2015. Washington: American Educational Research Association, p. 335.

Hódi, Á., Török, T., \& Kiss, R. (2014). Examining the relationship between text format and cognitive aspects to reading. In EARLI JURE 2014: Learning and instruction inside out: Contribution of Junior Researchers. Nicosia, Cyprus, 30 June-04 July 2014, p. 56.

Horváth, Zs. (1997). Szövegek és olvasóik. Helyzetkép a tanulók szövegértéséről [Texts and readers. Snapshot on students' reading comprehension]. In P. Vári (Ed.), Monitor'95: A tanulók tudásának felmérése [Monitor'95: Assessing students' literacy] (pp. 105-201). Budapest: Országos Közoktatási Intézet.

Hurd, P. D. (1958): Science literacy: Its meaning for American schools. Educational Leadership, 16(1), 1316.

IES NCES (2017). PIRLS countries. Retrieved from http://nces.ed.gov/surveys/pirls/countries.asp

Imre, N., \& Nagy, M. (2003). Pedagógusok [Teachers]. In G. Halász, \& J. Lannert (Eds.), Jelentés a közoktatásról [Report on the public education of Hungary] (pp. 273-307). Budapest: Országos Közoktatási Intézet.

Irwin, M. P. (1991). National Literacy Act of 1991: Major Provisions of P.L. 102-73. CRS Report for Congress. Library of Congress, Washington, D.C. Congressional Research Service. Retrieved from http://files.eric.ed.gov/fulltext/ED341851.pdf

Jacob, B. A. (2005). Accountability, incentives and behavior: The impact of high-stakes testing in the Chicago Public Schools. Journal of public Economics, 89(5), 761-796.

Jennings, K. D. (1993). Mastery motivation and the formation of self-concept from infancy through early childhood. In J. D. Messer (Ed.), Mastery motivation in early childhood: Development, measurement and social processes (pp. 36-54). New York: Routledge.

John-Steiner, V., \& Mahn, H. (1996). Sociocultural approaches to learning and development: A Vygotskian framework. Educational Psychologist, 31(3-4), 191-206.

Johnson, D. D. (1974). Sex differences in reading across cultures. Reading Research Quarterly, 9(1), 67-86. doi: $10.2307 / 747228$

Johnson, K. A. (2000). Do computers in the classroom boost academic achievement? A report of the Heritage Center for Data Analysis. Retrieved from http://files.eric.ed.gov/fulltext/ED442915.pdf

Joncas, M., \& Foy, P. (2012). Sampling design in TIMSS and PIRLS. In M.O. Martin, \& I.V.S. Mullis, (Eds.), Methods and procedures in TIMSS and PIRLS 2011 (pp. 1-21). Chestnut Hill, MA: TIMSS \& PIRLS International Study Center, Boston College.

Józsa, K. (2007). Az elsajátítási motiváció [Mastery motivation]. Budapest: Műszaki Kiadó.

Józsa, K., \& Steklács, J. (2009). Az olvasástanítás kutatásának aktuális kérdései [Current trends in research on reading instruction]. Magyar Pedagógia, 109(4), 365-397.

Józsa, K., Steklács, J., Hódi, Á., Csíkos, Cs., Adamikné Jászó, A., Molnár. E., K., \& Szenczi, B. (2012). Detailed framework for diagnostic assessment of reading. In B. Csapó, \& V. Csépe (Eds.), Framework for diagnostic assessment of reading (pp. 215-306). Budapest: Nemzeti Tankönyvkiadó.

Kádárné Fülöp, J. (1983). Az olvasás mint kommunikációs képesség [Reading as a communication ability]. Pedagógiai Szemle, 33(2), 140-150.

Kamerman, S. B. (2006). A global history of early childhood education and care. Background paper prepared for the Education for All Global Monitoring Report. Paris: UNESCO.

Kamil, M. L., Mosenthal, P. B., Pearson, P. D., \& Barr, R. (Eds.). (2008). Handbook of reading research. (Vol. 3). New York: Routledge.

Kamil, M. L., Pearson, P. D., Moje, E. B., \& Afflerbach, P. (Eds.). (2011). Handbook of reading research (Vol. 4). New York: Routledge.

Katzir, T., Lesaux, N. K., \& Kim, Y. S. (2009). The role of reading self-concept and home literacy practices in fourth grade reading comprehension. Reading and Writing, 22(3), 261-276.

Kelvin, W. T. (1883). Electrical units of measurement. In Sir W. Thomson (Ed.), Popular lectures and addresses, Volume 1 (pp. 73-136), London: Macmillan and Co.

Kertesi, G. (2008). A közoktatási intézmények teljesítményének mérése-értékelése, az iskolák elszámoltathatósága [Assessment and evaluation of the performance of public education institutions, accountability of schools]. In K. Fazekas, J. Köllö, \& J. Varga (Eds.), Zöld könyv a magyar közoktatás megújitásáért [Green book for the renewal of public education in Hungary] (pp. 167-189). Budapest: ECOSTAT. 
Kim, Y. S., Wagner, R. K., \& Foster, E. (2011). Relations among oral reading fluency, silent reading fluency, and reading comprehension: A latent variable study of first-grade readers. Scientific Studies of Reading, 15(4), 338-362. doi: 10.1080/10888438.2010.493964

Kincaid, J. P., Fishburne Jr, R. P., Rogers, R. L., \& Chissom, B. S. (1975). Derivation of new readability formulas (automated readability index, fog count and flesch reading ease formula) for navy enlisted personnel (No. RBR-8-75). Naval Technical Training Command Millington TN Research Branch.

Kintsch, W., \& Van Dijk, T. A. (1978). Toward a model of text comprehension and production. Psychological Review, 85(5), 363-394.

Kirsch, I. (2001). The international adult literacy survey (IALS): Understanding what was measured. Research report. Princeton, NJ: Educational Testing Service.

Retrieved from http://citeseerx.ist.psu.edu/viewdoc/download?doi=10.1.1.587.2479\&rep=rep1\&type=pdf

Kirsch, I., de Jong, J., Lafontaine, D., McQueen, J., Mendelovits, J., \& Monseur, C. (2002). Reading for change. Performance and engagement across countries. Results from PISA 2000. Paris: OECD Publishing. Retrieved from https://www.oecd.org/edu/school/programmeforinternationalstudentassessmentpisa/33690904.pdf

Kiss, E. (2003). Kiss Árpád műveltség-koncepciója a tudástársadalom perspektívájából [Árpád Kiss's literacy concept from the prespective of the knowledge-based society]. Új Pedagógiai Szemle, 53(5), 1623.

Konza, D. (2006). Teaching children with reading difficulties ( $2^{\text {nd }}$ ed.). Victoria: Thomson Scocial Science Press.

KSH (2015). Statisztikai tükör 2015/31 [Statistical reflections]. Retrieved from Retrieved from https://www.ksh.hu/docs/hun/xftp/idoszaki/oktat/oktatas1415.pdf.

Kuger, S., Klieme, E., Jude, N., \& Kaplan, D. (Eds.). (2016). Assessing contexts of learning: An international perspective. Dordrecht: Springer. doi: 10.1007/978-3-319-45357-6

Kuusela, H., \& Paul, P. (2000). A comparison of concurrent and retrospective verbal protocol analysis. American Journal of Psychology, University of Illinois Press. 113(3), 387404. doi: $10.2307 / 1423365$

LaBerge, D., \& Samuels, S. J. (1974). Toward a theory of automatic information processing in reading, Cognitive Psychology, 6(2), 293-323.

Lally, C. (1998). The application of first language reading models to second language study: A recent historical perspective. Reading Horizons, 38(4), 267-277.

Lee, P. S., \& Leung, L. (2006). Assessing the displacement effects of the Internet. Telematics and Informatics, 25(3), 145-155.

Leino, K. (2014). The relationship between ICT use and reading literacy. Focus on. Retrieved from https://ktl.jyu.fi/julkaisut/julkaisuluettelo/julkaisut/2014/t030.pdf

Lietz, P. (1996). Changes in reading comprehension across cultures and over time. Münster/New York: Waxmann Verlag GmbH.

Livingstone, S, \& Haddon, L. (2009). EU Kids Online: Final report. LSE, London: EU Kids Online. Retrieved from http://www.lse.ac.uk/media@1se/research/EUKidsOnline/EU\%20Kids\%20I\%20(20069)/EU\%20Kids\%20Online\%20I\%20Reports/EUKidsOnlineFinalReport.pdf

Loch, Á. (2003). A szövegkiválasztás szempontjai olvasásértési feladatokhoz [Text selection criteria for reading comprehension tasks]. In P. Majoros (Ed.), Tudományos évkönyv 2003: Magyarország a gazdasági fejlődés keresztútján [Scientific yearbook 2003: Hungary on the crossroads of economic development] (pp. 299-305). Budapest: Budapesti Gazdasági Főiskola.

Logan, S., \& Johnston, R. (2009). Gender differences in reading ability and attitudes: Examining where these differences lie. Journal of Research in Reading, 32(2), 199-214. doi: 10.1111/j.1467-9817.2008.01389.x

Looney, J. (2011). Developing High-Quality Teachers: Teacher evaluation for improvement. European Journal of Education, 46(4), 440-455.

Martini, F., \& Sénéchal, M. (2012). Learning literacy skills at home: parent teaching, expectations, and child interest. Canadian Journal of Behavioural Science, 44(3), 210-221.

Masny, D., \& Cole, D. R. (2009). Multiple literacies theory. Rotterdam: Sense.

McKenna, M. C., \& Kear, D. J. (1990). Measuring attitude toward reading: A new tool for teachers. The Reading Teacher, 43(9), 626-639.

McKenna, M. C., Kear, D. J., \& Ellsworth, R. A. (1995). Children's attitudes toward reading: A national survey. Reading Research Quarterly, 30(4), 934-956. 
McVee, M. B., Dunsmore, K., \& Gavelek, J. R. (2005). Schema theory revisited. Review of Educational Research, 75(4), 531-566.

McKinsey \& Company (2007). Mi áll a világ legsikeresebb iskolai rendszerei teljesitményének hátterében? [How the world's best-performing schools come out on top?]. Retrieved from http://mek.oszk.hu/09500/09575/09575.pdf http://mckinseyonsociety.com/downloads/reports/Education/Worlds_School_Systems_Final.pdf

Molnár, E. K. (2006). Olvasási képesség és iskolai tanulás [Reading and school learning]. In K. Józsa (Ed.), Az olvasási képesség fejlödése és fejlesztése [The development and improvement of reading skills] (pp. 43-60). Budapest: Dinasztia Tankönyvkiadó.

Molnár, E. K., Józsa, K., Molnár, É., \& B. Németh, M (2007, August). What makes a difference for beginning readers? Results from a longitudinal study. Paper presented at the 12th Biennial Conference for Research on Learning and Instruction, Budapest, August 28 - September 1, 2007.

Molnár, É., \& B. Németh, M. (2006). Az olvasásképesség fejlettsége az iskoláskor elején [The developmental of reading skills at the beginning of schooling]. In K. Józsa (Ed.), Az olvasási képesség fejlödése és fejlesztése [The development and improvement of reading skills] (pp. 107-131). Budapest: Dinasztia Tankönyvkiadó.

Molnár, Gy. (2015). A képességmérés dilemmái: a diagnosztikus mérések (eDia) szerepe és helye a magyar közoktatásban [Psychometric dilemmas: the role and place of diagnostic assessments (eDia) in the Hungarian public education]. Géniusz Mühely Kiadványok, 2, 16-29.

Molnár, Gy., \& Pásztor-Kovács, A. (2015). A számítógépes vizsgáztatás infrastrukturális kérdései: az iskolák eszközparkjának helyzete és a változás tendenciái [Issues of infrastructure regarding computer-based assessments: the condition of schools devices and shifting tendencies]. Iskolakultúra, 25(4), 49-61. doi: 10.17543/ISKKULT.2015.4.49

Molnár, Gy., \& Pásztor, A. (2015). A számítógép alapú mérések megvalósíthatósága kisiskolás diákok körében: első évfolyamos diákok egér- és billentyüzet-használati képességének fejlettségi szintje [The feasibility of computer-based measurements among lower primary school students: The developmental level of Year 1 students' keyboarding and mouse skills]. Magyar Pedagógia, 115(3), 237-252. doi: 10.17670/MPed.2015.3.239

Mullis, I. V. S., \& Martin, M. O. (Eds.). (2015). PIRLS 2016 assessment framework. Chestnut Hill, MA: TIMSS \& PIRLS International Study Center, Boston College. Retrieved from https://timssandpirls.bc.edu/pirls2016/downloads/P16_Framework_2ndEd.pdf

Mullis, I.V.S., Martin, M.O., \& Foy, P. (2013). The Impact of reading ability on TIMSS mathematics and science achievement at the fourth grade: An Analysis by Item Reading Demands. In M. O. Martin, \& I. V. S. Mullis (Eds.), TIMSS and PIRLS 2011: Relationships among reading, mathematics, and science achievement at the fourth grade-Implications for early learning (pp. 67-108). Chestnut Hill, MA: TIMSS \& PIRLS International Study Center, Boston College.

Mullis, I. V. S., Martin, M. O., Foy, P., \& Arora, A. (2012). TIMSS 2011 international results in mathematics. Chestnut Hill, MA: Boston College: TIMSS \& PIRLS International Study Center. Retrieved from https://timssandpirls.bc.edu/timss2011/downloads/T11_IR_Mathematics_FullBook.pdf

Mullis, I. V. S., Martin, M. O., Foy, P., \& Drucker, K. T. (2012). PIRLS 2011 international results in reading. Chestnut Hill, MA: TIMSS \& PIRLS International Study Center, Boston College. Retrieved from https://timssandpirls.bc.edu/pirls2011/downloads/P11_IR_FullBook.pdf

Mullis, I. V. S., Martin, M. O., Foy, P., \& Hooper, M. (2017). PIRLS 2016 international results in reading. Chestnut Hill, MA: TIMSS \& PIRLS International Study Center, Boston College. Retrieved from: http://timssandpirls.bc.edu/pirls2016/international-results/.

Mullis, I. V. S., Martin, M. O., \& Gonzalez, E. J. (2004). International achievement in the processes of reading comprehension: Results from PIRLS 2001 in 35 countries. Chestnut Hill, MA: TIMSS \& PIRLS International Study Center, Boston College.

Retrieved from https://timssandpirls.bc.edu/pirls2001i/pdf/Processes.pdf

Mullis, I. V. S., Martin, M. O., Gonzalez, E. J., \& Kennedy, A. M. (2003). PIRLS 2001 international report: IEA's study on the reading literacy achievement in primary schools in 35 countries. Chestnut Hill, MA: Boston College. Retrieved from https://timssandpirls.bc.edu/pirls2001i/pdf/p1_IR_book.pdf

Mullis, I. V. S., Martin, M. O., Kennedy, A. M., \& Foy, P. (2007). PIRLS 2006 international report: IEA's progress in international reading literacy study in primary schools in 40 countries. Chestnut Hill, MA: Boston College. Retrieved from https://timss.bc.edu/PDF/PIRLS2006_international_report.pdf 
Mullis, I. V. S., Martin, M. O., Kennedy, A. M., Trong, K. L., \& Sainsbury, M. (2009). PIRLS 2011 Assessment framework. Chestnut Hill, MA: TIMSS \& PIRLS International Study Center, Boston College. Retrieved from https://timssandpirls.bc.edu/pirls2011/downloads/PIRLS2011_Framework.pdf

Mullis, I. V. S., Martin, M. O., \& Sainsbury, M. (2015). PIRLS 2016 reading framework. In I. V. S. Mullis, \& M. O. Martin (Eds.), PIRLS 2016 Assessment framework (2 ${ }^{\text {nd }}$ ed.) (pp. 11-29). Chestnut Hill, MA: TIMSS \& PIRLS International Study Center, Boston College. Retrieved from https://timssandpirls.bc.edu/pirls2016/downloads/P16_FW_Chap1.pdf

Muthén, L. K., \& Muthén, B. O. (2010). Mplus user's guide, v. 6.1. Los Angeles, CA: Muthen and Muthen, UCLA.

Nagy, J. (2004a). A szóolvasó készség fejlődésének kritériumorientált diagnosztikus feltérképezése [Examining the criterion-referenced diagnostic assessment of the development of vocabulary knowledge]. Magyar Pedagógia, 104(2), 123-142.

Nagy, J. (2004b). Olvasástanítás: a megoldás stratégiai kérdései [Reading instruction: strategies for the solution]. Iskolakultúra, (2004)3, 3-26.

Nagy, J. (2006). Olvasástanítás: a megoldás stratégiai kérdései [Reading instruction: strategies for the solution]. In K. Józsa (Ed.), Az olvasási képesség fejlödése és fejlesztése [The development and improvement of reading skills] (pp. 17-42). Budapest: Dinasztia Tankönyvkiadó.

Nagy, J. (2008). Az alsó tagozatos oktatás megújítása [Renewing primary education]. In K. Fazekas, J. Köllö, \& J. Varga (Eds.), Zöld könyv a magyar közoktatás megújításáért [Green book for the renewal of public education in Hungary (pp. 53-69). Budapest: ECOSTAT.

Nagy, J., Józsa, K., Vidákovich, T., \& Fazekasné Fenyvesi, M. (2004). DIFER Programcsomag: Diagnosztikus fejlödésvizsgáló és kritériumorientált fejlesztö rendszer 4-8 évesek számára [DIFER test package: A diagnostic and criterion-referenced system for the development of 4-8-year-olds]. Szeged: Mozaik Kiadó.

Nemzeti alaptanterv [National Core Curriculum] (2012). Budapest: Emberi Erőforrások Minisztériuma.

Neuman, S. B. (1988). The displacement effect: Assessing the relation between television viewing and reading performance. Reading Research Quarterly, 23(4), 414-440.

Neuman, S. B. (1995). Literacy in the television age: The myth of the TV effect. Norwood, N.J.: Ablex.

O'Reilly, T., \& McNamara, D. S. (2007). The impact of science knowledge, reading skill, and reading strategy knowledge on more traditional "high-stakes" measures of high school students' science achievement. American Educational Research Journal, 44(1), 161-196.

OECD (1999). Measuring student knowledge and skills: A new framework for assessment. Paris: OECD Publishing. http://dx.doi.org/10.1787/9789264173125-en

OECD (2004a). The PISA 2003 assessment framework: mathematics, reading, science and problem solving knowledge and skills. Paris: OECD Publishing. http://dx.doi.org/10.1787/9789264101739-en

OECD (2004b). Learning for tomorrow's world: First results from PISA 2003. Paris: OECD Publishing. http://dx.doi.org/10.1787/9789264006416-en

OECD (2006). Assessing scientific, reading and mathematical literacy: A framework for PISA 2006. Paris: OECD Publishing. http://dx.doi.org/10.1787/9789264026407-en

OECD (2007). PISA 2006: Science competencies for tomorrow's world (Volume 1): Analysis. Paris: OECD Publishing. http://dx.doi.org/10.1787/9789264040014-en

OECD (2008). ICT familiarity component for the student questionnaire PISA 2009. Retrieved from https://www.acer.org/files/ms09_ict_eng.pdf

OECD (2009). OECD Program for International Student Assessment 2009: Student questionnaire. Retrieved from https://nces.ed.gov/surveys/pisa/pdf/quest_pisa_2009_student.pdf

OECD (2010a). PISA 2009 assessment framework: Key competencies in reading, mathematics and science. Paris: OECD Publishing. http://dx.doi.org/10.1787/9789264062658-en

OECD (2010b). PISA 2009 results: What students know and can do: Student Performance in Reading, Mathematics and Science (Volume I). Paris: OECD Publishing. http://dx.doi.org/10.1787/9789264091450-en

OECD (2013). PISA 2012 assessment and analytical framework: Mathematics, reading, science, problem solving and financial literacy. Paris: OECD Publishing. http://dx.doi.org/10.1787/9789264190511-en

OECD (2014a). PISA 2012 technical report. Paris: OECD Publishing.

Retrieved from https://www.oecd.org/pisa/pisaproducts/PISA-2012-technical-report-final.pdf 
OECD (2014b). PISA 2012 results: What students know and can do: Student performance in mathematics, reading and science (Volume I, Revised edition, February 2014). Paris: OECD Publishing. http://dx.doi.org/10.1787/9789264201118-en

OECD (2014c). How old are the teachers? Education Indicators in Focus (EDIF). Retrieved from http://www.oecd.org/edu/skills-beyond-school/EDIF2014No.20(eng).pdf. doi: 10.1787/5jz76b5dhsnx-en

OECD (2014d). Results in focus: What 15-year-olds know and what they can do with what they know. Retrieved from https://www.oecd.org/pisa/keyfindings/pisa-2012-results-overview.pdf

OECD (2015a). Education at a glance 2015: OECD indicators. Paris: OECD Publishing. doi: 10.1787/eag-2015-en

OECD (2015b). PISA in focus: What lies behind gender inequality in education? (Vol. 49). Paris: OECD Publishing. http://dx.doi.org/10.1787/5js4xffhhc30-en

OECD (2015c). Students, computers and learning: Making the connection. Paris: OECD Publishing. http://dx.doi.org/10.1787/9789264239555-en

OECD (2016a). PISA 2015 results (Volume I): Excellence and equity in education. Paris: OECD Publishing. http://dx.doi.org/10.1787/9789264266490-en

OECD (2016b). PISA 2015: Results in focus. Retrieved from https://www.oecd.org/pisa/pisa-2015-results-in-focus.pdf. doi: 10.1787/aa9237e6-en

OECD (2016c). PISA 2015 assessment and analytical framework: Science, reading, mathematic and financial literacy. Paris: OECD Publishing. http://dx.doi.org/10.1787/9789264255425-en

OECD (2017). PISA 2000 list of participating countries/economies.

Retrieved from http://www.oecd.org/pisa/aboutpisa/pisa2000listofparticipatingcountrieseconomies.htm

OH-OECD PISA (2009). OECD-Program a tanulói tudás feltérképezésére 2009: Iskolai kérdöiv [OECDProgram for the assessment of students' skills: Student questionnaire]. Budapest: Oktatási Hivatal Közoktatási és Mérési Értékelési Osztály.

Oktatási Hivatal (2007). Országos kompetenciamérés 2007. Országos jelentés [The National Assessment of Basic Competencies 2007. National report]. Budapest: Oktatási Hivatal. Retrieved from https://www.oktatas.hu/pub_bin/dload/kozoktatas/meresek/orszmer2007/orszagos_jelentes_2007.pdf

Oktatási Hivatal (2008). Országos kompetenciamérés 2008. Országos jelentés [The National Assessment of Basic Competencies 2008. National report]. Budapest: Oktatási Hivatal. Retrieved from https://www.oktatas.hu/pub_bin/dload/kozoktatas/meresek/orszmer2008/okm_2008_orszagos_jelentes.pdf

Oktatási Hivatal (2009). Országos kompetenciamérés 2009. Országos jelentés [The National Assessment of Basic Competencies 2009. National report]. Budapest: Oktatási Hivatal. Retrieved from https://www.oktatas.hu/pub_bin/dload/kozoktatas/meresek/orszmer2009/okm_2009_orszagos_jelentes.pdf

Oravecz, Cs., Váradi, T., \& Sass, B. (2014). The Hungarian gigaword corpus. In Proceedings of LREC 2014. Retrieved from http://mnsz.nytud.hu

Osterlind, S. J. (2001). Constructing test items: Multi-choice, constructed-response, performance, and other formats. Boston: Kluwer Academic Publishers.

Oulette, G. P., \& Haley, A. (2013). One complicated extended family: The influence of alphabetic knowledge and vocabulary on phonemic awareness. Journal of Research in Reading, 36(1), 29-41.

Petriné Feyér, J. (2003). Az oktatás eszközei, tárgyi feltételei [The tools and infrastructural conditions of instruction]. In I. Falus (Ed.), Didaktika [Didactics] (pp. 317-338). Budapest: Nemzeti Tankönyvkiadó.

Pongrácz, T., \& Tóth, I. Gy. (1999). Nőkről és férfiakról - a statisztika tükrében [About women and men - in light of the statistics]. In T. Pongrácz, \& I. Gy. Tóth (Eds.), Szerepváltozások. Jelentés a nök és férfiak helyzetéröl (pp. 283-356) [Shifting roles. A report on the status of women and men]. Budapest: TÁRKI, Szociális és Családügyi Minisztérium Nöképviseleti Titkársága.

Pressley, M., \& Afflerbach, P. (1995). Verbal protocols of reading: The nature of constructively responsive reading. Hillsdale, New Jersey: Erlbaum.

R. Tóth, K., \& Hódi, Á. (2011). Számítógépes és papír-ceruza teszteredmények összehasonlító vizsgálata az olvasás-szövegértés területén [A comparative study of students' reading comprehension achievement in computer-based and paper-and-pencil tests]. Magyar Pedagógia, 111(4), 313-332.

Radácsi, I. (2004). Minőségi oktatás minden fiatalnak: kihívások, trendek és prioritások - Az oktatás fejlesztése [Quality education for every young person - The development of education]. Budapest: Országos Közoktatási Intézet. Retrieved from http://ofi.hu/tudastar/oktataspolitikai/minosegi-oktatasminden 
Radnóti, K. (2007). Milyen oktatási és értékelési módszereket alkalmaznak a pedagógusok a mai magyar iskolában? [What teaching and assessment methods do teachers use in today's schools in Hungary?]. In Z. Kerber (Ed.), Hidak a tantárgyak között [Bridges among subjects] (pp. 131-167). Budapest: Országos Közoktatási Intézet.

Rasinski, T. V., Reutzel, D. R., Chard, D., \& Linan-Thompson, S. (2011). Reading fluency. In M. L. Kamil, P. D. Pearson, E. B. Moje, \& P. Afflerbach (Eds.), Handbook of reading research, Volume 4 (pp. 289319). London: Routledge. doi: 10.4324/9780203840412.ch13

Retelsdorf, J., Köller, O., \& Möller, J. (2014). Reading achievement and reading self-concept - Testing the reciprocal effects model. Learning and Instruction, 29, 21-30. https://doi.org/10.1016/j.learninstruc.2013.07.004

Réthy, E.né (2016). Miért fontos a tanárok kiegyensúlyozott érzelmi élete, elégedettsége, jól-léte? [Why are teachers' emotional balance, satisfaction and well-being important?]. Iskolakultúra, 26(2), 88-99.

Reutzel, D., \& Cooter Jr, R. B. (2012). The essentials of teaching children to read: The teacher makes the difference ( $3^{\text {rd }}$ ed.). Boston: Pearson Education/Allyn \& Bacon.

Rhodes, J. A., \& Robnolt, V. J. (2009). Digital literacies in the classroom. In L. Christenbury, R. Bomer, \& P. Smagorinsky (Eds.), Handbook of adolescent literacy research (pp. 153-169). New York: Guilford Press.

Rice, J. K. (2010). The impact of teacher experience: Examining the evidence and policy implications. Brief, 11, 1-7. Retrieved from http://www.urban.org/sites/default/files/publication/33321/1001455-The-Impactof-Teacher-Experience.pdf

Ridel, B., W. (2007). The relation between DIBELS, reading comprehension, and vocabulary in urban firstgrade students. Reading Research Quarterly, 42(4), 546-567. doi: 10.1598/RRQ.42.4.5

Rideout, V. J., Foehr, U. G., \& Roberts, D. F. (2010). Generation $M^{2}$ : Media in the lives of 8-to 18-yearolds. California: The Henry J. Kaiser Family Foundation.

Retrieved from http://files.eric.ed.gov/fulltext/ED527859.pdf

Robeck, M. C., \& Wallace, R. R. (1990). The psychology of reading: An interdisciplinary approach. Hillsdale, New Jersey: Lawrence Erlbaum.

Roberts, J., Jergens, J., \& Burchinal, M. (2005). The role of home literacy practices in preschool children's language and emergent literacy skills. Journal of Speech, Language, and Hearing Research, 48(2), $345-359$.

Roche, L. A, \& Marsh, H. W. (2002). Teaching self-concept in higher education: Reflecting on multiple dimensions of teaching effectiveness. In N. Hativa \& P. Goodyear (Eds.), Teacher thinking, beliefs and knowledge in higher education (pp. 179-218). Dordrecht: Kluwer. doi: 10.1007/978-94-010-0593-7_9

Rosén, M., \& Gustafsson, J. E. (2014). Has the increased access to computers at home caused reading achievement to decrease in Sweden? In R. Strietholt, W. Bos, J. E. Gustafsson, \& M. Rosén (Eds.), Educational policy evaluation through international comparative assessments. Muenster, New York: Waxmann Verlag.

Rosén, M., \& Gustafsson, J. E. (2016). Is computer availability at home causally related to reading achievement in grade 4 ? A longitudinal difference in differences approach to IEA data from 1991 to 2006. Large-scale Assessments in Education, 4(5), 1-19. doi: 10.1186/s40536-016-0020-8

Rouet, J. F., Lowe, R., \& Schnotz, W. (2008). Understanding multimedia documents: An introduction. In J. F. Rouet, R. Lowe, \& W. Schnotz (Eds.), Understanding multimedia documents (pp. 1-16). New York: Springer.

Rumelhart, D. E. (1977). Toward an interactive model of reading. In S. Dornic (Ed.), Attention and performance VI (pp. 573-603). Hillsdale, NJ: Lawrence Erlbaum.

Sabatini, J., \& O'Reilly, T. (2013). Rationale for a new generation of reading comprehension assessments. In B. Miller, L. Cutting, \& P. McCardle (Eds.), Unraveling the behavioral, neurobiological, and genetic components of reading comprehension (pp. 100-111). Baltimore, MD: Brookes.

Sabatini, J., O'Reilly, T., \& Deane, P. (2013). Preliminary reading literacy assessment framework: foundation and rationale for assessment and system design. ETS Research Report Series, 2013: i-50. doi:10.1002/j.2333-8504.2013.tb02337.x

Sadoski, M., Paivio, A., \& Goetz, E. T. (1991). Commentary: A critique of schema theory in reading and a dual coding alternative. Reading Research Quarterly, 26(4), 463-484.

Sass, B. (2009) "Mazsola" - eszköz a magyar igék bővítményszerkezetének vizsgálatára ["Mazsola" - a tool for the examination of Hungarian verb arguments]. In T. Váradi (Ed.), Válogatás az I. Alkalmazott 
Nyelvészeti Doktorandusz Konferencia elöadásaiból [A selection from the presentations held at the first Applied Linguistics Gradute Students Conference] (pp. 117-129). Budapest: MTA Nyelvtudományi Intézet. Retrieved from http://corpus.nytud.hu/mazsola

Schank, R. C., \& Abelson, R. P. (1977). Scripts, plans, goals and understanding: An inquiry into human knowledge structures. Hillsdale, NJ: L. Erlbaum.

Seidenberg, P. L. (1989). Relating text-processing research to reading and writing instruction for learning disabled students. Learning Disabilities Focus, 5(1), 4-12.

Sénéchal, M. (2011). A model of the concurrent and longitudinal relations between home literacy and child outcomes. In S. B. Neuman, \& D. K. Dickinson (Eds.), Handbook of Early Literacy Research. Volume III (pp. 175-189). New York, NY: Guilford.

Sénéchal, M., \& LeFevre, J. (2002). Parental involvement in the development of children's reading skill: A five-year longitudinal study. Child Development, 73(2), 445-460.

Sénéchal, M., Ouellette, G., \& Young, L. (2004). Testing the concurrent and predictive relations among articulation accuracy, speech perception, and phoneme awareness. Journal of Experimental Child Psychology, 89(3), 242-269.

Shanahan, T. (2012). Early literacy development: Sequence of acquisition (Rev. ed.). Encyclopedia of language and literacy development (1-7). London, ON: Western University. Retrieved from http://www.literacyencyclopedia.ca/pdfs/topic.php?topId=225

Shavelson, R. J., Hubner, J. J., \& Stanton, G. C. (1976). Self-concept: Validation of construct interpretations. Review of Educational Research, 46(3), 407-441.

Simonds, S. K. (1974). Health education as social policy. Health Education \& Behaviour, 2(1), 1-25.

Singleton, C. (1997). Computer-based assessment of reading. In J. R. Beech, \& C. Singleton (Eds.), The psychological Assessment of Reading (pp. 257-278). New York: Routledge.

Smagorinsky, P. (2001). If meaning is constructed, what is it made from? Toward a cultural theory of reading. Review of Educational Research, 71(2), 133-169.

Smith F, (1971). Understanding reading. New York: Holt Rinehart \& Winston.

Smith, F. (1978). Understanding reading, a psycholinguistic analysis of reading and learning to read. New York: Holt Rinehart \& Winston.

Smith, R., \& Betts, M. (2000). Learning as partners: Realising the potential of work-based learning. Journal of Vocational Education and Training, 52(4), 589-604. doi: 10.1080/13636820000200141

Snow, C. E. (2003). Assessment of reading comprehension: Researchers and practitioners helping themselves and each other. In A. P. Sweet, \& C. E. Snow (Eds.), Rethinking reading comprehension. Solving problems in the teaching of literacy (pp. 192-206). New York: Guilford Publications.

Snow, C. E., Burns, M. S., \& Griffin, P. (Eds.) (1998). Preventing reading difficulties in young children. Washington, D.C.: National Academy Press. doi: 10.17226/6023

Snow, C. E., \& Juel, C. (2005). Teaching children to read: What do we know about how to do it? In M. J. Snowling, \& C. Hulme (Eds.), The science of reading: A handbook (pp. 501-520). Blackwell Publishing. doi: $10.1002 / 9780470757642 . c h 26$

Snow, C. E., \& Sweet, A. P. (2003). Reading for comprehension. In A. P. Sweet, \& C. E. Snow (Eds.), Rethinking reading comprehension. Solving problems in the teaching of literacy (pp. 1-11). New York: Guilford Publications.

Spearritt, D. (1972). Identification of subskills of reading comprehension by maximum likelihood factor analysis. Reading Research Quarterly, 8(1), 92-111.

Stanovich, K. E. (1980). Toward an interactive-compensatory model of individual differences in the development of reading fluency. Reading Research Quarterly, 16(1), 32-71.

Stephens, M., \& Coleman, M. (2007). Comparing PIRLS and PISA with NAEP in Reading, Mathematics. and Science (Working Paper). U.S. Department of Education. Washington, D.C.: National Center for Education Statistics. Retrieved from http://nces.ed.gov/Surveys/PISA/pdf/comppaper12082004.pdf

SuliNova Kht. (2007). Országos kompetenciamérés 2006. Gyorsjelentés [The National Assessment of Basic Competencies 2006. Flash report]. Budapest: SuliNova Kht. Retrieved from https://www.oktatas.hu/pub_bin/dload/kozoktatas/meresek/orszmer2006/orszagos_jelentes_2006.pdf

Szabó, I., Szinger, V., Garbe, C., Kákonyi, L., Lafontaine, D., Mallows, D., Reményi-Somlai, J. Shiel, G., Valtin, R., \& Varga, K. (2016). Literacy in Hungary. Country report - short version. European literacy policy network. European Commission, Lifelong Learning Programme. Retrieved from http://www.eli-net.eu/fileadmin/ELINET/Redaktion/user_upload/Hungary_Short_Report1.pdf. 
Szenczi, B. (2008). Énkép és tanulás: Nemzetközi kutatási irányzatok és tendenciák [Self-concept and learning: International approaches and tendencies]. Iskolakultúra Online, 2, 104-118.

Szenczi, B. (2013). Olvasási motiváció 4., 6. és 8. osztályos tanulók körében [Reading motivation in 10- to 14-year-old schoolchildren]. Magyar Pedagógia, 113(4), 197-220.

Tarelli, I., \& Stubbe, T. C. (2010). Home literacy environment and reading achievement: A model for determining the relationship between socio-economic status, home literacy environment and reading achievement. In 4th International Research Congress of IEA.

TÁRKI-TUDOK (2010). Pedagógus 2010. Pedagógusok időmérleg vizsgálata [Teacher 2010. Time-scale analysis of teachers]. Budapest: TÁRKI-TUDOK Zrt. Retrieved from http://www.nefmi.gov.hu/letolt/kozokt/pedagogus_2010_kutzarojel_100507.pdf

Temple, C. M. (1997). Brain damage, behaviour and cognition: Developments in clinical neuropsychology. Developmental cognitive neuropsychology. Hove, England: Psychology Press/Erlbaum (UK) Taylor \& Francis.

Thorndike, R. L. (1973a). Reading as reasoning. Reading Research Quarterly, 9(2),135-147.

Thorndike, R.L. (1973b). Reading comprehension education in fifteen countries: An empirical study. Stockholm: Almqvist \& Wiksell.

Tolcsvai Nagy, G. (2001). A magyar nyelv szövegtana [The text linguistics of Hungarian]. Budapest: Nemzeti Tankönyvkiadó.

Torda, Á. (2006). Az olvasás- és írászavar diagnosztikája és terápiája [The diagnosis and therapy of reading and writing disorders]. In K. Józsa (Ed.), Az olvasási képesség fejlödése és fejlesztése [The development and imrpvement of reading skills] (pp. 207-233). Budapest: Dinasztia Tankönyvkiadó.

Tóth, E. (2014a). A nemzeti pedagógiai értékelési programok felértékelődése az oktatási rendszerek fejlesztésében [The appreciation of national assessment programs in the improvement of education systems]. Tani-tani Online, 4. Retrieved from http://www.tani-tani.info/a_nemzeti_ertekelesi_programok

Tóth Edit (2014b): Pedagógusok véleménye a rendszerszintü mérésekröl és azok tanitási folyamatra gyakorolt hatásáról. Ph.D. disszertáció [Teachers' opinion about system-level assessments and their impact on the teaching process]. SZTE BTK Neveléstudományi Doktori Iskola, Szeged. Retrieved from http://doktori.bibl.u-szeged.hu/2469/15/disszertacio_toth_vegleges.pdf

Tóth, E. (2015). Az Országos kompetenciamérés hatása a tanítási munkára pedagógusinterjúk alapján [Teachers' assumptions about the National Assessment of Basic Competencies and about the effect of those results on their teaching]. Magyar Pedagógia, 15(2), 115-138. doi: 10.17670/mped.2015.2.115

Tóth, E. , \& Hódi, Á. (2014). How do Teachers in Different Stages of Formal Education Respond to Accountability Pressure? In J. T. Karlovitz (Ed.), Some Current Issues in Pedagogy (pp. 151-162)., Komárno: International Research Institute.

Tóth, E., Molnár, Gy., \& Csapó, B. (2011). Az iskolák IKT-felszereltsége - helyzetkép országos reprezentatív minta alapján [School ICT infrastructure - status report on a nationally representative sample]. Iskolakultúra, 21(10-11), 124-137.

Tóth, L. (2002). Szövegmegértés az általános iskolában [Text comprehension in the primary grades]. Magyar Pedagógia, 102(3), 355-376.

Török, T., \& Hódi, Á. (2015). A fonológiai tudatosság fejlődése és szövegértéssel való kapcsolata az általános iskola első négy évfolyamán a szocioökonómiai státusz tükrében [The relationship between phonological awareness and reading comprehension in light of students' socioeconomic status]. Magyar Pszichológiai Szemle, 70(4), 807-826. https://doi.org/10.1556/0016.2015.70.4.6

Tremblay, S., Ross, N., \& Berthelot, J-M. (2001). Factors affecting Grade 3 student performance in Ontario: A multilevel analysis. Education Quarterly Review, 7(4), 25-36.

Turcsán, G. (1998a). Olvasókönyvek tartalomelemzése [Content analysis of reading books]. Új Pedagógiai Szemle, 3, 33-43.

Turcsán, G. (1998b). Olvasókönyvek tartalomelemzése II. [Content analysis of reading books II.]. Új Pedagógiai Szemle, 11, 63-67.

Turner, R., \& Adams, R. J. (2006). The Programme for International Student Assessment: An overview. Journal of Applied Measurement, 8(3), 237-248.

UNESCO (1965). World conference of ministers of education on the eradication of illiteracy. Teheran, 8-19 September 1965. Retrieved from: http://unesdoc.unesco.org/images/0012/001263/126383EB.pdf. 
Váradi, T. (2002). The Hungarian National Corpus. In Proceedings of the 3rd LREC Conference, Las Palmas, Spain, 2002, 385-389.

Retrieved from http://mnsz.nytud.hu

Vári, P., Bánfi, I., Felvégi, E., Krolopp, J., Rózsa, Cs., \& Szalay, B. (2000). A tanulók tudásának változása II. Jelentés a Monitor '99 vizsgálat eredményeiröl [Developmental tendencies in students' knowledge II. Report on the Monitor '99 assessment]. Új Pedagógiai Szemle, 50(7-8), 15-26.

Vári, P., Andor, Cs., Bánfi, I., Bérces, J., Krolopp, J., \& Rózsa, Cs. (1998). Jelentés a Monitor '97 felmérésröl [Report on the Monitor '97 assessment]. Új Pedagógiai Szemle, 48(1), 82-105.

Vitale, M. R., \& Romance, N. R. (2007). A knowledge-based framework for unifying content-area reading comprehension and reading comprehension strategies. In D. S. McNamara (Ed.), Reading comprehension strategies: Theories, interventions, and technologies (pp. 73-104). Mahwah, New Jersey: Lawrence Erlbaum Associates.

Vygotsky, L. (1978). Mind in society: The development of higher psychological processes. Cambridge, MA: Harvard University Press.

Werlich, E. (1976). A text grammar of English. Heidelberg: Quelle \& Meyer.

Whitehurst, J. C., \& Lonigan, J. C. (2003). Emergent Literacy: Development from prereaders to readers. In S. B. Neuman, \& D. K. Dickinson (Eds.), Handbook of early literacy research (pp. 11-29). New York: The Guilford Press.

Willams, J. P. (2005). Instruction in reading comprehension for primary-grade students: A focus on text structure. The Journal of Special Education, 39(1), 6-18.

Wolf, M. (2008). Proust and the squid: the story and science of the reading brain. Cambridge: Icon Books.

Wood, C. (2002). Parent-child pre-school activities can affect the development of literacy skills. Journal of Research in Reading, 25(3), 241-258.

Ziegler, J. C., \& Goswami, U. (2005). Reading acquisition, developmental dyslexia, and skilled reading across languages: A psycholinguistic grain size theory. Psychological Bulletin, 131(1), 3-29.

1993. évi LXXIX. számú törvény a közoktatásról - Kotv. és 1992. évi XXXIII. számú törvény a közalkalmazottak jogállásáról - Kjt. [Act LXXIX of 1993 on Education - Act XXXIII of 1992 on the Legal Status of Public Employees].

2011. évi CXC törvény a nemzeti köznevelésröl [Act CXC of 2011 on National Public Education].

277/1997. (XII. 22.) Kormányrendelet a pedagógus-továbbképzésről, a pedagógus-szakvizsgáról, valamint a továbbképzésben résztvevők juttatásairól és kedvezményeiről [Government decree on teacher in-service training, teacher examination and on the benefits and reductions provided for participants in in-service training].

32/2012. (X.8.) EMMI rendelet a sajátos nevelési igényü gyermekek óvodai nevelésének irányelve és a sajátos nevelési igényű tanulók iskolai oktatásának irányelve kiadásáról

326/2013. (VIII. 30.) Korm. Rendelet a pedagógusok előmeneteli rendszeréröl és a közalkalmazottak jogállásáról szóló 1992. évi XXXIII. törvény köznevelési intézményekben történő végrehajtásáról Retrieved from http://net.jogtar.hu/jr/gen/hjegy_doc.cgi?docid=A1300326.KOR 


\section{LIST OF FIGURES}

Figure 1.1. A heuristic model of reading comprehension .......................................... 4

Figure 4.1. Sample item from the subtest with the continuous text ................................... 47

Figure 4.2. Sample item from the subtest with the mixed text ........................................ 48

Figure 4.3. Sample item from the subtest with the non-continuous text ............................ 48

Figure 4.4. Sample item for the dragging and dropping function from the subtest

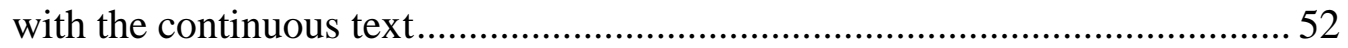

Figure 4.5. A structural model of reading literacy constituting three different text formats in grade 2

Figure 4.6. A structural model of reading literacy constituting three different

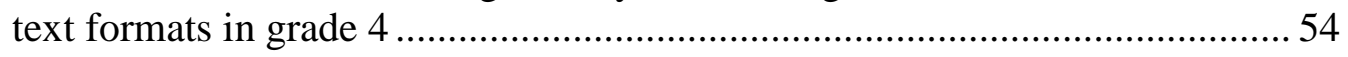

Figure 4.7. A structural model of reading literacy in grade 2 ......................................... 55

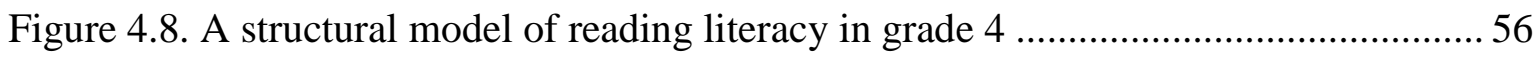

Figure 4.9. An 8-dimensional model on the nature of cognitive aspects of reading in grade 2

Figure 4.10. An 8-dimensional model on the nature of cognitive aspects of reading in grade 4

Figure 4.11. A 3-dimensional model on the nature of cognitive aspects of reading in grade 4

Figure 6.1. Years spent teaching and teaching reading...

Figure 6.2. The frequency of using continuous texts for teaching reading a week in the different age groups

Figure 6.3. The frequency of using non-continuous texts for teaching reading a week in the different age groups....

Figure 6.4. The frequency of using different teaching methods based on teachers' ranking......

Figure 6.5. Frequencies of weekly first language acquisition lessons.... 


\section{LIST OF TABLES}

Table 1.1 The data sources and methods of analysis used for the main research questions

Table 2.1 An overview of the studies and results of Hungarian students' reading achievement in different text formats in assessment cycles conducted by the IEA from 1970 to date

Table 2.2 An overview of the studies and results of Hungarian students' reading achievement in different text formats in assessment cycles conducted by the OECD from 2000 to date

Table 2.3 Current national and international system-level reading assessment programs in Hungary...

Table 2.4 An overview of the studies and results of Hungarian students' reading achievement in different text formats in Monitor assessment cycles between 1986 and 1999

Table 2.5 The terms used by the assessment programs PIRLS, PISA, Monitor and NABC showing what text formats are included in the measurement.

Table 3.1 Categories for the domain coverage of the construct of reading literacy 40

Table 4.1 Number of items and Cronbach's alpha indices for the reading literacy test and its subtests.

Table 4.2 Characteristics of the continuous, mixed and non-continuous texts

Table 4.3 The ratio of words included in the continuous, mixed and non-continuous texts based on word frequencies

Table 4.4 Goodness of fit indices for testing the underlying measurement model of reading literacy in grades 2 and $4(\mathrm{G} 2 ; \mathrm{G} 4)$

Table 4.5 Goodness of fit indices for testing the underlying measurement model of reading literacy for different text formats in grades 2 and 4 (G2; G4)

Table 4.6 Mean test scores and standard deviation between grades 2 and 4 and effect size at subtest level.....

Table 4.7 Differences in students' achievement in continuous, mixed and non-continuous text formats in grades 2 and 4 with paired samples t-tests ..... 57

Table 4.8 The distribution of students in the quartiles of the mixed and non-continuous text based on the quartiles of the continuous text in grades 2 and $4(\%)$

Table 4.9 Students' achievement on the cognitive aspects in different text formats within and between grades

Table 4.10 Differences in students' achievement in cognitive aspects to reading at subtest level representing different text formats in grades 2 and 4 with paired-samples t-tests.

Table 5.1 The dimensions of the main student questionnaire and the instruments used 
Table 5.2 The theoretical and empirical factor structure of the main student questionnaire.

Table 5.3 Frequency distribution of reading continuous texts and activating cognitive aspects of reading when learning during the month before test administration $(\%)$...

Table 5.4 Frequency distribution of reading non-continuous texts and activating cognitive aspects of reading when learning during the month before test administration (\%)

Table 5.5 Frequency distribution of computer and internet use for non-educational purposes $(\%)$

Table 5.6 The distribution of students' attitudes towards books and leisure reading $(\%)$

Table 5.7 The distribution of students' attitudes towards school and school-related reading $(\%)$

Table 5.8 The comparison of boys' and girls' achievements in reading continuous, mixed and non-continuous texts in grade 2 with independent-samples t-test

Table 5.9 The comparison of boys' achievement in the continuous, mixed and non-continuous subtests in grade 2 with paired samples t-tests

Table 5.10 Correlation coefficients between the factors and students' reading achievement in three different text formats

Table 5.11 The impact of non-cognitive factors on students' achievement in reading continuous, mixed and non-continuous texts $\left(\mathrm{r}^{*} \beta^{*} 100\right)$

Table 5.12 Frequencies (\%) of the short questionnaire based on the achievement quartiles in the three subtests

Table 5.13 Means and standard deviations of the frequencies of answers regarding the continuous, mixed and non-continuous subtests

Table 5.14 The comparison of means presented in Table 5.14 with paired samples t-tests.

Table 6.1 The structure of the teacher questionnaire.

Table 6.2 Frequency of using reading techniques in teachers' age groups a week (\%) .... 105

Table 6.3 Comparison of students' achievement in the continuous subtest based on the ICT- and assessment-related items with two-sample t-tests...

Table 6.4 Comparison of students' achievement in the mixed subtest based on the ICT- and assessment-related items with two-sample t-tests

Table 6.5 Comparison of students' achievement in the non-continuous subtest based on the ICT- and assessment-related items with two-sample t-tests.

Table 6.6 Summary of aspects of reading instruction influencing students' achievement in the continuous, mixed and non-continuous subtests 


\section{Appendix A}

\section{The reading literacy subtest with the continuous text}

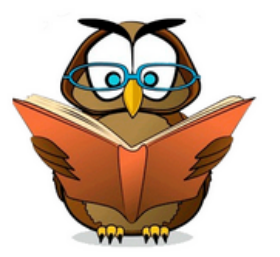

\section{Szövegértés-vizsgálat I.}

2. évfolyam

MTA-SZTE Képességfejlödés Kutatócsoport

Kedves Tanuló!

A következö feladatokkal azt vizsgáljuk, milyen jól olvasol.

Ha probléma adódik ( $\mathrm{pl}$. nem tudsz továbblépni, a gép nem fogadja a kattintást), kérj segítséget a felügyelő tanártól!

Kattints a Tovább gombra!

Egy mesét fogsz látni a képernyőn, amely a kertészkedö bocsokról szól.

Olvasd el figyelmesen, és oldd meg a feladatokat!

A szöveget a jobb oldalon található görgetösáv segítségével tudod mozgatni. 
Olvasd el a mesét és egészítsd ki a mondatokat! Kattints a legördülő menüre s kattintással válaszd ki a szövegbe illö szavakat!

\section{A kertészkedő bocsok}

Brumi és Cammogó, a két mackókölyök még a télen elhatározták, hogy veteményezni fognak a kiskertben. Alig várták, hogy kisüssön az első tavaszi Válassz! $\vee$. Vidáman kiballagtak a házuk melletti Válassz! $\vee$. Brumi Válassz! $\vee$ ragadott, és buzgón nekilátott a föld fellazításához. Cammogó a felásott területet ügyesen elgereblyézte egy kis gereblyével.

- Na jó, eddig megvolnánk. De mit ültessünk? - álltak tanácstalanul. Ekkor értek oda a barátaik. Bekiáltott Nyuszkó, a kis tapsifüles.

- Szerintem ültessetek répát és káposztát - javasolta a nyuszi, és már futott is tovább. Közbe szólt Rágcsa, a hörcsög is.

- Az lenne jó, ha kukoricát is vetnétek - mondta Rágcsa. - És tököt is - kotnyeleskedett Vili, a varjú a fáról.

A Válassz! $\vee$ negfogadtáka tanácsokat, és munkához láttak. Barázdákat húztak a földbe kapával, melyekbe ügyesen elszórták a Válassz! $\quad \checkmark$. Miután végeztek, vizet hoztak a folyóból, és alaposan meglocsolták a Válassz! $\vee$

A növények napról napra szebben fejlödtek, hiszen a két kis kertész állandóan Válassz! $\vee$ a kertet. Nyárra az övék lett a legszebb veteményes az egész erdöben, s mire eljött az ösz, minden Válassz! $\quad \vee$ meg tudták vendégelni kedvenc csemegéjével.

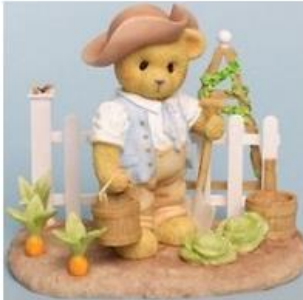

\section{Kiegészítetted az összes mondatot?}

Ha Tovább gombra kattintansz, már NEM TUDSZ VISSZATÉRNI az elöző feladathoz. 


\section{A kertészkedő bocsok}

Brumi és Cammogó, a két mackókölyök még a télen elhatározták, hogy veteményezni fognak a kiskertben. Alig várták, hogy kisüssön az elsö tavaszi napocska. Vidáman kiballagtak a házuk melletti kertbe. Brumi ásót ragadott, és buzgón nekilátott a föld fellazításához. Cammogó a felásott területet ügyesen elgereblyézte egy kis gereblyével.

- Na jó, eddig megvolnánk. De mit ültessünk? - álltak tanácstalanul. Ekkor értek oda a barátaik.

Bekiáltott Nyuszkó, a kis tapsifüles.

- Szerintem ültessetek répát és káposztát - javasolta a nyuszi, és már futott is tovább. Közbe szólt Rágcsa, a hörcsög is.

- Az lenne jó, ha kukoricát is vetnétek - mondta a Rágcsa. - Es tököt is - kotnyeleskedett Vili, a varjú a fáról.

A bocsok megfogadták a tanácsokat, és munkához láttak. Barázdákat húztak a földbe kapával, melyekbe ügyesen elszórták a magvakat. Miután végeztek, vizet hoztak a folyóból, és alaposan meglocsolták a földet.

A növények napról napra szebben fejlödtek, hiszen a két kis kertész állandóan ápolta a kertet. Nyárra az övék lett a legszebb veteményes az egész erdöben, $s$ mire eljött az ösz, minden barátjukat meg tudták vendégelni kedvenc csemegéjével.

Kik voltak a kertészek? Kik voltak a kertészek barátai? Kattintással válaszolj!

\begin{tabular}{|c|c|c|c|c|c|}
\hline Nyuszi & - barát & - kertész & Cammogó & - barát & - kertész \\
\hline Rágcsa & - barát & - kertész & Vili & - barát & - kertész \\
\hline Brumi & - barát & - kertész & & & \\
\hline
\end{tabular}

\section{A kertészkedő bocsok}

Brumi és Cammogó, a két mackókölyök még a télen elhatározták, hogy veteményezni fognak a kiskertben. Alig várták, hogy kisüssön az első tavaszi napocska. Vidáman kiballagtak a házuk melletti kertbe. Brumi ásót ragadott, és buzgón nekilátott a föld fellazításához. Cammogó a felásott területet ügyesen elgereblyézte egy kis gereblyével.

- Na jó, eddig megvolnánk. De mit ültessünk? - álltak tanácstalanul. Ekkor értek oda a barátaik.

Bekiáltott Nyuszkó, a kis tapsifüles.

- Szerintem ültessetek répát és káposztát - javasolta a nyuszi, és már futott is tovább. Közbe szólt Rágcsa, a hörcsög is.

- Az lenne jó, ha kukoricát is vetnétek - mondta a Rágcsa. - Ess tököt is - kotnyeleskedett Vili, a varjú a fáról.

A bocsok megfogadták a tanácsokat, és munkához láttak. Barázdákat húztak a földbe kapával, melyekbe ügyesen elszórták a magvakat. Miután végeztek, vizet hoztak a folyóból, és alaposan meglocsolták a földet.

A növények napról napra szebben fejlödtek, hiszen a két kis kertész állandóan ápolta a kertet. Nyárra az övék lett a legszebb veteményes az egész erdöben, s mire eljött az ösz, minden barátjukat meg tudták vendégelni kedvenc csemegéjével.

Ki javasolta, hogy répát ültessenek? Kattints a képére!
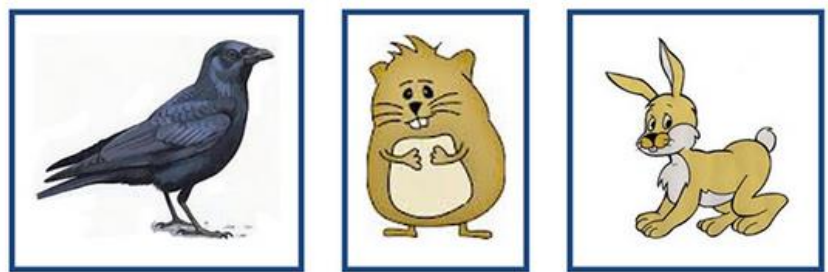


\section{A kertészkedő bocsok}

Brumi és Cammogó, a két mackókölyök még a télen elhatározták, hogy veteményezni fognak a kiskertben. Alig várták, hogy kisüssön az első tavaszi napocska. Vidáman kiballagtak a házuk melletti kertbe. Brumi ásót ragadott, és buzgón nekilátott a föld fellazításához. Cammogó a felásott területet ügyesen elgereblyézte egy kis gereblyével.

- Na jó, eddig megvolnánk. De mit ültessünk? - álltak tanácstalanul. Ekkor értek oda a barátaik. Bekiáltott Nyuszkó, a kis tapsifüles.

- Szerintem ültessetek répát és káposztát - javasolta a nyuszi, és már futott is tovább. Közbe szólt Rágcsa, a hörcsög is.

- Az lenne jó, ha kukoricát is vetnétek - mondta a Rágcsa. - És tököt is - kotnyeleskedett Vili, a varjú a fáról.

A bocsok megfogadták a tanácsokat, és munkához láttak. Barázdákat húztak a földbe kapával, melyekbe ügyesen elszórták a magvakat. Miután végeztek, vizet hoztak a folyóból, és alaposan meglocsolták a földet.

A növények napról napra szebben fejlödtek, hiszen a két kis kertész állandóan ápolta a kertet. Nyárra az övék lett a legszebb veteményes az egész erdöben, s mire eljött az ösz, minden barátjukat meg tudták vendégelni kedvenc csemegéjével.

Ki javasolta, hogy tököt ültessenek? Kattints a képére!
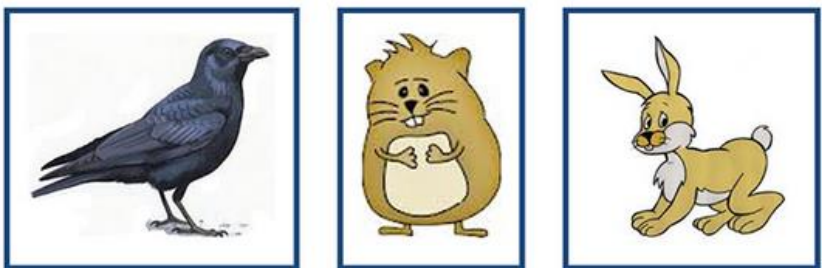

\section{A kertészkedő bocsok}

Brumi és Cammogó, a két mackókölyök még a télen elhatározták, hogy veteményezni fognak a kiskertben. Alig várták, hogy kisüssön az elsổ tavaszi napocska. Vidáman kiballagtak a házuk melletti kertbe. Brumi ásót ragadott, és buzgón nekilátott a föld fellazításához. Cammogó a felásott területet ügyesen elgereblyézte egy kis gereblyével. - Na jó, eddig megvolnánk. De mit ültessünk? - álltak tanácstalanul. Ekkor értek oda a barátaik. Bekiáltott Nyuszkó, a kis tapsifüles.

- Szerintem ültessetek répát és káposztát - javasolta a nyuszi, és már futott is tovább. Közbe szólt Rágcsa, a hörcsög is.

- Az lenne jó, ha kukoricát is vetnétek - mondta a Rágcsa. - És tököt is - kotnyeleskedett Vili, a varjú a fáról. A bocsok megfogadták a tanácsokat, és munkához láttak. Barázdákat húztak a földbe kapával, melyekbe ügyesen elszórták a magvakat. Miután végeztek, vizet hoztak a folyóból, és alaposan meglocsolták a földet.

A növények napról napra szebben fejlödtek, hiszen a két kis kertész állandóan ápolta a kertet. Nyárra az övék lett a legszebb veteményes az egész erdöben, s mire eljött az ösz, minden barátjukat meg tudták vendégelni kedvenc csemegéjével.

Ki javasolta, hogy káposztát ültessenek? Kattints a képére!
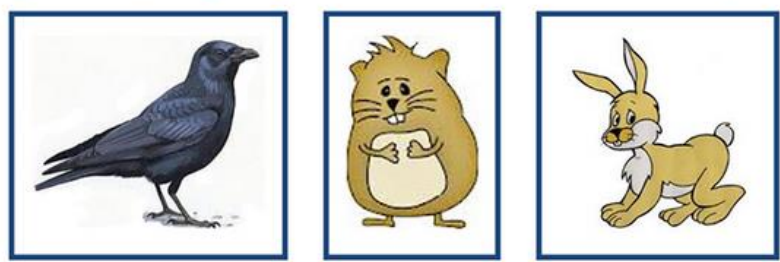


\section{A kertészkedő bocsok}

Brumi és Cammogó, a két mackókölyök még a télen elhatározták, hogy veteményezni fognak a kiskertben. Alig várták, hogy kisüssön az első tavaszi napocska. Vidáman kiballagtak a házuk melletti kertbe. Brumi ásót ragadott, és buzgón nekilátott a föld fellazításához. Cammogó a felásott területet ügyesen elgereblyézte egy kis gereblyével.

- Na jó, eddig megvolnánk. De mit ültessünk? - álltak tanácstalanul. Ekkor értek oda a barátaik. Bekiáltott Nyuszkó, a kis tapsifüles.

- Szerintem ültessetek répát és káposztát - javasolta a nyuszi, és már futott is tovább. Közbe szólt Rágcsa, a hörcsög

- Az lenne jó, ha kukoricát is vetnétek - mondta a Rágcsa. - És tököt is - kotnyeleskedett Vili, a varjú a fáról.

A bocsok megfogadták a tanácsokat, és munkához láttak. Barázdákat húztak a földbe kapával, melyekbe ügyesen elszórták a magvakat. Miután végeztek, vizet hoztak a folyóból, és alaposan meglocsolták a földet.

A növények napról napra szebben fejlödtek, hiszen a két kis kertész állandóan ápolta a kertet. Nyárra az övék lett a legszebb veteményes az egész erdöben, s mire eljött az ôsz, minden barátjukat meg tudták vendégelni kedvenc csemegéjével.

Ki javasolta, hogy kukoricát ültessenek? Kattints a képére!
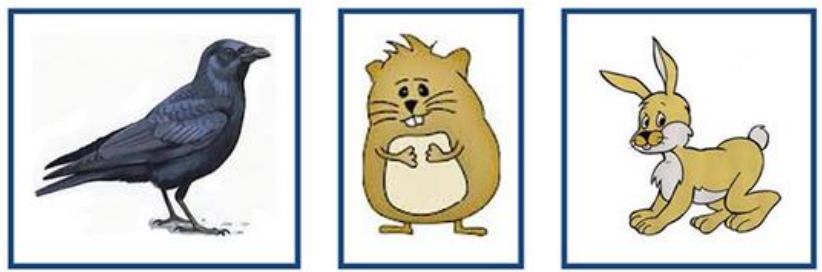

\section{A kertészkedő bocsok}

Brumi és Cammogó, a két mackókölyök még a télen elhatározták, hogy veteményezni fognak a kiskertben. Alig várták, hogy kisüssön az első tavaszi napocska. Vidáman kiballagtak a házuk melletti kertbe. Brumi ásót ragadott, és buzgón nekilátott a föld fellazításához. Cammogó a felásott területet ügyesen elgereblyézte egy kis gereblyével.

- Na jó, eddig megvolnánk. De mit ültessünk? - álltak tanácstalanul. Ekkor értek oda a barátaik. Bekiáltott Nyuszkó, a kis tapsifüles.

- Szerintem ültessetek répát és káposztát - javasolta a nyuszi, és már futott is tovább. Közbe szólt Rágcsa, a hörcsög is.

- Az lenne jó, ha kukoricát is vetnétek - mondta a Rágcsa. - És tököt is - kotnyeleskedett Vili, a varjú a fáról.

A bocsok megfogadták a tanácsokat, és munkához láttak. Barázdákat húztak a földbe kapával, melyekbe ügyesen elszórták a magvakat. Miután végeztek, vizet hoztak a folyóból, és alaposan meglocsolták a földet.

A növények napról napra szebben fejlödtek, hiszen a két kis kertész állandóan ápolta a kertet. Nyárra az övék lett a legszebb veteményes az egész erdöben, s mire eljött az ösz, minden barátjukat meg tudták vendégelni kedvenc csemegéjével.

Kire igaz a következő tulajdonság? Kattintással válaszolj!

szorgalmas
a két bocsra
- a nyuszira
a a hörcsögre
mindegyikre 


\section{A kertészkedő bocsok}

Brumi és Cammogó, a két mackókölyök még a télen elhatározták, hogy veteményezni fognak a kiskertben. Alig várták, hogy kisüssön az első tavaszi napocska. Vidáman kiballagtak a házuk melletti kertbe. Brumi ásót ragadott, és buzgón nekilátott a föld fellazításához. Cammogó a felásott területet ügyesen elgereblyézte egy kis gereblyével. - Na jó, eddig megvolnánk. De mit ültessünk? - álltak tanácstalanul. Ekkor értek oda a barátaik. Bekiáltott Nyuszkó, a kis tapsifüles.

- Szerintem ültessetek répát és káposztát - javasolta a nyuszi, és már futott is tovább. Közbe szólt Rágcsa, a hörcsög is.

- Az lenne jó, ha kukoricát is vetnétek - mondta a Rágcsa. - Es tököt is - kotnyeleskedett Vili, a varjú a fáról.

A bocsok megfogadták a tanácsokat, és munkához láttak. Barázdákat húztak a földbe kapával, melyekbe ügyesen elszórták a magvakat. Miután végeztek, vizet hoztak a folyóból, és alaposan meglocsolták a földet.

A növények napról napra szebben fejlödtek, hiszen a két kis kertész állandóan ápolta a kertet. Nyárra az övék lett a legszebb veteményes az egész erdöben, s mire eljött az ôsz, minden barátjukat meg tudták vendégelni kedvenc csemegéjével.

Kire igaz a következő tulajdonság? Kattintással válaszolj!

kedves

a két bocsra $\circ \quad$ a nyuszira $\circ \quad$ a hörcsögre $\circ$ mindegyikre

\section{A kertészkedö bocsok}

Brumi és Cammogó, a két mackókölyök még a télen elhatározták, hogy veteményezni fognak a kiskertben. Alig várták, hogy kisüssön az első tavaszi napocska. Vidáman kiballagtak a házuk melletti kertbe. Brumi ásót ragadott, és buzgón nekilátott a föld fellazításához. Cammogó a felásott területet ügyesen elgereblyézte egy kis gereblyével. - Na jó, eddig megvolnánk. De mit ültessünk? - álltak tanácstalanul. Ekkor értek oda a barátaik. Bekiáltott Nyuszkó, a kis tapsifüles.

- Szerintem ültessetek répát és káposztát - javasolta a nyuszi, és már futott is tovább. Közbe szólt Rágcsa, a hörcsög is.

- Az lenne jó, ha kukoricát is vetnétek - mondta a Rágcsa. - És tököt is - kotnyeleskedett Vili, a varjú a fáról.

A bocsok megfogadták a tanácsokat, és munkához láttak. Barázdákat húztak a földbe kapával, melyekbe ügyesen elszórták a magvakat. Miután végeztek, vizet hoztak a folyóból, és alaposan meglocsolták a földet.

A növények napról napra szebben fejlödtek, hiszen a két kis kertész állandóan ápolta a kertet. Nyárra az övék lett a legszebb veteményes az egész erdöben, s mire eljött az ôsz, minden barátjukat meg tudták vendégelni kedvenc csemegéjével.

Kire igaz a következő tulajdonság? Kattintással válaszolj!

ötletes

a varjúra $\circ$ a nyuszira $\circ$ a hörcsögre $\circ$ mindegyikre




\section{A kertészkedő bocsok}

Brumi és Cammogó, a két mackókölyök még a télen elhatározták, hogy veteményezni fognak a kiskertben. Alig várták, hogy kisüssön az elsö tavaszi napocska. Vidáman kiballagtak a házuk melletti kertbe. Brumi ásót ragadott, és buzgón nekilátott a föld fellazításához. Cammogó a felásott területet ügyesen elgereblyézte egy kis gereblyével. - Na jó, eddig megvolnánk. De mit ültessünk? - álltak tanácstalanul. Ekkor értek oda a barátaik. Bekiáltott Nyuszkó, a kis tapsifüles.

- Szerintem ültessetek répát és káposztát - javasolta a nyuszi, és már futott is tovább. Közbe szólt Rágcsa, a hörcsög is.

- Az lenne jó, ha kukoricát is vetnétek - mondta a Rágcsa. - És tököt is - kotnyeleskedett Vili, a varjú a fáról.

A bocsok megfogadták a tanácsokat, és munkához láttak. Barázdákat húztak a földbe kapával, melyekbe ügyesen elszórták a magvakat. Miután végeztek, vizet hoztak a folyóból, és alaposan meglocsolták a földet.

A növények napról napra szebben fejlödtek, hiszen a két kis kertész állandóan ápolta a kertet. Nyárra az övék lett a legszebb veteményes az egész erdöben, s mire eljött az ösz, minden barátjukat meg tudták vendégelni kedvenc csemegéjével.

Húzogatással rakd helyes sorrendbe az eseményeket!

Vissza

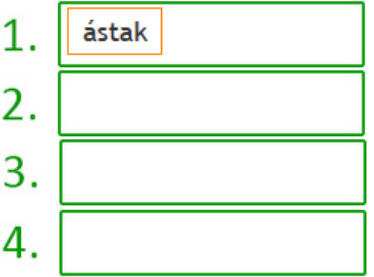

barázdát húztak

locsoltak

elszórták a magokat

\section{A kertészkedő bocsok}

Brumi és Cammogó, a két mackókölyök még a télen elhatározták, hogy veteményezni fognak a kiskertben. Alig várták, hogy kisüssön az első tavaszi napocska. Vidáman kiballagtak a házuk melletti kertbe. Brumi ásót ragadott, és buzgón nekilátott a föld fellazításához. Cammogó a felásott területet ügyesen elgereblyézte egy kis gereblyével. - Na jó, eddig megvolnánk. De mit ültessünk? - álltak tanácstalanul. Ekkor értek oda a barátaik. Bekiáltott Nyuszkó, a kis tapsifüles.

- Szerintem ültessetek répát és káposztát - javasolta a nyuszi, és már futott is tovább. Közbe szólt Rágcsa, a hörcsög is.

- Az lenne jó, ha kukoricát is vetnétek - mondta a Rágcsa. - És tököt is - kotnyeleskedett Vili, a varjú a fáról.

A bocsok megfogadták a tanácsokat, és munkához láttak. Barázdákat húztak a földbe kapával, melyekbe ügyesen elszórták a magvakat. Miután végeztek, vizet hoztak a folyóból, és alaposan meglocsolták a földet.

A növények napról napra szebben fejlödtek, hiszen a két kis kertész állandóan ápolta a kertet. Nyárra az övék lett a legszebb veteményes az egész erdöben, s mire eljött az ôsz, minden barátjukat meg tudták vendégelni kedvenc csemegéjével.

Használták-e a bocsok a képen látható eszközt? Kattintással válaszolj!

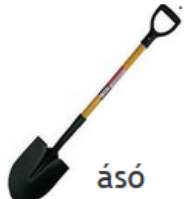




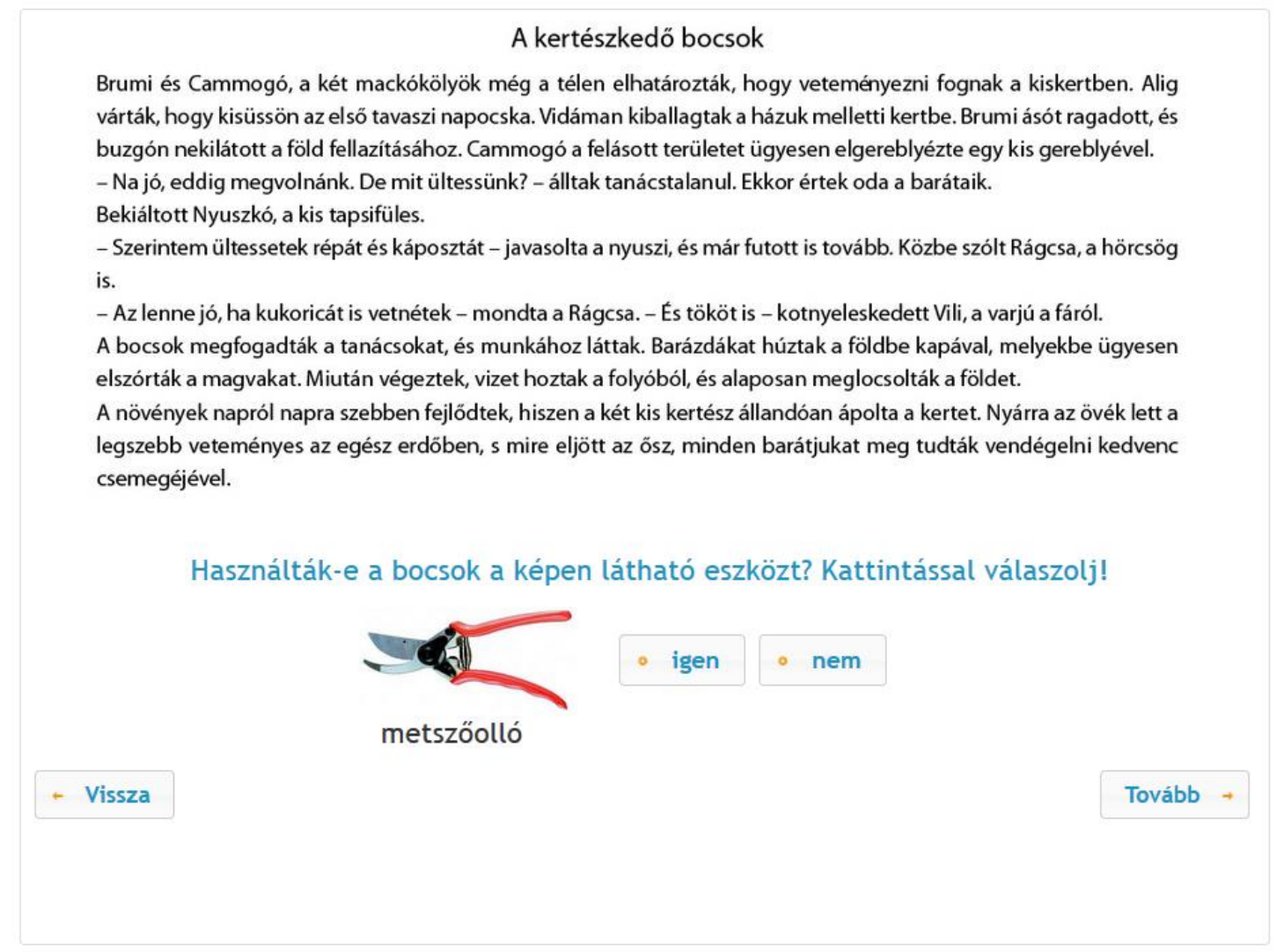

\section{A kertészkedő bocsok}

Brumi és Cammogó, a két mackókölyök még a télen elhatározták, hogy veteményezni fognak a kiskertben. Alig várták, hogy kisüssön az elsö tavaszi napocska. Vidáman kiballagtak a házuk melletti kertbe. Brumi ásót ragadott, és buzgón nekilátott a föld fellazításához. Cammogó a felásott területet ügyesen elgereblyézte egy kis gereblyével. - Na jó, eddig megvolnánk. De mit ültessünk? - álltak tanácstalanul. Ekkor értek oda a barátaik. Bekiáltott Nyuszkó, a kis tapsifüles.

- Szerintem ültessetek répát és káposztát - javasolta a nyuszi, és már futott is tovább. Közbe szólt Rágcsa, a hörcsög is.

- Az lenne jó, ha kukoricát is vetnétek - mondta a Rágcsa. - És tököt is - kotnyeleskedett Vili, a varjú a fáról.

A bocsok megfogadták a tanácsokat, és munkához láttak. Barázdákat húztak a földbe kapával, melyekbe ügyesen elszórták a magvakat. Miután végeztek, vizet hoztak a folyóból, és alaposan meglocsolták a földet.

A növények napról napra szebben fejlödtek, hiszen a két kis kertész állandóan ápolta a kertet. Nyárra az övék lett a legszebb veteményes az egész erdöben, $s$ mire eljött az ösz, minden barátjukat meg tudták vendégelni kedvenc csemegéjével.

Használhatták-e a bocsok a képen látható eszközt? Kattintással válaszolj!

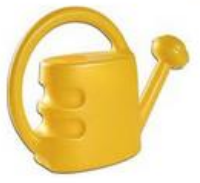




\section{A kertészkedő bocsok}

Brumi és Cammogó, a két mackókölyök még a télen elhatározták, hogy veteményezni fognak a kiskertben. Alig várták, hogy kisüssön az első tavaszi napocska. Vidáman kiballagtak a házuk melletti kertbe. Brumi ásót ragadott, és buzgón nekilátott a föld fellazításához. Cammogó a felásott területet ügyesen elgereblyézte egy kis gereblyével.

- Na jó, eddig megvolnánk. De mit ültessünk? - álltak tanácstalanul. Ekkor értek oda a barátaik. Bekiáltott Nyuszkó, a kis tapsifüles.

- Szerintem ültessetek répát és káposztát - javasolta a nyuszi, és már futott is tovább. Közbe szólt Rágcsa, a hörcsög is.

- Az lenne jó, ha kukoricát is vetnétek - mondta a Rágcsa. - És tököt is - kotnyeleskedett Vili, a varjú a fáról.

A bocsok megfogadták a tanácsokat, és munkához láttak. Barázdákat húztak a földbe kapával, melyekbe ügyesen elszórták a magvakat. Miután végeztek, vizet hoztak a folyóból, és alaposan meglocsolták a földet.

A növények napról napra szebben fejlödtek, hiszen a két kis kertész állandóan ápolta a kertet. Nyárra az övék lett a legszebb veteményes az egész erdöben, s mire eljött az ősz, minden barátjukat meg tudták vendégelni kedvenc csemegéjével.

Használták-e a bocsok a képen látható eszközt? Kattintással válaszolj!

gereblye

ताIIII)

\section{A kertészkedő bocsok}

Brumi és Cammogó, a két mackókölyök még a télen elhatározták, hogy veteményezni fognak a kiskertben. Alig várták, hogy kisüssön az elsö tavaszi napocska. Vidáman kiballagtak a házuk melletti kertbe. Brumi ásót ragadott, és buzgón nekilátott a föld fellazításához. Cammogó a felásott területet ügyesen elgereblyézte egy kis gereblyével. - Na jó, eddig megvolnánk. De mit ültessünk? - álltak tanácstalanul. Ekkor értek oda a barátaik. Bekiáltott Nyuszkó, a kis tapsifüles.

- Szerintem ültessetek répát és káposztát - javasolta a nyuszi, és már futott is tovább. Közbe szólt Rágcsa, a hörcsög

- Az lenne jó, ha kukoricát is vetnétek - mondta a Rágcsa. - És tököt is - kotnyeleskedett Vili, a varjú a fáról.

A bocsok megfogadták a tanácsokat, és munkához láttak. Barázdákat húztak a földbe kapával, melyekbe ügyesen elszórták a magvakat. Miután végeztek, vizet hoztak a folyóból, és alaposan meglocsolták a földet.

A növények napról napra szebben fejlödtek, hiszen a két kis kertész állandóan ápolta a kertet. Nyárra az övék lett a legszebb veteményes az egész erdöben, s mire eljött az ősz, minden barátjukat meg tudták vendégelni kedvenc csemegéjével.

\section{Fejezd be a megkezdett mondatot! Kattints a helyes befejezésre!}

Ősszel a bocsok minden barátjukat meg tudták vendégelni, mert ...

a kertben megtermett minden.

hidegre fordult az idő.

Vissza $\quad$ lehullottak a sárga levelek.

nem volt munka a kertben. 


\section{A kertészkedő bocsok}

Brumi és Cammogó, a két mackókölyök még a télen elhatározták, hogy veteményezni fognak a kiskertben. Alig várták, hogy kisüssön az elsö tavaszi napocska. Vidáman kiballagtak a házuk melletti kertbe. Brumi ásót ragadott, és buzgón nekilátott a föld fellazításához. Cammogó a felásott területet ügyesen elgereblyézte egy kis gereblyével.

- Na jó, eddig megvolnánk. De mit ültessünk? - álttak tanácstalanul. Ekkor értek oda a barátaik. Bekiáltott Nyuszkó, a kis tapsifüles.

- Szerintem ültessetek répát és káposztát - javasolta a nyuszi, és már futott is tovább. Közbe szólt Rágcsa, a hörcsög is.

- Az lenne jó, ha kukoricát is vetnétek - mondta a Rágcsa. - Es tököt is - kotnyeleskedett Vili, a varjú a fáról.

A bocsok megfogadták a tanácsokat, és munkához láttak. Barázdákat húztak a földbe kapával, melyekbe ügyesen elszórták a magvakat. Miután végeztek, vizet hoztak a folyóból, és alaposan meglocsolták a földet.

A növények napról napra szebben fejlödtek, hiszen a két kis kertész állandóan ápolta a kertet. Nyárra az övék lett a legszebb veteményes az egész erdöben, s mire eljött az ösz, minden barátjukat meg tudták vendégelni kedvenc csemegéjével.

Fejezd be a megkezdett mondatot! Kattints a helyes befejezésre!

Összel a bocsok minden barátjukat megvendégelték és ...

sokat beszélgettek.

hasznos tanácsokat adtak.

Vissza

betakarították a termést.

A kertészkedö bocsok

Brumi és Cammogó, a két mackókölyök még a télen elhatározták, hogy veteményezni fognak a kiskertben. Alig várták, hogy kisüssön az első tavaszi napocska. Vidáman kiballagtak a házuk melletti kertbe. Brumi ásót ragadott, és buzgón nekilátott a föld fellazításához. Cammogó a felásott területet ügyesen elgereblyézte egy kis gereblyével. - Na jó, eddig megvolnánk. De mit ültessünk? - álltak tanácstalanul. Ekkor értek oda a barátaik. Bekiáltott Nyuszkó, a kis tapsifüles.

- Szerintem ültessetek répát és káposztát - javasolta a nyuszi, és már futott is tovább. Közbe szólt Rágcsa, a hörcsög is.

- Az lenne jó, ha kukoricát is vetnétek - mondta a Rágcsa. - És tököt is - kotnyeleskedett Vili, a varjú a fáról.

A bocsok megfogadták a tanácsokat, és munkához láttak. Barázdákat húztak a földbe kapával, melyekbe ügyesen elszórták a magvakat. Miután végeztek, vizet hoztak a folyóból, és alaposan meglocsolták a földet.

A növények napról napra szebben fejlödtek, hiszen a két kis kertész állandóan ápolta a kertet. Nyárra az övék lett a legszebb veteményes az egész erdöben, s mire eljött az ôsz, minden barátjukat meg tudták vendégelni kedvenc csemegéjével.

Melyik szólás illik a történethez? Kattintással válaszolj!

\begin{tabular}{|c|c|c|}
\hline Aki kíváncsi, hamar megöregszik. & - illik & - nem illik \\
\hline A jó munka dicséri mesterét. & 。 illik & - nem illik \\
\hline Madarat tolláról, embert barátjáról. & - illik & - nem illik \\
\hline Ki mint veti ágyát, úgy alussza álmát. & 。 illik & - nem illik \\
\hline
\end{tabular}




\section{Appendix B}

The reading literacy subtest with the non-continuous text

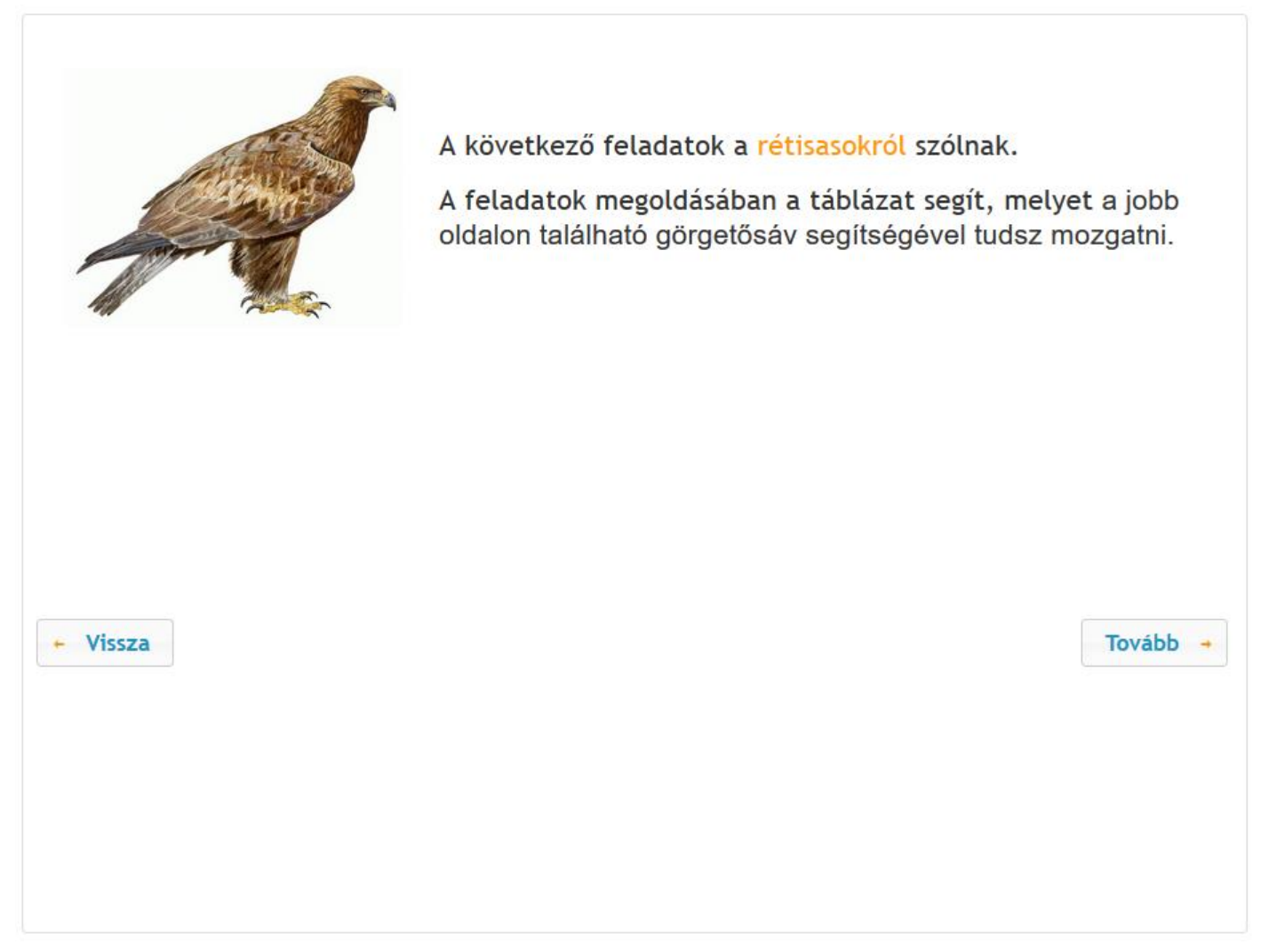

\begin{tabular}{|l|l|l|l|}
\hline \multicolumn{2}{|c|}{ ÁLLOMÁNYADATOK } & \multicolumn{2}{c|}{ FÉszKELÉs } \\
\hline \hline Megfigyelési idö (év): & 2003 & Fészkelö helye: & $\begin{array}{l}\text { ädök, vizek melletti } \\
\text { erdógek, erdei tavas területek }\end{array}$ \\
\hline Fészkelö állomány nagysága: & $118-130$ fészkelö pár & Fészek helye: & fán \\
\hline Hazai védettség: & fokozottan védett & Fészek típusa: & gallyfészek \\
\hline Pénzben kifejezett érték (Ft): & 1000000 & Fészkelési típus: & magányosan fészkelö \\
\hline Európai veszélyeztetettség: & ritka faj & Fiókák száma (db): & $1-3$ \\
\hline $\begin{array}{l}\text { Hazai elöfordulási idöszak: } \\
\text { Hazai elöfordulási státusz: }\end{array}$ & $\begin{array}{l}\text { egész évben } \\
\text { rendszeres fészkelö }\end{array}$ & $\begin{array}{l}\text { Kikelési idö (nap): } \\
\text { Kirepülési idó (nap): }\end{array}$ & $\begin{array}{l}38-40 \\
80-90\end{array}$ \\
\hline Telelési helye: & hazai élöhelyei & Fiókák fejlettsége: & fészeklakó \\
\hline Testhossz $(\mathrm{cm}):$ & $70-90$ & Évenkénti költés száma: & 1 \\
\hline Szárnyfesztávolság $(\mathrm{cm}):$ & $200-240$ & Életmódja; tápláléka: & $\begin{array}{l}\text { ragadozó; madarak (vízimadarak, } \\
\text { vadludak), halak, emlösök (nyulak, } \\
\text { nagyvadak zsigerei, dögök) } \\
\text { kerecsensólyom (a fészkére } \\
\text { pályázik) }\end{array}$ \\
\hline Hím tömege $(\mathrm{g}):$ & $3075-5430$ & Ellensége, konkurenciája: & \\
\hline Tojó tömege $(\mathrm{g}):$ & $4080-6920$ & & \\
\hline
\end{tabular}

Mi a rétisas természetes ellensége? Kattintással válaszolj!
halászsas
kerecsensólyom
erdei bagoly
kékvércse 


\begin{tabular}{|l|l|l|l|}
\hline \multicolumn{2}{|c|}{ ÁLLOMÁNYADATOK } & \multicolumn{2}{c|}{ FÉSzKELÉs } \\
\hline \hline Megfigyelési idö (év): & 2003 & Fészkelö helye: & $\begin{array}{l}\text { ártéri erdök, vizek melletti } \\
\text { erdöségek, erdei tavas területek }\end{array}$ \\
\hline Fészkelö állomány nagysága: & $118-130$ fészkelö pár & Fészek helye: & fán \\
\hline Hazai védettség: & fokozottan védett & Fészek típusa: & gallyfészek \\
\hline Pénzben kifejezett érték (Ft): & 1000000 & Fészkelési típus: & magányosan fészkelö \\
\hline Európai veszélyeztetettség: & ritka faj & Fiókák száma (db): & $1-3$ \\
\hline $\begin{array}{l}\text { Hazai elöfordulási idöszak: } \\
\text { Hazai elöfordulási státusz: }\end{array}$ & $\begin{array}{l}\text { egész évben } \\
\text { rendszeres fészkelö }\end{array}$ & $\begin{array}{l}\text { Kikelési idö (nap): } \\
\text { Kirepülési idö (nap): }\end{array}$ & $\begin{array}{l}38-40 \\
80-90\end{array}$ \\
\hline Telelési helye: & hazai élöhelyei & Fiókák fejlettsége: & fészeklakó \\
\hline Testhossz $(\mathrm{cm}):$ & $70-90$ & Évenkénti költés száma: & 1 \\
\hline Szárnyfesztávolság $(\mathrm{cm}):$ & $200-240$ & Életmódja; tápláléka: & $\begin{array}{l}\text { ragadozó; madarak (vízimadarak, } \\
\text { vadludak), halak, emlösök (nyulak, } \\
\text { nagyvadak zsigerei, dögök) } \\
\text { kerecsensólyom (a fészkére } \\
\text { pályázik) }\end{array}$ \\
\hline Him tömege $(\mathrm{g}):$ & $3075-5430$ & Ellensége, konkurenciája: & \\
\hline Tojó tömege $(\mathrm{g}):$ & $4080-6920$ & & \\
\hline
\end{tabular}

Mi a rétisas fészkének alapanyaga? Kattintással válaszolj!
sár
nád
fü
gally

Vissza

\begin{tabular}{|l|l|l|l|}
\hline \multicolumn{2}{|c|}{ ÁLLOMÁNYADATOK } & \multicolumn{2}{c|}{ FÉSZKELÉs } \\
\hline \hline Megfigyelési idö (év): & 2003 & Fészkelö helye: & $\begin{array}{l}\text { ártéri erdök, vizek melletti } \\
\text { erdöségek, erdei tavas területek }\end{array}$ \\
\hline Fészkelö állomány nagysága: & $118-130$ fészkelö pár & Fészek helye: & fán \\
\hline Hazai védettség: & fokozottan védett & Fészek típusa: & gallyfészek \\
\hline Pénzben kifejezett érték (Ft): & 1000000 & Fészkelési típus: & magányosan fészkelö \\
\hline Európai veszélyeztetettség: & ritka faj & Fiókák száma (db): & $1-3$ \\
\hline $\begin{array}{l}\text { Hazai elöfordulási idöszak: } \\
\text { Hazai elöfordulási státusz: }\end{array}$ & $\begin{array}{l}\text { egész évben } \\
\text { rendszeres fészkelö }\end{array}$ & $\begin{array}{l}\text { Kikelési idö (nap): } \\
\text { Kirepülési idó (nap): }\end{array}$ & $\begin{array}{l}38-40 \\
80-90\end{array}$ \\
\hline Telelési helye: & hazai élöhelyei & Fiókák fejlettsége: & fészeklakó \\
\hline Testhossz $(\mathrm{cm}):$ & $70-90$ & Évenkénti költés száma: & 1 \\
\hline Szárnyfesztávolság (cm): & $200-240$ & Életmódja; tápláléka: & $\begin{array}{l}\text { ragadozó; madarak (vízimadarak, } \\
\text { vadludak), halak, emlösök (nyulak, } \\
\text { nagyvadak zsigerei, dögök) } \\
\text { kerecsensólyom (a fészkére } \\
\text { pályázik) }\end{array}$ \\
\hline Hím tömege $(\mathrm{g}):$ & $3075-5430$ & Ellensége, konkurenciája: & \\
\hline Tojó tömege $(\mathrm{g}):$ & $4080-6920$ & &
\end{tabular}

Melyik kép ábrázolja a rétisast? Kattints rá!
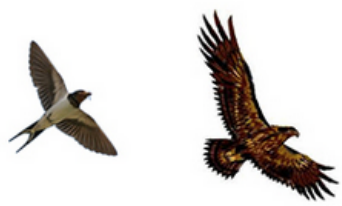


\begin{tabular}{|c|c|c|c|}
\hline \multicolumn{2}{|c|}{ ÁLLOMÁNYADATOK } & \multicolumn{2}{|c|}{ FÉSZKELÉS } \\
\hline Megfigyelési idö (év): & 2003 & Fészkelö helye: & $\begin{array}{l}\text { ártéri erdök, vizek melletti } \\
\text { erdöségek, erdei tavas területek }\end{array}$ \\
\hline Fészkelö állomány nagysága: & 118-130 fészkelö pár & Fészek helye: & fán \\
\hline Hazai védettség: & fokozottan védett & Fészek típusa: & gallyfészek \\
\hline Pénzben kifejezett érték (Ft): & 1000000 & Fészkelési típus: & magányosan fészkelö \\
\hline Európai veszélyeztetettség: & ritka faj & Fiókák száma $(d b)$ : & $1-3$ \\
\hline Hazai elöfordulási idöszak: & egész évben & Kikelési idö (nap): & $38-40$ \\
\hline Hazai elöfordulási státusz: & rendszeres fészkelö & Kirepülési idő (nap): & $80-90$ \\
\hline Telelési helye: & hazai élöhelyei & Fiókák fejlettsége: & fészeklakó \\
\hline Testhossz $(\mathrm{cm})$ : & $70-90$ & Évenkénti költés száma: & 1 \\
\hline Szárnyfesztávolság $(\mathrm{cm})$ : & $200-240$ & \multirow{2}{*}{ Életmódja; tápláléka: } & \multirow{2}{*}{$\begin{array}{l}\text { ragadozó; madarak (vízimadarak, } \\
\text { vadludak), halak, emlösök (nyulak, } \\
\text { nagyvadak zsigerei, dögök) }\end{array}$} \\
\hline Him tömege $(\mathrm{g})$ : & $3075-5430$ & & \\
\hline Tojó tömege $(g)$ : & $4080-6920$ & Ellensége, konkurenciája: & $\begin{array}{l}\text { kerecsensólyom (a fészkére } \\
\text { pályázik) }\end{array}$ \\
\hline
\end{tabular}

Keresd ki a táblázatból a rétisas TESTHOSSZÁT, és kattintással válaszolj!
- $38-40 \mathrm{~cm}$
$70-90 \mathrm{~cm}$
$80-90 \mathrm{~cm}$

Keresd ki a táblázatból a rétisas SZÁRNYFESZTÁVOLSÁGÁT, és kattintással válaszolj!
- $118-130 \mathrm{~cm}$
- $200-240 \mathrm{~cm}$
$375-543 \mathrm{~cm}$

Vissza

\begin{tabular}{|l|l|l|l|}
\hline \multicolumn{2}{|c|}{ ÁLLOMÁNYADATOK } & \multicolumn{2}{c|}{ FÉSZKELÉs } \\
\hline \hline Megfigyelési idö (év): & 2003 & Fészkelö helye: & áriöségek, erdei tavas területek \\
\hline Fészkelö állomány nagysága: & $118-130$ fészkelö pár & Fészek helye: & fán \\
\hline Hazai védettség: & fokozottan védett & Fészek tipusa: & gallyfészek \\
\hline Pénzben kifejezett érték (Ft): & 1000000 & Fészkelési típus: & magányosan fészkelö \\
\hline Európai veszélyeztetettség: & ritka faj & Fiókák száma (db): & $1-3$ \\
\hline $\begin{array}{l}\text { Hazai elöfordulási idöszak: } \\
\text { Hazai elöfordulási státusz: }\end{array}$ & $\begin{array}{l}\text { egész évben } \\
\text { rendszeres fészkelö }\end{array}$ & $\begin{array}{l}\text { Kikelési idö (nap): } \\
\text { Kirepülési idő (nap): }\end{array}$ & $\begin{array}{l}38-40 \\
80-90\end{array}$ \\
\hline Telelési helye: & hazai élöhelyei & Fiókák fejlettsége: & fészeklakó \\
\hline Testhossz $(\mathrm{cm}):$ & $70-90$ & Évenkénti költés száma: & 1 \\
\hline Szárnyfesztávolság $(\mathrm{cm}):$ & $200-240$ & Életmódja; tápláléka: & $\begin{array}{l}\text { ragadozó; madarak (vízimadarak, } \\
\text { vadludak), halak, emlösök (nyulak, } \\
\text { nagyvadak zsigerei, dögök) } \\
\text { kerecsensólyom (a fészkére } \\
\text { pályázik) }\end{array}$ \\
\hline Himm tömege $(\mathrm{g}):$ & $3075-5430$ & Ellensége, konkurenciája: & \\
\hline Tojó tömege $(\mathrm{g}):$ & $4080-6920$ & & \\
\hline
\end{tabular}

Fészkel itt a rétisas? Kattintással válaszolj!

folyóparti fás területen $\circ$ Igen $\circ$ Nem 


\begin{tabular}{|c|c|c|c|}
\hline \multicolumn{2}{|c|}{ ÁLLOMÁNYADATOK } & \multicolumn{2}{|c|}{ FÉSZKELÉS } \\
\hline Megfigyelési idó (év): & 2003 & Fészkelö helye: & $\begin{array}{l}\text { ártéri erdök, vizek melletti } \\
\text { erdöségek, erdei tavas területek }\end{array}$ \\
\hline Fészkeló állomány nagysága: & 118-130 fészkelö pár & Fészek helye: & fán \\
\hline Hazai védettség: & fokozottan védett & Fészek típusa: & gallyfészek \\
\hline Pénzben kifejezett érték (Ft): & 1000000 & Fészkelési típus: & magányosan fészkelö \\
\hline Európai veszélyeztetettség: & ritka faj & Fiókák száma $(d b)$ : & $1-3$ \\
\hline Hazai elöfordulási időszak: & egész évben & Kikelési idö (nap): & $38-40$ \\
\hline Hazai elöfordulási státusz: & rendszeres fészkelö & Kirepülési idó (nap): & $80-90$ \\
\hline Telelési helye: & hazai élöhelyei & Fiókák fejlettsége: & fészeklakó \\
\hline Testhossz $(\mathrm{cm})$ : & $70-90$ & Évenkénti költés száma: & 1 \\
\hline Szárnyfesztávolság $(\mathrm{cm})$ : & $200-240$ & \multirow{2}{*}{ Életmódja; tápláléka: } & \multirow{2}{*}{$\begin{array}{l}\text { ragadozó; madarak (vízimadarak, } \\
\text { vadludak), halak, emlösök (nyulak } \\
\text { nagyvadak zsigerei, dögök) }\end{array}$} \\
\hline Him tömege (g): & $3075-5430$ & & \\
\hline Tojó tömege (g): & $4080-6920$ & Ellensége, konkurenciája: & $\begin{array}{l}\text { kerecsensólyom (a fészkére } \\
\text { pályázik) }\end{array}$ \\
\hline
\end{tabular}

Fészkel itt a rétisas? Kattintással válaszolj!

magas hegyekben $\circ$ Igen $\circ$ Nem

\begin{tabular}{|c|c|c|c|}
\hline \multicolumn{2}{|c|}{ ÁLLOMÁNYADATOK } & \multicolumn{2}{|c|}{ FÉSZKELÉS } \\
\hline Megfigyelési idö (év): & 2003 & Fészkelö helye: & $\begin{array}{l}\text { ártéri erdök, vizek melletti } \\
\text { erdöségek, erdei tavas területek }\end{array}$ \\
\hline Fészkelö állomány nagysága: & 118-130 fészkelö pár & Fészek helye: & fán \\
\hline Hazai védettség: & fokozottan védett & Fészek típusa: & gallyfészek \\
\hline Pénzben kifejezett érték (Ft): & 1000000 & Fészkelési tipus: & magányosan fészkelö \\
\hline Európai veszélyeztetettség: & ritka faj & Fiókák száma $(d b)$ : & $1-3$ \\
\hline Hazai elöfordulási idôszak: & egész évben & Kikelési idó (nap): & $38-40$ \\
\hline Hazai elöfordulási státusz: & rendszeres fészkelö & Kirepülési idö (nap): & $80-90$ \\
\hline Telelési helye: & hazai élöhelyei & Fiókák fejlettsége: & fészeklakó \\
\hline Testhossz $(\mathrm{cm})$ : & $70-90$ & Évenkénti költés száma: & 1 \\
\hline Szárnyfesztávolság (cm): & $200-240$ & \multirow{2}{*}{ Életmódja; tápláléka: } & \multirow{2}{*}{$\begin{array}{l}\text { ragadozó; madarak (vízimadarak, } \\
\text { vadludak), halak, emlösök (nyulak, } \\
\text { nagyvadak zsigerei, dögök) }\end{array}$} \\
\hline Him tömege $(\mathrm{g})$ : & $3075-5430$ & & \\
\hline Tojó tömege $(\mathrm{g})$ : & $4080-6920$ & Ellensége, konkurenciája: & $\begin{array}{l}\text { kerecsensólyom (a fészkére } \\
\text { pályázik) }\end{array}$ \\
\hline
\end{tabular}

Fészkel itt a rétisas? Kattintással válaszolj!

$$
\text { erdös, vizes területen } \quad \circ \text { Igen } \quad \circ \text { Nem }
$$




\begin{tabular}{|c|c|c|c|}
\hline \multicolumn{2}{|c|}{ ÁLLOMÁNYADATOK } & \multicolumn{2}{|c|}{ FÉSZKELÉS } \\
\hline Megfigyelési idö (év): & 2003 & Fészkelö helye: & $\begin{array}{l}\text { ártéri erdök, vizek melletti } \\
\text { erdöségek, erdei tavas területek }\end{array}$ \\
\hline Fészkelö állomány nagysága: & 118-130 fészkelö pár & Fészek helye: & fán \\
\hline Hazai védettség: & fokozottan védett & Fészek típusa: & gallyfészek \\
\hline Pénzben kifejezett érték (Ft): & 1000000 & Fészkelési típus: & magányosan fészkelö \\
\hline Európai veszélyeztetettség: & ritka faj & Fiókák száma (db): & $1-3$ \\
\hline Hazai elöfordulási idöszak: & egész évben & Kikelési idó (nap): & $38-40$ \\
\hline Hazai elöfordulási státusz: & rendszeres fészkelö & Kirepülési idố (nap): & $80-90$ \\
\hline Telelési helye: & hazai élöhelyei & Fiókák fejlettsége: & fészeklakó \\
\hline Testhossz $(\mathrm{cm})$ : & $70-90$ & Évenkénti költés száma: & 1 \\
\hline Szárnyfesztávolság (cm): & $200-240$ & \multirow{2}{*}{ Életmódja; tápláléka: } & \multirow{2}{*}{$\begin{array}{l}\text { ragadozó; madarak (vizimadarak, } \\
\text { vadludak), halak, emlösök (nyulak } \\
\text { nagyvadak zsigerei, dögök) }\end{array}$} \\
\hline Him tömege $(\mathrm{g})$ : & $3075-5430$ & & \\
\hline Tojó tömege (g): & $4080-6920$ & Ellensége, konkurenciája: & $\begin{array}{l}\text { kerecsensólyom (a fészkére } \\
\text { pályázik) }\end{array}$ \\
\hline
\end{tabular}

Fejezd be a mondatot a táblázat segítségével! Kattintással válaszolj!

A rétisas pár...

csoportosan fészkel.

hímje színesebb tollú.

Vissza

tojója nagyobb tömegú.

\begin{tabular}{|l|l|l|l|}
\hline \multicolumn{2}{|c|}{ ÁLLOMÁNYADATOK } & & $\begin{array}{l}\text { ártéri erdök, vizek melletti } \\
\text { erdöségek, erdei tavas területek }\end{array}$ \\
\hline \hline Megfigyelési idó (év): & 2003 & Fészkelö helye: & fán \\
\hline Fészkelö állomány nagysága: & $118-130$ fészkelö pár & Fészek helye: & gallyfészek \\
\hline Hazai védettség: & fokozottan védett & Fészek típusa: & magányosan fészkelö \\
\hline Pénzben kifejezett érték (Ft): & 1000000 & Fiókák száma (db): & $1-3$ \\
\hline Európai veszélyeztetettség: & ritka faj & $\begin{array}{l}\text { Kikelési idö (nap): } \\
\text { Kirepülési idö (nap): }\end{array}$ & $\begin{array}{l}38-40 \\
80-90\end{array}$ \\
\hline $\begin{array}{l}\text { Hazai elöfordulási idöszak: } \\
\text { Hazai elöfordulási státusz: }\end{array}$ & $\begin{array}{l}\text { egész évben } \\
\text { rendszeres fészkelö }\end{array}$ & hiókák fejlettsége: & fészeklakó \\
\hline Telelési helye: & $70-90$ & Évenkénti költés száma: & 1 \\
\hline Testhossz $(\mathrm{cm}):$ & $200-240$ & Életmódja; tápláléka: & $\begin{array}{l}\text { ragadozó; madarak (vizimadarak, } \\
\text { vadludak), halak, emlösök (nyulak, } \\
\text { nagyvadak zsigerei, dögök) } \\
\text { kerecsensólyom (a fészkére } \\
\text { pályázik) }\end{array}$ \\
\hline Szárnyfesztávolság $(\mathrm{cm}):$ & $3075-5430$ & Ellensége, konkurenciája: & \\
\hline Tojó tömegömege $(\mathrm{g}):$ & $4080-6920$ & &
\end{tabular}

\section{Egészítsd ki a mondatot a táblázat segítségével! Kattintással válaszolj!}

$A$ rétisas egy évben rak tojásokat.
- egyszer
- kétszer
háromszor 


\begin{tabular}{|c|c|c|c|}
\hline \multicolumn{2}{|c|}{ ÁLLOMÁNYADATOK } & \multicolumn{2}{|c|}{ FÉSZKELÉS } \\
\hline Megfigyelési idö (év): & 2003 & Fészkelö helye: & $\begin{array}{l}\text { ártéri erdök, vizek melletti } \\
\text { erdöségek, erdei tavas területek }\end{array}$ \\
\hline Fészkelö állomány nagysága: & 118-130 fészkelö pár & Fészek helye: & fán \\
\hline Hazai védettség: & fokozottan védett & Fészek típusa: & gallyfészek \\
\hline Pénzben kifejezett érték (Ft): & 1000000 & Fészkelési típus: & magányosan fészkelö \\
\hline Európai veszélyeztetettség: & ritka faj & Fiókák száma $(d b)$ : & $1-3$ \\
\hline Hazai elöfordulási idöszak: & egész évben & Kikelési idö (nap): & $38-40$ \\
\hline Hazai elöfordulási státusz: & rendszeres fészkelö & Kirepülési idö (nap): & $80-90$ \\
\hline Telelési helye: & hazai élöhelyei & Fiókák fejlettsége: & fészeklakó \\
\hline Testhossz $(\mathrm{cm})$ : & $70-90$ & Évenkénti költés száma: & 1 \\
\hline Szárnyfesztávolság $(\mathrm{cm})$ : & $200-240$ & \multirow{2}{*}{ Életmódja; tápláléka: } & \multirow{2}{*}{$\begin{array}{l}\text { ragadozó; madarak (vízimadarak, } \\
\text { vadludak), halak, emlösök (nyulak, } \\
\text { nagyvadak zsigerei, dögök) }\end{array}$} \\
\hline Him tömege $(\mathrm{g})$ : & $3075-5430$ & & \\
\hline Tojó tömege (g): & $4080-6920$ & Ellensége, konkurenciája: & $\begin{array}{l}\text { kerecsensólyom (a fészkére } \\
\text { pályázik) }\end{array}$ \\
\hline
\end{tabular}

\section{Fejezd be a mondatot a táblázat segítségével! Kattintással válaszolj!}

\section{A rétisas élete...}

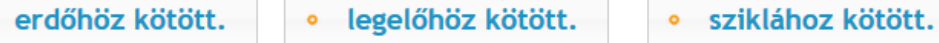

\begin{tabular}{|c|c|c|c|}
\hline \multicolumn{2}{|c|}{ ÁLLOMÁNYADATOK } & \multicolumn{2}{|c|}{ FÉSZKELÉS } \\
\hline Megfigyelési idö (év): & 2003 & Fészkelö helye: & $\begin{array}{l}\text { ártéri erdök, vizek melletti } \\
\text { erdőségek, erdei tavas területek }\end{array}$ \\
\hline Fészkelö állomány nagysága: & 118-130 fészkelö pár & Fészek helye: & fán \\
\hline Hazai védettség: & fokozottan védett & Fészek típusa: & gallyfészek \\
\hline Pénzben kifejezett érték (Ft): & 1000000 & Fészkelési tipus: & magányosan fészkelö \\
\hline Európai veszélyeztetettség: & ritka faj & Fiókák száma $(d b)$ : & $1-3$ \\
\hline Hazai elöfordulási idốszak: & egész évben & Kikelési idö (nap): & $38-40$ \\
\hline Hazai elöfordulási státusz: & rendszeres fészkelö & Kirepülési idố (nap): & $80-90$ \\
\hline Telelési helye: & hazai élöhelyei & Fiókák fejlettsége: & fészeklakó \\
\hline Testhossz $(\mathrm{cm})$ : & $70-90$ & Évenkénti költés száma: & 1 \\
\hline Szárnyfesztávolság (cm): & $200-240$ & \multirow{2}{*}{-Életmódja; tápláléka: } & \multirow{2}{*}{$\begin{array}{l}\text { ragadozó; madarak (vízimadarak, } \\
\text { vadludak), halak, emlösök (nyulak, } \\
\text { nagyvadak zsigerei, dögök) }\end{array}$} \\
\hline Him tömege $(\mathrm{g})$ : & $3075-5430$ & & \\
\hline Tojó tömege $(\mathrm{g})$ : & $4080-6920$ & Ellensége, konkurenciája: & $\begin{array}{l}\text { kerecsensólyom (a fészkére } \\
\text { pályázik) }\end{array}$ \\
\hline
\end{tabular}

Fejezd be a mondatot a táblázat segítségével! Kattintással válaszolj!

\section{A rétisas télen ...}

nem vált élőhelyet. délre költözik. a kerecsensólyommal fészkel. 


\begin{tabular}{|c|c|c|c|}
\hline \multicolumn{2}{|c|}{ ÁLLOMÁNYADATOK } & \multicolumn{2}{|c|}{ FÉSZKELÉS } \\
\hline Megfigyelési idö (év): & 2003 & Fészkelö helye: & $\begin{array}{l}\text { ártéri erdök, vizek melletti } \\
\text { erdöségek, erdei tavas területek }\end{array}$ \\
\hline Fészkelö állomány nagysága: & 118-130 fészkelö pár & Fészek helye: & fán \\
\hline Hazai védettség: & fokozottan védett & Fészek típusa: & gallyfészek \\
\hline Pénzben kifejezett érték (Ft): & 1000000 & Fészkelési tipus: & magányosan fészkelö \\
\hline Európai veszélyeztetettség: & ritka faj & Fiókák száma (db): & $1-3$ \\
\hline Hazai elöfordulási időszak: & egész évben & Kikelési idö (nap): & $38-40$ \\
\hline Hazai elöfordulási státusz: & rendszeres fészkelö & Kirepülési idö (nap): & $80-90$ \\
\hline Telelési helye: & hazai élőhelyei & Fiókák fejlettsége: & fészeklakó \\
\hline Testhossz $(\mathrm{cm})$ : & $70-90$ & Évenkénti költés száma: & 1 \\
\hline Szárnyfesztávolság $(\mathrm{cm})$ : & $200-240$ & \multirow{2}{*}{ Életmódja; tápláléka: } & \multirow{2}{*}{$\begin{array}{l}\text { ragadozó; madarak (vízimadarak, } \\
\text { vadludak), halak, emlösök (nyulak, } \\
\text { nagyvadak zsigerei, dögök) }\end{array}$} \\
\hline Him tömege $(\mathrm{g})$ : & $3075-5430$ & & \\
\hline Tojó tömege (g): & $4080-6920$ & Ellensége, konkurenciája: & $\begin{array}{l}\text { kerecsensólyom (a fészkére } \\
\text { pályázik) }\end{array}$ \\
\hline
\end{tabular}

Egészítsd ki a mondatot a táblázat segítségével! Kattintással válaszolj!

A rétisas szülők napig gondozzák a fiókákat.
$38-40$
$70-90$
$80-90$

\section{Az olvasásteszt végére értél.}

Ha továbblépsz, már NEM TUDSZ VISSZATÉRNI az tesztfeladatokhoz.

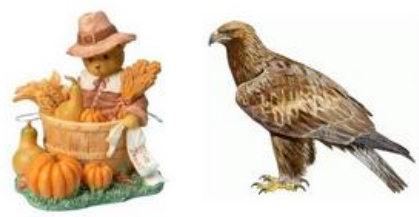

A továbbiakban az olvasott szövegekröl és a feladatokról kérdezünk.

Nincsnek sem jó, sem rossz, sem elvárt válaszok. A véleményedre vagyunk kíváncsiak. Fontos, hogy őszinte légy. Kérünk, válaszolj a kérdésekre!

Olvasd el a kérdéseket, és kattints a véleményedet leginkább kifejező válaszra! Fontold meg a válaszodat, mert NEM lehet visszalépni!

Kattints a Tovább gombra! 
Ismerted a szövegeket a teszt kitöltését megelőzően?

Kattintással válaszolj!

A kertészkedő bocsok

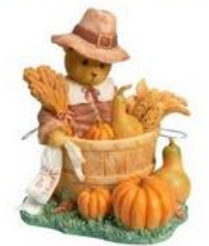

- Igen $\quad$ Nem
A rétisas

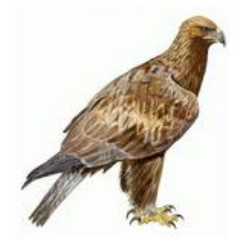

- Igen $\quad$ Nem

Mennyire tetszettek az olvasott szövegek?

Kattints arra gombra, amelyik leginkább kifejezi a véleményedet!

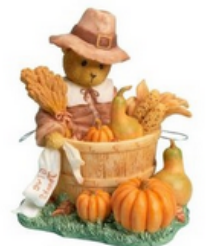

A kertészkedő bocsok
- Egyáltalán nem
- Inkább nem
- Inkább igen
- Nagyon

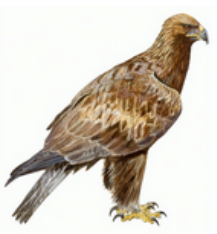

$A$ rétisas

- Egyáltalán nem

- Inkább nem

- Inkább igen

- Nagyon 
Mennyire találtad nehéznek a szövegeket?

Kattints arra gombra, amelyik leginkább kifejezi a véleményedet!

A kertészkedő bocsok
- Egyáltalán nem
Inkább nem
Inkább igen
Nagyon

A rétisas

Inkább nem

Inkább igen

Nagyon

Mennyire tetszettek a szövegekhez kapcsolódó feladatok?

Kattints arra gombra, amelyik leginkább kifejezi a véleményedet!

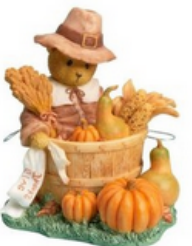

A kertészkedő bocsok
- Egyáltalán nem
- Inkább nem
Inkább igen
Nagyon

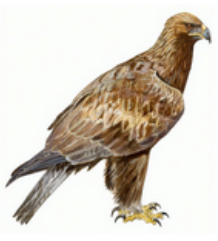

A rétisas

- Egyáltalán nem

- Inkább nem

- Inkább igen

- Nagyon 
Mennyire találtad nehéznek a szövegekhez kapcsolódó feladatokat?

Kattints arra gombra, amelyik leginkább kifejezi a véleményedet!

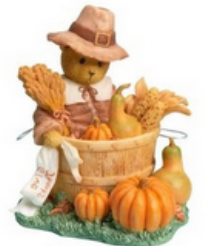

A kertészkedő bocsok
- Egyáltalán nem
- Inkább nem
Inkább igen
- Nagyon

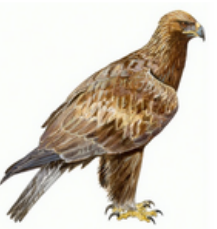

$A$ rétisas

- Egyáltalán nem

Inkább nem

- Inkább igen

Nagyon 


\section{Appendix C}

\section{The reading literacy subtest with the mixed text}

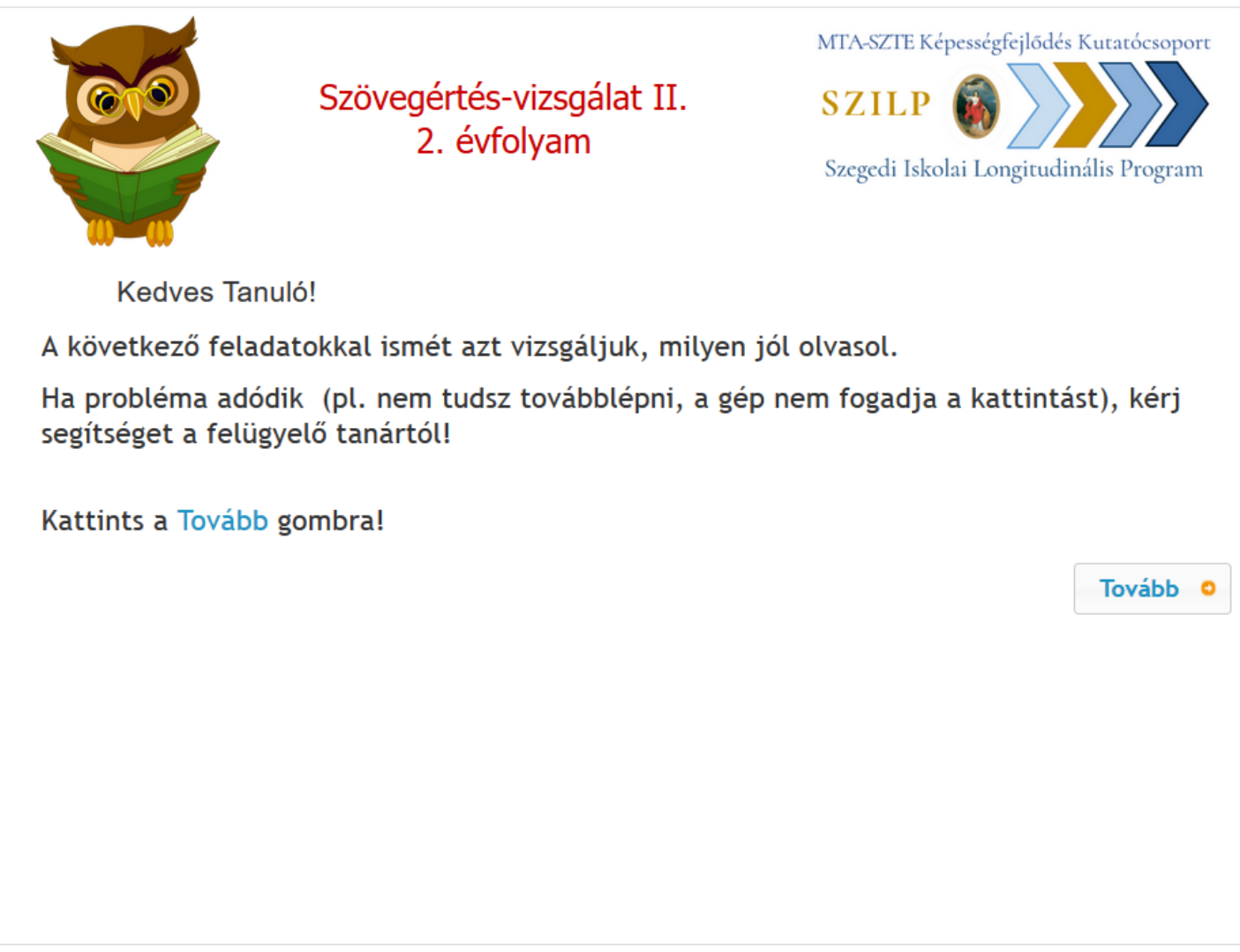

A képernyőn egy színházi előadás plakátját fogod látni, amely a Szamárbör királyfi című mesejátékhoz készült.

A képernyőn a plakátnak csak egy része látható.

A TELJES SZÖVEGET a jobb oldalon található GÖRGETŐSÁV mozgatásával tudod elolvasni.

Tanulmányozd, és oldd meg a feladatokat!

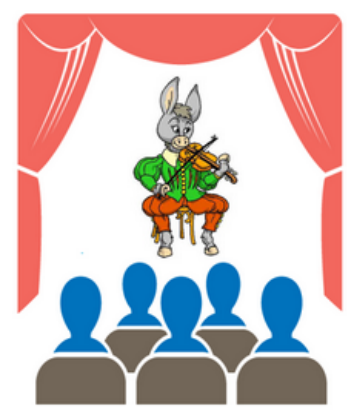

A tesztben a Tovább gombra kattintásal tudsz a következő feladatra lépni, és a Vissza gomb segítségével térhetsz vissza a nem megoldott feladatokra. Van, ahol NEM lehet visszalépni. Figyelj azokra az oldalakra, amelyek erre figyelmeztetnek!

A képernyő tetején narancssárga sáv mutatja, hogy hol tartasz a feladatok megoldásában, amelyhez 45 perc áll rendelkezésedre.

Kezdjük a munkát! Kattints a Tovább gombra! 


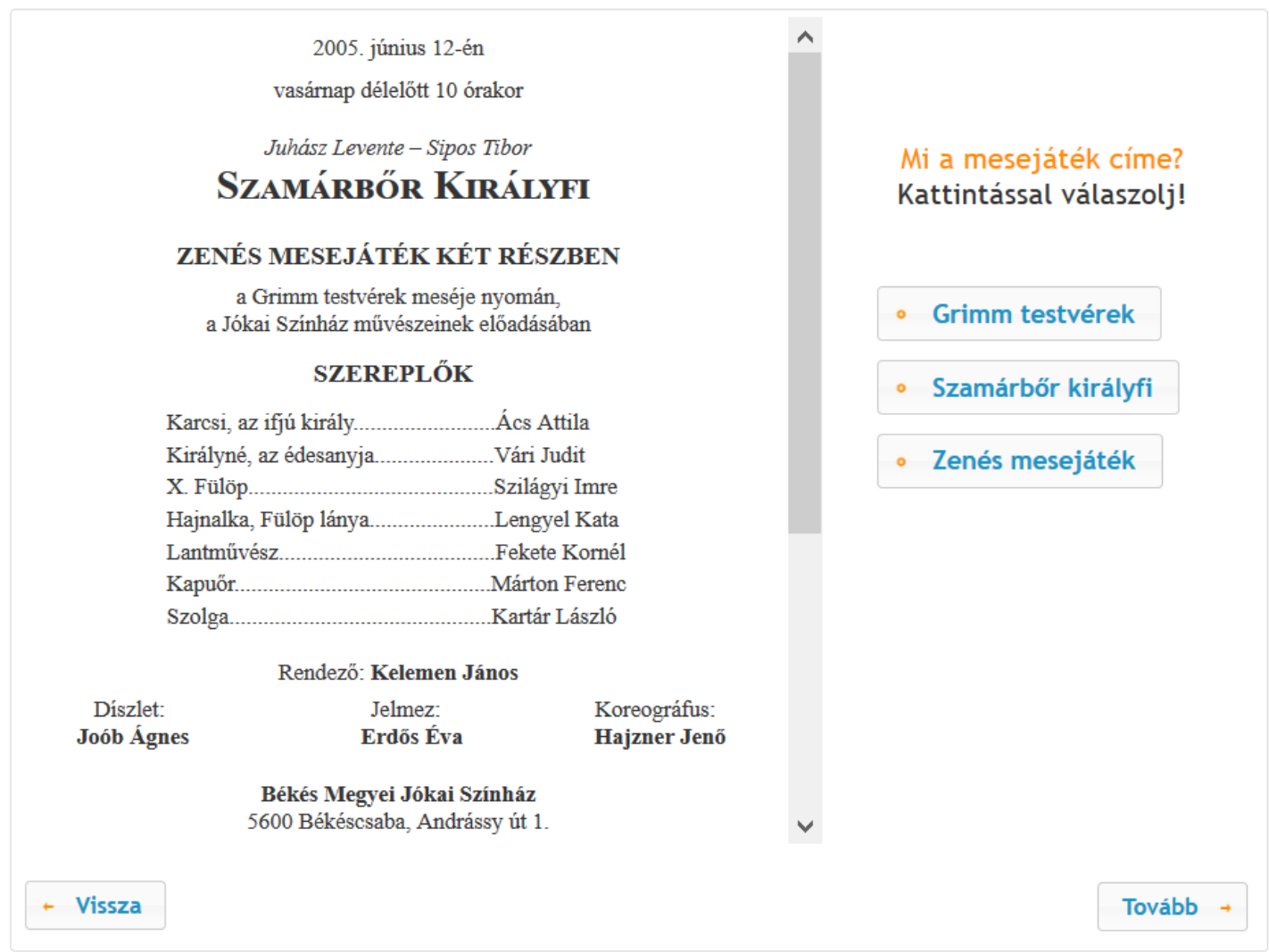

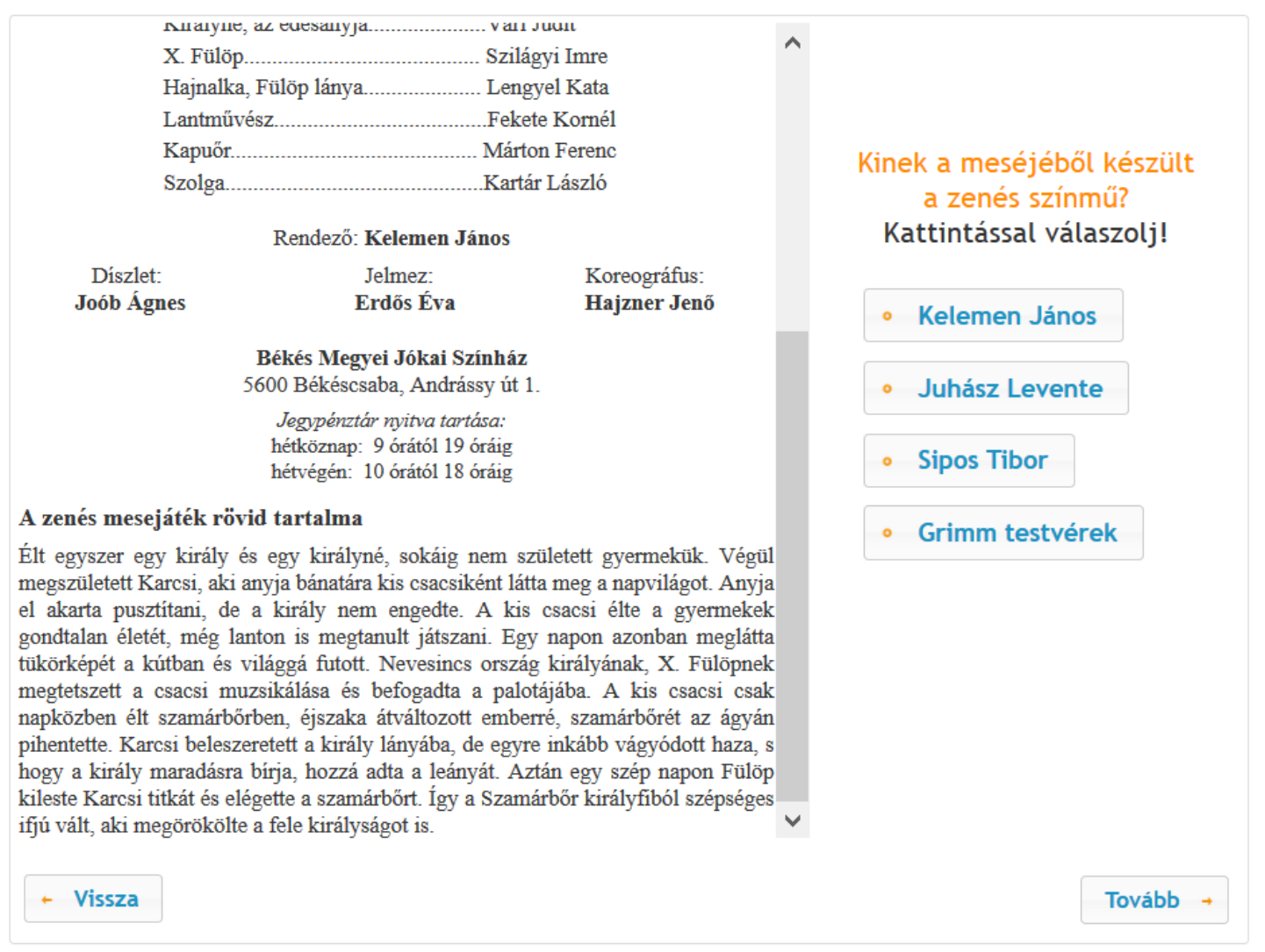




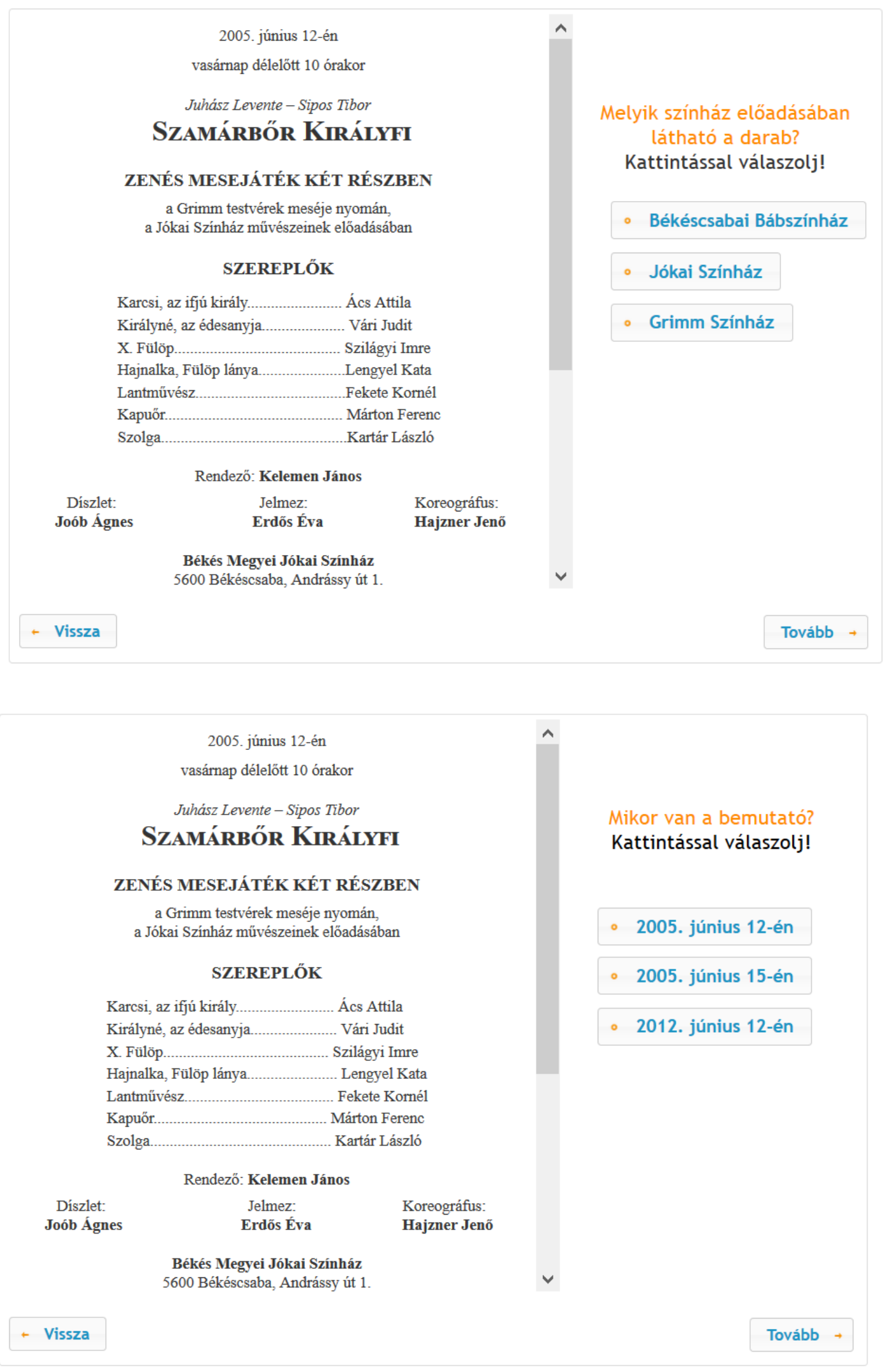



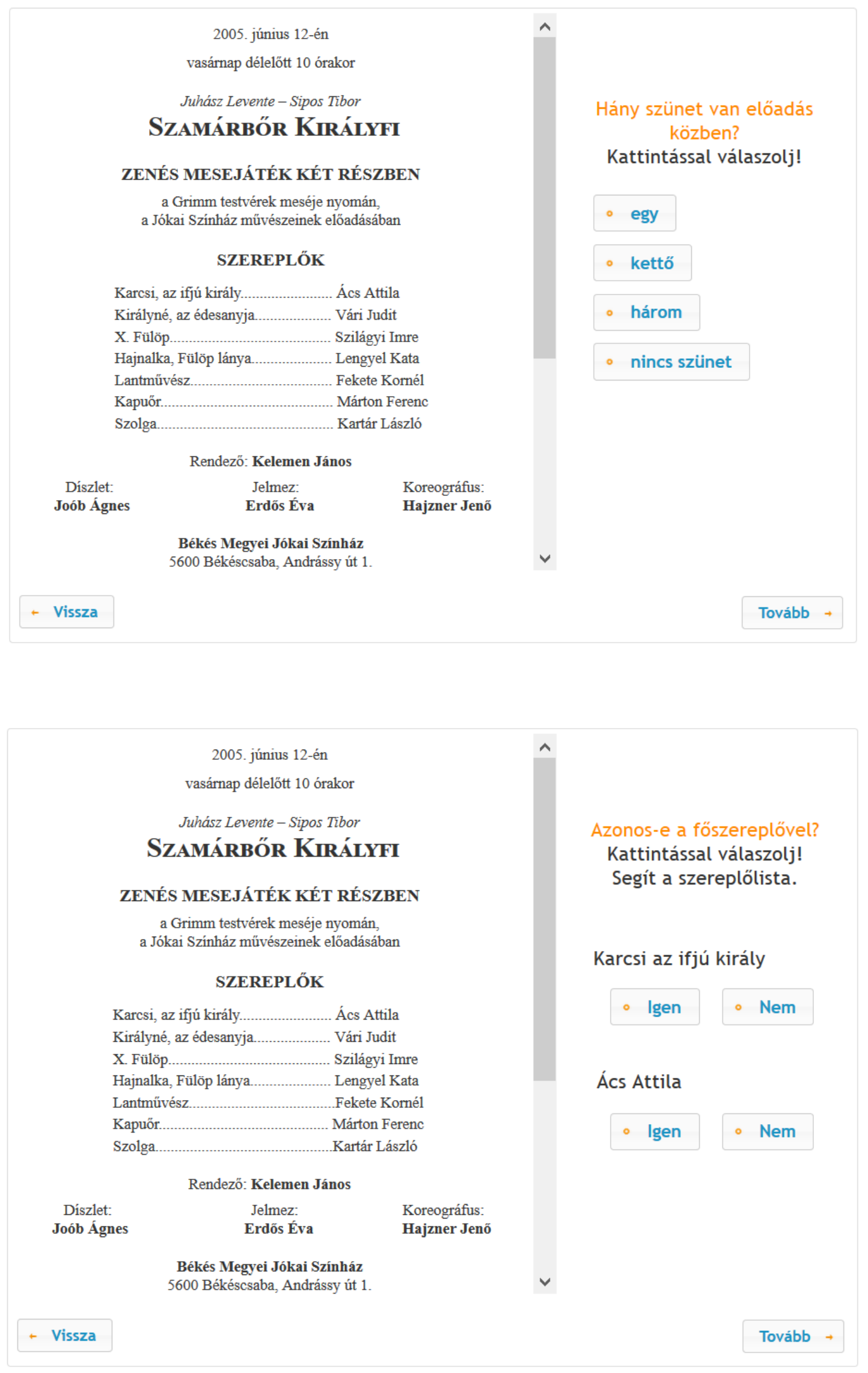


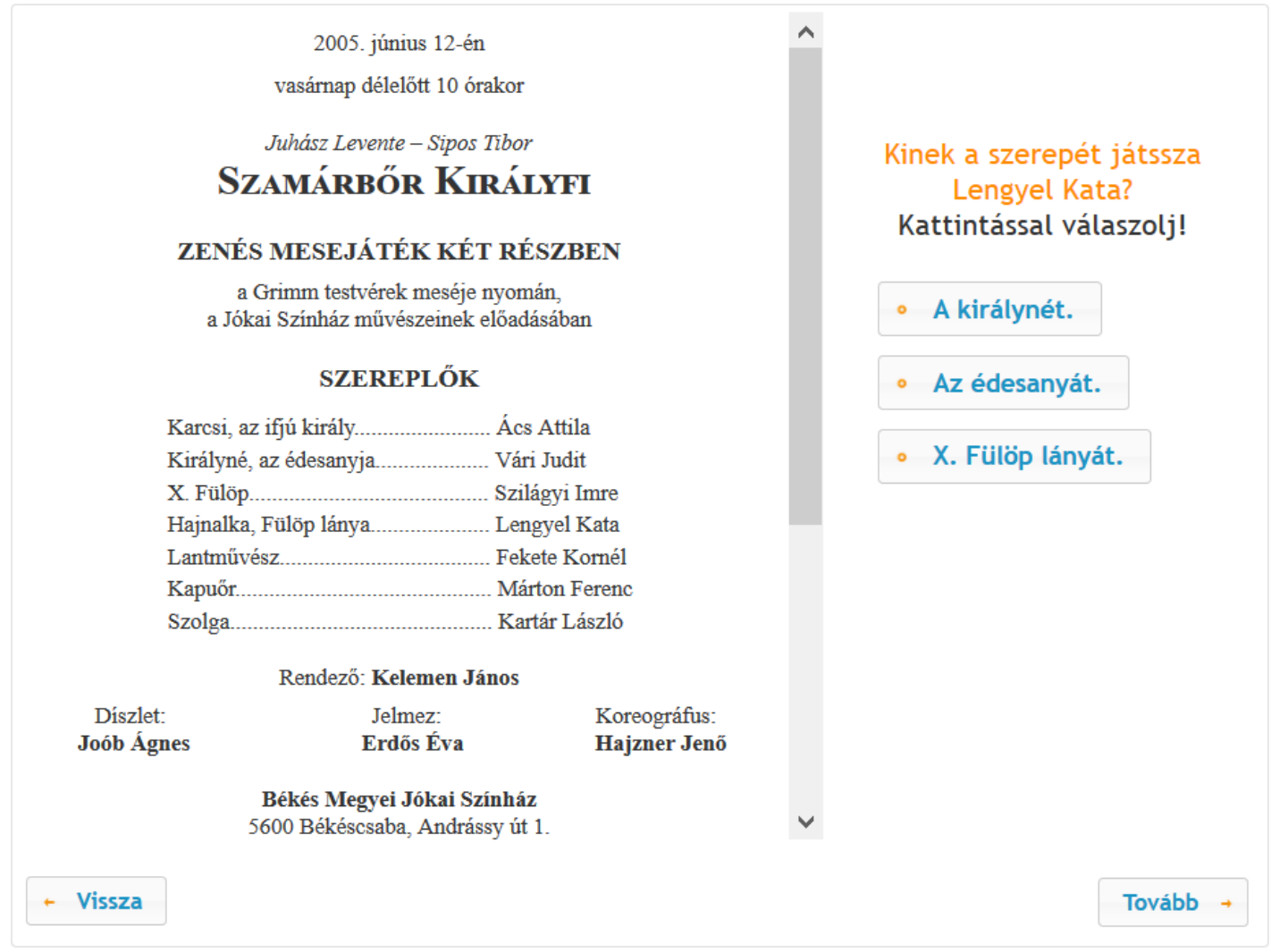

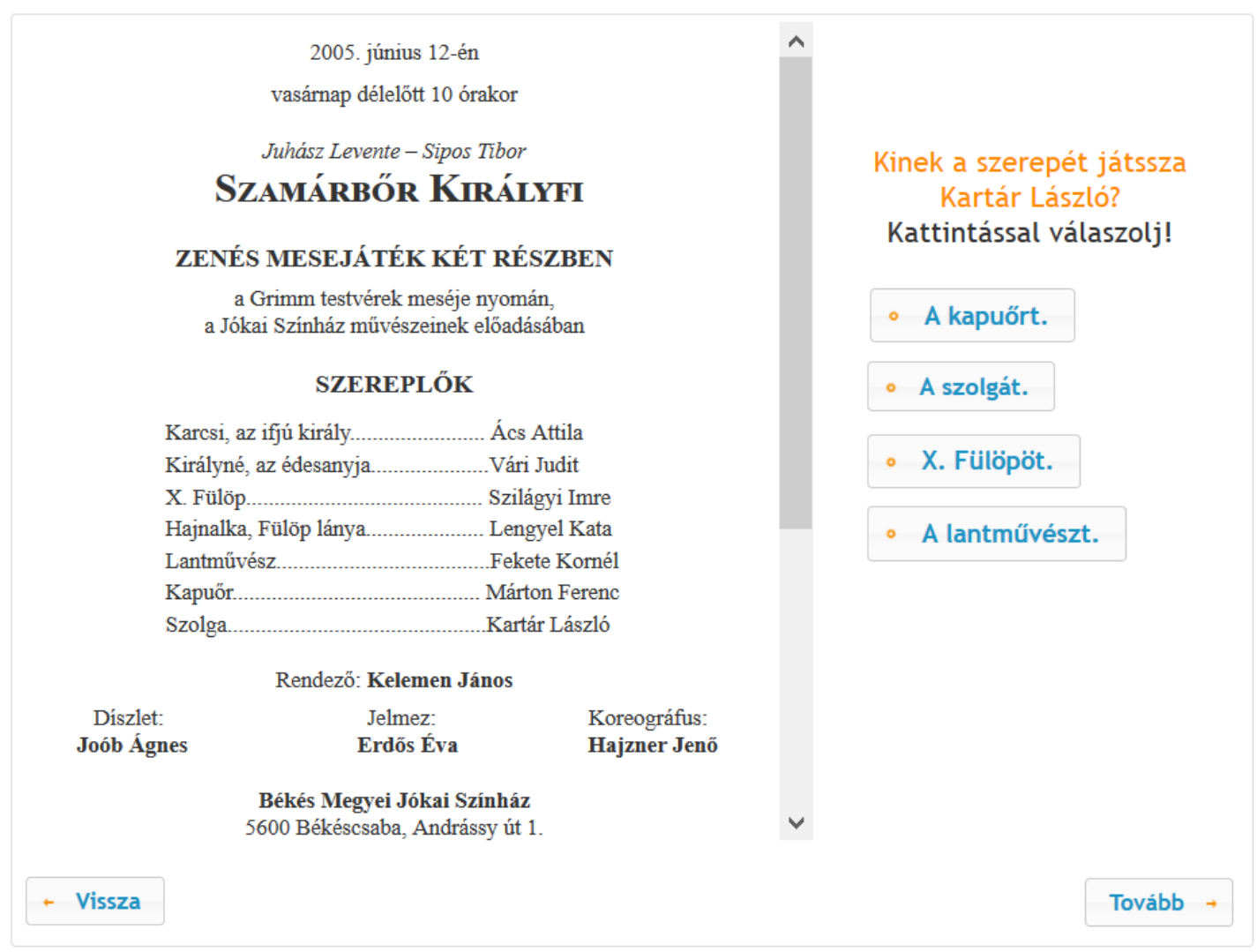




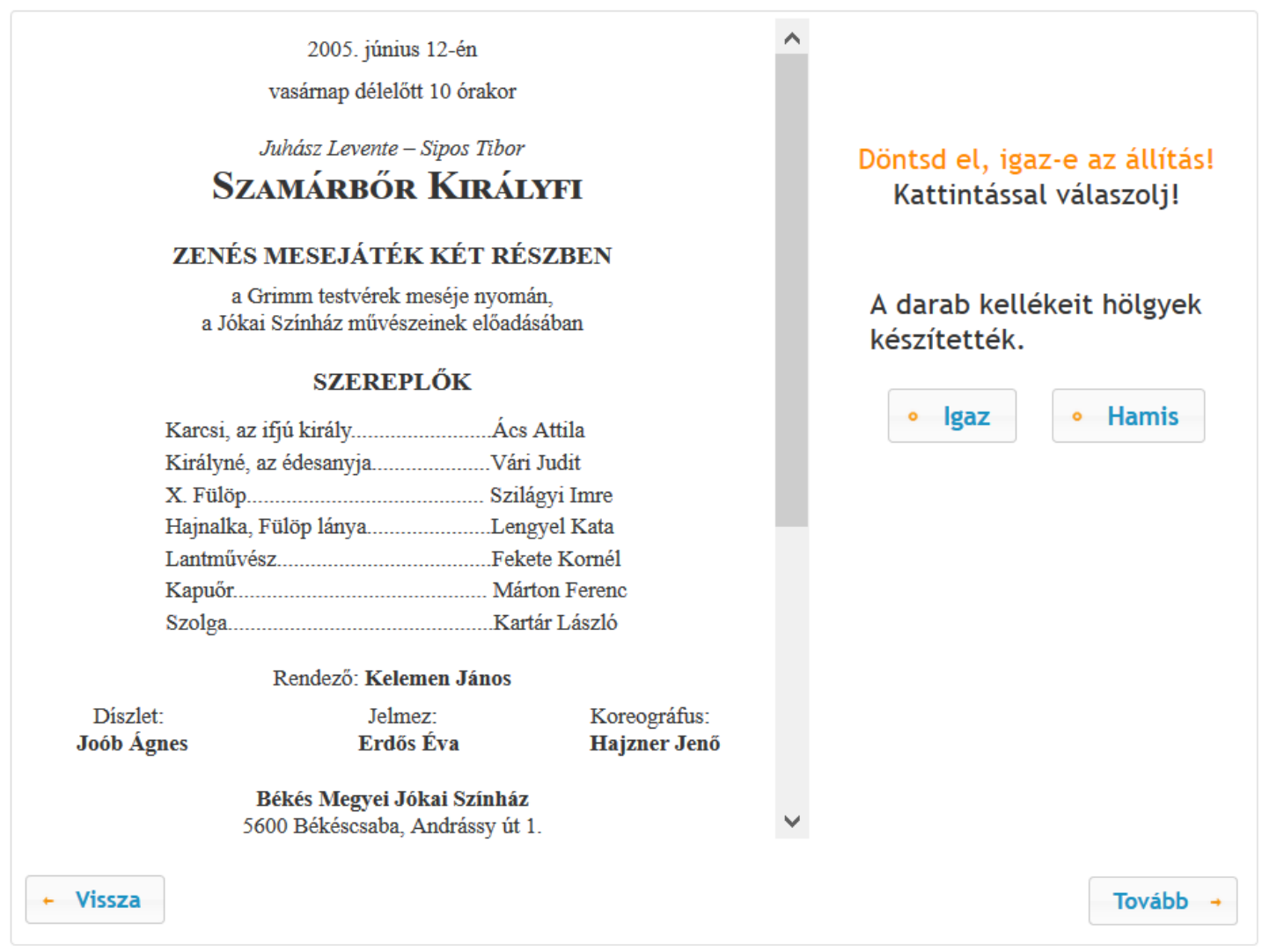

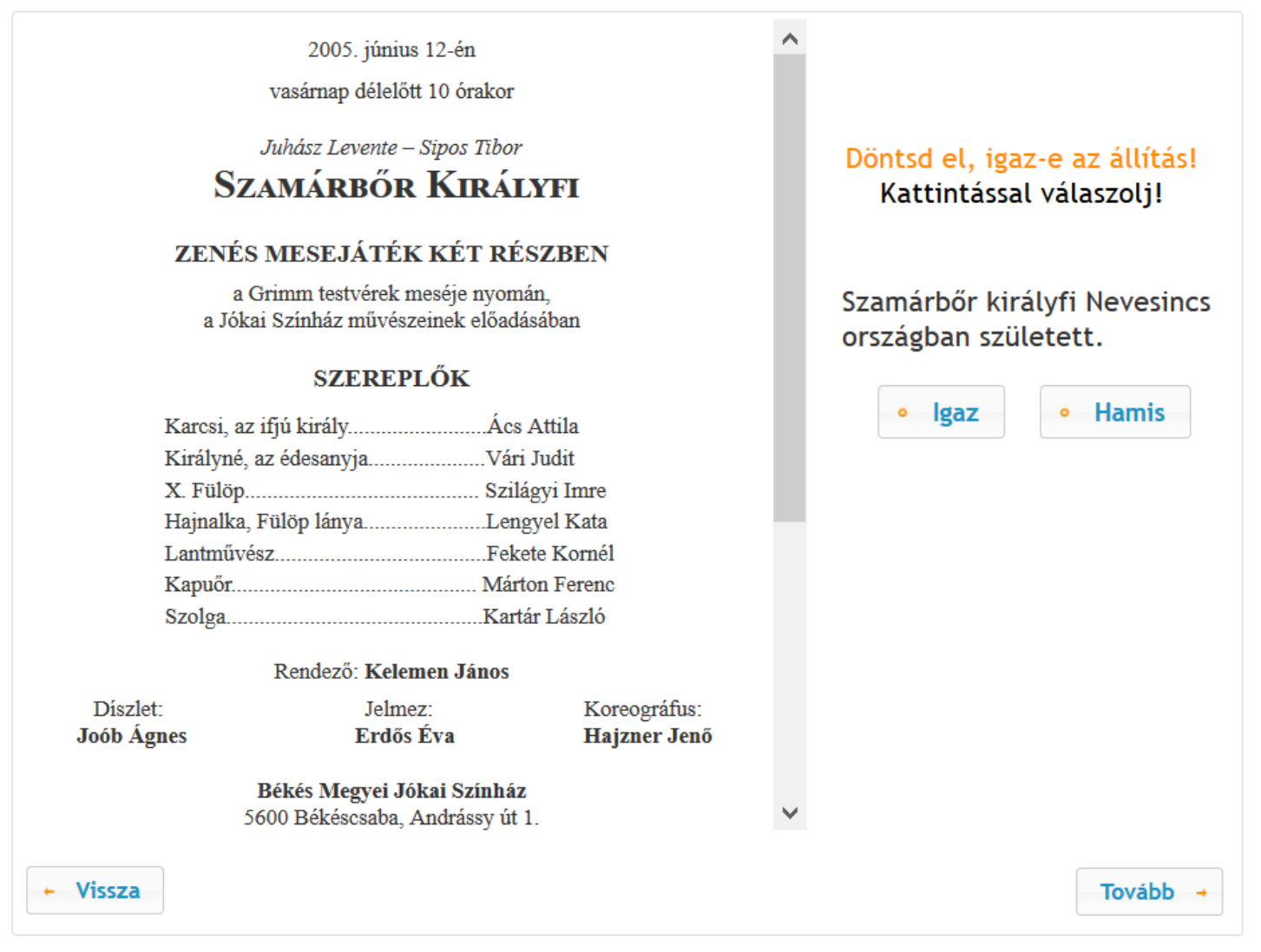


Task 12

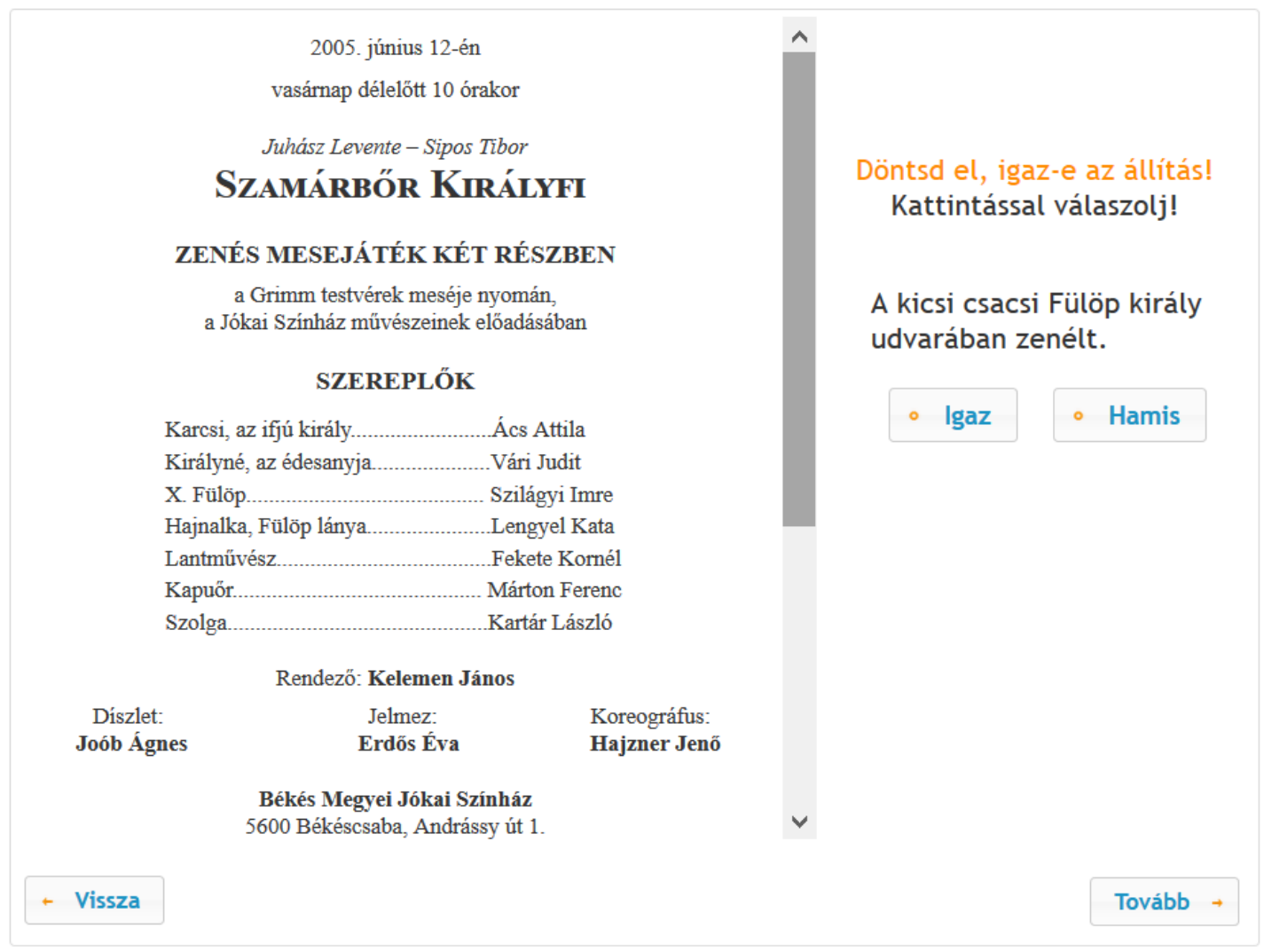

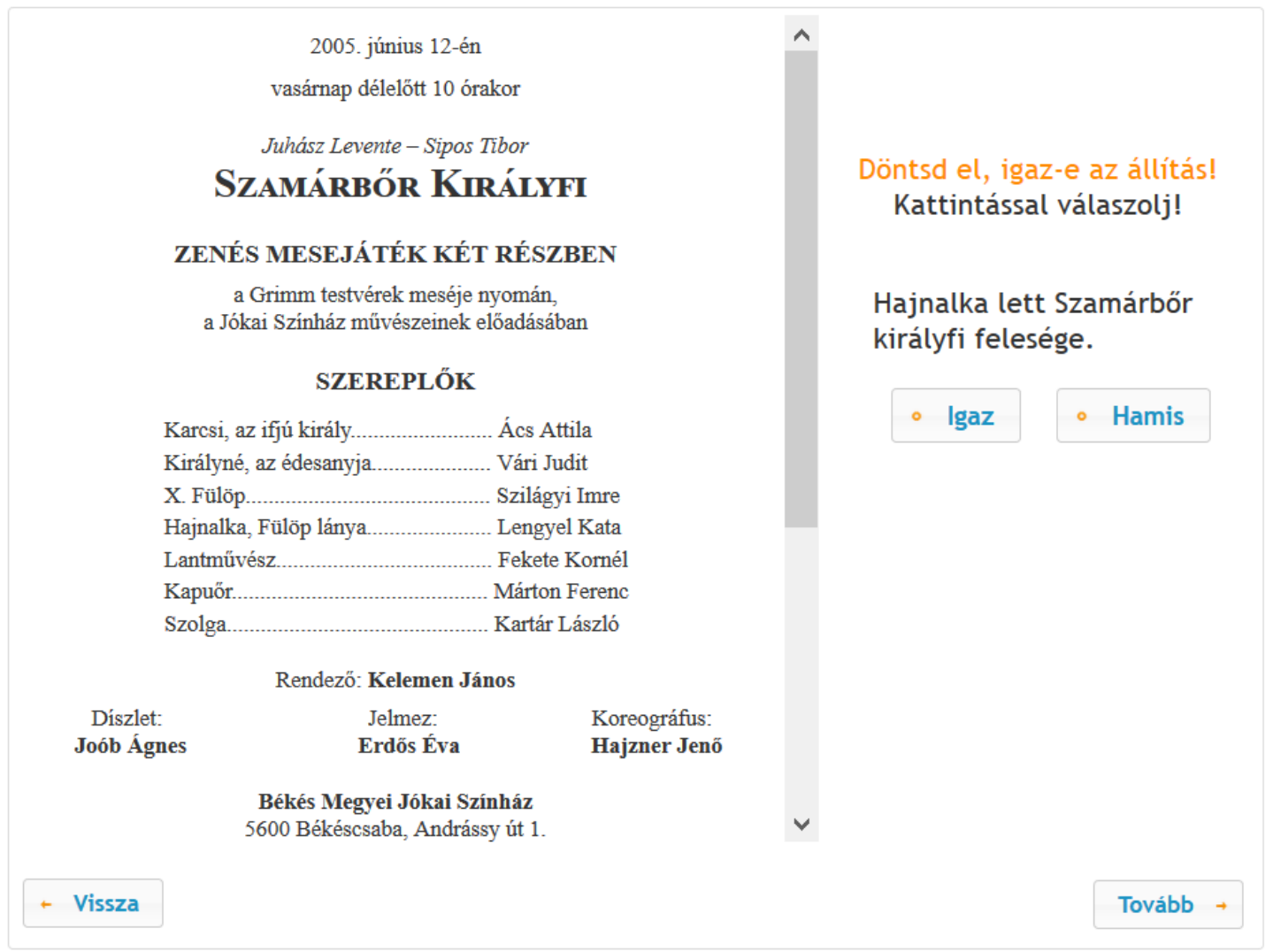




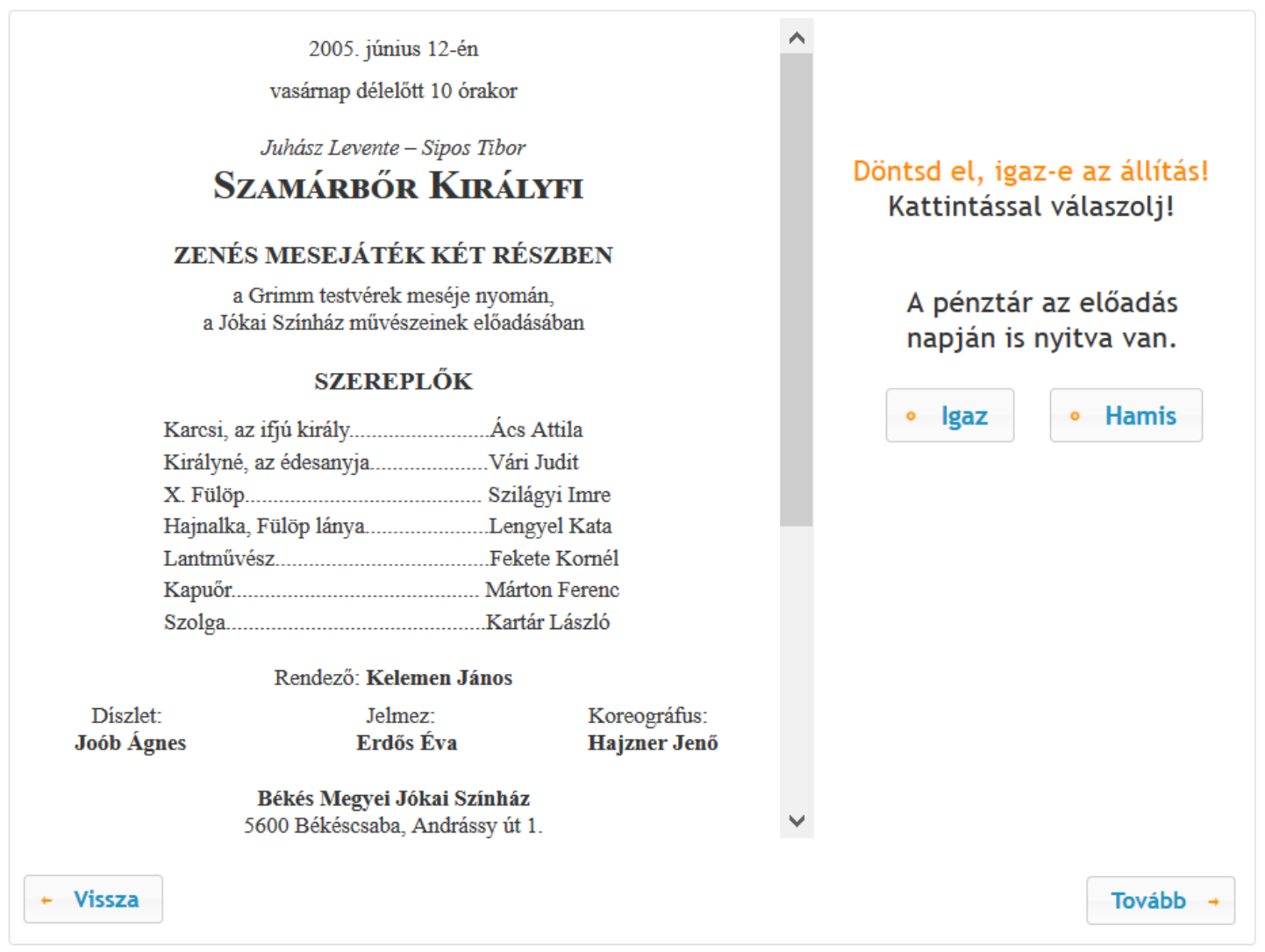

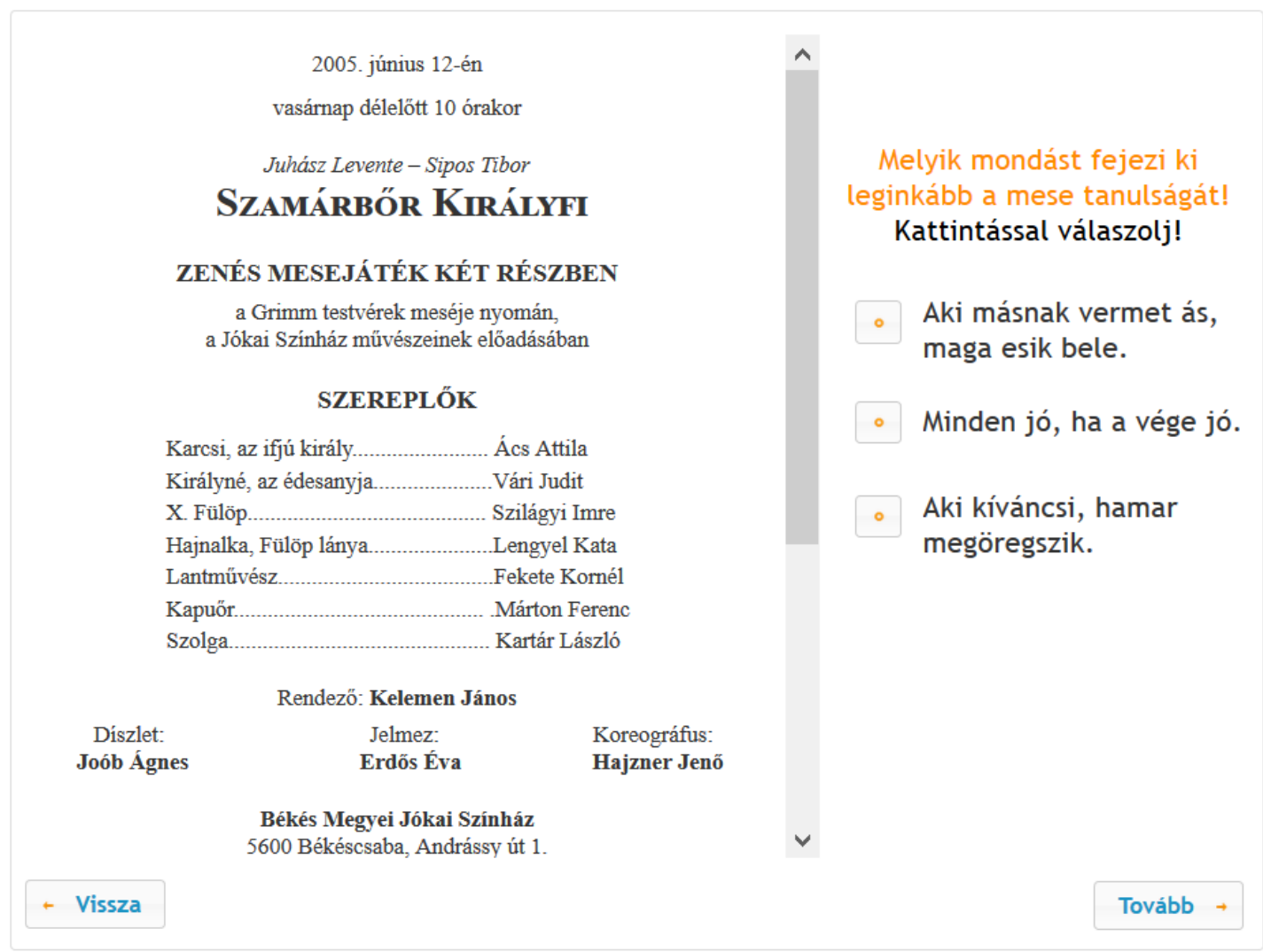



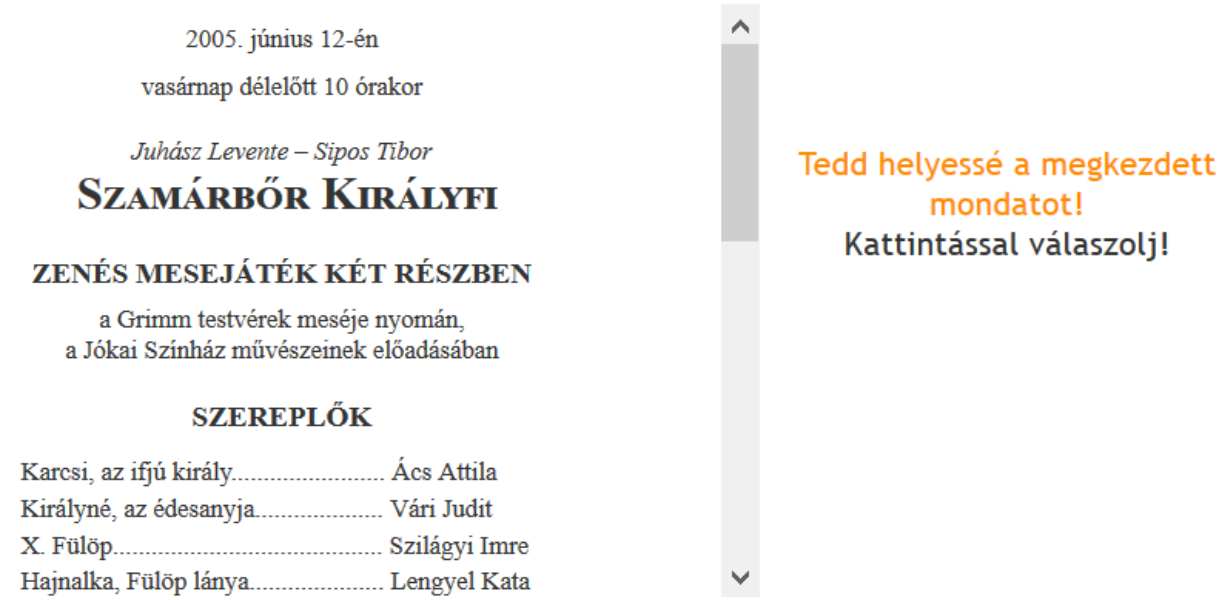

A szereplők nevének két oszlopra bontását azzal indokolhatjuk, hogy...

- az első oszlopban a színészek, a másodikban a kellékesek nevei találhatók.

az első oszlopban a színészek, a másodikban a mesehősök nevei találhatók.

az első oszlopban a mesehősök, a másodikban a színészek nevei találhatók.

- az első oszlopban a kellékesek, a másodikban a színészek nevei találhatók.

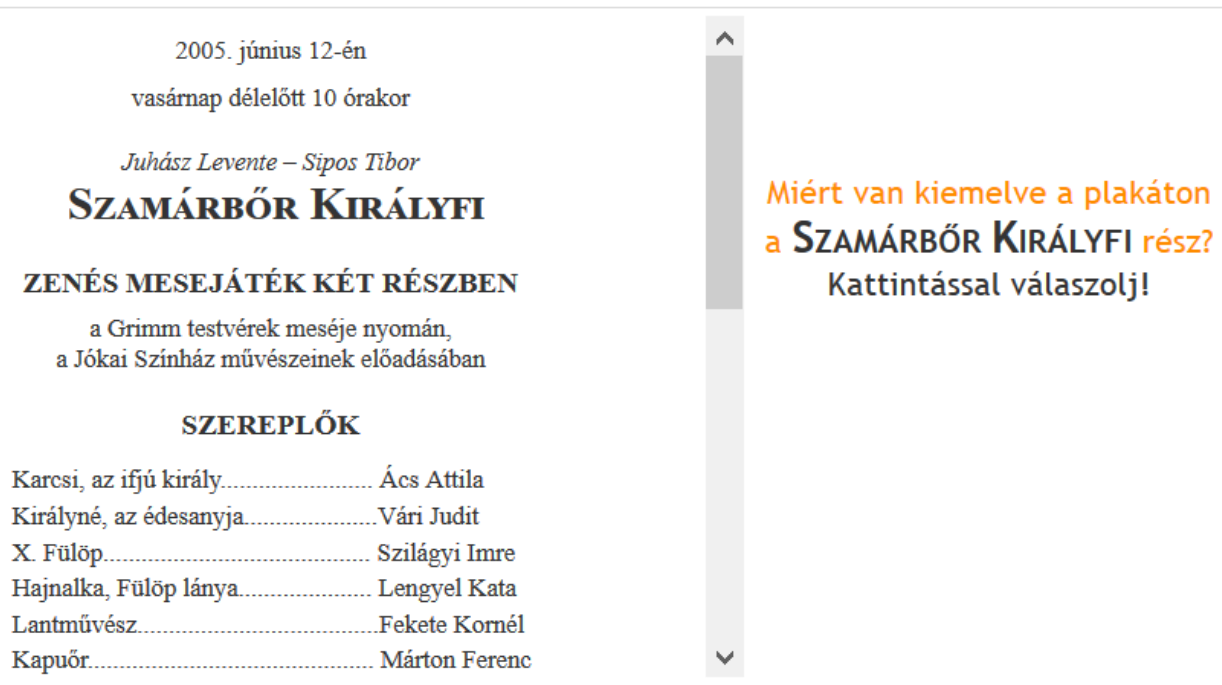

A szerkesztő azért emelte ki, mert ...

a szamárbőr királyfi volt a színészek kedvence.

a színészek szerepük szerint szamárbőrbe bújtak.

a színpadi darab címére akarta irányítani a figyelmet. 


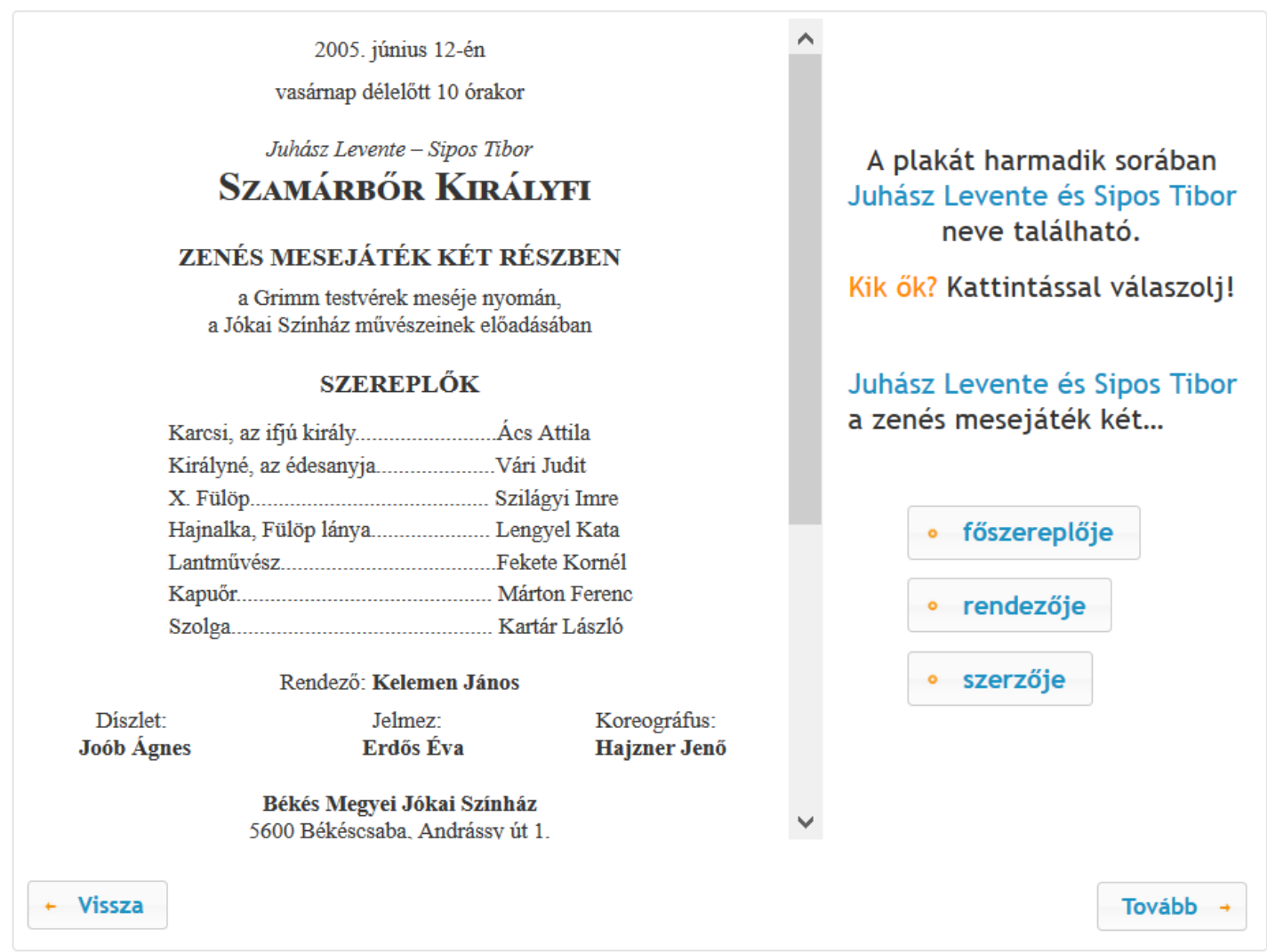

\section{A teszt végére értél.}

Ha továbblépsz, már NEM TUDSZ VISSZATÉRNI az tesztfeladatokhoz.

A továbbiakban a szövegröl és a feladatokról kérdezünk.

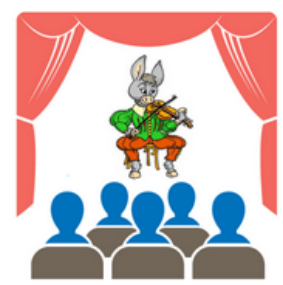

\section{Nincsnek sem jó, sem rossz, sem elvárt válaszok.}

A véleményedre vagyunk kíváncsiak. Fontos, hogy öszinte légy.

Kérünk, válaszolj a kérdésekre! Kattints a véleményedet leginkább kifejező válaszra!

Fontold meg a válaszodat, mert NEM lehet visszalépni!

Kattints a Tovább gombra!

+ Vissza 
Ismerted a szöveget a teszt kitöltését megelőzően?

Kattintással válaszolj!

A színházi előadás plakátja

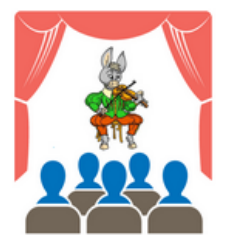

A színházi előadás plakátja

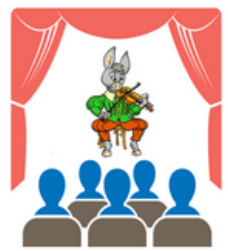

Egyáltalán nem

- Inkább nem

- Inkább Igen

- Nagyon 


\section{Mennyire találtad nehéznek a szöveget?}

Kattints arra gombra, amelyik leginkább kifejezi a véleményedet!

A színházi előadás plakátja

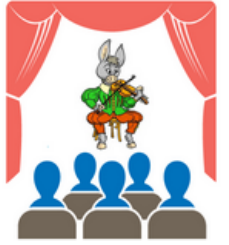

Egyáltalán nem

- Inkább nem

Inkább igen

- Nagyon

Tovább

Mennyire tetszettek a szövegekhez kapcsolódó feladatok?

Kattints arra gombra, amelyik leginkább kifejezi a véleményedet!

A színházi előadás plakátja

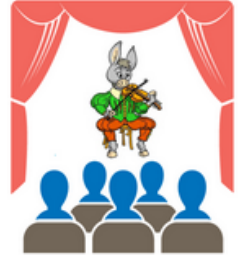

- Egyáltalán nem

- Inkább nem

- Inkább igen

- Nagyon 
Mennyire tetszettek a szövegekhez kapcsolódó feladatok?

Kattints arra gombra, amelyik leginkább kifejezi a véleményedet!

A színházi előadás plakátja

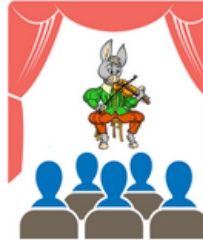

Egyáltalán nem

- Inkább nem

Inkább igen

- Nagyon

Tovább 


\section{Appendix D}

\section{Student questionnaire}

Milyen gyakran teszed?

Mennyire igaz RÁD?

MTA-SZTE Képességfejlōdés Kutatócsoport

SZILP

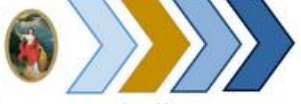

Szegedi Iskolai Longitudinális Program

\section{Kedves Tanuló!}

Arról kell döntened, hogy mennyire igazak RÁD a kérernyőn megjelenő állitások.

Nincsenek sem jó, sem rossz, sem elvárt válaszok.

A véleményedre vagyunk kíváncsiak. Fontos, hogy őszinte légy.

Kérünk, válaszolj a kérdésekre! Kattints a véleményedet leginkább kifejező válaszra!

Fontold meg a válaszodat, mert NEM lehet visszalépni!

Kattints a Tovább gombra!

Fiú vagy lány vagy? Kattints a megfelelő képre, majd a Tovább gombra!
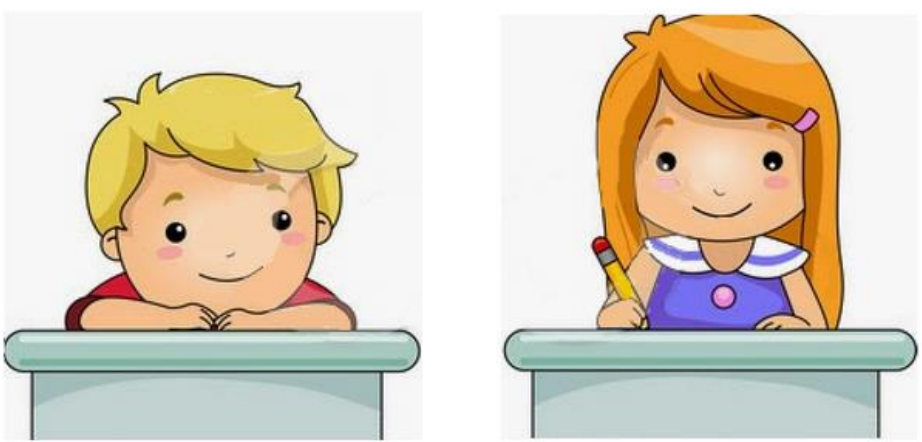
Válaszolj a kérdésekre! Kattints a rád leginkább jellemző válaszra!

Egy héten milyen gyakran...

soha $\quad 1-2 \quad 3-5 \quad$ több mint 5 alkalommal alkalommal alkalommal

használsz számítógépet/internetet saját szórakozásodra az iskolán kívül?

látogatsz különbözö közösségi oldalakat? (pl. iWiW, Network.hu, MyVip, Hotdog, Facebook, MySpace ...)

írsz elektronikus leveleket (e-maileket)?

olvasol elektronikus leveleket (e-maileket)?

Válaszolj a kérdésekre! Kattints a rád leginkább jellemző válaszra!

Amikor tanulsz (pl. matematika, történelem, természetismeret órán vagy házi feladatot készítesz) különböző szövegeket kell olvasnod.

Milyen gyakran olvastál az ELMÚLT HÓNAPBAN

olyan szöveget, amely..

soha

térképet tartalmaz?

táblázatot tartalmaz?

müfaja szerint mese?

müfaja szerint reklám (hirdetés plakát, szórólap)?
1-2 $\quad 3-5 \quad$ több mint 5 alkalommal alkalommal alkalommal

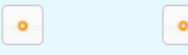

$\circ \quad \circ$

$\circ \quad 0$

$\circ$

$\circ$

(forrás: OECD PISA, 2009) 
Válaszolj a kérdésekre! Kattints a rád leginkább jellemző válaszra!

Milyen gyakran kellett az ELMÚLT HÓNAPBAN a következőket tenned, amikor tanultál (pl. matematika, történelem, természetismeretórán vagy házi feladatot készítettél)?

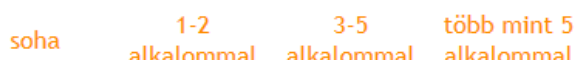

Információt keresni egy táblázatban vagy térképen.

Jellemezni, mi alapján van az információ elrendezve egy táblázatban vagy egy térképen.

Megmagyarázni a szövegben olvasott esemény(ek), jelenség(ek) okait.

Megmagyarázni az olvasott szöveg szereplőinek viselkedését.

Milyen gyakran kellett az ELMÚLT HÓNAPBAN a következőket tenned, amikor tanultál (pl. matematika, történelem, természetismeretórán vagy házi feladatot készítettél)?

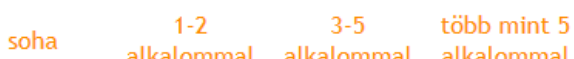

Jellemezni az olvasott szöveg szereplőit külső vagy belső tulajdonság alapján..

Megmagyarázni az olvasott szöveg célját vagy a szerző szándékát.

Kívülröl megtanulni egy szöveget (pl. verset, regényrészletet, színdarabrészletet). 
Mennyire értesz egyet a következő állításokkal?

Kattints a rád leginkább jellemző válaszra!

$\begin{array}{cccc}\begin{array}{c}\text { egyáltalán } \\ \text { nem értek } \\ \text { egyet }\end{array} & \begin{array}{c}\text { inkább nem } \\ \text { értek egyet }\end{array} & \begin{array}{c}\text { inkább } \\ \text { egyetértek }\end{array} & \begin{array}{c}\text { teljesen } \\ \text { egyetértek }\end{array}\end{array}$

egyet értek egyet egyetértek egyetértek

Jó olvasó vagyok.

Gyors olvasó vagyok.

Szeretek másokkal beszélgetni arról, amit olvasok.

Következö

Mennyire értesz egyet a következő állításokkal?

Kattints a rád leginkább jellemző válaszra!

$\begin{array}{cccc}\text { egyáltalán } & \text { inkább nem } & \text { inkább } & \text { teljesen } \\ \text { nem értek } & \text { értek egyet } & \text { egyetértek } & \text { egyetértek }\end{array}$

egyet

értek egyet

Szeretem az olvasás órát.

Szeretek olvasás órán olvasni.

Tetszenek az iskolában olvasott szövegek (kötelezö/ajánlott). 
Mennyire értesz egyet a következő állításokkal?

Kattints a rád leginkább jellemzö válaszra!

$$
\begin{array}{cccc}
\begin{array}{c}
\text { egyáltalán } \\
\text { nem értek } \\
\text { egyet }
\end{array} & \begin{array}{c}
\text { inkább nem } \\
\text { értek egyet }
\end{array} & \begin{array}{c}
\text { inkább } \\
\text { egyetértek }
\end{array} & \begin{array}{c}
\text { teljesen } \\
\text { egyetértek }
\end{array}
\end{array}
$$

Örülök, ha könyvet kapok ajándékba.

Azt gondolom, hogy olvasni unalmas.

Szeretek a szabadidőmben olvasni.

Szeretek játék helyett olvasni.

Szeretek iskolába járni.

Következö 


\section{Appendix E \\ Teacher questionnaire}

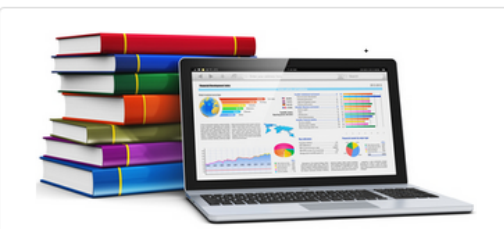

Online tanítói kérdőív

az olvasástanításról

a 2. évfolyamon
MTA-SZTE Képességfejlôdés Kutatócsoport

\section{Kedves Kolléga!}

A kutatási programunkban részt vevő tanulók szövegértésének fejlettségéröl különböző formátumú és típusú szövegek, illetve azokhoz tartozó, más-más olvasási műveletek elvégzését igénylő feladatok mentén igyekszünk képet alkotni. Ez lehetőséget biztosít arra, hogy beazonosítsuk, mely ponton akadt meg a tanulók fejlődése, illetve mely területek igényelnek beavatkozást, további fejlesztést. Emellett célunk, hogy megértsük, milyen demográfiai, környezeti (otthoni és iskolai) és affektív tényezök befolyásolják a szövegértési teljesítményt. E célból hazai és nemzetközi minták alapján készült el az online tanítói kérdőív az olvasáshoz. A nemzetközi trendekhez igazodva kutatócsoportunk a longitudinális program történetében először gyüjt adatokat a tanárok jellemzőiről, attitűdjéről, alkalmazott módszereiről és tanulókról alkotott véleményéröl a tanulók olvasásteljesítményének minél szélesebb körü értelmezhetősége érdekében. Az adatfelvétel nem az iskolában folyó munka minősitésére irányul. Célunk annak vizsgálata, hogy mely módszerek és környezeti feltételek együttállása mentén tehető hatékonyabbá az értő olvasás elsajátítása.

E kérdőívvel azt szeretnénk feltárni, hogy mi jellemző az olvasástanításra, illetve a tanulás iskolai körülményeire. Kérjük, hogy válaszait arra a 2. évfolyamos osztályra vonakozóan adja meg, amely részt vesz a Szegedi Iskolai Longitudinális Programban.

A válaszok megadása után a Következő gombra kattintással tud továbblépni.

Most kattintson a Tovább gombra.

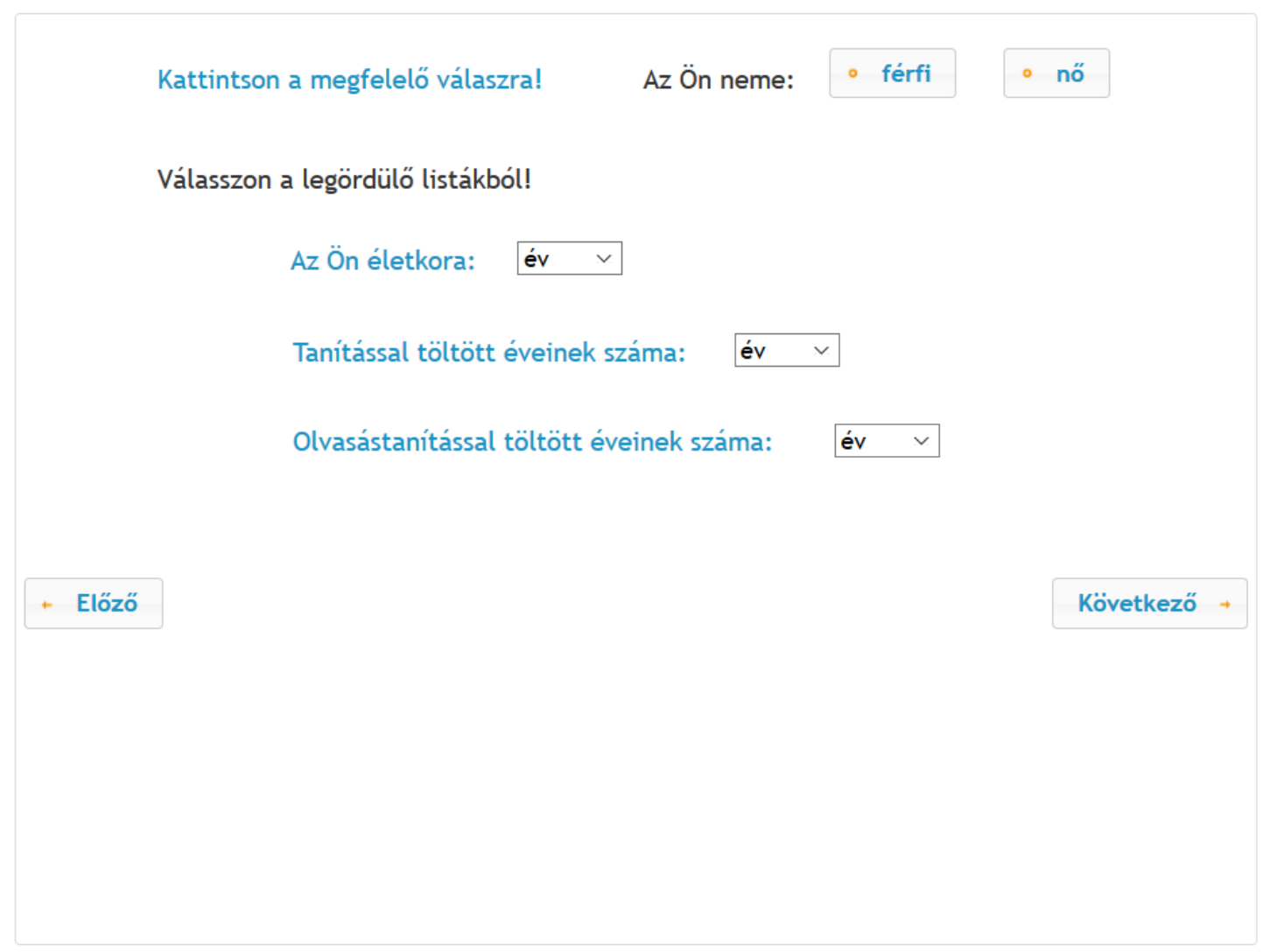




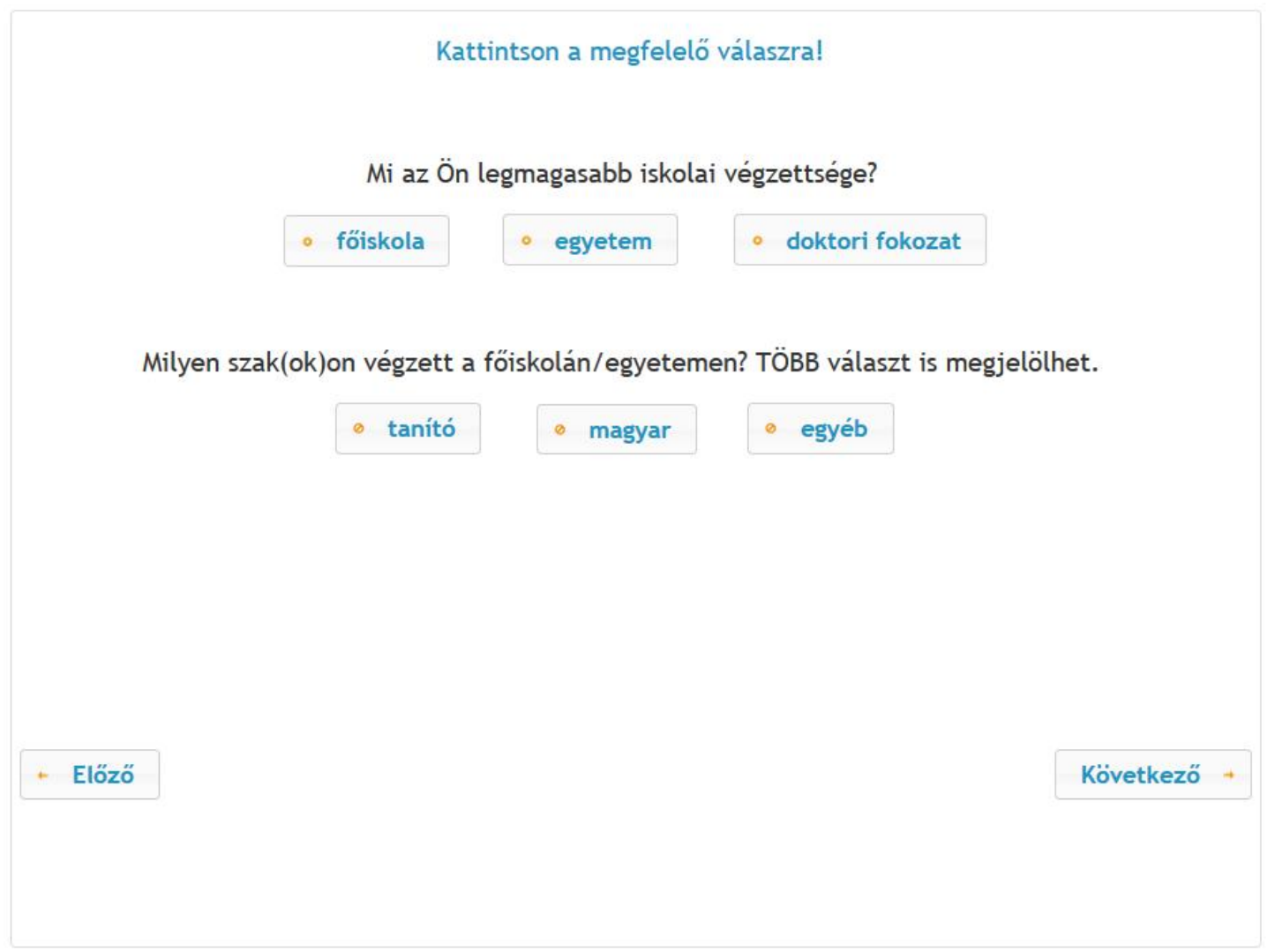

Kattintson a megfelelő válaszra!

Mennyi időt tölt hetente szakmai tudásának fejlesztésével?

- semennyit

kevesebb, mint egy órát

- 1 órát

2-3 órát

4 vagy annál több órát 
Kattintson a megfelelö válaszra!

Mennyi időt tölt olvasással hetente saját szórakozására?

- semennyit

- kevesebb, mint egy órát

- 1 órát

2-3 órát

4 vagy annál több órát

Hány írásórája volt hetente ebben az osztályban? Kattintson a megfelelö válaszra!
- 1 óra
- 2 óra
- 3 óra
4 vagy annál több

Hány olvasásórája volt hetente ebben az osztályban? Kattintson a megfelelő válaszra!
1 óra
- 2 óra
- 3 óra
- 4 vagy annál több

Hány fogalmazásórája volt hetente ebben az osztályban? Kattintson a megfelelő válaszra!
- 1 óra
- 2 óra
- 3 óra
- 4 vagy annál több 


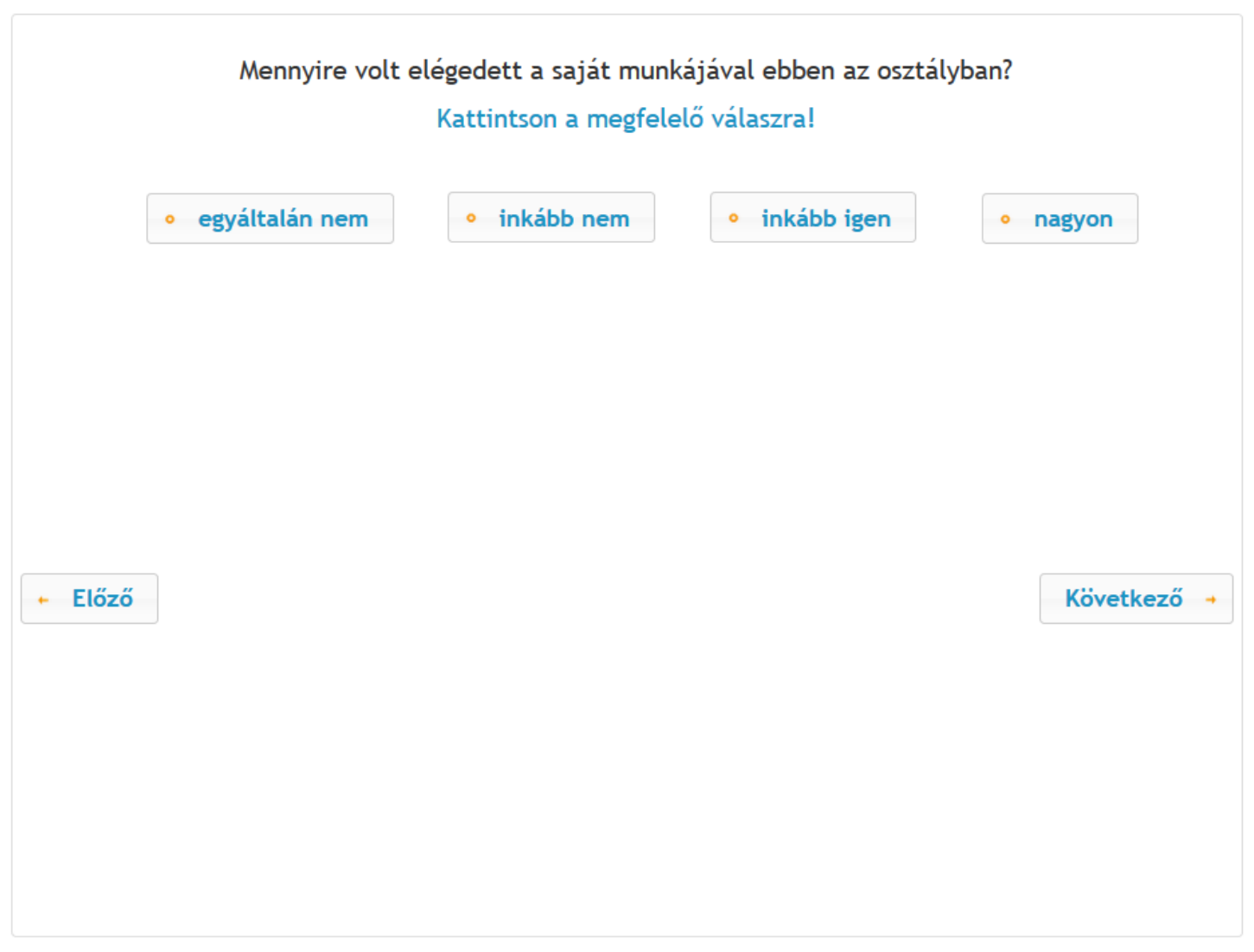

Rangsorolja az alkalmazás gyakorisága szerint az olvasásórákon használt oktatásszervezési formákat! Kattintással válaszoljon! A kattintás sorrendje számít!

frontális

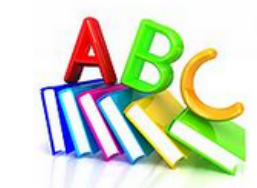

csoportmunka

párosmunka

szerepjáték 


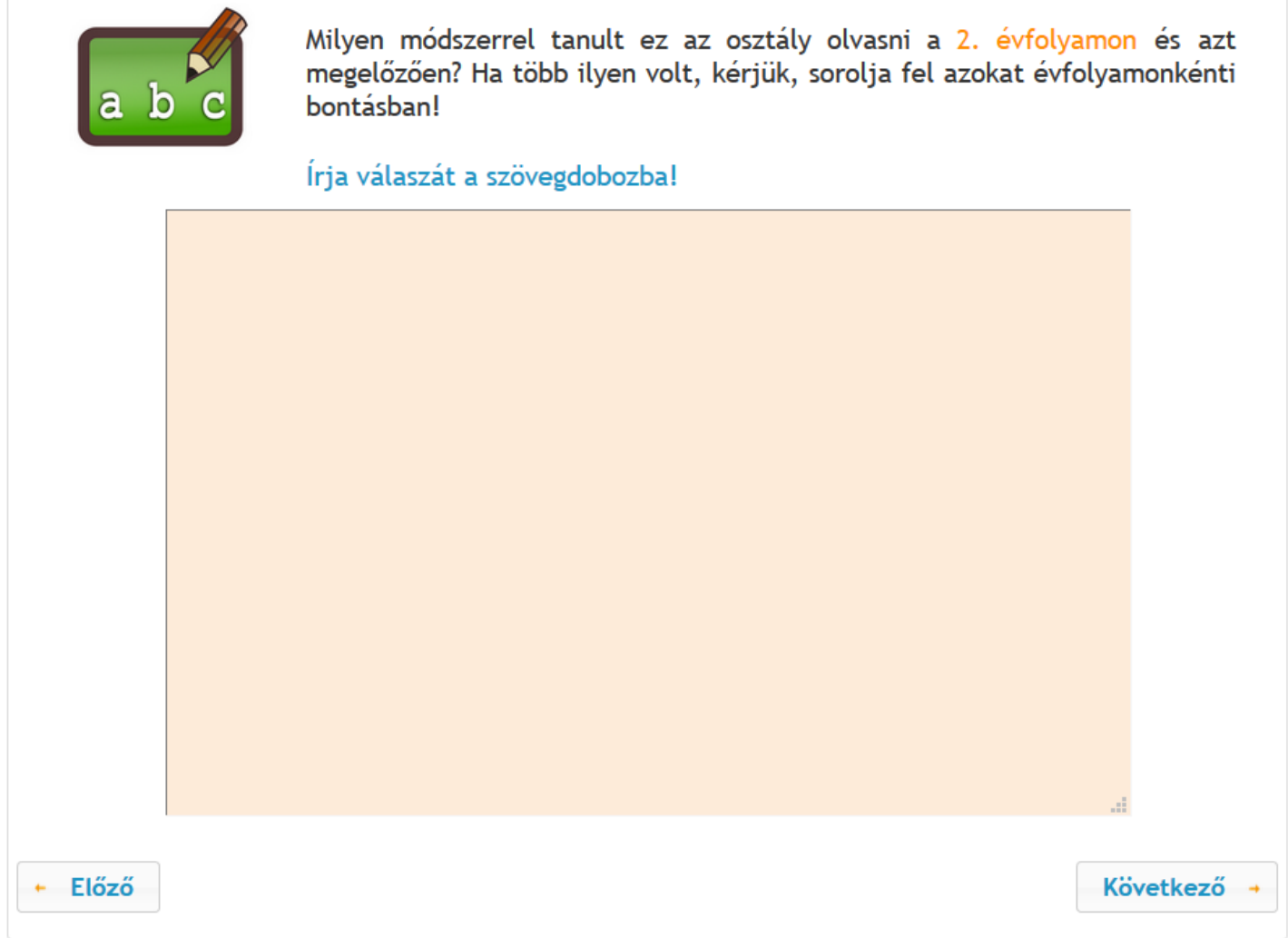

Mely tankönyv(ek)et használta ebben az osztályban az olvasásórákon a 2. évfolyamon és azt megelözöen? Ha több ilyen volt, kérjük, sorolja fel azokat évfolyamonkénti bontásban! Kérjük, adja meg a tankönyv(ek) szerzőinek nevét, címét és kiadóját!

Írja válaszát a szövegdobozba! 


\section{Kattintson a válaszra!}

Ebben az osztályban a 2. évfolyamon egy héten milyen gyakran... olvasott fel hosszabb szöveget hangosan?

- soha 1-2 alkalommal -5 alkalommal $\circ$ 5-nél több alkalommal

olvastatott fel hosszabb szöveget a tanulókkal?

- soha 1-2 alkalommal $\circ 3-5$ alkalommal $\circ$ 5-nél több alkalommal

alkalmazta a néma olvastatás módszerét?

- soha $\circ$ 1-2 alkalommal $\circ$ 3-5 alkalommal 5-nél több alkalommal

\section{Kattintson a válaszra!}

Milyen gyakran használt egy héten olvasástanítás céljából ...

folyamatos szövegeket (pl. leírást, elbeszélést) a 2. évfolyamon?

。 soha 1-2 alkalommal $\circ 3-5$ alkalommal $\circ$ 5-nél több alkalommal

nem folyamatos szövegeket (pl. táblázatot, diagramot) a 2. évfolyamon?

- soha $\circ$ 1-2 alkalommal $\circ 3-5$ alkalommal $\quad \circ$ 5-nél több alkalommal


Milyen gyakran használt egy héten olvasástanitás céljából interaktív táblát a 2 . évfolyamon? Kattintson a megfelelő válaszra!
soha
1-2 alkalommal
3-5 alkalommal
5-nél több alkalommal

Elöző

Következő

Milyen gyakran használt egy héten olvasástanítás céljából számítógépet a 2 . évfolyamon? Kattintson a megfelelö válaszra!

- soha

- 1-2 alkalommal

3-5 alkalommal

5-nél több alkalommal 
Milyen gyakran használt egy héten olvasástanitás céljából a tanórákon internetet a 2. évfolyamon? Kattintson a megfelelö válaszra!

- soha $\therefore$ 1-2 alkalommal $\circ 3-5$ alkalommal $\circ$ 5-nél több alkalommal

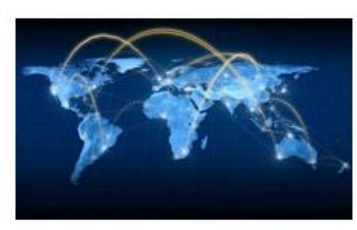

Elözö

Következö

Tartott-e olvasásórát ennek az osztálynak számítógépekkel felszerelt teremben a 2. évfolyamon? Kattintson a megfelelő válaszra!
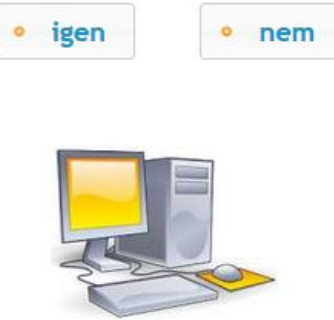
Amikor az olvasásórát a számítógépteremben tartotta, használták-e a tanulók a számítógépeket? Kattintson a megfelelő válaszra!

$$
\text { - igen } \quad \circ \text { nem }
$$
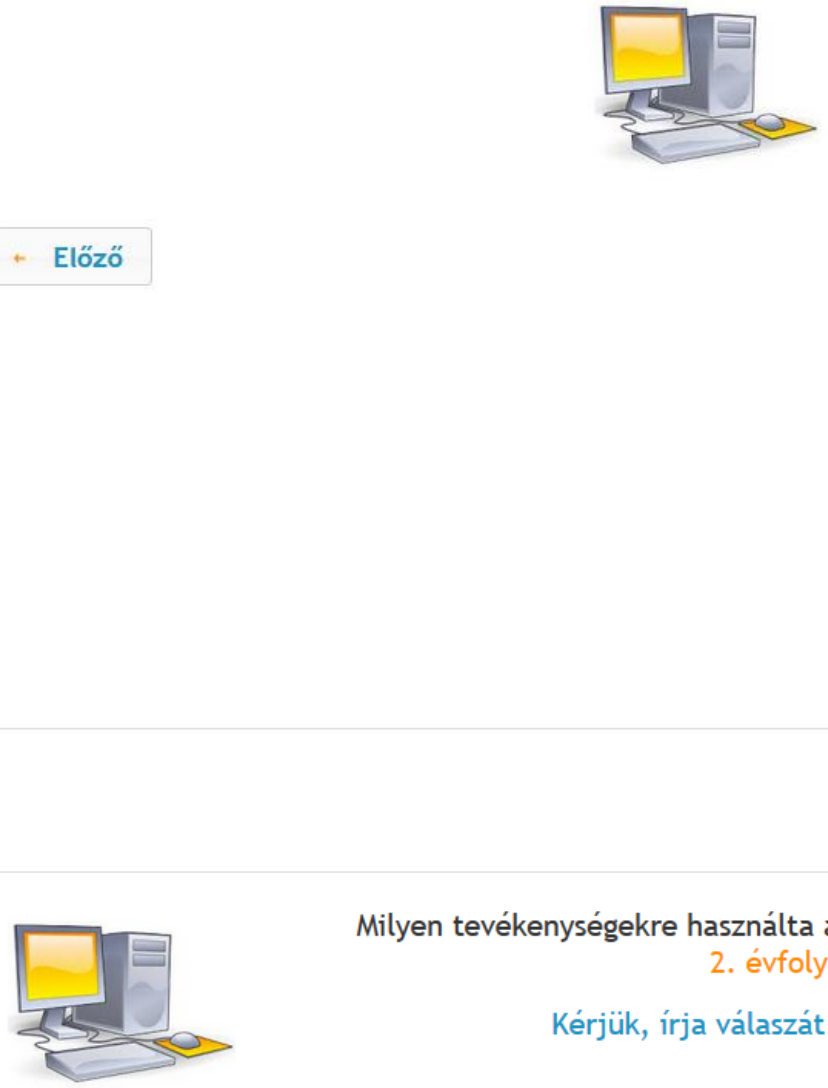

Milyen tevékenységekre használta az olvasásóráin a számítógépet a

2. évfolyamon?

Kérjük, írja válaszát a szövegdobozba! 
Ismert-e az interneten elérhető olvasástanítási szoftvereket?

Kattintson a megfelelö válaszra!

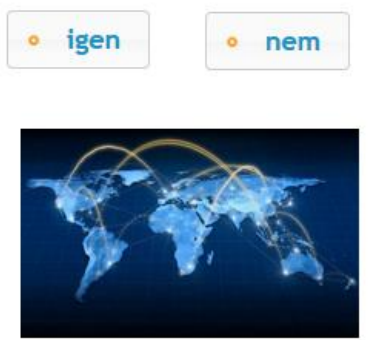

Elözö

Következö

Használt-e az óráin interneten elérhető olvasástanítási szoftvereket a 2. évfolyamon? Kattintson a megfelelő válaszra!

Eddig még nem használtam.

- Egyszer már használtam.

- Néhányszor használtam.

- Gyakran, amikor csak lehetett, használtam. 
Hány órát töltött egy héten tanítványai szövegértésének / olvasáskészségeinek fejlesztésével a tanórán kívül ebben az osztályban a 2. évfolyamon?

Válasszon a legördülö listából!

\section{órát}

\section{Milyen eszközöket használt a tanulók fejlödésének értékelésére?}

Kattintson a megfelelö válaszokra! Több választ is megjelölhet.

szóbeli kikérdezést (pl. feleltetést, beszélgetést)

• saját készítésü papír alapú méröeszközöket (pl. feladatlapot)

- tankönyvekben található (vagy vásárolható) papír alapú mérőeszközöket

- számítógépes mérőeszközöket

tanulói portfóliót 
Milyen gyakran íratott egy héten a tanulókkal olvasásteszteket a 2. évfolyamon?

Kattintson a megfelelő válaszra!

- ritkábban, mint hetente

1 alkalommal

2-3 alkalommal

minden órán

Felhasználta-e tanítási gyakorlatában rendszerszintủ olvasásvizsgálatok (Országos kompetenciamérés, IEA PIRLS, OECD PISA) eredményeit, ajánlásait, letölthetö tesztjeit ebben az osztályban a 2. évfolyamon?

Kattintson a megfelelő válaszra!

$$
\text { - igen } \quad \circ \text { nem }
$$

Indokolja válaszát a szövegdobozban! 
Havonta milyen gyakran beszélt a szülökkel gyermekük olvasásfejlődéséröl?

Kattintson a megfelelő válaszra!

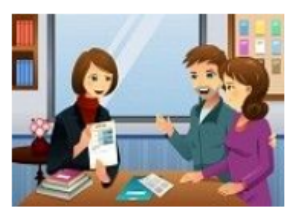

- soha

- ritkábban, mint havonta

- 1-2 alkalommal

- 3-4 alkalommal

5 alkalommal vagy annál többször

Az Ön megítélése szerint mennyire voltak jó olvasók (dekódolók) az osztály tanulói a 2. évfolyamon? Kattintson a megfelelő válaszra!

- nagyon gyengék voltak jók

- inkább gyengék voltak

- inkább jók voltak

- nagyon jók voltak 
Az Ön megítélése szerint mennyire volt jó az osztály tanulóinak szövegértése a 2. évfolyamon? Kattintson a megfelelő válaszra!

$$
\begin{array}{|l|}
\hline \text { - nagyon gyenge volt } \\
\hline \text { - inkább gyenge volt } \\
\hline \text { - inkább volt jó } \\
\hline \text { - nagyon jó volt }
\end{array}
$$

\section{Válasszon a legördülö listákból!}

Hány tanulónak volt problémája a 2. évfolyamon a beszédmegértéssel?

tanulónak

Hivatalosan hány diszlexiás tanuló volt ebben az osztályban a 2. évfolyamon?

tanuló 
Részt vett-e az osztály mindegyik diszlexiás tanulója speciális olvasásfejlesztő programban a 2. évfolyamon?

Kattintson a megfelelö válaszra!

- igen $\circ$ nem

Segítette-e az Ön munkáját gyógypedagógus ebben az osztályban a 2. évfolyamon? Kattintson a megfelelö válaszra!

$\circ$ igen $\quad \circ$ nem




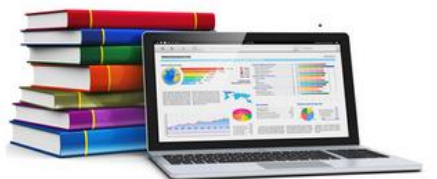

Online tanítói kérdőív az olvasástanításról a 2. évfolyamon

KÖSZÖNJÜK, hogy válaszaival támogatta a munkánkat. MTA-SZTE Képességfejlődés Kutatócsoport munkatársai 


\section{Appendix F}

\section{Continuous text}

\begin{tabular}{|c|c|c|c|c|c|}
\hline \multirow[b]{2}{*}{ Variables } & \multicolumn{4}{|c|}{ Test of Homogeneity of Variances } & \multirow{2}{*}{$\begin{array}{c}\text { One Wav } \\
\text { ANOVA Pos } \\
\text { Hoc Multiple } \\
\text { Comparison }\end{array}$} \\
\hline & $\begin{array}{c}\text { Levene's } \\
\text { Test }\end{array}$ & $p$ & $F$ & $p$ & \\
\hline
\end{tabular}

TEACHERS' BACKGROUND

\begin{tabular}{llllll}
\hline Age (age groups - 10-year categories) & 4.474 & 0.004 & 3.089 & 0.026 & Dunnett's T3 \\
\hline Years spent teaching in general (10-year categories) & 0.950 & 0.415 & 4.589 & 0.003 & Tukey's-b \\
\hline Years spent teaching reading (10-year categories) & 1.087 & 0.353 & 5.506 & 0.001 & Tukey's-b \\
\hline Qualification & 1.831 & 0.139 & 1.654 & 0.175 & \\
\hline Time spent reading for professional development & 0.540 & 0.706 & 2.195 & 0.067 & \\
\hline Time spent reading for pleasure & 2.821 & 0.015 & 3.876 & 0.002 & Dunnett's T3 \\
\hline Professional self-concept: satisfaction & 10.434 & 0.000 & 25.928 & 0.000 & Dunnett's T3 \\
\hline
\end{tabular}

ASPECTS OF TEACHING READING AND READING DEVELOPMENT

\begin{tabular}{llllll}
\hline Frontal teaching ranking & 2.457 & 0.061 & 9.623 & 0.000 & Tukey's-b \\
\hline Group work ranking & 0.556 & 0.644 & 2.108 & 0.097 & \\
\hline Pair work ranking & 1.788 & 0.147 & 2.994 & 0.030 & Tukey's-b \\
\hline Role-playing ranking & 1.745 & 0.156 & 3.669 & 0.012 & Tukey's-b \\
\hline Textbooks for teaching reading & 3.350 & 0.005 & 10.802 & 0.000 & Dunnett's T3 \\
\hline Methods of teaching reading & 3.307 & 0.019 & 5.739 & 0.001 & Dunnett's T3 \\
\hline Frequency of teachers' reading aloud to their students & 2.729 & 0.042 & 6.476 & 0.000 & Dunnett's T3 \\
\hline Frequency of students' oral reading & 1.196 & 0.302 & 1.565 & 0.209 & \\
\hline Frequency of students' silent reading & 10.531 & 0.000 & 7.259 & 0.001 & Dunnett's T3 \\
\hline Frequency of using continuous texts & 7.296 & 0.001 & 7.44 & 0.001 & Dunnett's T3 \\
\hline Frequency of using non-continuous texts & 2.018 & 0.109 & 2.184 & 0.088 & \\
\hline Frequency of using interactive whiteboard & 2.948 & 0.032 & 6.407 & 0.000 & Dunnett's T3 \\
\hline Frequency of using interactive computer & 6.939 & 0.000 & 6.019 & 0.000 & Dunnett's T3 \\
\hline Frequency of using the internet & 3.047 & 0.028 & 1.913 & 0.126 & \\
\hline Use of online reading programs & 4.233 & 0.006 & 3.791 & 0.010 & Dunnett's T3 \\
\hline Frequency of using reading tests & 2.000 & 0.112 & 3.110 & 0.025 & Tukey's-b \\
\hline Frequency of consulting parents & 2.857 & 0.022 & 0.520 & 0.721 & \\
\hline
\end{tabular}

CONDITIONS OF TEACHING AND LEARNING READING

\begin{tabular}{lccccc}
\hline Number of writing lessons & 2.301 & 0.075 & 3.06 & 0.027 & Tukey's-b \\
\hline Number of reading lessons & 1.335 & 0.263 & 1.326 & 0.266 & \\
\hline Number of composition lessons & 0.386 & 0.763 & 2.351 & 0.070 & \\
\hline Opinion about students' decoding developmental level & 17.350 & 0.000 & 43.993 & 0.000 & Dunnett's T3 \\
\hline $\begin{array}{l}\text { Opinion about students' reading comprehension } \\
\text { developmental level }\end{array}$ & 7.056 & 0.000 & 22.445 & 0.000 & Dunnett's T3 \\
\hline \hline
\end{tabular}


Mixed text

\begin{tabular}{|c|c|c|c|c|c|}
\hline \multirow[b]{2}{*}{ Variables } & \multicolumn{4}{|c|}{ Test of Homogeneity of Variances } & \multirow{2}{*}{$\begin{array}{c}\text { One Wav } \\
\text { ANOVA Post } \\
\text { Hoc Multiple } \\
\text { Comparisons }\end{array}$} \\
\hline & $\begin{array}{c}\text { Levene's } \\
\text { Test }\end{array}$ & $p$ & $F$ & $p$ & \\
\hline
\end{tabular}

TEACHERS' BACKGROUND

\begin{tabular}{lccccc}
\hline Age (age groups - 10-year categories) & 10.070 & 0.000 & 7.353 & 0.000 & Dunnett's T3 \\
\hline Years spent teaching in general (10-year categories) & 12.851 & 0.000 & 13.666 & 0.000 & Dunnett's T3 \\
\hline Years spent teaching reading (10-year categories) & 12.155 & 0.000 & 8.41 & 0.000 & Dunnett's T3 \\
\hline Qualification & 5.667 & 0.001 & 2.926 & 0.033 & Dunnett's T3 \\
\hline Time spent reading for professional development & 9.595 & 0.000 & 5.148 & 0.000 & Dunnett's T3 \\
\hline Time spent reading for pleasure & 1.898 & 0.091 & 5.785 & 0.000 & Tukey's-b \\
\hline Professional self-concept: satisfaction & 1.255 & 0.285 & 17.226 & 0.000 & Tukey's-b \\
\hline
\end{tabular}

ASPECTS OF TEACHING READING AND READING DEVELOPMENT

\begin{tabular}{lccccc}
\hline Frontal teaching ranking & 10.735 & 0.000 & 6.156 & 0.000 & Dunnett's T3 \\
\hline Group work ranking & 1.765 & 0.152 & 5.138 & 0.002 & Tukey's-b \\
\hline Pair work ranking & 3.207 & 0.022 & 4.958 & 0.002 & Dunnett's T3 \\
\hline Role-playing ranking & 4.988 & 0.002 & 2.062 & 0.103 & \\
\hline Textbooks for teaching reading & 26.557 & 0.000 & 49.498 & 0.000 & Dunnett's T3 \\
\hline Methods of teaching reading & 15.227 & 0.000 & 3.383 & 0.017 & Dunnett's T3 \\
\hline Frequency of teachers' reading aloud to their students & 3.438 & 0.016 & 7.811 & 0.000 & Dunnett's T3 \\
\hline Frequency of students' oral reading & 9.743 & 0.000 & 3.473 & 0.031 & Dunnett's T3 \\
\hline Frequency of students' silent reading & 1.578 & 0.207 & 5.587 & 0.004 & Tukey's-b \\
\hline Frequency of using continuous texts & 14.277 & 0.000 & 3.268 & 0.038 & Dunnett's T3 \\
\hline Frequency of using non-continuous texts & 3.697 & 0.011 & 3.49 & 0.015 & Dunnett's T3 \\
\hline Frequency of using interactive whiteboard & 13.462 & 0.000 & 7.644 & 0.000 & Dunnett's T3 \\
\hline Frequency of using interactive computer & 19.185 & 0.000 & 1.366 & 0.251 & \\
\hline Frequency of using the internet & 1.494 & 0.214 & 1.47 & 0.221 & \\
\hline Use of online reading programs & 6.144 & 0.000 & 6.871 & 0.000 & Dunnett's T3 \\
\hline Frequency of using reading tests & 4.407 & 0.004 & 1.064 & 0.363 & \\
\hline Frequency of consulting parents & 6.578 & 0.000 & 1.294 & 0.270 & \\
\hline
\end{tabular}

CONDITIONS OF TEACHING AND LEARNING READING

\begin{tabular}{lccccc}
\hline Number of writing lessons & 2.710 & 0.044 & 8.773 & 0.000 & Dunnett's T3 \\
\hline Number of reading lessons & 3.473 & 0.031 & 1.311 & 0.270 & \\
\hline Number of composition lessons & 1.569 & 0.195 & 1.956 & 0.118 & \\
\hline Opinion about students' decoding developmental level & 0.853 & 0.465 & 36.816 & 0.000 & Tukey's-b \\
\hline $\begin{array}{l}\text { Opinion about students' reading comprehension } \\
\text { developmental level }\end{array}$ & 3.705 & 0.011 & 23.064 & 0.000 & Dunnett's T3 \\
\hline \hline
\end{tabular}




\section{Non-continuous text}

\begin{tabular}{|c|c|c|c|c|c|}
\hline \multirow[b]{2}{*}{ Variables } & \multicolumn{4}{|c|}{ Test of Homogeneity of Variances } & \multirow{2}{*}{$\begin{array}{c}\text { One Wav } \\
\text { ANOVA Post } \\
\text { Hoc Multiple } \\
\text { Comparisons }\end{array}$} \\
\hline & $\begin{array}{c}\text { Levene's } \\
\text { Test }\end{array}$ & $p$ & $F$ & $p$ & \\
\hline
\end{tabular}

TEACHERS' BACKGROUND

\begin{tabular}{lccccc}
\hline Age (age groups - 10-year categories) & 0.448 & 0.718 & 5.76 & 0.001 & Tukey's-b \\
\hline Years spent teaching in general (10-year categories) & 0.169 & 0.917 & 17.949 & 0.000 & Tukey's-b \\
\hline Years spent teaching reading (10-year categories) & 1.467 & 0.222 & 10.762 & 0.000 & Tukey's-b \\
\hline Qualification & 0.356 & 0.785 & 9.341 & 0.000 & Tukey's-b \\
\hline Time spent reading for professional development & 1.692 & 0.015 & 2.122 & 0.076 & \\
\hline Time spent reading for pleasure & 5.267 & 0.000 & 2.116 & 0.061 & \\
\hline Professional self-concept: satisfaction & 4.540 & 0.011 & 3.327 & 0.036 & Dunnett's T3 \\
\hline
\end{tabular}

ASPECTS OF TEACHING READING AND READING DEVELOPMENT

\begin{tabular}{lccccc}
\hline Frontal teaching ranking & 0.054 & 0.984 & 1.207 & 0.305 & \\
\hline Group work ranking & 4.186 & 0.006 & 3.1 & 0.026 & Dunnett's T3 \\
\hline Pair work ranking & 4.968 & 0.002 & 3.617 & 0.013 & Dunnett's T3 \\
\hline Role-playing ranking & 1.551 & 0.199 & 1.412 & 0.237 & \\
\hline Textbooks for teaching reading & 2.756 & 0.017 & 13.158 & 0.000 & Dunnett's T3 \\
\hline Methods of teaching reading & 1.385 & 0.245 & 8.126 & 0.000 & Tukey's-b \\
\hline Frequency of teachers' reading aloud to their students & 0.753 & 0.520 & 20.934 & 0.000 & Tukey's-b \\
\hline Frequency of students' oral reading & 1.376 & 0.253 & 7.746 & 0.000 & Tukey's-b \\
\hline Frequency of students' silent reading & 0.207 & 0.813 & 2.306 & 0.100 & \\
\hline Frequency of using continuous texts & 2.955 & 0.052 & 6.426 & 0.002 & Tukey's-b \\
\hline Frequency of using non-continuous texts & 2.335 & 0.072 & 1.244 & 0.292 & \\
\hline Frequency of using interactive whiteboard & 0.076 & 0.973 & 7.47 & 0.000 & Tukey's-b \\
\hline Frequency of using interactive computer & 1.401 & 0.241 & 4.69 & 0.003 & Tukey's-b \\
\hline Frequency of using the internet & 0.888 & 0.447 & 3.098 & 0.026 & Tukey's-b \\
\hline Use of online reading programs & 2.562 & 0.054 & 3.227 & 0.022 & Tukey's-b \\
\hline Frequency of using reading tests & 2.539 & 0.055 & 1.098 & 0.349 & \\
\hline Frequency of consulting parents & 1,608 & 0.169 & 1.376 & 0.240 & \\
\hline
\end{tabular}

CONDITIONS OF TEACHING AND LEARNING READING

\begin{tabular}{lccccc}
\hline Number of writing lessons & 3.446 & 0.016 & 4.145 & 0.006 & Dunnett's T3 \\
\hline Number of reading lessons & 1.411 & 0.244 & 1.538 & 0.215 & \\
\hline Number of composition lessons & 3.302 & 0.019 & 7.46 & 0.000 & Dunnett's T3 \\
\hline $\begin{array}{l}\text { Opinion about students' decoding developmental level } \\
\begin{array}{l}\text { Opinion about students' reading comprehension } \\
\text { developmental level }\end{array}\end{array}$ & 0.309 & 0.819 & 23.756 & 0.000 & Tukey's-b \\
\hline \hline
\end{tabular}

